\title{
Evaluation of 2004 Toyota Prius Hybrid Electric Drive System
}

\section{Prepared by:}

Oak Ridge National Laboratory

Mitch Olszewski, Program Manager

Submitted to:

Energy Efficiency and Renewable Energy

FreedomCAR and Vehicle Technologies

Vehicle Systems Team

Susan A. Rogers, Technology Development Manager 
NATIONAL LABORATORY

MANAGED BY UT-BATTELLE FOR THE DEPARTMENT OF ENERGY

\section{Evaluation of 2004 Toyota Prius Hybrid Electric Drive System}

\author{
R. H. Staunton \\ C. W. Ayers \\ L. D. Marlino \\ J. N. Chiasson \\ University of Tennessee-Knoxville \\ T. A. Burress \\ Oak Ridge Institute for Science and Education \\ Publication Date: May 2006 \\ Prepared by the \\ OAK RIDGE NATIONAL LABORATORY \\ Oak Ridge, Tennessee 37831 \\ managed by \\ UT-BATTELLE, LLC \\ for the \\ U.S. DEPARTMENT OF ENERGY \\ Under contract DE-AC05-00OR22725
}




\section{DOCUMENT AVAILABILITY}

Reports produced after January 1, 1996, are generally available free via the U.S. Department of Energy (DOE) Information Bridge:

Web site: http://www.osti.gov/bridge

Reports produced before January 1, 1996, may be purchased by members of the public from the following source:

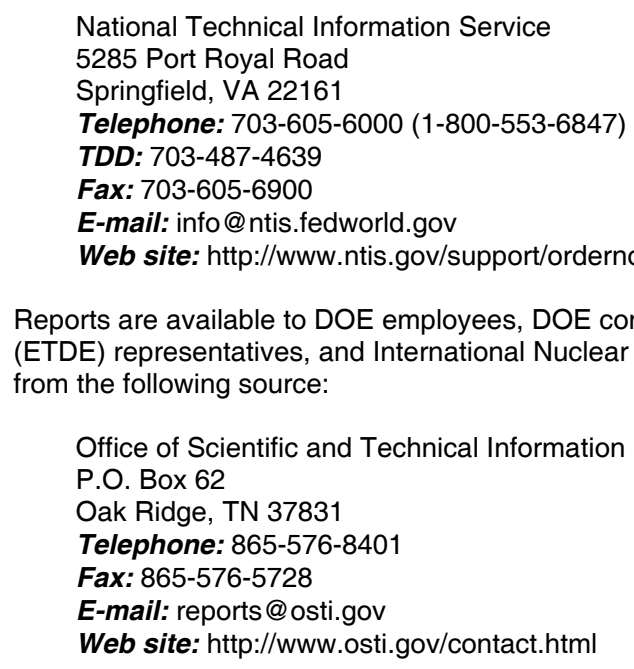
from the following source:

Office of Scientific and Technical Information

P.O. Box 62

Oak Ridge, TN 37831

Telephone: 865-576-8401

Fax: 865-576-5728

E-mail: reports@osti.gov

Web site: http://www.osti.gov/contact.html

Reports are available to DOE employees, DOE contractors, Energy Technology Data Exchange (ETDE) representatives, and International Nuclear Information System (INIS) representatives

This report was prepared as an account of work sponsored by an agency of the United States Government. Neither the United States government nor any agency thereof, nor any of their employees, makes any warranty, express or implied, or assumes any legal liability or responsibility for the accuracy, completeness, or usefulness of any information, apparatus, product, or process disclosed, or represents that its use would not infringe privately owned rights. Reference herein to any specific commercial product, process, or service by trade name, trademark, manufacturer, or otherwise, does not necessarily constitute or imply its endorsement, recommendation, or favoring by the United States Government or any agency thereof. The views and opinions of authors expressed herein do not necessarily state or reflect those of the United States Government or any agency thereof. 


\section{TABLE OF CONTENTS}

\section{Page}

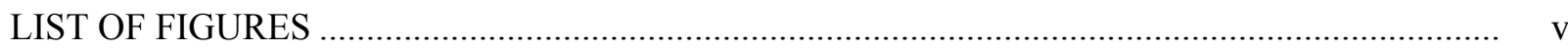

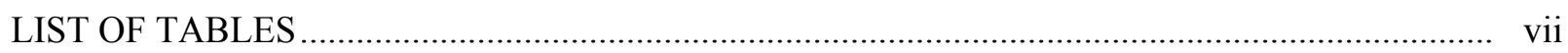

ACRONYMS AND ABBREVIATIONS ................................................................................... viii

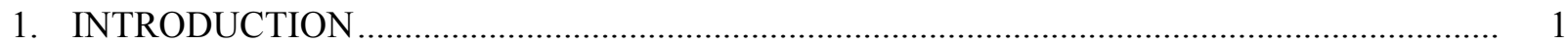

1.1 PROGRAM OVERVIEW ..............................................................................

1.2 TESTING FACILITIES ………………………………………………………. 2

1.3 SCOPE AND OBJECTIVE....................................................................................... 2

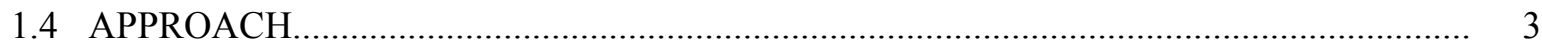

2. HYBRID ELECTRIC DRIVE SYSTEM DESCRIPTION ........................................................

2.1 DESIGN REQUIREMENTS ………………………….................................... 7

2.2 SYSTEM SUBASSEMBLIES ........................................................................... 7

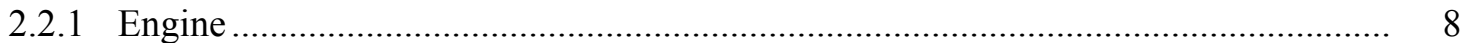

2.2.2 Power-Split Device ...................................................................................... 8

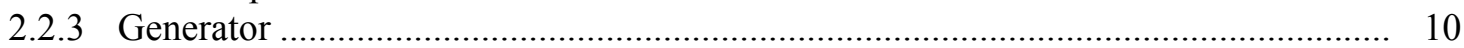

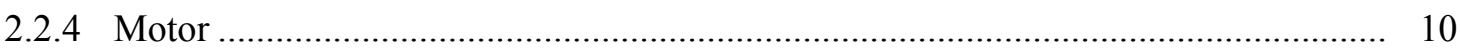

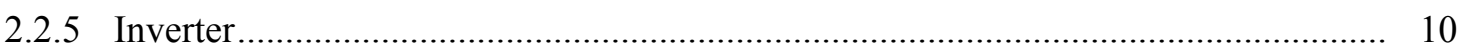

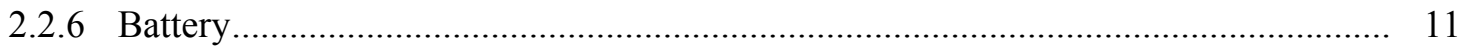

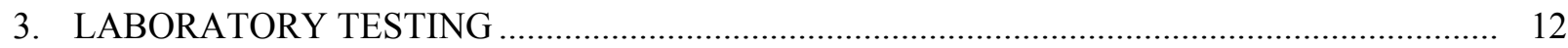

3.1 ANL VEHICLE -EVEL PERFORMANCE TESTS …………………………………..... 12

3.1.1 Initial Performance Testing at ANL................................................................... 12

3.1.2 Vehicle Data Characterizing Boost-Converter Operation............................................ 14

3.2 ORNL SUBSYSTEM-LEVEL PERFORMANCE AND VALIDATION TESTS ………….. 18

3.2.1 Locked Rotor Tests ...................................................................................... 19

3.2.2 Back-emf Tests ............................................................................................... 21

3.2.2.1 Motor tests ………………………………………………………... 21

3.2.2.2 Generator tests ...................................................................................... 22

3.2.3 Hybrid Drive System Loss Tests .......................................................................... 23

3.3 HEV SYSTEM TESTING OVER THE FULL DESIGN RANGE …………………………. 28

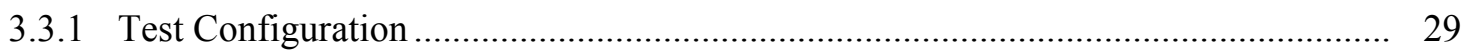

3.3.2 General Test Plan and Data Verification ............................................................. 30

3.3.3 Motor/Inverter Test Data and Efficiency Maps …………………………………... 33

3.3.4 Buck/Boost-Converter Test Data and Efficiency Maps............................................ 36

4. INVERTER, CONTROLLER, AND Z-SOURCE ACTIVITIES ................................................ 40

4.1 INVERTER ARCHITECTURE OVERVIEW ............................................................ 40

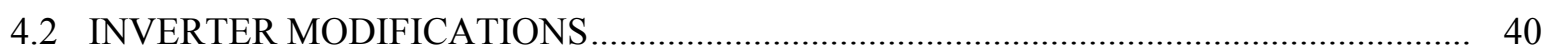

4.3 CONTROLLER DEVELOPMENT ……………………………………………….... 41

4.3.1 Establishing the Need for Field Weakening ............................................................ 42

4.3.2 Controller Software....................................................................................... 43

4.3.3 Controller Hardware ........................................................................................ 44 


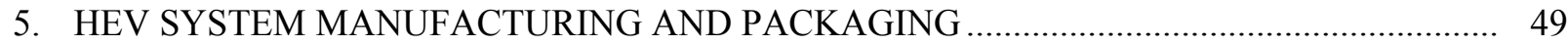

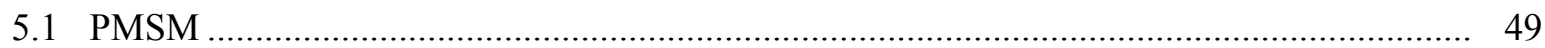

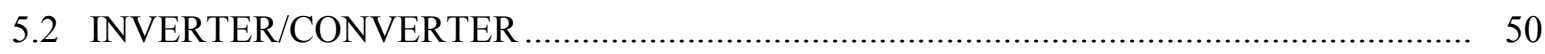

5.3 CONVERTER COMPONENTS ........................................................................ 56

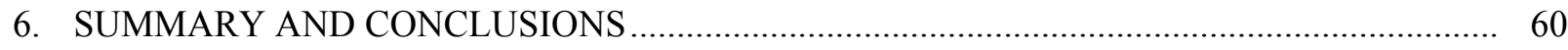

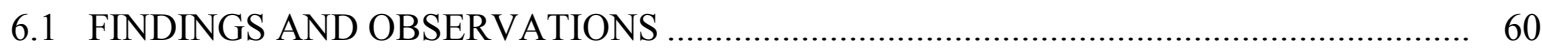

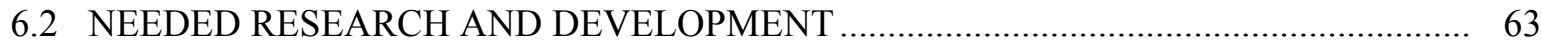

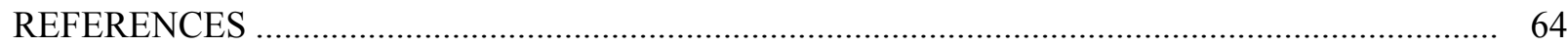

APPENDIX A - DRIVE-CYCLE PLOTS SHOWING CONVERTER OPERATION ..................... 65

APPENDIX B - PRIUS PERFORMANCE-MAPPING DATA _................................................ 69 


\section{LIST OF FIGURES}

Figure

1.1 Predominant project challenge represented by a highly integrated vehicle

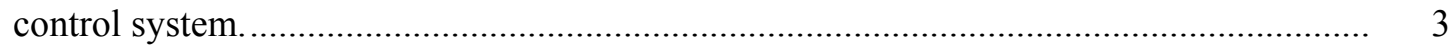

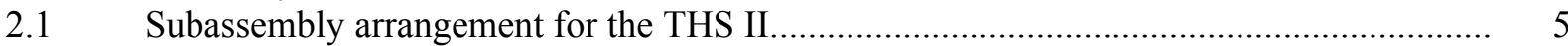

$2.2 \quad 2004$ Prius engine and hybrid drive assembly .................................................................. 5

2.3 Heat removal and lubrication scheme for the 2004 Prius ................................................ 6

$2.4 \quad$ Diagram of the 2004 Prius power-split device ............................................................ 8

2.5 Diagram of the 2004 Prius gear train between the motor and wheels ............................... 9

$2.6 \quad 2004$ Prius gears with number of gear teeth shown ...................................................... 9

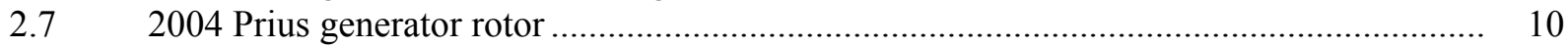

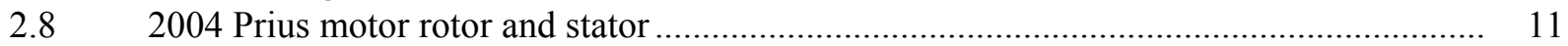

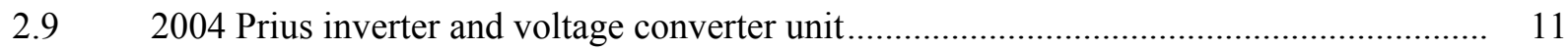

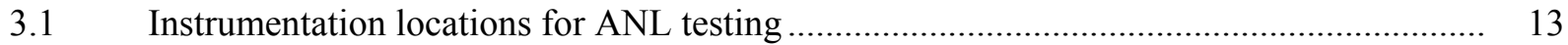

3.2 Sample power measurements under varying speed conditions.......................................... 13

3.3 Sample power measurements under controlled speed conditions..................................... 14

3.4 Extrapolation of generator back-emf data for generator speeds up to $10,000 \mathrm{rpm} \ldots \ldots \ldots \ldots . . . . .15$

3.5 Drive-cycle data from ANL showing voltage-boost converter response............................ 16

3.6 Second drive-cycle data set from ANL showing voltage-boost converter response ........... 16

3.7 Third drive-cycle data set from ANL showing voltage-boost converter response .............. 17

3.8 Drive-cycle data set showing voltage boost at high speeds .......................................... 17

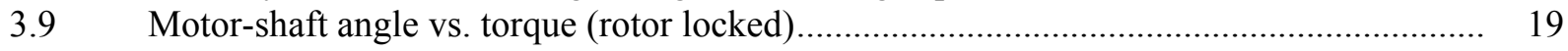

3.10 Locked rotor peak torque as a function of current.................................................. 20

3.11 Motor back-emf voltage vs. motor-shaft speed ....................................................... 22

3.12 Generator back-emf voltage vs. generator shaft speed .................................................. 23

3.13 Hybrid electric drive system and component/subassembly losses at $25^{\circ} \mathrm{C} \mathrm{\ldots \ldots \ldots \ldots \ldots \ldots \ldots \ldots ..........24}$

3.14 Configuration B losses as a function of oil temperature................................................. 28

3.15 The test configuration for Prius performance characterization tests. ................................. 29

3.16 The test hardware for Prius performance characterization tests. ...................................... 29

3.17 Maximum torque-speed performance specifications for the 2004 Prius ........................... 31

3.182004 Prius motor efficiency contour map. ..................................................................... 34

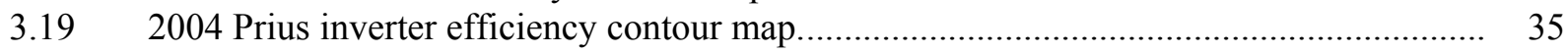

3.20 2004 Prius combined motor/inverter efficiency contour map ....................................... 35

3.21 Boost-converter efficiency vs. output power............................................................ 36

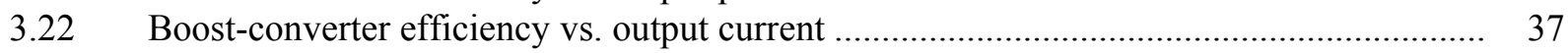

4.1 TC placement at IPEM area of cold plate.............................................................. 41

4.2 Limitations in operation of PMSM where field weakening is not used ............................ 43

$4.3 \quad$ Upper-level flow diagram of Prius controller system................................................... 46

4.4 Configurations for (a) conventional boosted inverter and (b) new Z-source inverter ......... 7

4.5 Efficiency comparisons of inverter topologies and inverter/motor systems...................... 48

5.1 Casing of the 2004 Prius PMSM with dimensions and volume calculations .................... 50

5.2 Overall subsystem packaging in the 2004 Prius inverter/converter .................................. 51

5.3 Overview of packaging in an opened 2004 Prius inverter/converter................................. 51

5.4 Overview of packaging in a 2004 Prius inverter/converter with capacitor

5.5 Empty inverter/converter housing showing cold plate surfaces ..................................... 53

5.6 Power module 18-pack dye array in a 2004 Prius inverter............................................. 53 


\section{LIST OF FIGURES (cont’d)}

Figure $\quad$ Page

5.7 Close-up of a IGBT/diode pair in the 2004 Prius inverter............................................. 54

5.8 Packaging of the 2004 Prius compressor inverter and dc-to-dc converter circuit .............. 54

5.9 Overall volume and mass of the 2004 Prius inverter/converter.......................................... 55

$5.10 \quad$ Radiator for Prius engine (upper) and hybrid subsystems (lower) .................................. 56

$5.11 \quad$ General circuit schematic of the Prius inverter............................................................ 56

5.12 Disassembly of the converter power module................................................................. 57

5.13 Close-up of converter IGBTs and diodes ............................................................... 57

$5.14 \quad$ Voltage-boost converter auto-transformer.................................................................. 58

5.15 Conceptual change to inverter/converter casing for excluding the

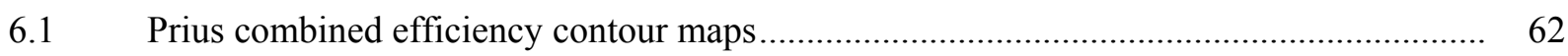

A.1 Drive-cycle plot chosen to illustrate a rapid acceleration ................................................ 65

A.2 Second drive-cycle plot chosen to illustrate a rapid acceleration ................................... 66

A.3 Drive-cycle plot chosen to illustrate a fluctuating boosted voltage ................................... 66

A.4 Drive-cycle plot chosen to illustrate a gradual acceleration ......................................... 67

A.5 Consideration of curve smoothening on the boosted voltage plot.................................... 67

A.6 Drive-cycle plot chosen to illustrate a high level of change for each parameter ............... 68

A.7 Drive-cycle plot chosen to illustrate a $70 \mathrm{mph}$ sustained speed ....................................... 68

B.1 Speed-torque combinations at which data sets were obtained....................................... 69 


\section{LIST OF TABLES}

\section{Table}

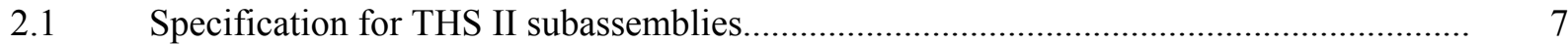

3.1 Measurement variables for ANL testing program ….................................................... 12

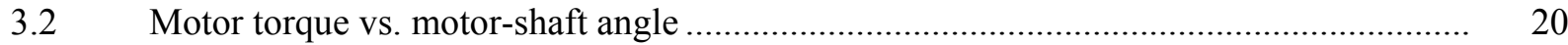

3.3 Test conditions for back-emf voltage measurements......................................................... 21

3.4 Back-emf voltage measurements for the 2004 Prius motor ............................................... 21

3.5 Back-emf voltage measurements for the 2004 Prius generator ......................................... 22

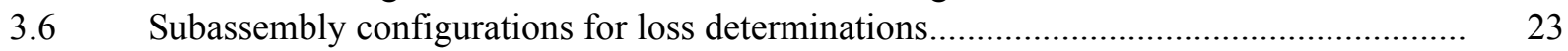

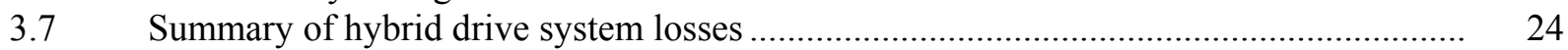

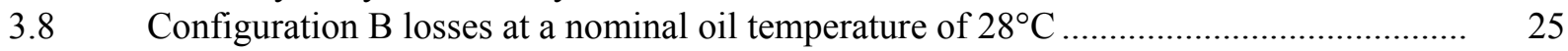

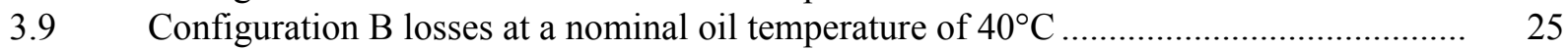

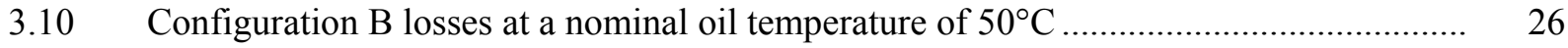

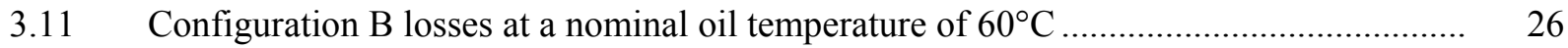

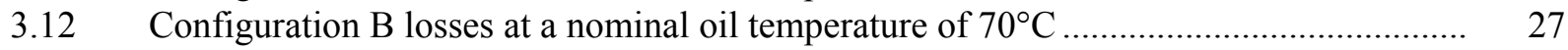

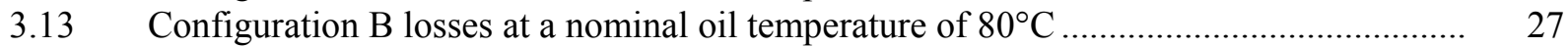

3.14 Cooling and coolant temperature and flow limits.................................................... 31

3.15 Boost-converter test data including efficiency, motor load, and electrical parameters ..... 38

4.1 Efficiency comparisons of inverter topologies and inverter/motor systems..................... 48

5.1 Physical characterization of the PMSM, inverter, converter, and cooling system ........... 59

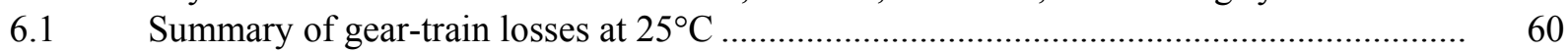

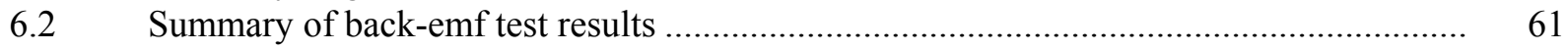

6.3 Summary of motor current and torque test results................................................... 61

B-1 Mechanical, operational, electrical, and thermal data from the Prius

performance-mapping test 


\section{ACRONYMS AND ABBREVIATIONS}

\begin{tabular}{|c|c|c|c|}
\hline ac & alternating current & IPM & integrated power module (converter) \\
\hline ANL & Argonne National Laboratory & IR & International Rectifier \\
\hline \multirow[t]{2}{*}{ APRF } & Advanced Powertrain Research & $\mathrm{km} / \mathrm{h}$ & kilometers per hour \\
\hline & Facility & $\mathrm{kW}$ & kilowatt \\
\hline \multirow[t]{2}{*}{ ATPZEV } & advanced technology partial zero & $\mathrm{mph}$ & miles per hour \\
\hline & emission vehicle & NTRC & National Transportation \\
\hline CAFE & Corporate Average Fuel Economy & & Research Center \\
\hline CPSR & constant power speed ratio & $\mathrm{Nm}$ & Newton meter \\
\hline $\mathrm{CT}$ & current transformer & OEM & original equipment manufacturer \\
\hline DAS & data acquisition system & ORNL & Oak Ridge National Laboratory \\
\hline dc & direct current & PEEMRC & Power Electronics and Electric \\
\hline DOE & U.S. Department of Energy & & Machinery Research Center \\
\hline ECU & electronic-control unit & PI & proportional integral \\
\hline EERE & Energy Efficiency and Renewable Energy & PM & permanent magnet \\
\hline emf & electromotive force (measured in volts) & PMSM & permanent magnet synchronous motor \\
\hline EMI & electromagnetic interference & PWM & pulse-width modulation \\
\hline FCVT & FreedomCAR and Vehicle Technologies & SDP & switching device power \\
\hline FEA & finite-element analysis & SUV & sport utility vehicle \\
\hline GMR & Giant Magneto Resistive & $\mathrm{rms}$ & root mean square \\
\hline HEV & hybrid electric vehicle & $\mathrm{rpm}$ & revolutions per minute \\
\hline $\mathrm{i}_{\mathrm{d}}$ & direct-axis current & TC & thermocouple \\
\hline & quadrature-axis current & THS II & Toyota Hybrid System \\
\hline IGBT & insulated-gate bipolar transistor & & (second generation) \\
\hline $\mathrm{I} / \mathrm{O}$ & input/output & $\mathrm{V}$ & volts \\
\hline IPEM & integrated power electronics module & $\mathrm{W}$ & watts \\
\hline
\end{tabular}




\section{INTRODUCTION}

The 2004 Toyota Prius is a hybrid automobile equipped with a gasoline engine and a battery- and generator-powered electric motor. Both of these motive-power sources are capable of providing mechanical-drive power for the vehicle. The engine can deliver a peak-power output of 57 kilowatts $(\mathrm{kW})$ at 5000 revolutions per minute $(\mathrm{rpm})$ while the motor can deliver a peak-power output of $50 \mathrm{~kW}$ over the speed range of 1200-1540 rpm. Together, this engine-motor combination has a specified peakpower output of $82 \mathrm{~kW}$ at a vehicle speed of $85 \mathrm{kilometers} \mathrm{per} \mathrm{hour}(\mathrm{km} / \mathrm{h})$. In operation, the 2004 Prius exhibits superior fuel economy compared to conventionally powered automobiles.

To acquire knowledge and thereby improve understanding of the propulsion technology used in the 2004 Prius, a full range of design characterization studies were conducted to evaluate the electrical and mechanical characteristics of the 2004 Prius and its hybrid electric drive system. These characterization studies included (1) a design review, (2) a packaging and fabrication assessment, (3) bench-top electrical tests, (4) back-electromotive force (emf) and locked rotor tests, (5) loss tests, (6) thermal tests at elevated temperatures, and most recently (7) full-design-range performance testing in a controlled laboratory environment. This final test effectively mapped the electrical and thermal results for motor/inverter operation over the full range of speeds and shaft loads that these assemblies are designed for in the Prius vehicle operations.

This testing was undertaken by the Oak Ridge National Laboratory (ORNL) as part of the U.S. Department of Energy (DOE) - Energy Efficiency and Renewable Energy (EERE) FreedomCAR and Vehicle Technologies (FCVT) program through its vehicle systems technologies subprogram.

The thermal tests at elevated temperatures were conducted late in 2004, and this report does not discuss this testing in detail. The thermal tests explored the derating of the Prius motor design if operated at temperatures as high as is normally encountered in a vehicle engine. The continuous ratings at base speed (1200 rpm) with different coolant temperatures are projected from test data at $900 \mathrm{rpm}$. A separate, comprehensive report on this thermal control study is available [1].

\subsection{PROGRAM OVERVIEW}

The hybrid electric vehicle (HEV) program officially began in 1993 as a five-year cost-shared partnership between DOE and American auto manufacturers: General Motors, Ford, and DaimlerChrysler. Currently, HEV research and development is conducted by DOE through its FCVT program. The mission of the FCVT program is to develop more energy efficient and environmentally friendly highway transportation technologies. Program activities include research, development, demonstration, testing, technology validation, and technology transfer. These activities are aimed at developing technologies that can be domestically produced in a clean and cost-competitive manner.

The vehicle systems technologies subprogram is one of four subprograms under the FCVT program which supports the efforts of FCVT through a three-phase approach intended to:

- Identify overall propulsion and vehicle-related needs by analyzing programmatic goals and reviewing industry's recommendations and requirements then develop the appropriate technical targets for systems, subsystems, and component research and development activities;

- Develop and validate individual subsystems and components including electric motors, emissioncontrol devices, battery systems, power electronics, accessories, and devices to reduce parasitic losses; and 
- Determine how well the components and subassemblies work together in a vehicle environment or as a complete propulsion system and whether the efficiency and performance targets at the vehicle level have been achieved.

Source: http://www.eere.energy.gov/vehiclesandfuels/technologies/systems/index.shtml

The research performed under the vehicle systems subprogram will help remove technical and cost barriers to enable technology for use in such advanced vehicles as hybrid and fuel-cell-powered vehicles.

\subsection{TESTING FACILITIES}

Evaluation of the 2004 Prius and its hybrid electric drive system involved both vehicle-level and subassembly-level performance testing. Vehicle-level testing is being conducted at the Advanced Powertrain Research Facility (APRF) located at the Argonne National Laboratory (ANL), in Argonne, Illinois. The APRF is a multi-dynamometer vehicle test facility capable of testing conventional and hybrid vehicle propulsion systems and vehicles. Subassembly-level testing is being conducted by ORNL at its Power Electronics and Electric Machinery Research Center (PEEMRC). The PEEMRC is a broadbased research center for power electronic inverters and electric machinery (motor) development. Located in the recently constructed national user facility known as the National Transportation Research Center (NTRC), the PEEMRC has more than 9000 square feet of space for developing and building the next generation prototypes of inverters, rectifiers, and electric machine technology.

\subsection{SCOPE AND OBJECTIVE}

This report summarizes vehicle-level and subsystem-level test results obtained for the 2004 Prius and various electrical and mechanical subassemblies of its hybrid electric drive system. The primary objective of these tests was to (1) characterize the electrical and mechanical performance of the 2004 Prius, and (2) map the performance of the inverter/motor system over the full design speed and load ranges.

Information about the 2004 Prius and its technical design features is presented in Section 2 to serve as a foundation for subsequent discussions about the various subassemblies of the hybrid electric drive system that were tested. Laboratory test results are summarized in Section 3. They include electrical and mechanical data that have been acquired to date at ANL and ORNL. The objectives of these tests were to characterize the functional performance of the hybrid electric drive system and to understand the design methodology used in the construction of the various system subassemblies - specifically the generator, traction motor, and inverters.

Information about the inverters and converter is presented in Section 4. This information includes discussions about the functional characteristics and control development for the motor inverter and converter and a description of inverter modifications that will provide a way to measure current and voltage values at specific locations. Packaging and volume/weight data is provided in Section 5. This information includes the derivation of peak-power-to-volume and -weight ratios which are related to key FCVT design targets. Preliminary conclusions and findings based on the acquired test data along with areas of needed research and development are presented in Section 6. 


\subsection{APPROACH}

Complementary electrical and mechanical data from vehicle-level and subsystem-level tests were acquired to gain a full understanding of the 2004 Prius performance. These data were then used to determine back-emf voltage and energy loss values over the specified operating range of the vehicle.

Vehicle-level tests were performed at the APRF with the electrical and mechanical systems installed in the original factory configuration. The inverter, motor, generator, axles, and related subassemblies are instrumented to acquire power-flow data needed to characterize vehicle performance.

Subsystem-level tests were performed at the NTRC by removing the hybrid electric drive system and inverter from the vehicle and mechanically connecting the shaft to a dynamometer. This arrangement required a reconfiguration of the inverter so that it will operate outside the vehicle (see below). Using this approach makes it possible to separately evaluate the performance of each power-related subsystem of the hybrid electric drive system. Subsystem-level test results provide data needed to characterize the overall performance of the 2004 Prius HEV system.

Operating the permanent magnet synchronous motor (PMSM) and inverter systems outside the vehicle represents a considerable challenge. Figure 1.1 shows a partial diagram of the electronic-control unit (ECU) and some of the many interconnected vehicle systems. The ECU is the "brain" of the highly integrated vehicle electrical system. In order to operate the inverter and PMSM outside the vehicle, it was necessary to sever the many interconnecting lines between the inverter/PMSM/boost-converter system and the ECU (many more lines exist than are shown in the simplified schematic). Extracting and operating the ECU with the subassemblies of interest would have meant attending to the hundreds of signals it must have to operate (an option that was not chosen). Therefore, to accomplish out-of-vehicle operation, ORNL was forced to replace the ECU with a sophisticated and versatile inverter controller capable of providing complex control features such as a high-speed control loop and field weakening.
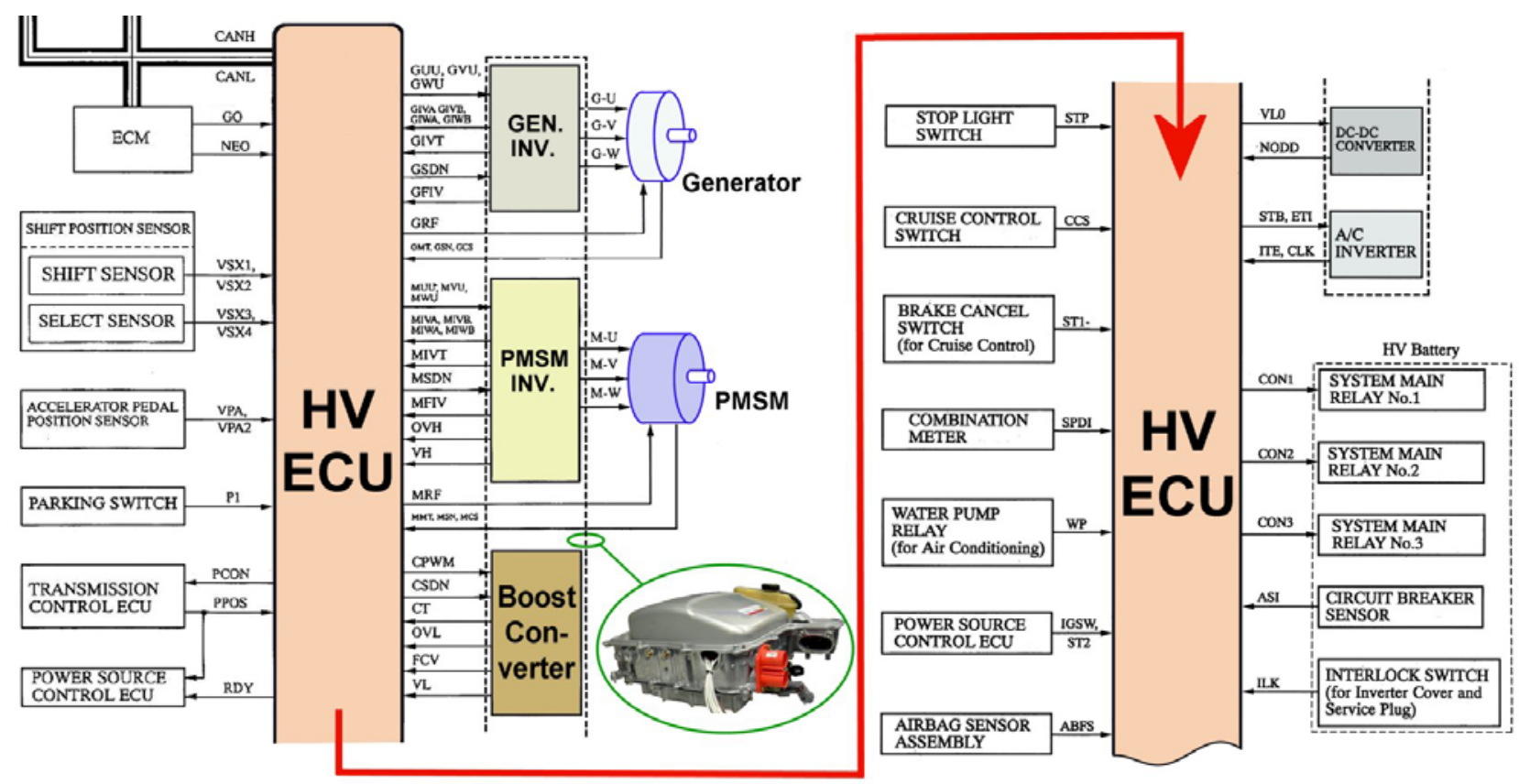

Fig. 1.1. Predominant project challenge represented by a highly integrated vehicle control system. 


\section{HYBRID ELECTRIC DRIVE SYSTEM DESCRIPTION}

The 2004 Prius is a new-generation hybrid automobile that was introduced into the market in September 2003 by the Toyota Motor Corporation. As a hybrid vehicle, the 2004 Prius uses both a gasoline-powered internal combustion engine capable of delivering a peak-power output of $57 \mathrm{~kW}$ and a battery-powered electric motor capable of delivering a peak-power output of $50 \mathrm{~kW}$ as motive power sources. Combining these two-motive power sources results in improved fuel efficiency and reduced emissions compared to traditional automobiles and provides the 2004 Prius with the following energysaving characteristics.

- Energy-loss reduction is achieved by automatically stopping the engine when idling.

- Energy is recovered and reused by capturing kinetic energy that is normally wasted as heat during deceleration and braking. The starter and electric motor then convert this energy to electricity for use.

- Engine is able to operate at peak-efficiency speed a high percentage of the time.

- Supplementary power is provided by the electric motor during acceleration when engine efficiency is low.

- Optimal vehicle efficiency is realized by using the electric motor to run the vehicle under operating conditions when engine efficiency is low and by generating electricity when engine efficiency is high.

Enhanced performance of the 2004 Prius is attributed to the new-generation Toyota Hybrid System (THS II). This system is a power train consisting of a high-power motor, generator, and a battery of relatively low power. Major subassemblies of the THS II are shown in Fig. 2.1. As this figure indicates, a mechanical subassembly referred to as a power-split device (planetary-gear set) separates power supplied by the gasoline engine into two paths. In the mechanical path, engine power is transmitted to the vehicle's wheels directly through the transmission. In the electrical path, a generator converts mechanical energy from the engine into electrical energy. Electricity produced by the generator is then available for either supplementing the battery power to the electric motor or charging the battery, or both. By using energy in this manner, the 2004 Prius requires no external power source for battery charging. The powersplit device allows the engine to function at or near its optimal operating speed, regardless of vehicle speed, while still being able to efficiently add power to the wheels and simultaneously drive the generator. A photograph of the engine and hybrid drive assembly after removal from the car is shown in Fig. 2.2.

In operation, the 2004 Prius is capable of functioning in the following modes:

- When engine efficiency is low, such as during start-up and mid-range speeds, motive power is provided by the motor alone using energy stored in the battery.

- Under normal driving conditions, overall efficiency is optimized by controlling the power allocation so that some of the engine power is used for turning the generator to supply electricity for the motor while the remaining power is used for turning the wheels.

- During periods of acceleration when extra power is needed, the generator supplements the electricity being drawn from the battery so the motor is supplied with the required level of electrical energy. 
- While decelerating and braking, the motor acts as a generator that is driven by the wheels thus allowing the recovery of kinetic energy. The recovered kinetic energy is converted to electrical energy that is stored in the battery.

- When necessary, the generator recharges the battery to maintain sufficient reserves.

- At times when the vehicle is not moving and when the engine moves outside of certain speed and load conditions, the engine stops automatically.

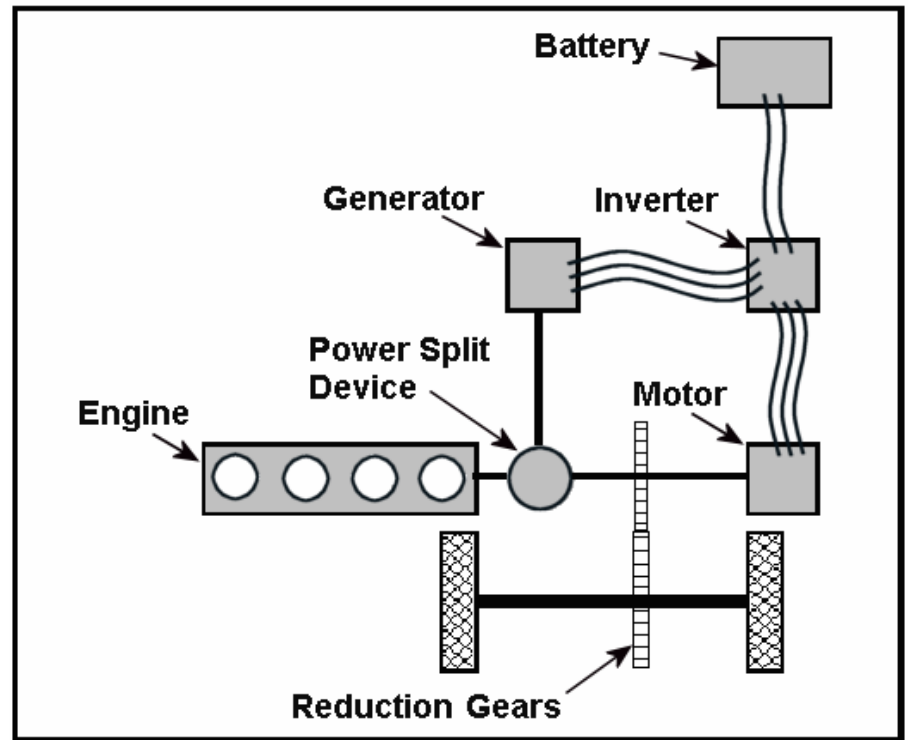

Fig. 2.1. Subassembly arrangement for the THS II.

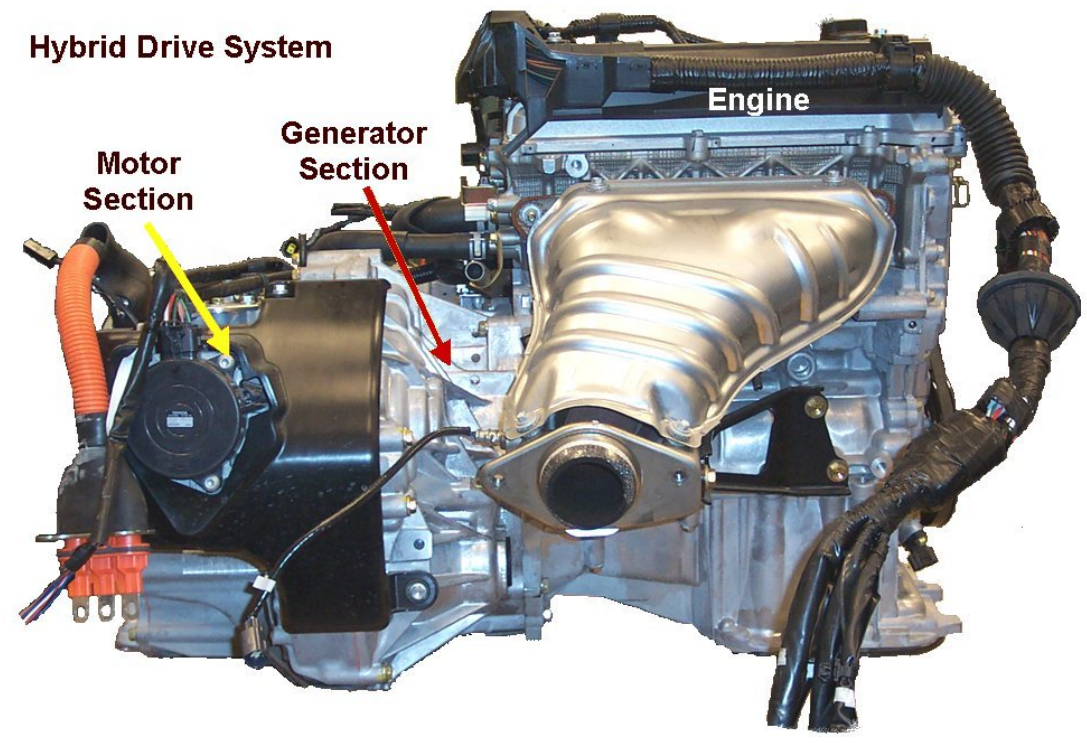

Fig. 2.2. 2004 Prius engine and hybrid drive assembly.

Additional information about the capabilities and properties of the 2004 Prius are presented in a separate ORNL report [2]. 
To maintain the operating temperature of the various system components within an acceptable range, the 2004 Prius has two separate ethylene glycol based coolant systems. The arrangement of these coolant systems and a brief description of their functional characteristics are presented in Fig. 2.3.

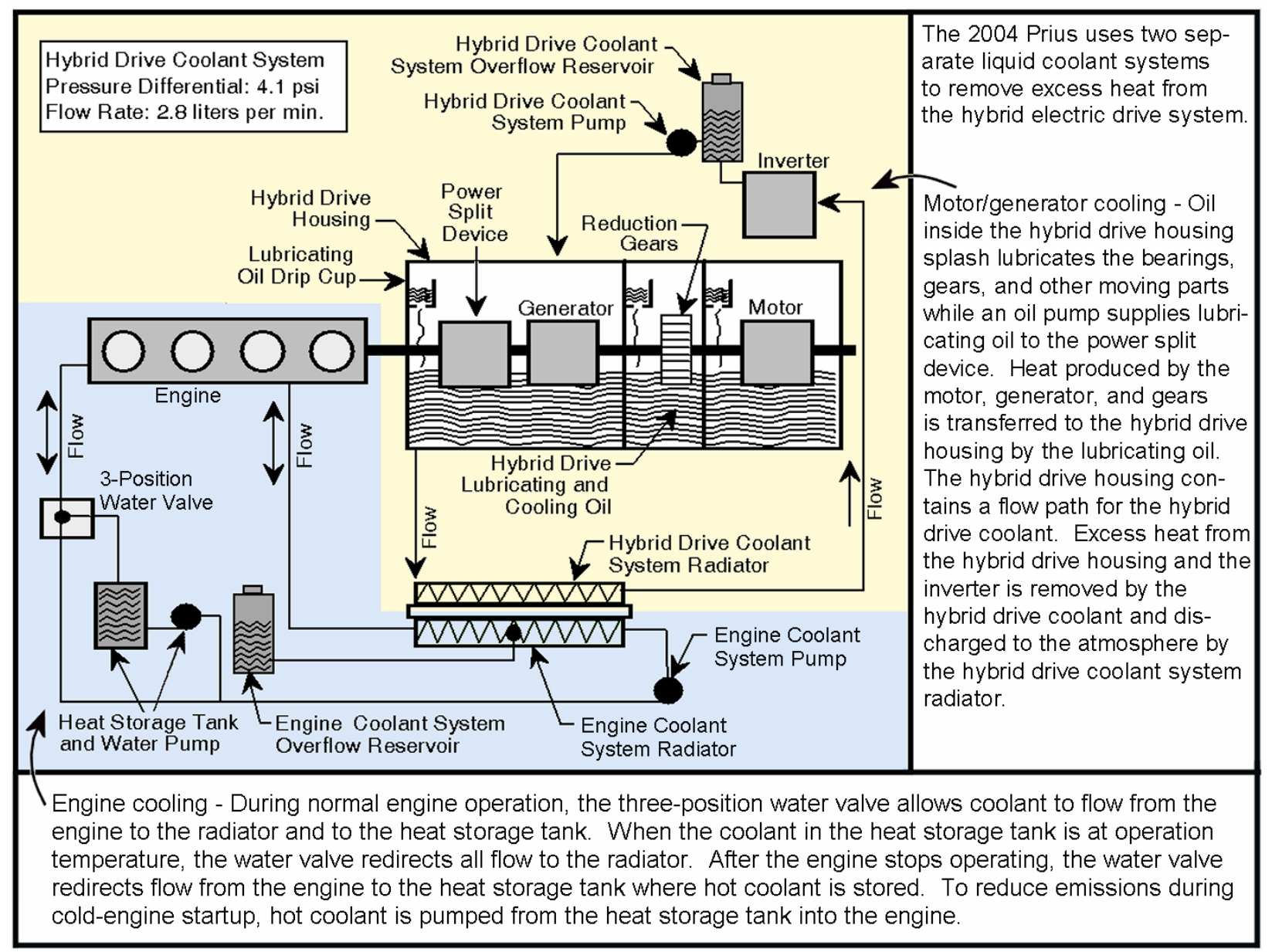

Fig. 2.3. Heat removal and lubrication scheme for the 2004 Prius.

The engine-coolant system is similar to the coolant system in a traditional automobile. Its purpose is to circulate a liquid coolant through the engine to remove excess thermal energy generated by fuel combustion. A pump forces the coolant to flow from the engine to a radiator where the waste heat is dumped. To keep the coolant from escaping, the coolant is confined in a closed loop that is protected from over pressurization by a self-closing pressure relief valve (radiator cap). This valve vents at a pressure that is slightly above atmospheric pressure thereby allowing the coolant to remain liquid at a temperature slightly above the boiling point of water. To accommodate changes in coolant volume caused by temperature and pressure fluctuations, the system includes a tank that functions as an overflow reservoir. The engine-coolant system also includes an insulated coolant storage bottle that stores hot coolant during shutdown and makes it available when the engine is restarted. Using hot coolant in this way reduces exhaust-gas emissions produced during cold-engine startup. 
The hybrid-drive-coolant system is separate from the engine-coolant system because the two systems operate at different temperatures ${ }^{1}$. Powered by an electric pump, the liquid coolant in this closed-loop system flows continuously through the motor, generator, inverter, and radiator. Heat removed from these electrical components is transferred to the surrounding atmosphere by the radiator. Like the enginecoolant system, the hybrid-coolant system also includes a tank that functions as an overflow reservoir.

Detailed information about the 2004 Prius and its operation and maintenance is provided in the threevolume repair manual published by the Toyota Motor Corporation [3-5].

\subsection{DESIGN REQUIREMENTS}

The high-voltage power circuit in the THS II, which includes the motor and generator, is designed to operate over a variable voltage range of $200-500 \mathrm{Vdc}$. This elevated-voltage design feature results in an increase in efficiency because electrical power can be supplied to the motor using less current. In addition, the elevated voltage allows the motor to operate at higher speeds where high emf would inhibit the speed of a lower voltage motor.

\subsection{SYSTEM SUBASSEMBLIES}

Major THS II subassemblies in the 2004 Prius include the:
- engine
- motor
- power-split device
- inverter
- generator
- battery

The specification for these subassemblies is shown in Table 2.1 (Sources include http://www.toyota.co.jp/en/tech/environment/ths2/ and http://www.toyota.com/vehicles/2005/prius/specs.html).

Table 2.1. Specification for THS II subassemblies

\begin{tabular}{cll}
\hline Subassembly & \multicolumn{1}{c}{ Property Description } & \multicolumn{1}{c}{ Property Value } \\
\hline Engine & Type & 1.5 liter gasoline (high-expansion ratio cycle) \\
& Maximum output & $57 \mathrm{~kW}$ at $5000 \mathrm{rpm}$ \\
& Maximum torque & $115 \mathrm{Newton}$ meter $(\mathrm{Nm})$ at $4200 \mathrm{rpm}$ \\
\hline \multirow{2}{*}{ Motor } & Type & Synchronous alternating current (ac) \\
& Mermanent magnet (PM) motor \\
& Maximum output & $50 \mathrm{~kW}$ between 1200 and $1540 \mathrm{rpm}$ \\
& Mystem* & $400 \mathrm{Nm}$ between 0 and $1540 \mathrm{rpm}$ \\
& Maximum output & $82 \mathrm{~kW}$ at $85 \mathrm{~km} / \mathrm{h}$ and higher \\
& lower & $478 \mathrm{Nm}$ \\
\hline Battery & Type & Nickel-metal hydride \\
& Construction & $28 \mathrm{~km} / \mathrm{h}$ or \\
& Voltage & $201.6 \mathrm{~V}$ \\
& Power output & $21 \mathrm{~kW}$ \\
\hline
\end{tabular}

* Maximum combined engine and hybrid-battery output and torque constantly available within a specified vehicle speed range.

\footnotetext{
${ }^{1}$ Although the reason for using two separate coolant systems cannot be confirmed, it is believed that this decision was made to allow the motor, generator, and inverter to operate well below $100^{\circ} \mathrm{C}$, the boiling point of water.
} 


\subsubsection{Engine}

The design of the Type 1NZ-FXE 1.5-liter engine in the 2004 Prius is based on the Atkinson Cycle in which compression stroke and expansion stroke duration can be set independently. The transverseoriented, water-cooled, 4-stroke engine features 4 in-line cylinders, 16 valves, a double overhead cam with chain drive, and a 13:1 compression ratio. The high expansion ratio cycle engine design has helped to certify the vehicle as an advanced technology partial zero emission vehicle (ATPZEV).

\subsubsection{Power-Split Device}

Major transmission subassemblies in the THS II include the power-split device (planetary-gear set), the generator, the electric motor, and the reduction gears. The purpose for the power-split device is to allow power from the engine to turn the generator and the wheels simultaneously. In operation, shaft power from the engine is transmitted via the planetary carrier. The rotational shaft of the planetary carrier inside the gear mechanism is directly linked to the engine and transmits the motive power to the outer-ring gear and the inner-sun gear via pinion gears. The rotating shaft of the ring gear is directly linked to the motor and transmits traction-drive force while the rotating shaft of the sun gear is directly linked to the generator. Diagrams of the power-split device and the gear train that connect the motor to the front wheels are shown in Figs. 2.4 and 2.5, respectively. The actual gear arrangement is shown in Fig. 2.6.

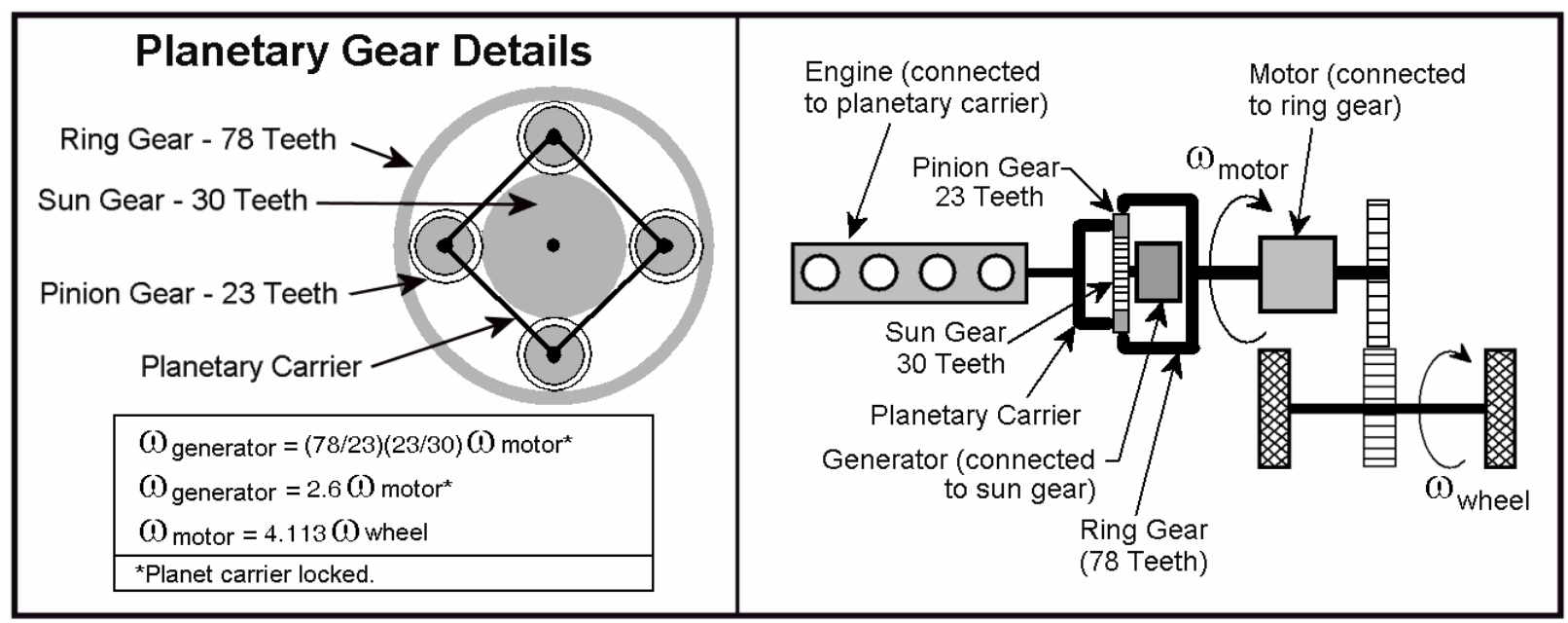

Fig. 2.4. Diagram of the 2004 Prius power-split device. 


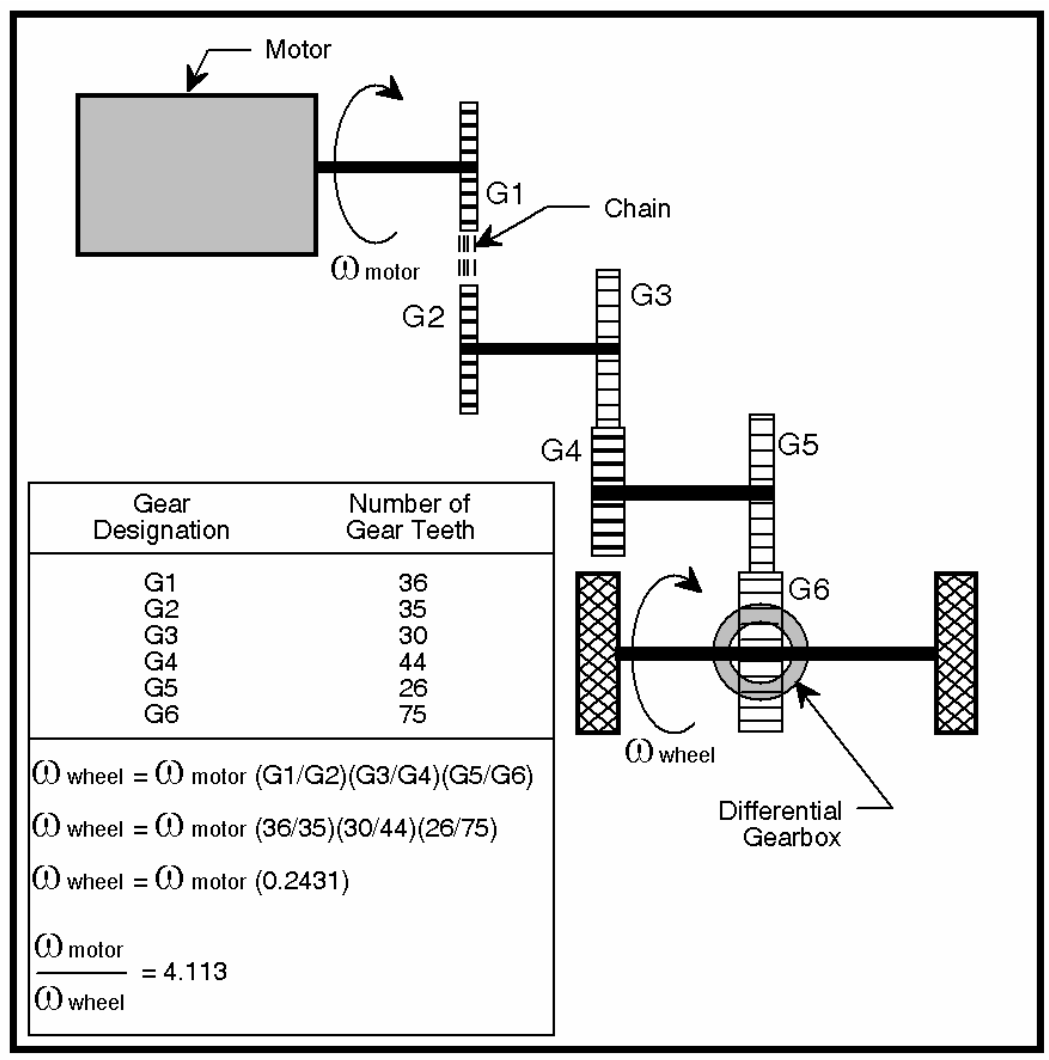

Fig. 2.5. Diagram of the 2004 Prius gear train between the motor and wheels.

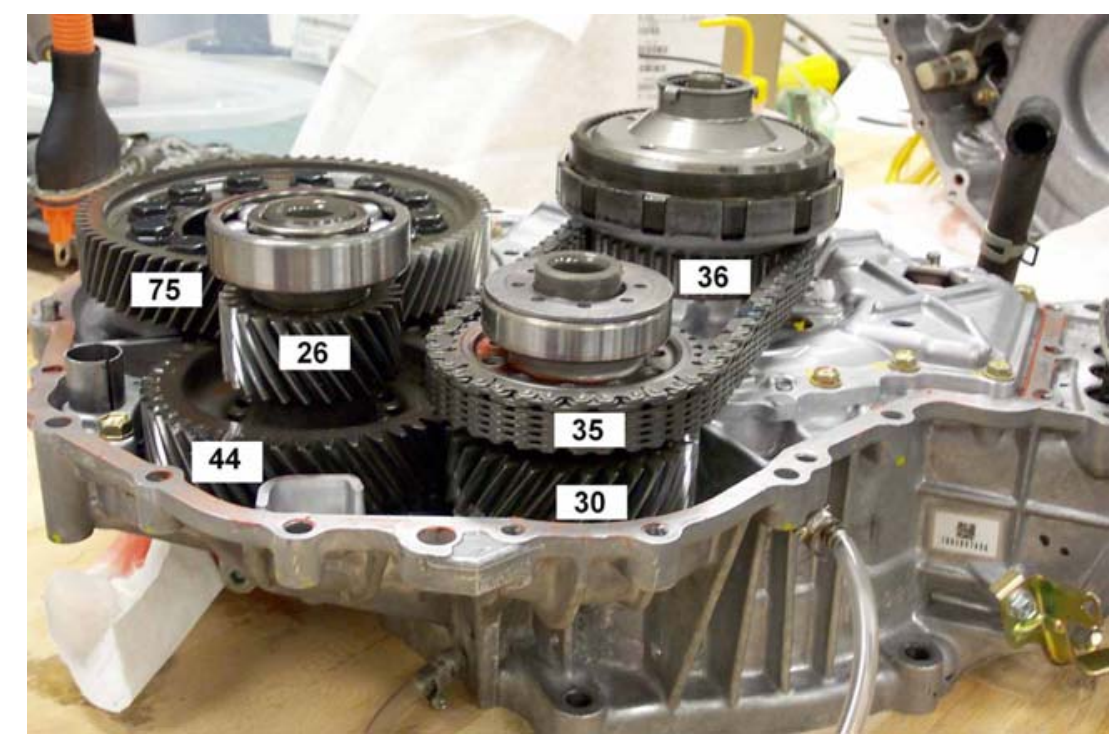

Fig. 2.6. 2004 Prius gears with number of gear teeth shown. 


\subsubsection{Generator}

The THS II includes a synchronous-type ac generator that rotates at high speeds up to $10,000 \mathrm{rpm}$. By rotating at high speeds, the generator, which is an eight-pole PM device, provides high-power density for charging the battery and supplementing motor power requirements. In addition, the generator also functions as the engine starter. At start up, the generator rotates the sun gear in the power-split device and thereby provides cranking power for the engine. The configuration of the generator rotor is shown in Fig. 2.7.

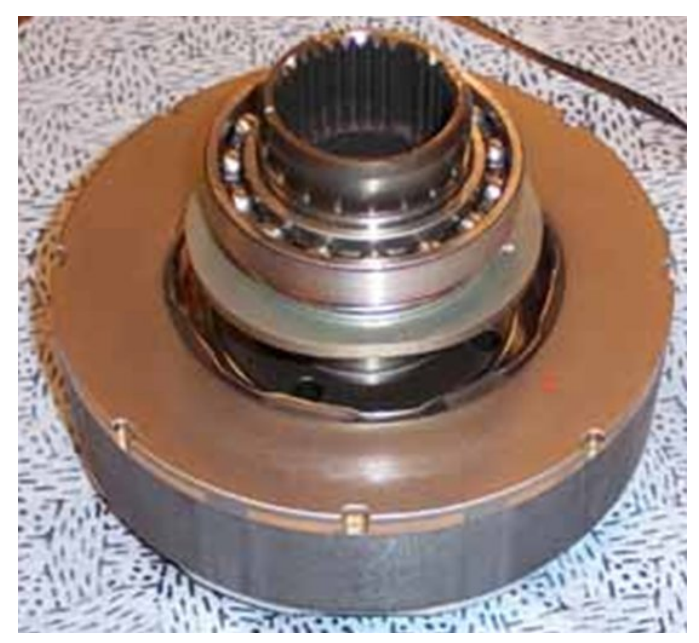

Fig. 2.7. 2004 Prius generator rotor.

\subsubsection{Motor}

The eight-pole, PMSM features high low-speed torque and high power output. It is designed as a highefficiency, brushless direct current $(\mathrm{dc})$ motor. The motor rotor is constructed with interior PMs and laminated stacked electromagnetic steel plates. The PMs are arranged in a V-shape as opposed to conventional radial alignment. In addition, with a high supply voltage up to $500 \mathrm{~V}$, the peak-power output of the motor is $50 \mathrm{~kW}$. The configuration of the motor and stator are shown in Fig. 2.8. Additional details about the design and manufacture of the motor are contained in a report that was recently published by ORNL [6]. Supplementary information about locked rotor torque and current performance, which is addressed in Section 3.2.1, is contained in another ORNL report [2].

\subsubsection{Inverter}

The power control unit consists of the following subassemblies

- motor inverter,

- generator inverter,

- voltage-buck/boost converter,

- air-conditioning compressor inverter, and

- a $12 \mathrm{~V}$ dc-to-dc converter. 


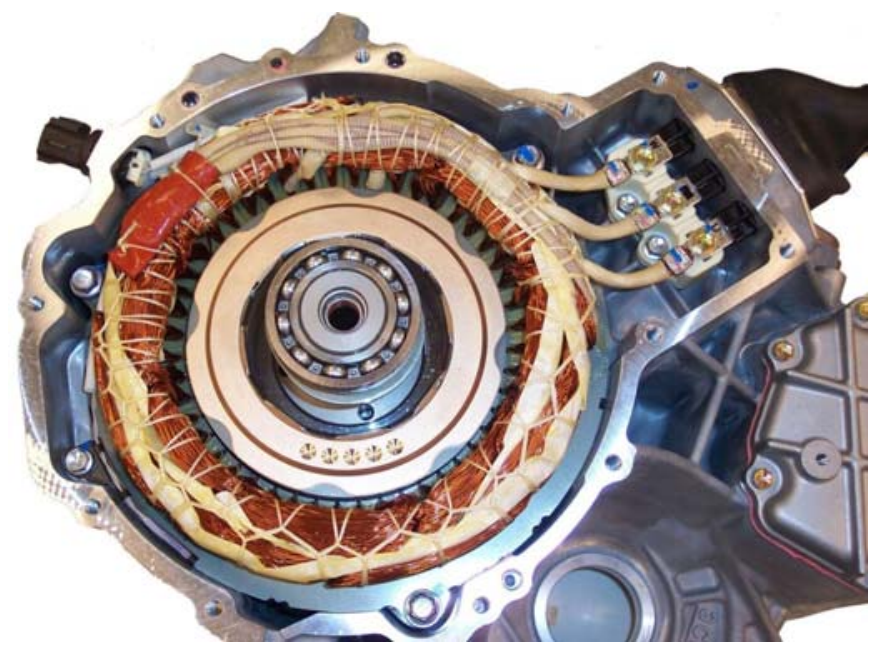

Fig. 2.8. 2004 Prius motor rotor and stator.

The unit, which is shown in Fig. 2.9, contains an inverter that produces 3-phase ac for driving the motor and includes a dc-to-dc converter that produces $12 \mathrm{~V}$ for auxiliary equipment. It also includes a highvoltage, bi-directional, dc-to-dc converter that boosts the $200 \mathrm{~V}$ battery up to a maximum of $500 \mathrm{Vdc}$ link, or bucks the higher voltage dc link (that may range from $200-500 \mathrm{~V}$ ) down to charge the $200 \mathrm{~V}$ battery.

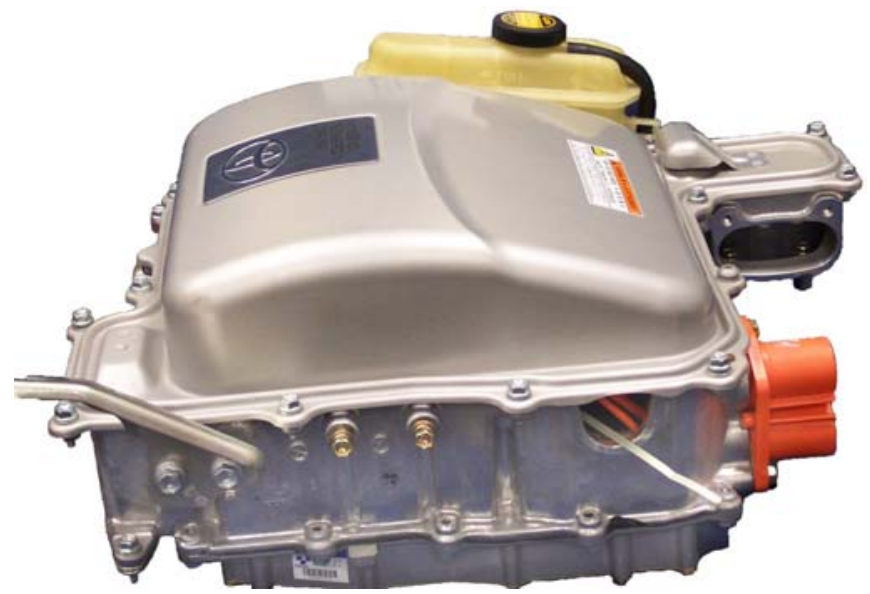

Fig. 2.9. 2004 Prius inverter and voltage converter unit.

\subsubsection{Battery}

A compact, high-performance nickel-metal hydride rechargeable battery is used in the 2004 Prius. The battery consists of 28 low-voltage modules $(7.2 \mathrm{~V}$ each) connected in series to produce a nominal $201.6 \mathrm{~V}$. It provides electricity to the motor and receives charging energy from the generator. The specified power output from the battery is $21 \mathrm{~kW}$. 


\section{LABORATORY TESTING}

Laboratory testing of the 2004 Prius hybrid electric drive system and its subassemblies is being conducted at ANL and ORNL. The objectives of these testing programs are to characterize the functional performance of the hybrid electric drive system and to understand the design methodology used in the construction of its various subassemblies, specifically the traction motor, inverter, generator, and coolant system.

\subsection{ANL VEHICLE-LEVEL PERFORMANCE TESTS}

This section describes in two subsections the early performance testing of the Prius and later test data that focuses on the operation of the voltage-boost converter.

\subsubsection{Initial Performance Testing at ANL}

Beginning in early 2004, a vehicle-level performance-testing program was initiated at ANL. Objectives of this ongoing collaboration are to determine the operating characteristics and to quantify efficiencies of the 2004 Prius hybrid electric drive system as installed in the vehicle and as operated based on algorithms contained in the ECU. The tests are being conducted at the APRF under both steady-state and dynamic conditions. To acquire the necessary electrical data, all accessible power-flow points were instrumented to measure voltage and current. Power measurements were obtained between the following locations:

- Generator and inverter (Phase A current, Phase B current, A-C line voltage, B-C line voltage),

- Traction motor and inverter (Phase A current, Phase B current, A-C line voltage, B-C line voltage),

- Boost converter and battery (battery current, battery dc voltage), and

- Boost converter to main inverters (dc voltage, current).

Test variables that were measured are identified in Table 3.1.

Table 3.1. Measurement variables for ANL testing program

\begin{tabular}{lcc}
\hline \multicolumn{1}{c}{ Variable Description } & Variable Designation & Measurement Type \\
\hline Generator power & $\mathrm{P}_{\text {genAC }}$ & Electrical \\
Motor power out (to wheels) & $\mathrm{P}_{\mathrm{mtr}}$ & Mechanical \\
Inverter power out (inverter to & $\mathrm{P}_{\mathrm{mtrAC}}$ & Electrical \\
motor) & $\mathrm{P}_{\text {boostHI }}$ & Electrical \\
Boost power high side & $\mathrm{P}_{\mathrm{BATT}}$ & Electrical \\
Battery power (battery dc link) & &
\end{tabular}

Each test run was conducted with the air-conditioner compressor inverter and the auxiliary $12 \mathrm{~V}$ dc-to-dc converter disabled. To ensure precise acceleration and speed settings during the tests, the accelerator position was remotely controlled.

The ANL chassis dynamometer is normally set up to monitor vehicle emissions under various driving cycles. Testing of a HEV requires a greater monitoring effort to cover the additional electrical devices incorporated in the vehicle. In addition, the joint ANL and ORNL testing effort requires very precise power measurements to fully characterize 2004 Prius performance. The test setup for the 2004 Prius 
hybrid electric drive system involves current and voltage measurements at numerous points within the system. Figure 3.1 shows the configuration of the basic electrical system for the 2004 Prius hybrid electric drive system and the locations of the installed instrumentation. Details about the ANL inverter modifications are discussed in Section 4.3.

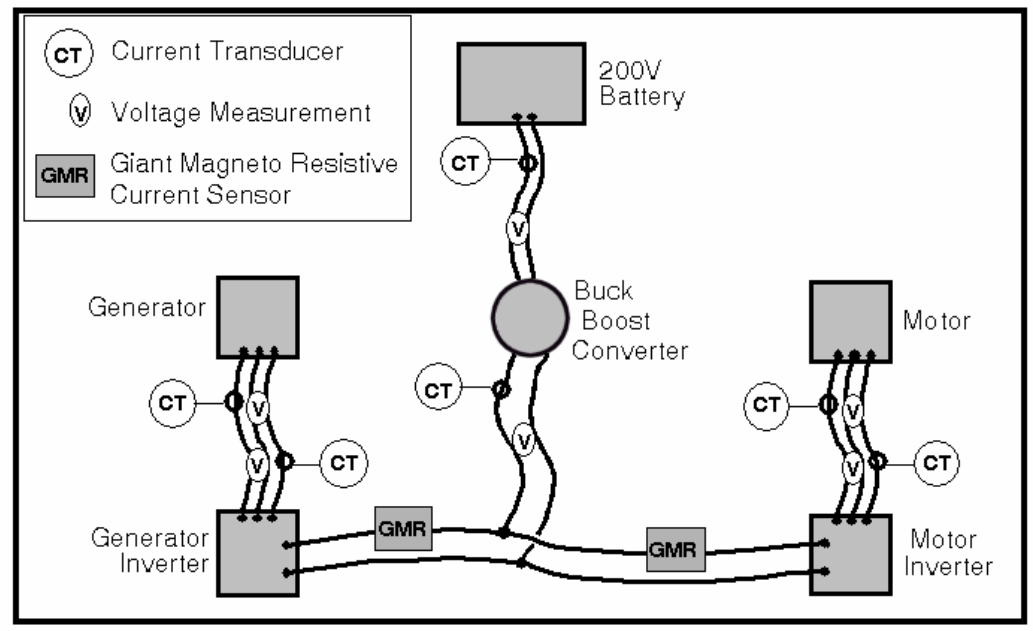

Fig. 3.1. Instrumentation locations for ANL testing.

An example time trace of data being acquired during the tests is presented in Fig. 3.2. It shows the power flow in different parts of the hybrid electric drive system with the vehicle speed overlaid on the graph. Review of this graph reveals that engine power is high when the vehicle is accelerating to higher speeds and drops to zero when the vehicle speed is constant, thus allowing the electric motor to propel the vehicle without assistance from the engine. At the highest speeds, however, the engine and the motor simultaneously supply power for the vehicle. Subsequent to the test, calibration checks of the powersensing equipment indicated possible offsets and discrepancies in the data. Additional data is needed to fully characterize vehicle-level performance.

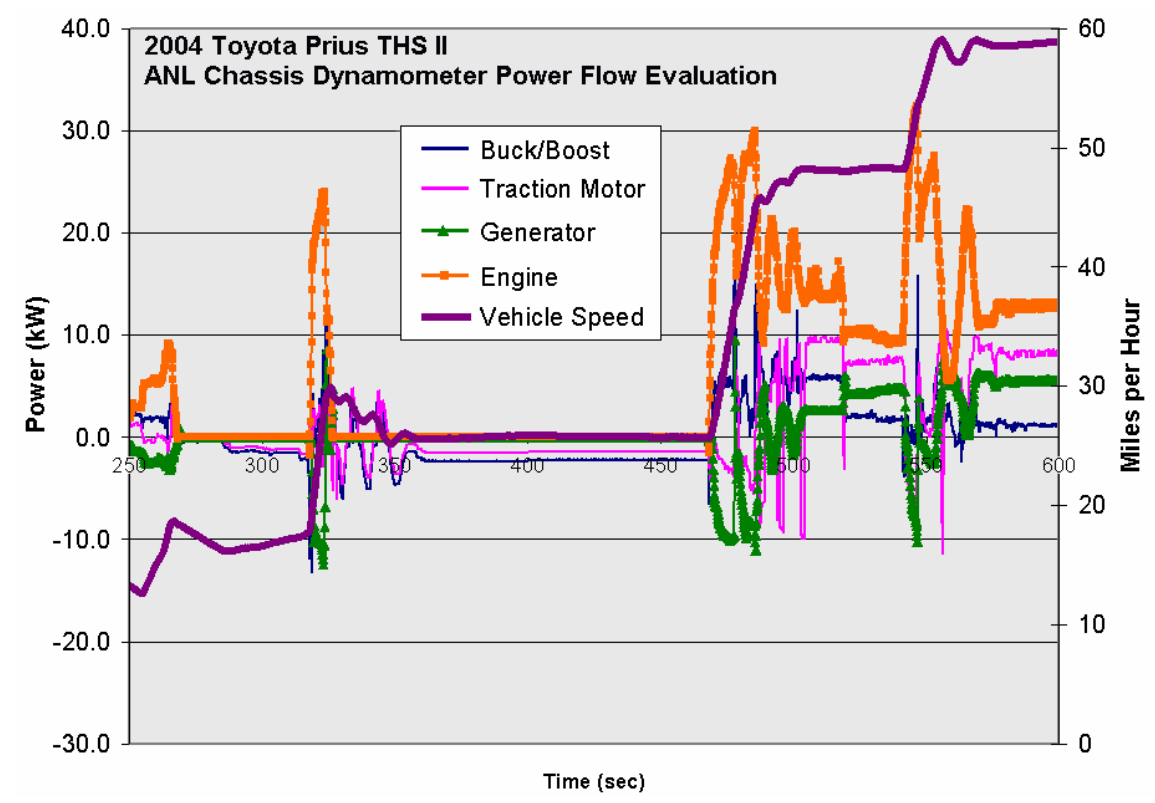

Fig. 3.2. Sample power measurements under varying speed conditions. 
Another example data plot that illustrates the relationship between battery power, boost-converter power, and motor power is shown in Fig. 3.3. This data was acquired under controlled conditions in which all auxiliary equipment was switched off (i.e., air-conditioning compressor inverter and $12 \mathrm{~V}$ dc-to-dc converter) so the battery, boost, and motor power levels would be directly related to each other. Boost power is very close to the battery power because boost converters have low losses. Motor electrical power should be approximately the same but slightly lower due to efficiency losses in the motor inverter. Gross efficiencies can be inferred from this data, but more detailed efficiency results from additional tests are needed.

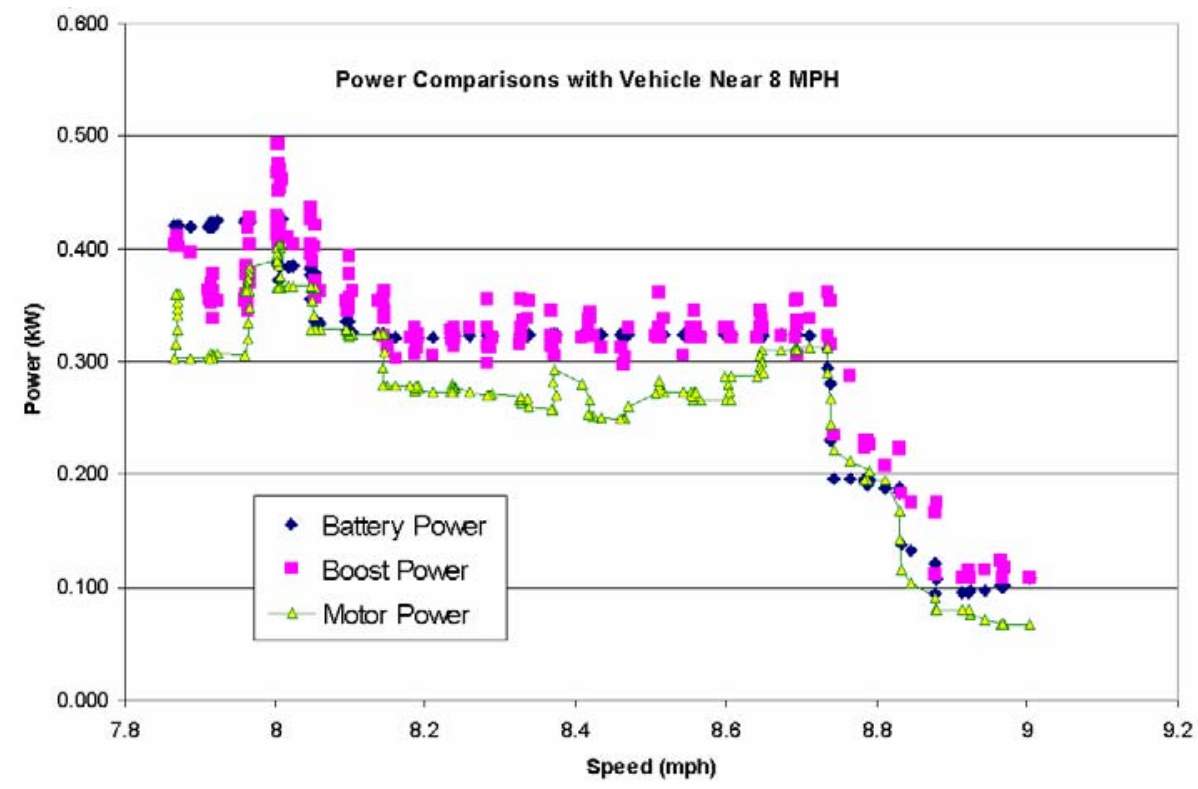

Fig. 3.3. Sample power measurements under controlled speed conditions.

Although this graph validates the measurement results, slight discrepancies in the data and other factors indicate the need to improve sensor calibrations and data acquisition system (DAS) settings prior to future tests.

\subsubsection{Vehicle Data Characterizing Boost-Converter Operation}

With planning underway for detailed performance testing at ORNL, it was necessary to review ANL data that made clear the operation of the voltage-boost circuit in the Prius. In addition, there was considerable technical interest in boost converters, including both their packaging (see Sections 5.2 and 5.3) and operation. (Note: ORNL converter test data and efficiency maps are provided in Section 3.3.4.) In the Prius HEV system, the PMSM obtains most of its power from the generator and the rest from the HEVbattery-converter-inverter system. Thus, the converter's power rating is less than half of the PMSM's rating.

Of high interest is how the generator voltage, which increases with vehicle speed, compares to the voltage that the ECU directs the converter to produce. In order to determine this, the generator back-emf data plot was modified ${ }^{2}$ as shown in Fig. 3.4 to show, by extrapolation, the voltage-speed relationship at speeds up to $10,000 \mathrm{rpm}$. Also, the vehicle speed is included in the plot so that the data can be compared to vehicle operation data provided by ANL. Note that the peak voltage developed in the generator is in the variable

${ }^{2}$ The full set of generator data is provided in Section 3.2.2.2. 
range of the dc converter when the vehicle is traveling from $25-65$ miles per hour (mph). This relationship will prove useful in the discussion below.

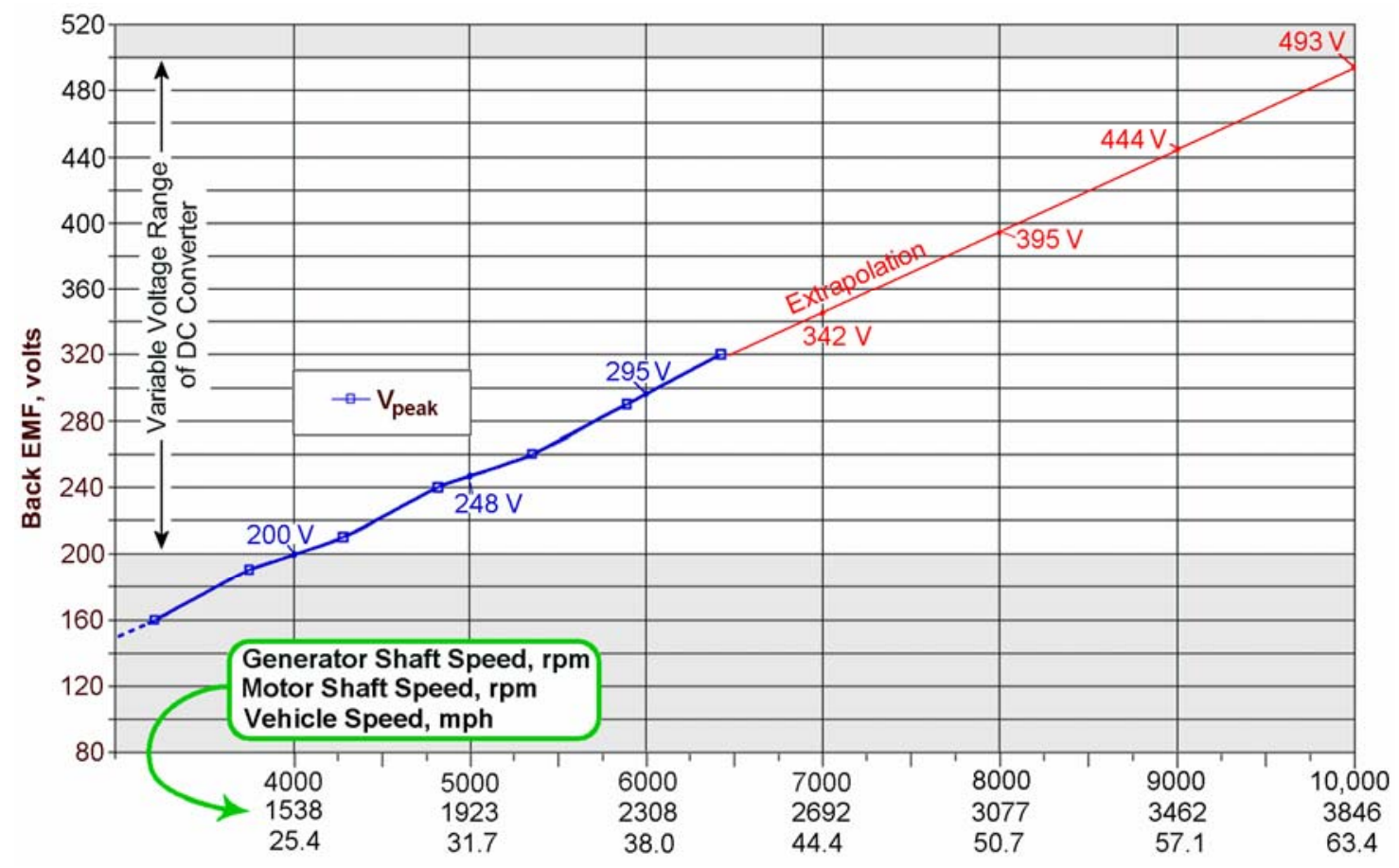

Fig. 3.4. Extrapolation of generator back-emf data for generator speeds up to $10,000 \mathrm{rpm}$.

Subsequent to the testing at ANL described in Section 3.1.1, ANL generated additional test data and, at ORNL's request, transmitted converter-related data to ORNL in April 2005. This data helped to characterize the operation of the voltage-boost converter relative to acceleration and vehicle speed. The voltage-buck operation is not reflected in the data, but clearly the battery-charging function requires a reduction from the generator and PMSM output voltages to a voltage a few volts higher than the 201.6 volts (V) battery voltage.

The plots that follow show the following five parameters: V and I output from the converter, accelerator pedal position output, brake-pedal position output, and vehicle speed. Note that positive current powers the PMSM and negative current charges the HEV battery. Units are excluded since the plots are intended to provide qualitative comparisons.

Figure 3.5 shows data from a drive cycle where the vehicle was accelerated to about $31.5 \mathrm{mph}$, based on chassis-dyne data, followed by braking. A portion of the y-axis scale is expanded to enlarge/clarify the plots at the bottom of the chart (also making the depiction qualitative). As indicated in the figure, there are three instances where a current spike from the output of the voltage-boost circuit preceded or accompanied a rise in the output voltage from the boost circuit. The voltage then remained elevated for different periods and then fell. Two occurred during acceleration and one at the end of the acceleration period. The data does not appear to provide a full picture of what is happening and this is not surprising since the ECU algorithm is unknown. 


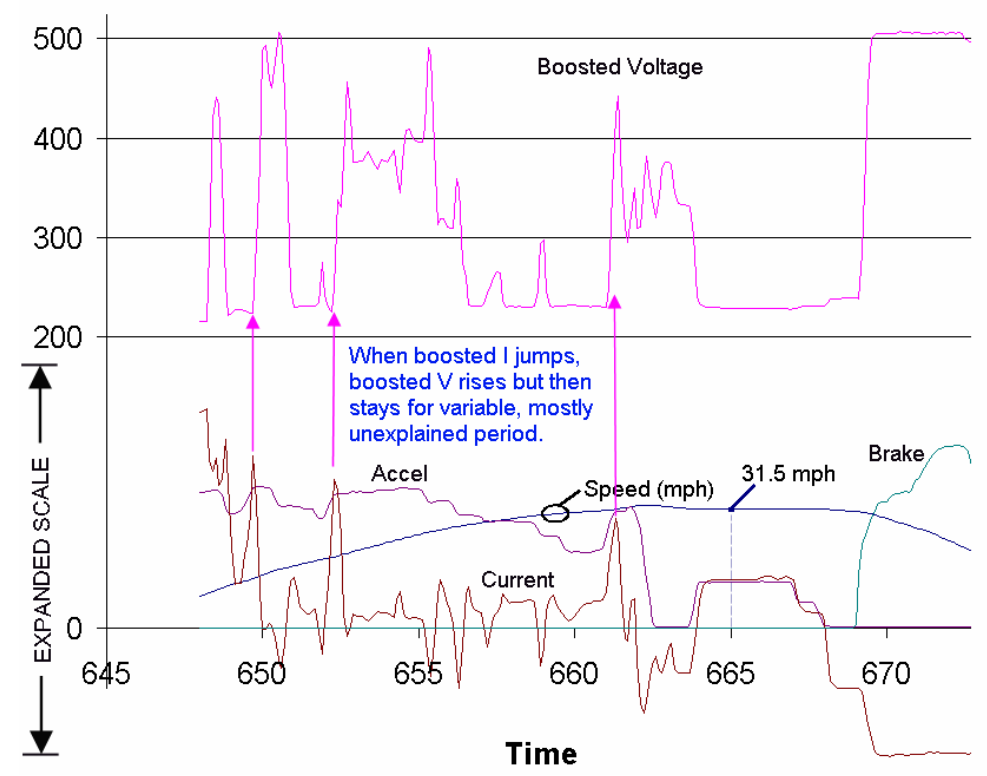

Fig. 3.5. Drive-cycle data from ANL showing voltage-boost converter response.

Note that braking causes a maximum boost to $500 \mathrm{~V}$ to support the regeneration battery-charging mode. Since ORNL testing will not include an evaluation of this process, periods of braking will be excluded from the drive-cycle plots which follow.

In Fig. 3.6, the second drive-cycle period shows an elevated voltage level corresponding to a rapid acceleration followed by an extended period of time at the minimum voltage (just above $200 \mathrm{~V}$ ). This is followed by a few brief, voltage spikes of unknown causes that are postulated to be of no value to the operation of the inverter/motor system.

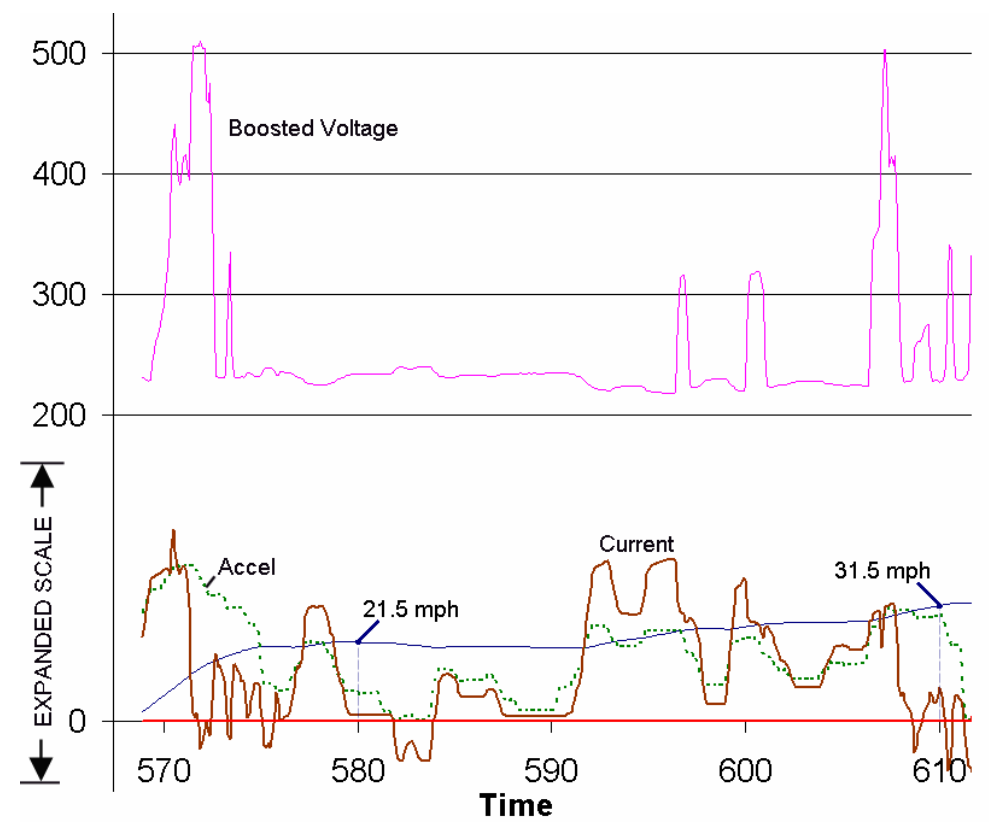

Fig. 3.6. Second drive-cycle data set from ANL showing voltage-boost converter response. 
In Fig. 3.7, the third drive-cycle period shows a rapid acceleration followed by operation at vehicle speeds above $40 \mathrm{mph}$. These data show a sustained voltage boost to well above $300 \mathrm{~V}$ and the maximum of 500 $\mathrm{V}$ during acceleration. The plot depicts an intermediate voltage-boost state that occurs at these vehicle speeds.

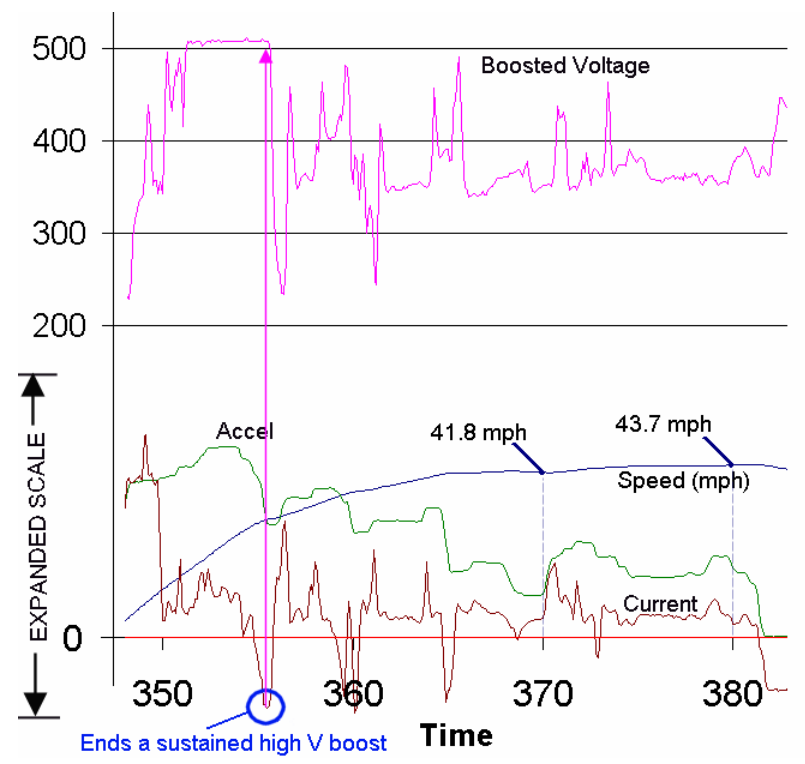

Fig. 3.7. Third drive-cycle data set from ANL showing voltage-boost converter response.

Much of what the preceding figures have shown is further clarified in the fourth drive-cycle plot in Fig. 3.8. In this case the vehicle is accelerated to about $68 \mathrm{mph}$. Because the level of acceleration is varied, the voltage boost swings between minimum and maximum several times. From $28.1-49.8 \mathrm{mph}$, maximum voltage results from both the acceleration process and the increasing speed. Between $49.8-$ $59.7 \mathrm{mph}$, there is minimal tendency for voltage to drop below the maximum level. Above $59.7 \mathrm{mph}$, voltage remains at the maximum level. Notice that the plot also specifies the rotational speed of the $\mathrm{PMSM}^{3}$ at specified points.

Figure 3.8 also shows the peak back-emf from the generator based on ORNL component testing as presented earlier in this section (Fig. 3.4). The points are plotted at the calculated equivalent vehicle speeds and then approximate interconnecting lines are added for clarity. The data shows how the boosted voltage rarely falls below the generator's peak voltage. Although the actual ECU algorithm for controlling the voltage boost is unknown, this plot and the preceding plots present a clear picture of how voltage is generally controlled during acceleration, high speeds, and braking. Because the rating of the converter prevents it from providing full power to the Prius motor, the converter was not used in performance characterization testing at ORNL.

Six additional plots of drive-cycle data from a different drive-cycle test are provided in Appendix A. These plots are useful in further characterizing the operation of the voltage-boost converter and the ECUdictated converter-control scheme.

\footnotetext{
${ }^{3}$ The rotational speed of the PMSM (rpm) is 60.66 times the vehicle speed in mph. This is based on the constant gear ratio of the Prius, wheel/tire diameter, and conversion of units.
} 


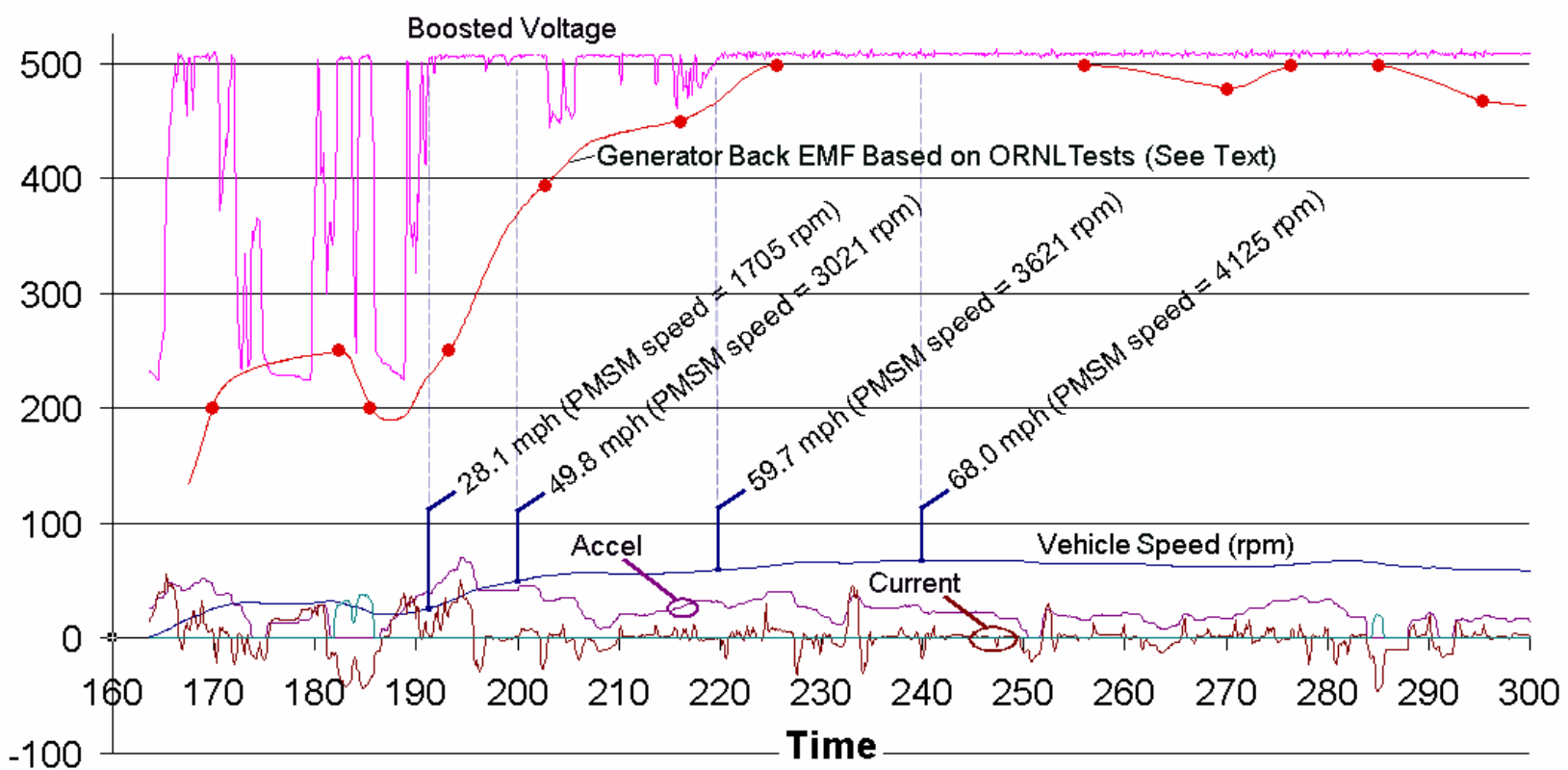

Fig. 3.8. Drive-cycle data set from ANL/ORNL showing voltage boost at high speeds (ANL data).

\subsection{ORNL SUBSYSTEM-LEVEL PERFORMANCE AND VALIDATION TESTS}

The hybrid electric drive system for the 2004 Prius was also tested at ORNL under a variety of operating conditions to characterize its electrical and mechanical performance. Objectives of the testing program were to measure motor and generator back-emf voltages, evaluate motor starting torque capacity, and determine gearbox-related power losses over a specified range of shaft speeds and lubricating oil temperatures. To eliminate effects of engine friction from the evaluation, the engine was removed from the system prior to the tests.

Accomplishing the testing program objectives required connecting the hybrid electric drive system to a dynamometer that was capable of providing the power needed to turn the system components at specified rotational speeds. To ensure that both axles rotated at the same speed, the differential was modified so the internal gears of the differential could not rotate. By blocking rotation of these gears, it was possible to measure torque from one of the two drive wheel axles. In this modified configuration, the gear-reduction ratio, which is a function of the number of gear teeth, was determined to be 4.113 motor rotations to one axle rotation.

To understand effects of oil temperature on power loss, a system for heating the gearbox lubricating oil to a specified nominal temperature was developed and used during the tests. In this blocked differential configuration, the following measurements were obtained:

- The gear ratio from the motor shaft to the dynamometer was measured, calculated, and documented.

- The gear, windage, cogging, and other friction losses were measured without energizing the generator or the motor. Measurements were obtained with the engine spline free spinning and with it locked.

For initial motor testing, the engine input spline was allowed to float with either the motor or the dynamometer providing the driving power. During the generator tests, the engine spline was fixed from 
rotating which effectively locks the planetary-carrier arm. In this configuration, the planetary-gear train transmitted torque to the generator shaft. Details of the power-split device and the gear train that connects the motor to the wheels are presented in Figs. 2.4 and 2.5 (see Section 2).

To provide a better understanding of the thermal management system, data collected as part of the overall testing effort included (1) gearbox lubricating oil temperature, and (2) hybrid-drive-coolant system flow. A diagram showing the lubricating and cooling oil inside the three compartments of hybrid drive housing is presented in Fig. 2.3 (see Section 2). This figure also presents the hybrid-drive-coolant system flow rate and pressure that were determined as part of the testing effort. Besides lubricating the bearings and gears, this oil also removes excess heat from the gears, motor, and generator and transfers it to the hybrid drive system coolant.

\subsubsection{Locked Rotor Tests}

A series of locked rotor tests [2] were performed in 2004 and 2005 to determine the general operating capabilities of the traction motor. The 2005 test used a new mechanical-gear mechanism capable of precisely positioning and locking the rotor based on readings from the absolute position sensor in the Prius.

The motor-driven gear mechanism was used to position the motor shaft and rotate it incrementally in degree segments while otherwise remaining locked. Torque values were obtained by supplying sinusoidal current to the motor windings at varying degrees of shaft angle. The resulting data were used to produce torque-vs.-shaft-angle plots, which are shown in Fig. 3.9 for various current levels. Current and corresponding torque values are listed in Table 3.2. Following the test, it was verified that no demagnetization damage ${ }^{4}$ occurred due to rotor heating.

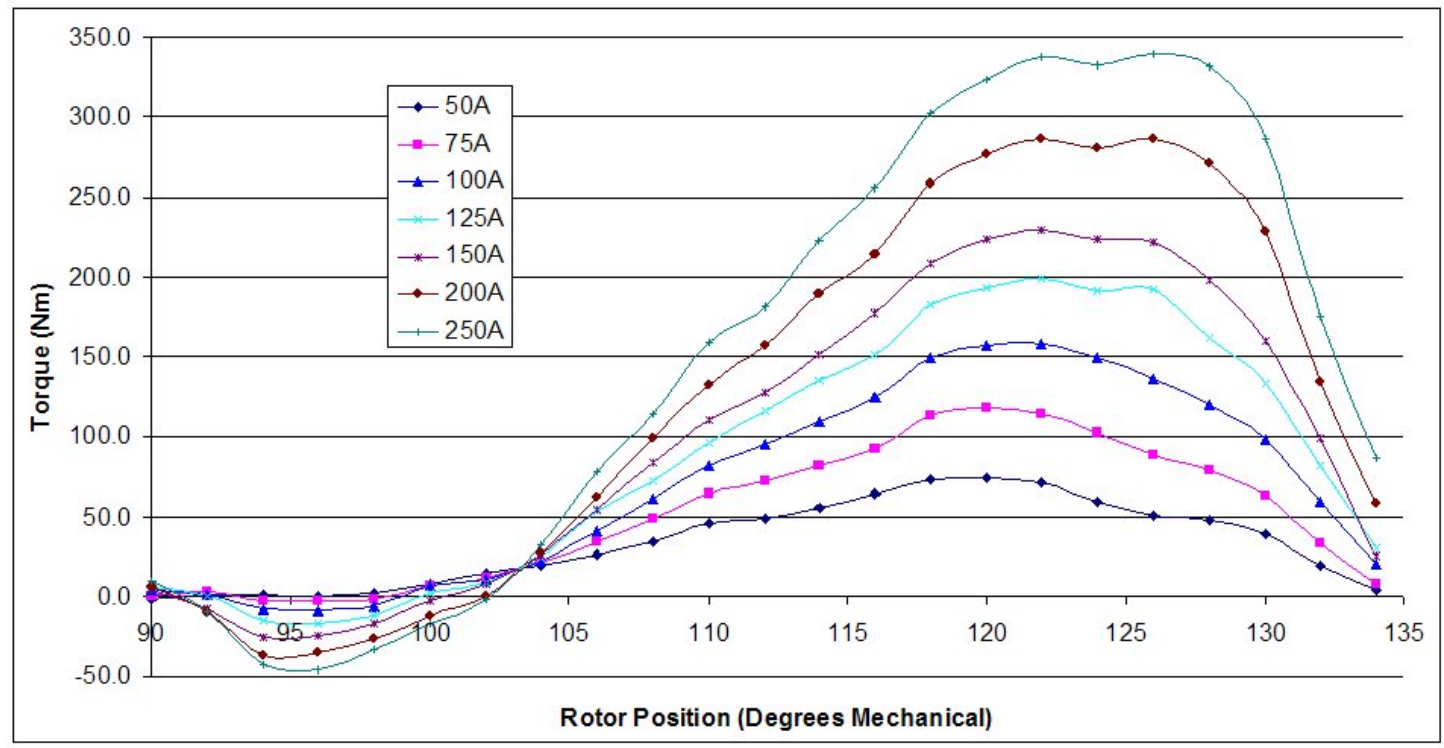

Fig. 3.9. Motor-shaft angle vs. torque (rotor locked).

${ }^{4}$ Although this potential was based on thermal tests conducted on the motor in November 2004, the likelihood of demagnetization is very low based on before and after back-emf tests. 
Table 3.2. Motor torque vs. motor-shaft angle

\begin{tabular}{|c|c|c|c|c|c|c|c|}
\hline \multirow{2}{*}{$\begin{array}{l}\text { Motor- } \\
\text { Shaft } \\
\text { Angle, } \\
\text { Degrees }\end{array}$} & \multicolumn{7}{|c|}{ Motor-Shaft Torque, Nm } \\
\hline & $50 \mathrm{~A}$ & 75A, & 100A, & 125A, & $150 \mathrm{~A}$ & 200A & $250 \mathrm{~A}$ \\
\hline 90 & -1.9 & -0.6 & 3.5 & 5.3 & 3.6 & 6.0 & 10.0 \\
\hline 92 & 0.7 & 2.4 & 0.7 & 0.0 & -7.6 & -9.6 & -10.1 \\
\hline 94 & 1.0 & -2.8 & -8.1 & -15.0 & -25.7 & -37.6 & -43.3 \\
\hline 96 & 0.2 & -3.0 & -9.0 & -17.0 & -24.7 & -35.4 & -46.2 \\
\hline 98 & 1.9 & -2.3 & -5.8 & -12.0 & -17.3 & -26.7 & -33.8 \\
\hline 100 & 7.3 & 6.1 & 6.1 & 2.0 & -3.5 & -11.7 & -16.4 \\
\hline 102 & 14.5 & 11.8 & 10.4 & 9.0 & 7.4 & 0.0 & -1.9 \\
\hline 104 & 19.6 & 20.8 & 22.0 & 24.0 & 25.8 & 27.0 & 31.7 \\
\hline 106 & 25.8 & 34.0 & 41.0 & 53.0 & 54.8 & 62.0 & 78.1 \\
\hline 108 & 34.1 & 48.3 & 61.0 & 72.0 & 83.6 & 99.2 & 114.2 \\
\hline 110 & 45.5 & 64.0 & 82.0 & 96.0 & 109.9 & 132.0 & 158.5 \\
\hline 112 & 48.2 & 72.4 & 95.0 & 116.0 & 127.8 & 157.0 & 181.6 \\
\hline 114 & 55.8 & 81.9 & 109.0 & 135.0 & 151.0 & 189.2 & 222.0 \\
\hline 116 & 63.9 & 92.6 & 125.0 & 151.0 & 177.4 & 214.3 & 255.0 \\
\hline 118 & 73.1 & 112.5 & 149.0 & 182.0 & 208.1 & 258.6 & 302.0 \\
\hline 120 & 74.0 & 117.7 & 157.0 & 193.0 & 223.0 & 277.0 & 324.0 \\
\hline 122 & 70.9 & 114.1 & 158.0 & 199.0 & 229.0 & 286.1 & 337.0 \\
\hline 124 & 59.1 & 102.1 & 149.0 & 191.0 & 223.0 & 280.4 & 332.0 \\
\hline 126 & 50.2 & 89.0 & 136.0 & 192.0 & 221.0 & 286.6 & 339.0 \\
\hline 128 & 47.3 & 79.0 & 120.0 & 162.0 & 198.2 & 271.2 & 331.0 \\
\hline 130 & 38.8 & 63.5 & 98.0 & 133.0 & 159.6 & 228.2 & 287.0 \\
\hline 132 & 19.0 & 33.0 & 59.0 & 82.0 & 99.7 & 134.2 & 175.0 \\
\hline 134 & 3.4 & 7.1 & 20.4 & 30.0 & 25.3 & 58.3 & 87.0 \\
\hline
\end{tabular}

The seven peak-torque values for the different current levels are plotted in Fig. 3.10. These peak values are based on June and August 2005 data, with a preference to August 2005 data in the cases where slight differences exist. This series of tests was effective in characterizing the starting torque capability of the 2004 Prius traction motor.

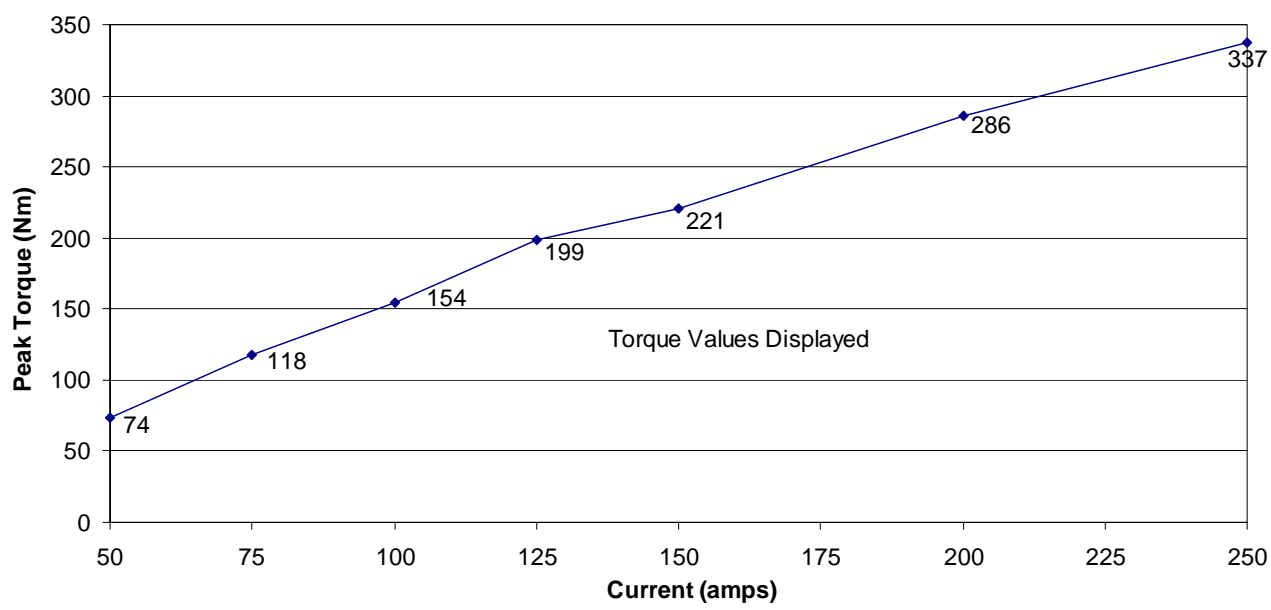

Fig. 3.10. Locked rotor peak torque as a function of current. 


\subsubsection{Back-emf Tests}

The back-emf voltage generated by the motor and the generator was measured using two slightly different hybrid electric drive system configurations. Test conditions and subsystem arrangements for the motor and generator tests are defined in Table 3.3. During the tests, an oscilloscope was used to measure both $\mathrm{rms}^{5}$ (Vrms) and peak (Vpeak) back-emf voltage values.

Table 3.3. Test conditions for back-emf voltage measurements

\begin{tabular}{lcc}
\hline \multicolumn{1}{c}{ Test Condition } & Motor Tests & Generator Tests \\
\hline Shaft speed range, rpm & $500-6000$ & $1000-6500$ \\
Oil temperature range, ${ }^{\circ} \mathrm{C}$ & $25-80$ & $25-80$ \\
Motor rotor & Installed & Installed \\
Oil pump & Installed & Installed \\
Sun gear & Installed & Installed \\
Planetary gears & Installed & Installed \\
Rotating subassemblies: & & \\
- Motor $\quad$ Functional & Functional \\
- $\quad$ Generator & Idle & Functional \\
Planetary gears & Idle & Functional \\
\hline
\end{tabular}

\subsubsection{Motor tests}

Measured back-emf voltage values from the motor are shown in Table 3.4 and plotted in Fig. 3.11. The lubricating oil temperature during this motor test was a nominal $25^{\circ} \mathrm{C}$. It should be noted that the Vpeak to Vrms ratio is greater than the square root of 2 because of the harmonics content in the back-emf. The results of the back-emf test were verified one year later, just prior to the full design range testing/mapping (Section 3.3), and the agreement between the two data sets was excellent.

Table 3.4. Back-emf voltage measurements for the 2004 Prius motor

\begin{tabular}{cccccc}
\hline $\begin{array}{c}\text { Axle } \\
\text { Speed, } \\
\text { rpm }\end{array}$ & $\begin{array}{c}\text { Motor-Shaft } \\
\text { Speed, rpm }\end{array}$ & $\begin{array}{c}\text { Axle } \\
\text { Torque, } \\
\text { Nm }\end{array}$ & $\begin{array}{c}\text { Electrical } \\
\text { Frequency, Hz }\end{array}$ & $\begin{array}{c}\text { Scaled Back- } \\
\text { emf (Vrms) }\end{array}$ & $\begin{array}{c}\text { Scaled Back- } \\
\text { emf (Vpeak) }\end{array}$ \\
\hline 122 & 502 & 8.0 & 33.8 & 42.0 & 75 \\
243 & 1000 & 8.4 & 66.5 & 85.7 & 150 \\
365 & 1502 & 9.3 & 99.8 & 132.3 & 225 \\
486 & 1999 & 10.2 & 134.4 & 181.6 & 300 \\
608 & 2501 & 10.8 & 168.1 & 221.8 & 350 \\
729 & 2999 & 11.3 & 200.2 & 269.3 & 425 \\
851 & 3501 & 12.0 & 233.9 & 315.7 & 500 \\
972 & 3999 & 12.6 & 265.4 & 354.6 & 575 \\
1094 & 4501 & 13.1 & 295.7 & 405.5 & 625 \\
1215 & 4999 & 13.6 & 333.0 & 440.4 & 700 \\
1337 & 5500 & 14.6 & 366.3 & 503.4 & 775 \\
1458 & 5998 & 15.6 & 401.3 & 539.8 & 850 \\
\hline
\end{tabular}

Note: Testing was conducted with the differential gears blocked from rotating and oil near room temperature.

${ }^{5}$ Root mean square (rms). 


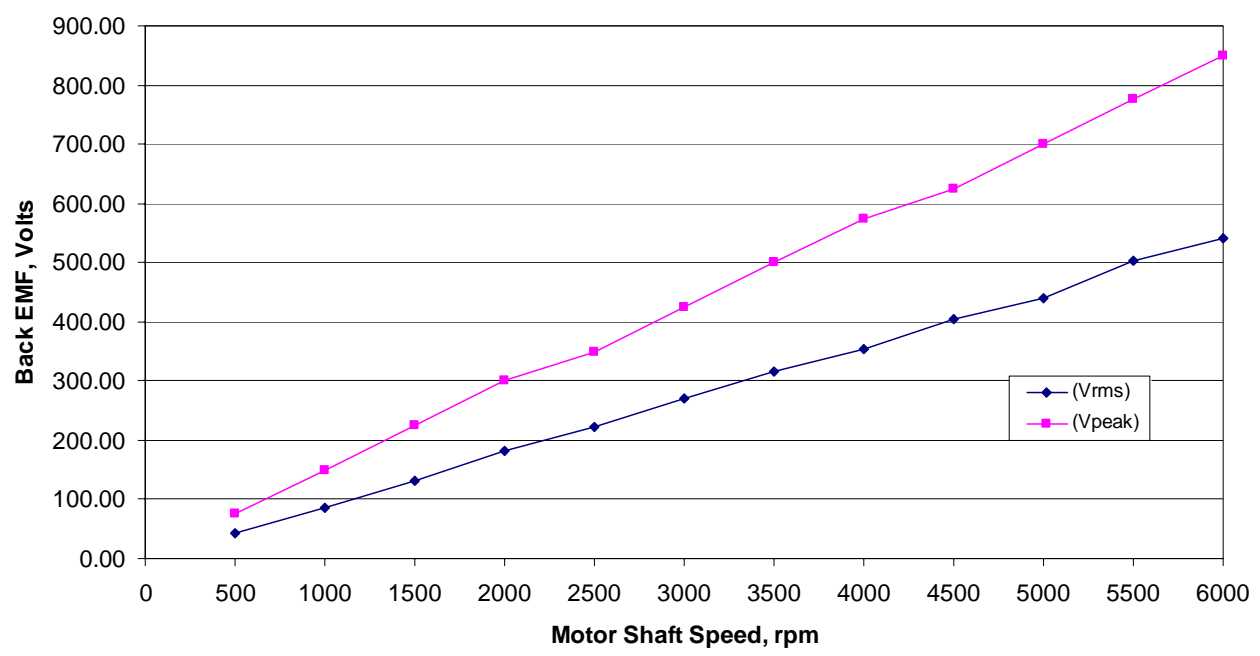

Fig. 3.11. Motor back-emf voltage vs. motor-shaft speed.

\subsubsection{Generator tests}

Measured back-emf voltage values from the generator are shown in Table 3.5 and plotted in Fig. 3.12. The lubricating oil temperature during this generator test was a nominal $80^{\circ} \mathrm{C}$.

Table 3.5. Back-emf voltage measurements for the 2004 Prius generator

\begin{tabular}{cccccc}
\hline $\begin{array}{c}\text { Axle } \\
\text { Speed, } \\
\text { rpm }\end{array}$ & $\begin{array}{c}\text { Generator } \\
\text { Shaft Speed, } \\
\text { rpm }\end{array}$ & $\begin{array}{c}\text { Axle } \\
\text { Torque, } \\
\text { Nm }\end{array}$ & Frequency, Hz & $\begin{array}{c}\text { Scaled Back- } \\
\text { emf (Vrms) }\end{array}$ & $\begin{array}{c}\text { Scaled Back- } \\
\text { emf (Vpeak) }\end{array}$ \\
\hline 100 & 1070 & 8.2 & 70.0 & 31.6 & 52.5 \\
150 & 1605 & 9.4 & 109.4 & 49.4 & 80.0 \\
200 & 2140 & 9.6 & 141.3 & 67.0 & 110.0 \\
250 & 2675 & 9.0 & 180.6 & 83.5 & 135.0 \\
300 & 3210 & 9.1 & 213.3 & 96.5 & 160.0 \\
350 & 3745 & 9.5 & 247.9 & 113.5 & 190.0 \\
400 & 4280 & 10.2 & 287.0 & 134.5 & 210.0 \\
450 & 4815 & 10.8 & 320.6 & 144.5 & 240.0 \\
500 & 5350 & 11.3 & 357.9 & 167.0 & 260.0 \\
550 & 5885 & 11.6 & 392.2 & 182.0 & 290.0 \\
600 & 6420 & 12.2 & 430.5 & 195.0 & 320.0 \\
\hline
\end{tabular}

Note: Testing was conducted with the differential gears blocked from rotating and a nominal oil temperature of $80^{\circ} \mathrm{C}$. 


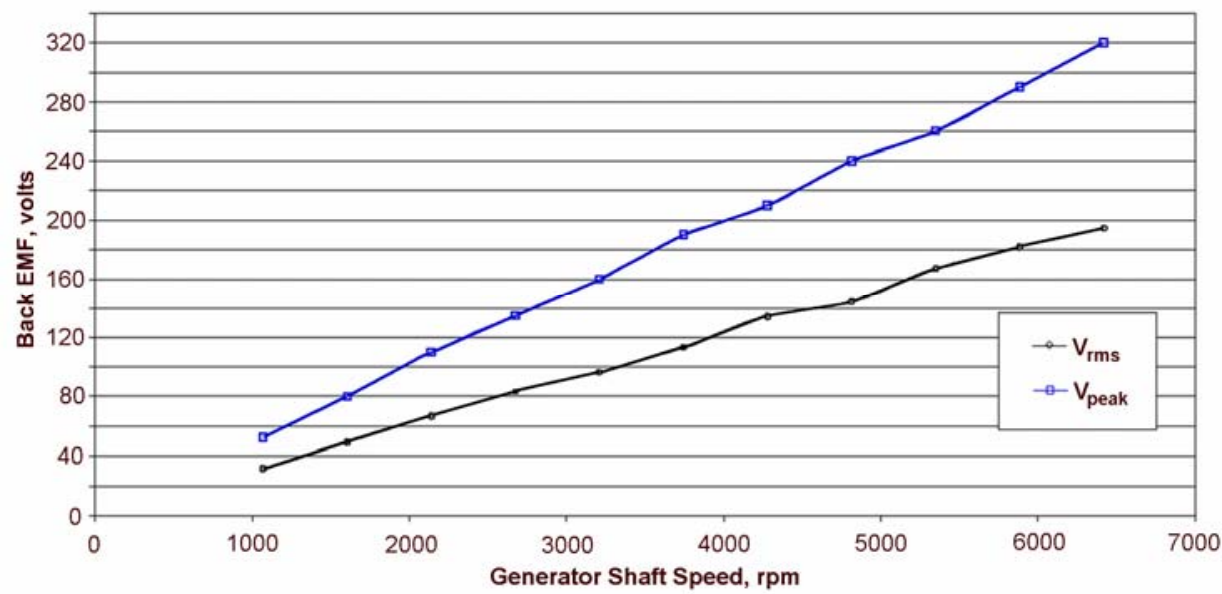

Fig. 3.12. Generator back-emf voltage vs. generator shaft speed.

In order to mechanically link the generator into the system, the engine shaft was not allowed to rotate during the tests (i.e., the planetary carrier was fixed from rotating). Using this arrangement allowed the generator to either drive or be driven by the hybrid drive gear train. The location of the planetary carrier relative to the other hybrid electric drive system components is shown in Fig. 2.4 (see Section 2).

\subsubsection{Hybrid Drive System Loss Tests}

Three types of power losses that affect the overall efficiency of the hybrid electric drive system were studied. These losses, which are reported in watts (W), include: (1) gear losses; (2) motor-rotor losses; and (3) planetary gears, sun gear, and generator-rotor losses. Determining the magnitude of each of these types of losses was achieved by separately testing three hybrid drive system configurations at different motor-shaft speeds and lubricating oil temperatures. Subassemblies installed as part of each configuration are identified in Table 3.6.

Table 3.6. Subassembly configurations for loss determinations

\begin{tabular}{lccc}
\hline \multicolumn{1}{c}{ Subassembly } & Configuration A & Configuration B & Configuration C \\
\hline Engine & Not installed & Not installed & Not installed \\
Motor rotor & Installed & Removed* & Removed \\
Generator rotor & Installed & Installed & Removed \\
Sun gear & Installed & Installed & Removed \\
Planetary gears & Installed & Installed & Removed \\
$\begin{array}{l}\text { Main drive gears, drive } \\
\text { chain, and differential }\end{array}$ & Installed & Installed & Installed \\
\hline
\end{tabular}

*A substitute rotor that provides no loading was installed in place of the motor rotor in order to provide the necessary mechanical support for the adjacent gearbox and planetary components.

Overall power loss for the entire hybrid drive system was determined by testing the components and subassemblies included in Configuration A. Losses associated with the motor rotor were determined by testing the components and subassemblies included in Configuration B. These tests were conducted with the motor rotor removed and a simulated rotor $^{6}$ installed in its place. For Configuration $\mathrm{C}$, additional

${ }^{6}$ The simulated rotor, consisting of a dummy shaft and bearings, was intended to keep the other components in their normal positions. 
components including the generator rotor, sun gear, and planetary gears were removed leaving only the main drive gears, drive chain, and differential. Under these test conditions, it was possible to determine the gear losses. This testing approach also made it possible to determine losses associated with the planetary gears, generator rotor, and sun gear by subtracting the motor-rotor losses and the gear losses from the losses for the entire hybrid electric drive system. Loss values determined with the lubricating oil near room temperature are shown in Table 3.7 and plotted in Fig. 3.13. This data was compiled based on tests of all three configurations.

Table 3.7. Summary of hybrid drive system losses ${ }^{1}$

\begin{tabular}{rrrccc}
\hline $\begin{array}{c}\text { Axle } \\
\text { Speed, } \\
\text { rpm }\end{array}$ & $\begin{array}{c}\text { Motor- } \\
\text { Shaft } \\
\text { Speed, } \\
\text { rpm }\end{array}$ & Gear Losses, W & $\begin{array}{c}\text { Motor-Rotor } \\
\text { Losses, W }\end{array}$ & $\begin{array}{c}\text { Planetary Gears, } \\
\text { Generator Rotor, and } \\
\text { Sun-Gear Losses, W }\end{array}$ & $\begin{array}{c}\text { Hybrid Drive } \\
\text { System Losses, W }\end{array}$ \\
\hline 120 & 494 & 74.9 & 19.8 & 7.1 & 102 \\
243 & 1000 & 158.5 & 31.6 & 23.7 & 214 \\
366 & 1506 & 261.8 & 60.2 & 33.2 & 355 \\
484 & 1991 & 369.8 & 109.0 & 40.5 & 519 \\
608 & 2501 & 487.9 & 135.9 & 63.6 & 687 \\
731 & 3007 & 617.2 & 161.7 & 84.2 & 1063 \\
851 & 3501 & 745.2 & 205.3 & 118.8 & 1283 \\
972 & 3999 & 915.6 & 242.1 & 125.5 & 1501 \\
1095 & 4505 & 1058.2 & 297.4 & 145.2 & 2044 \\
1215 & 4999 & 1220.8 & 323.9 & 186.5 & 2383 \\
1335 & 5492 & 1425.2 & 404.9 & 214.3 & \\
1460 & 6006 & 1645.3 & 472.8 & 264.9 & \\
\hline
\end{tabular}

${ }^{1}$ Testing was conducted with the differential gears blocked from rotating and oil near room temperature.

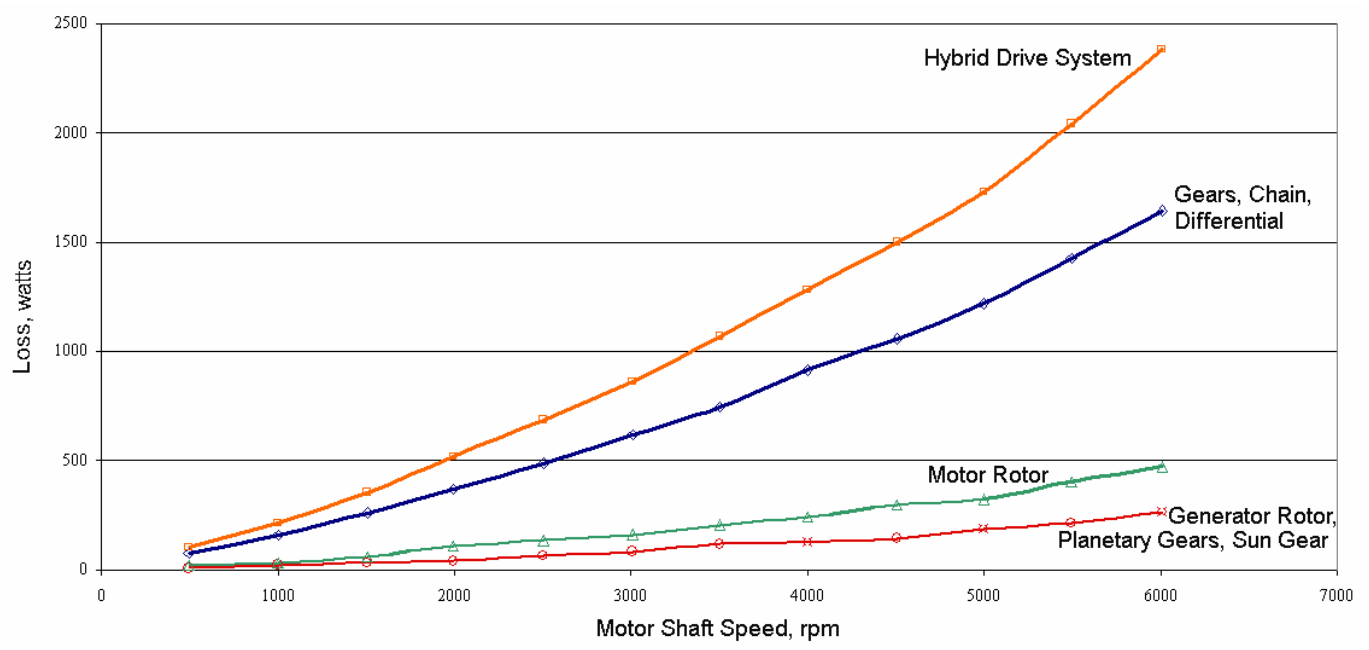

Fig. 3.13. Hybrid electric drive system and component/subassembly losses at $25^{\circ} \mathrm{C}$.

Losses that were determined for Configuration B at various elevated lubricating oil temperatures are listed in Tables 3.8-3.13. As Fig. 3.14 indicates, losses tend to decrease as the lubricating oil temperatures increase, presumably due to viscosity changes. 
Table 3.8. Configuration B losses at a nominal oil temperature of $28^{\circ} \mathrm{C}$

\begin{tabular}{ccccc}
\hline Axle Speed, rpm & $\begin{array}{c}\text { Motor-Shaft } \\
\text { Speed, rpm }\end{array}$ & Axle Torque, Nm & Losses, $\mathbf{W}$ & Oil Temperature, ${ }^{\circ} \mathbf{C}$ \\
\hline 122 & 502 & 5.8 & 72.8 & 27.0 \\
243 & 1000 & 6.7 & 170.4 & 27.0 \\
365 & 1502 & 7.6 & 291.1 & 27.0 \\
486 & 1999 & 7.9 & 400.2 & 28.0 \\
608 & 2501 & 8.4 & 534.6 & 28.5 \\
729 & 2999 & 8.9 & 681.0 & 29.0 \\
851 & 3501 & 9.4 & 837.3 & 29.0 \\
972 & 3999 & 9.8 & 997.0 & 29.5 \\
1094 & 4501 & 10.3 & 1180.5 & 30.0 \\
1215 & 4999 & 10.7 & 1360.7 & 30.5 \\
1337 & 5500 & 11.2 & 1565.0 & 31.5 \\
1458 & 6006 & 12.1 & 1849.0 & 32.0 \\
\hline
\end{tabular}

Table 3.9. Configuration $B$ losses at a nominal oil temperature of $40^{\circ} \mathrm{C}$

\begin{tabular}{ccccc}
\hline Axle Speed, rpm & $\begin{array}{c}\text { Motor-Shaft } \\
\text { Speed, rpm }\end{array}$ & Axle Torque, Nm & Losses, W & Oil Temperature, ${ }^{\circ} \mathbf{C}$ \\
\hline 122 & 502 & 5.3 & 66.6 & 40.5 \\
243 & 1000 & 6.0 & 152.6 & 40.5 \\
365 & 1502 & 6.7 & 256.7 & 40.5 \\
486 & 1999 & 7.2 & 364.7 & 41.0 \\
608 & 2501 & 7.7 & 490.0 & 41.0 \\
729 & 2999 & 8.2 & 627.4 & 41.5 \\
851 & 3501 & 8.5 & 757.1 & 42.0 \\
972 & 3999 & 9.1 & 925.8 & 42.5 \\
1094 & 4501 & 9.5 & 1088.8 & 43.0 \\
1215 & 4999 & 10.2 & 1297.1 & 44.0 \\
1337 & 5500 & 10.6 & 1481.1 & 44.5 \\
1458 & 6006 & 11.3 & 1726.8 & 45.0 \\
\hline
\end{tabular}


Table 3.10. Configuration B losses at a nominal oil temperature of $50^{\circ} \mathrm{C}$

\begin{tabular}{ccccc}
\hline Axle Speed, rpm & $\begin{array}{c}\text { Motor-Shaft } \\
\text { Speed, rpm }\end{array}$ & Axle Torque, Nm & Losses, $\mathbf{W}$ & Oil Temperature, ${ }^{\circ} \mathbf{C}$ \\
\hline 122 & 502 & 5.2 & 65.3 & 50.0 \\
243 & 1000 & 6.0 & 152.6 & 50.5 \\
365 & 1502 & 6.5 & 249.0 & 51.0 \\
486 & 1999 & 7.0 & 354.6 & 51.5 \\
608 & 2501 & 7.4 & 470.9 & 51.0 \\
729 & 2999 & 7.9 & 604.4 & 51.5 \\
851 & 3501 & 8.3 & 739.3 & 52.0 \\
972 & 3999 & 8.6 & 874.9 & 52.0 \\
1094 & 4501 & 9.1 & 1043.0 & 52.5 \\
1215 & 4999 & 9.7 & 1233.5 & 53.0 \\
1337 & 5500 & 10.2 & 1425.2 & 53.5 \\
1458 & 6006 & 10.7 & 1635.1 & 54.5 \\
\hline
\end{tabular}

Table 3.11. Configuration B losses at a nominal oil temperature of $60^{\circ} \mathrm{C}$

\begin{tabular}{ccccc}
\hline Axle Speed, rpm & $\begin{array}{c}\text { Motor-Shaft } \\
\text { Speed, rpm }\end{array}$ & Axle Torque, Nm & Losses, W & Oil Temperature, ${ }^{\circ} \mathbf{C}$ \\
\hline 122 & 502 & 5.0 & 62.8 & 59.5 \\
243 & 1000 & 5.5 & 139.9 & 59.5 \\
365 & 1502 & 6.2 & 237.5 & 60.0 \\
486 & 1999 & 6.8 & 344.5 & 60.0 \\
608 & 2501 & 7.2 & 458.2 & 60.0 \\
729 & 2999 & 7.9 & 604.4 & 60.0 \\
851 & 3501 & 8.3 & 739.3 & 60.0 \\
972 & 3999 & 8.6 & 874.9 & 60.0 \\
1094 & 4501 & 8.9 & 1020.0 & 60.5 \\
1215 & 4999 & 9.4 & 1195.4 & 61.0 \\
1337 & 5500 & 10.0 & 1397.3 & 61.5 \\
1458 & 6006 & 10.6 & 1619.8 & 62.0 \\
\hline
\end{tabular}


Table 3.12. Configuration B losses at a nominal oil temperature of $70^{\circ} \mathrm{C}$

\begin{tabular}{ccccc}
\hline Axle Speed, rpm & $\begin{array}{c}\text { Motor-Shaft } \\
\text { Speed, rpm }\end{array}$ & Axle Torque, Nm & Losses, $\mathbf{~}$ & Oil Temperature, ${ }^{\circ} \mathbf{C}$ \\
\hline 122 & 502 & 4.7 & 59.0 & 70.0 \\
243 & 1000 & 5.5 & 139.9 & 70.0 \\
365 & 1502 & 6.2 & 237.5 & 70.0 \\
486 & 1999 & 6.8 & 344.5 & 70.0 \\
608 & 2501 & 7.1 & 451.8 & 70.0 \\
729 & 2999 & 7.7 & 589.1 & 69.5 \\
851 & 3501 & 8.2 & 730.4 & 69.5 \\
972 & 3999 & 8.3 & 844.4 & 69.5 \\
1094 & 4501 & 8.8 & 1008.6 & 70.0 \\
1215 & 4999 & 9.1 & 1157.2 & 70.5 \\
1337 & 5500 & 9.6 & 1341.4 & 71.0 \\
1458 & 6006 & 10.1 & 1543.4 & 71.5 \\
\hline
\end{tabular}

Table 3.13. Configuration B losses at a nominal oil temperature of $80^{\circ} \mathrm{C}$

\begin{tabular}{ccccc}
\hline Axle Speed, rpm & $\begin{array}{c}\text { Motor-Shaft } \\
\text { Speed, rpm }\end{array}$ & Axle Torque, Nm & Losses, W & Oil Temperature, ${ }^{\circ} \mathbf{C}$ \\
\hline 122 & 502 & 4.0 & 50.2 & 82.5 \\
243 & 1000 & 4.4 & 111.9 & 82.0 \\
365 & 1502 & 5.5 & 210.7 & 80.5 \\
486 & 1999 & 6.1 & 309.0 & 80.5 \\
608 & 2501 & 6.6 & 420.0 & 80.5 \\
729 & 2999 & 7.2 & 550.9 & 81.0 \\
851 & 3501 & 7.8 & 694.8 & 81.0 \\
972 & 3999 & 8.2 & 834.2 & 81.0 \\
1094 & 4501 & 8.5 & 974.2 & 81.0 \\
1215 & 4999 & 8.8 & 1119.1 & 81.5 \\
1337 & 5500 & 9.2 & 1285.5 & 82.0 \\
1458 & 6006 & 9.7 & 1482.3 & 82.0 \\
\hline
\end{tabular}




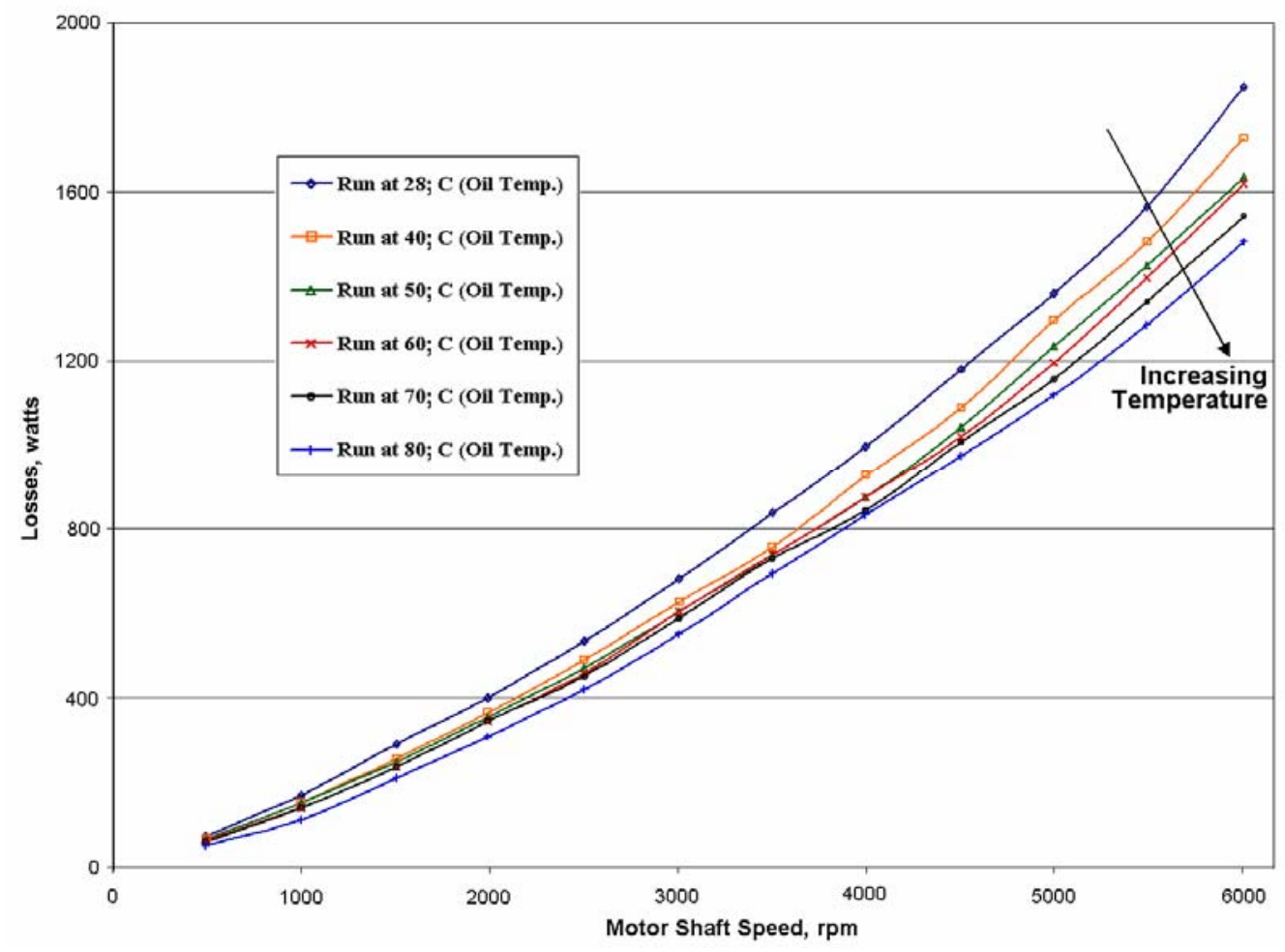

Fig. 3.14. Configuration B losses as a function of oil temperature.

\subsection{HEV SYSTEM TESTING OVER THE FULL DESIGN RANGE}

From the time that the benchmarking project began, one of the primary goals was to operate the Prius HEV system in a test cell and collect operating and performance data over the full speed range and over the full shaft-loading range. This presented considerable challenges as discussed in Section 1.4.

The following summarizes the major technical efforts during 2004 and 2005 leading up to HEV system testing:

- Instrumenting the inverter and motor hardware,

- Planning and preparing a controller algorithm to maximize torque and provide field weakening,

- Resolving persistent electromagnetic interference (EMI) problems in the feedback control loop,

- Setting gains in proportional integral (PI) controllers partly by trial and error,

- Using a motor model for testing/verifying the controller algorithm,

- Preparing a DAS, and

- Calibrating all essential equipment and verified sensors.

The intention of the full-design-range Prius testing is to characterize the performance of the Prius PMSM, inverter, and buck/boost-converter ${ }^{7}$ subsystems. This will not necessarily reflect the operation of these items in the Prius vehicle where the ECU algorithm dictates operation, but rather it will reflect the full capabilities of these Prius subsystems when operated to maximize torque and/or efficiency over the full speed range. Thus, this report provides HEV subsystem design information, packaging information, and data that fully define the performance potential of the as-described hardware.

${ }^{7}$ Tested separately at lower power levels after testing the other two subsystems. 


\subsubsection{Test Configuration}

A simplified depiction of the test configuration for Prius performance characterization tests is illustrated in Fig. 3.15. The left-hand portion of the figure shows computer systems for (1) controlling the operation of the Prius HEV system, (2) real-time monitoring of thermal and electrical parameters, and (3) data acquisition/storage. The figure shows that the Yokogawa PZ 4000 power analyzer and the Keithley 2700 DAS collect all electrical, thermal, and mechanical parameters. A closed-loop coolant system is used to regulate the temperature and flow rate of the coolant sent to the inverter and PMSM.

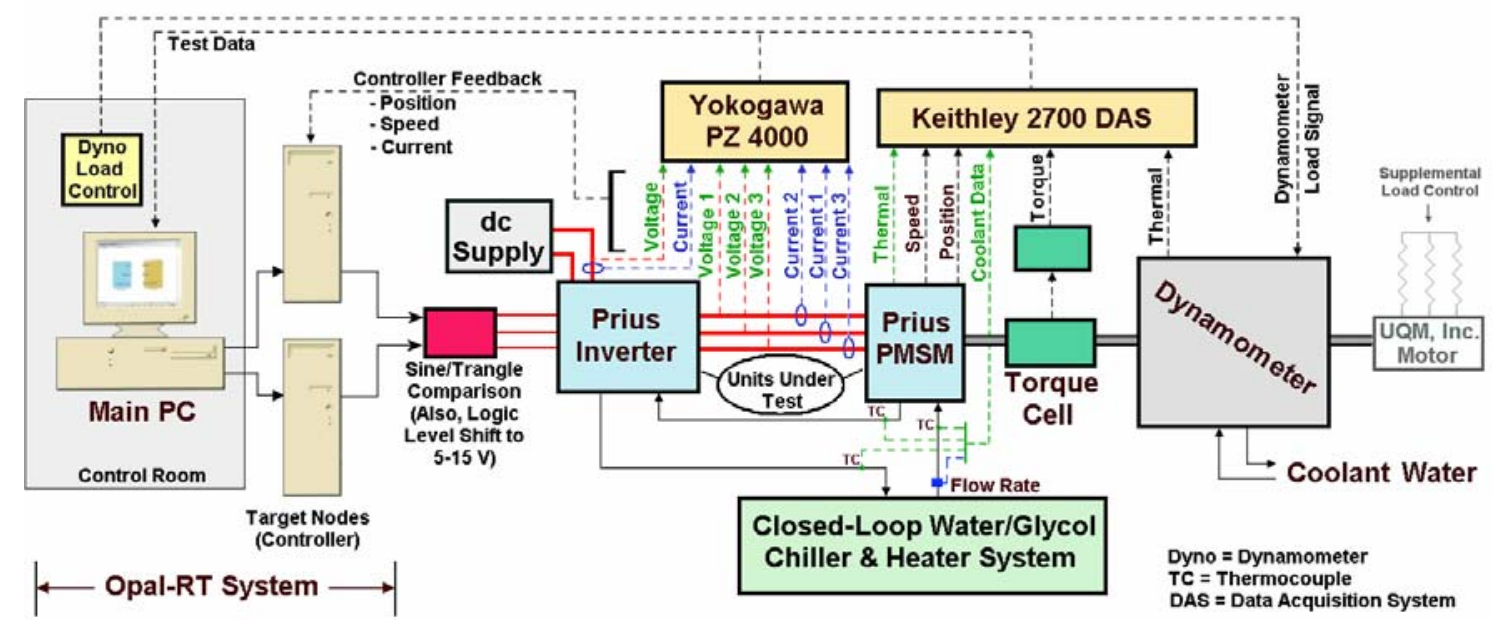

Fig. 3.15. The test configuration for Prius performance characterization tests.

The motor was modified for this test so that the rotor is directly coupled to the shaft; thus, the dynamometer rotational speed matches that of the PMSM rotor. This eliminates issues relating to gear losses. Figure 3.16 shows the subassemblies and test-related hardware in the laboratory just prior to the final sequence of tests. At the end of testing, the Solectria motor was replaced by a synchronous motor from UQM, Inc. to provide supplemental loading at load speeds.

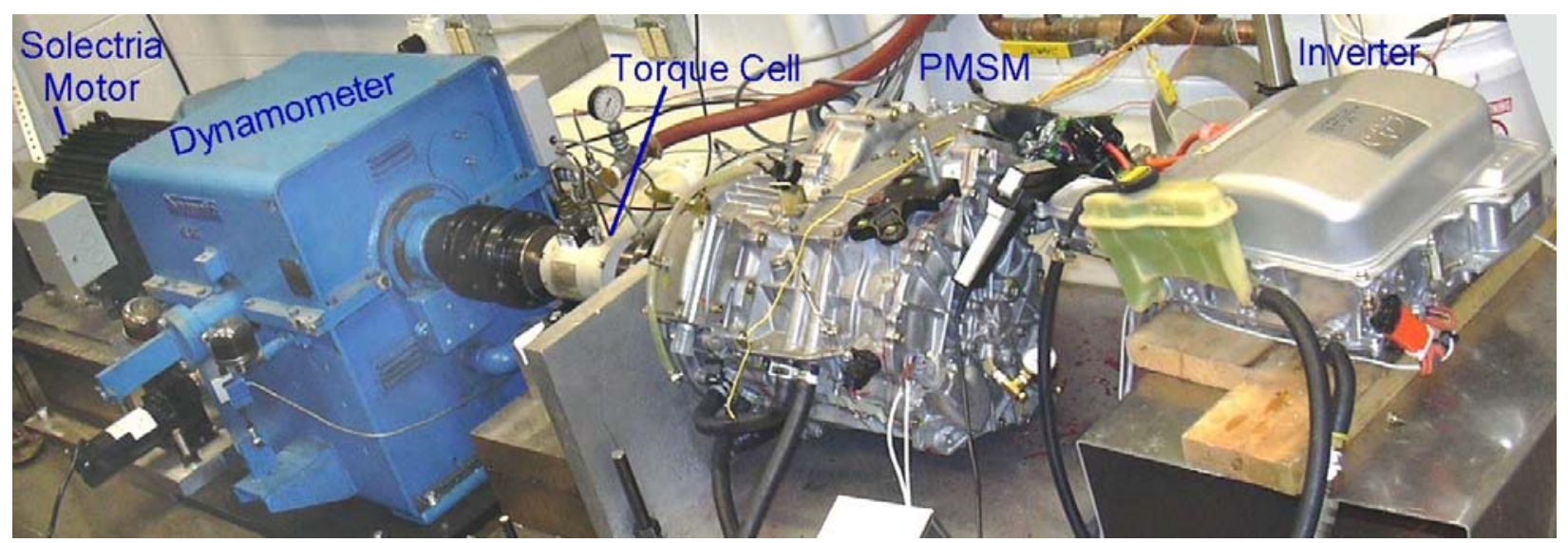

Fig. 3.16. The test hardware for Prius performance characterization tests. 


\subsubsection{General Test Plan and Data Verification}

This section provides (1) details relative to the test plan for the motor/inverter performance tests, (2) data sampling details, and (3) an investigation into higher-than-expected inverter efficiency data.

\section{$\underline{\text { General Test Plan }}$}

The test data were obtained from an array of sensors and from a power analyzer. A Himmelstein torque cell was installed between the dynamometer and the PMSM. The Himmelstein torque cell provided the shaft loading. External equipment was also available for providing cooling and coolant temperature measurements. Motor power measurements were obtained using a Yokogawa PZ4000.

Sensors in the inverter, PMSM, and dynamometer test fixture provided the following electrical and thermal data:

$\begin{array}{ll}\text { dc voltage to inverter } & \text { voltage taps } \\ \text { dc current to inverter } & \text { one current transformer (CT) } \\ \text { PMSM input current } & \text { two CTs, rms processor circuit } \\ \text { PMSM input voltage } & \text { two voltage taps, rms processor circuit } \\ \text { Shaft speed, unprocessed } & \text { existing Prius sensor (resolver) } \\ \text { Position, unprocessed } & \text { existing Prius absolute position sensor (resolver) } \\ \text { Position and speed } & \text { Tawagama encoder (Section 4.3.3) } \\ \text { Torque } & \text { Himmelstein dynamometer torque cell } \\ \text { Inverter-heat sink } & \text { two thermocouples (TCs), motor bridge A and B } \\ \text { PMSM coolant in/out } & \text { two TCs } \\ \text { PMSM stator windings } & \text { three TCs } \\ \text { PMSM cooling oil } & \text { one TC, bottom of casing (internal) } \\ \text { Motor casing } & \text { one TC, top of casing (internal) } \\ \text { Dynamometer coolant in/out } & \text { two TCs } \\ \text { Coolant-flow rate } & \text { one flow meter }\end{array}$

The plan for collecting test data was roughly bounded by published data [7] from Toyota indicating what the speed and load ranges were for the 2004 Prius motor. These data were adapted and plotted in Fig. 3.17.

The testing was generally limited by the top rated speed of the Prius motor (i.e. $6000 \mathrm{rpm}$ ) and peakpower ratings, which are reported by the manufacturer to be $30 \mathrm{~kW}$ continuous ${ }^{8}$ and $50 \mathrm{~kW}(68 \mathrm{hp})$ from $1200-5000 \mathrm{rpm}$ for $20 \mathrm{~s}$. The test data that was obtained does not necessarily agree with these specifications. The peak-torque ratings of the motor are $400 \mathrm{Nm}$ (295 lb.-ft) from 1-1200 rpm consistent with power rating time limitations.

${ }^{8}$ In earlier thermal testing at ORNL [1], the continuous motor ratings were determined to be $15 \mathrm{~kW}$ using $105^{\circ} \mathrm{C}$ coolant and $21 \mathrm{~kW}$ using $35^{\circ} \mathrm{C}$ coolant. Therefore, much of the performance testing was time-restricted. 


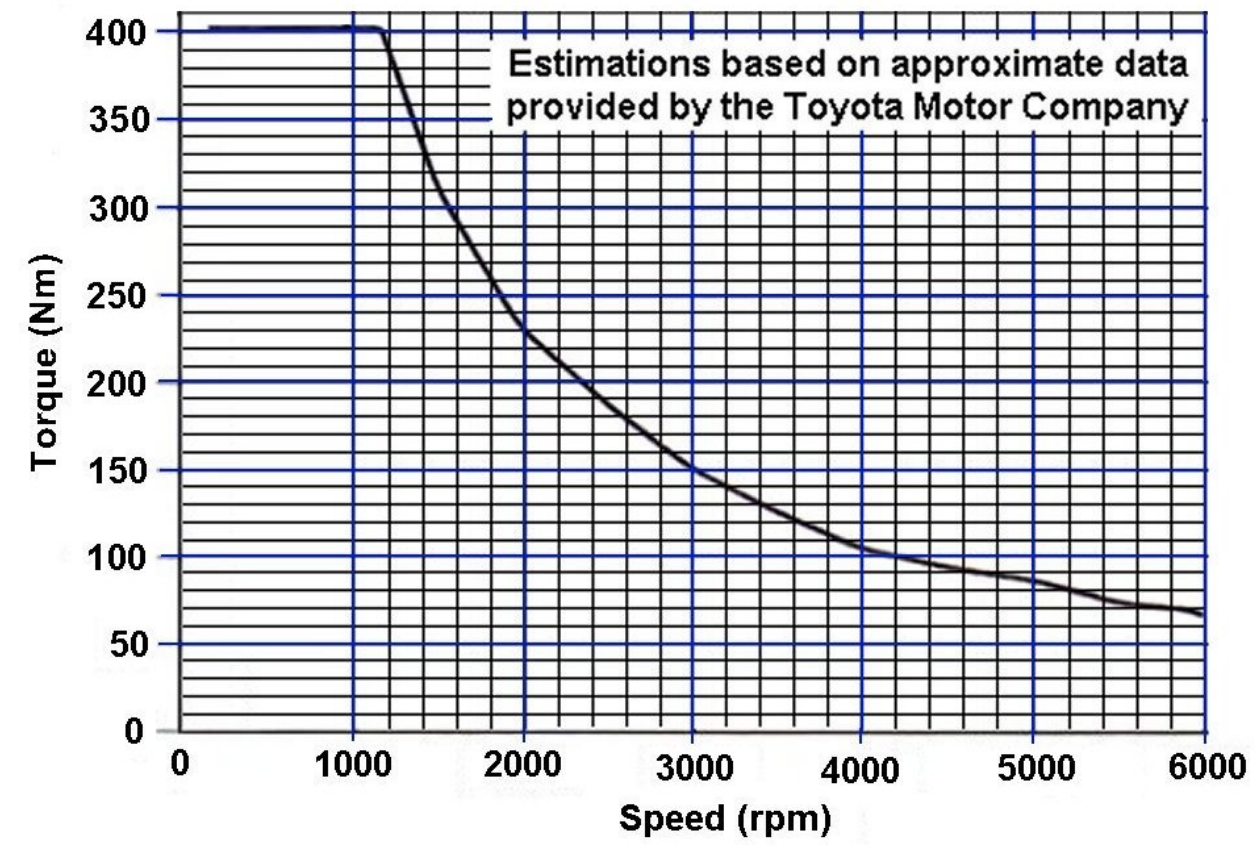

Fig. 3.17. Maximum torque-speed performance specifications for the 2004 Prius.

Other important specifications include those listed in Table 3.14.

Table 3.14. Cooling and coolant temperature and flow limits

\begin{tabular}{|l|c|l|}
\hline \multicolumn{1}{|c|}{ Parameter } & Limit & \multicolumn{1}{c|}{ Basis } \\
\hline Maximum temperature of cooling oil $\left({ }^{\circ} \mathrm{C}\right)$ & $\sim 160-170$ & To support effective winding cooling \\
\hline Maximum temperature of stator winding $\left({ }^{\circ} \mathrm{C}\right)$ & 200 & Elevated limit - see text below \\
\hline Normal temperature of coolant $\left({ }^{\circ} \mathrm{C}\right)$ & 65 & {$[$ Ref. 7] } \\
\hline Typical, measured coolant temperature $\left({ }^{\circ} \mathrm{C}\right)$ & 55 & Average of ANL vehicle test data ${ }^{9}$ \\
\hline Published minimum flow rate of coolant $(\mathrm{L} / \mathrm{min})$ & 10 & {$[$ Ref. 7] } \\
\hline Actual flow rate of coolant $(\mathrm{L} / \mathrm{min})$ & 10.6 & Measured using Prius pump/piping \\
\hline
\end{tabular}

In the Prius vehicle, the stator-thermal protection is set at $174^{\circ} \mathrm{C}$, which indicates that Toyota is protecting the winding as if it is a Class $\mathrm{H}$ motor winding. Class $\mathrm{H}$ allows operation at up to $180^{\circ} \mathrm{C}$ for an average life of $20,000 \mathrm{hrs}$. Literature shows that Class $\mathrm{H}$ can be operated at just above $200^{\circ} \mathrm{C}$ and still have a $5000 \mathrm{hr}$ life (Apogee Interactive, Inc.: http://elpaso.apogee.net/md/mfnrins.asp). Thus, operating up to $200^{\circ} \mathrm{C}$ for $<\mathbf{1 0} \mathbf{~ h r s}$, as for this test, would be inconsequential as far as the stator life is concerned. Also, transmission cooling oil with a high flash point $\left(246^{\circ} \mathrm{C}\right)$ was substituted for the Toyota spec oil and placed in the motor casing.

HEVs use intermittent-duty motors. The Prius motor must deliver torques in the $300-400 \mathrm{Nm}$ range for only seconds at a time during hard accelerations. The motor is not thermally designed for anything more. However, this performance-mapping test requires operating in the very high torque range for up to a minute or more to set field weakening and collect redundant sets of data. This is why is was necessary to

${ }^{9}$ The ANL Prius vehicle test data show that $50^{\circ} \mathrm{C}$ was not exceeded in a mild urban drive cycle, while $60^{\circ} \mathrm{C}$ was not exceeded in the most demanding drive cycle that the vehicle could track (Pittsburgh cycle). Thus, $55^{\circ} \mathrm{C}$ is selected for the coolant temperature. 
(1) allow stator temperatures to go very high, (2) set the coolant-flow rate higher than in the Prius vehicle, and (3) use very cold coolant temperatures for a portion of the testing.

For performance testing, coolant flow was supplied to the Prius inverter/PMSM system with an inlet temperature of $55^{\circ} \mathrm{C}$ with a flow rate of $\sim 7 \mathrm{~L} / \mathrm{min}$. Obtaining certain low-speed, high-torque data well into the intermittent-duty portion of the operating window required lowering the coolant temperature substantially to $0^{\circ} \mathrm{C}$ and increasing the flow rate to $7-10 \mathrm{~L} / \mathrm{min}$. A fan was aimed at the motor casing for the entire test for limited convection cooling as typically occurs during vehicle operation. The current for the inverter was controlled based on controller algorithms developed specifically for Prius operation and/or operator control settings.

The testing entailed varying speed and then load through several levels in an iterative fashion. At low speeds, data was collected in 100-200 rpm increments; at high speeds, where efficiency changes more gradually, data was collected in 400-500 rpm increments. At each speed, the torque was increased through a series of levels as data is collected. Data was recorded at every $10 \mathrm{Nm}$ for loading up to $120 \%$ torque if temperature limits were not exceeded. At each speed/torque condition, direct-axis current $\left(\mathrm{i}_{\mathrm{d}}\right)$ was varied through several values to find the minimum necessary level, which is known to correspond to the highest motor efficiency.

Each test condition (i.e., torque at a given speed) was maintained for at least 30 seconds unless temperature limits are about to be exceeded, in which case a note was made to that effect. At each test condition, 10 or more data points were recorded for use in averaging in order to eliminate the effects of data scatter. Inverter current and voltage waveforms were recorded with the motor operating at $1200 \mathrm{rpm}$ and $2500 \mathrm{rpm}$ with a maximum rated torque load.

\section{Data Sampling}

Regardless of speed and therefore electrical frequency, a sample length was used that contains at least five fundamental cycles for each test speed. This ensures that information is not omitted and that power measurements are consistent. To provide additional consistency, the power analyzer was set to trigger on one of the ac phase currents. Since the sample rate varies with the sample length and thus with test speed, a specific sample length was not used throughout the tests, but can be approximated to be 2.5 mega samples per second.

The data acquisition program sampled data from multiple measurement instruments every 4-5 seconds. For each speed and torque, at least five samples were taken and each sample was stored in a row of a spreadsheet. Therefore, after moving to a different operating point, steady-state conditions were first verified and then the row numbers corresponding to the correct data were logged. Furthermore, the data for each operation point was averaged and the efficiency maps provided below were generated using the averaged data.

\section{$\underline{\text { High Inverter Efficiency Investigation }}$}

During testing, inverter data at certain speed and load combinations showed efficiencies that were as high as $99.0 \%$, which is just beyond the expected range. Because only precision, calibrated instrumentation and sensors were used, it was believed that inaccuracies (if indeed any existed) could only be caused by the noise/EMI observed in the inverter-output current signals. Several solutions and/or special tests were identified.

Researchers investigated all but Item 3 of the following potential solutions to the high efficiency issue: 
1. Take additional data using internal-current shunts to compare with suspect data,

2. Locate the power analyzer and CT power supply closer to the motor and inverter using shorter cables,

3. Make use of the CTs that Toyota has built into the inverter (higher signal-to-noise ratio but accuracy must be checked carefully),

4. Look for the root cause of the high EMI, and

5. Investigate the observed fact that when we remove the voltage signal coming from the $500 \mathrm{Vdc}$ supply to one of the Yokogawa power analyzer inputs, the noise from the threephase CTs drops down somewhat. (This signal coupling effect was subsequently reduced by reconfiguring equipment/signal lines and adding additional grounds/shields.)

The most significant outcome of the above investigation resulted when several special tests were run in February 2004 to verify/validate the performance-mapping data recorded in the prior month.

The special tests included the following:

1. Testing Using Shunts - Subsystem testing was performed at low current using internal Yokogawa shunts, which is the most precise power measurement configuration possible. The three-phase inverter-to-motor lines were routed through the power analyzer for this testing. The results matched earlier test data using CTs on the three-phase lines.

2. Use of Filtering - Data was obtained with and without digital filters on the three-phase voltage and current with no significant difference in power and efficiency measurements.

3. Use of Pseudo Neutrals - Data was obtained using external pseudo neutrals on the threephase lines and then using the impedance of the power analyzer for the pseudo neutral. There was no significant difference in power and efficiency measurements.

4. Line/Channel Isolation - Inverter input/output (I/O) lines were connected/disconnected to the power analyzer in all combinations to verify isolation of channels. In this way, inverter I/O electrical data were fed to the power analyzer sequentially. Again, no significant difference in power and efficiency could be seen.

The above testing greatly increased the confidence that ORNL researchers had in the performancemapping tests and led to the conclusion that there were indeed certain speed/load combinations in which the inverter performed with very high efficiency. The inverter efficiencies are expected to be high for these operating conditions since the pulse-width modulation (PWM) control signal is over-modulated to create the maximum voltage available from the power supply. This means that the inverter is switching less often per fundamental cycle and therefore switching losses are very low.

\subsubsection{Motor/Inverter Test Data and Efficiency Maps}

This section provides Prius subsystem performance-mapping data including efficiency contour mapping plots. The most challenging data to obtain were those at high load levels since the Prius motor is an intermittent design and high thermal excursions in the stator were frequent. Overheating was not a problem in the inverter integrated power electronics module (IPEM). For full loading at speeds below $1300 \mathrm{rpm}$, it was necessary to use an auxiliary-synchronous motor to supplement the loading from the eddy-current dynamometer. Those changes that were necessary in the cooling of the Prius motor (see Section 3.3.1) were deemed unlikely to have any significant effect on the electrical data obtained from the inverter and Prius motor.

The motor efficiency contour map, ranging from 300-6000 rpm, is presented in Fig. 3.18. It shows efficiencies peaking at $93-94 \%$ in the $1750-3000 \mathrm{rpm}$ range at moderate torque levels $(50-150 \mathrm{Nm})$. The lowest efficiencies are evident at several fringe regions of the contour, especially at low-speed, high- 
torque conditions. Since one of the primary applications of the motor is to accelerate the vehicle from a stop, the low-speed and/or high-torque regions are quite significant.

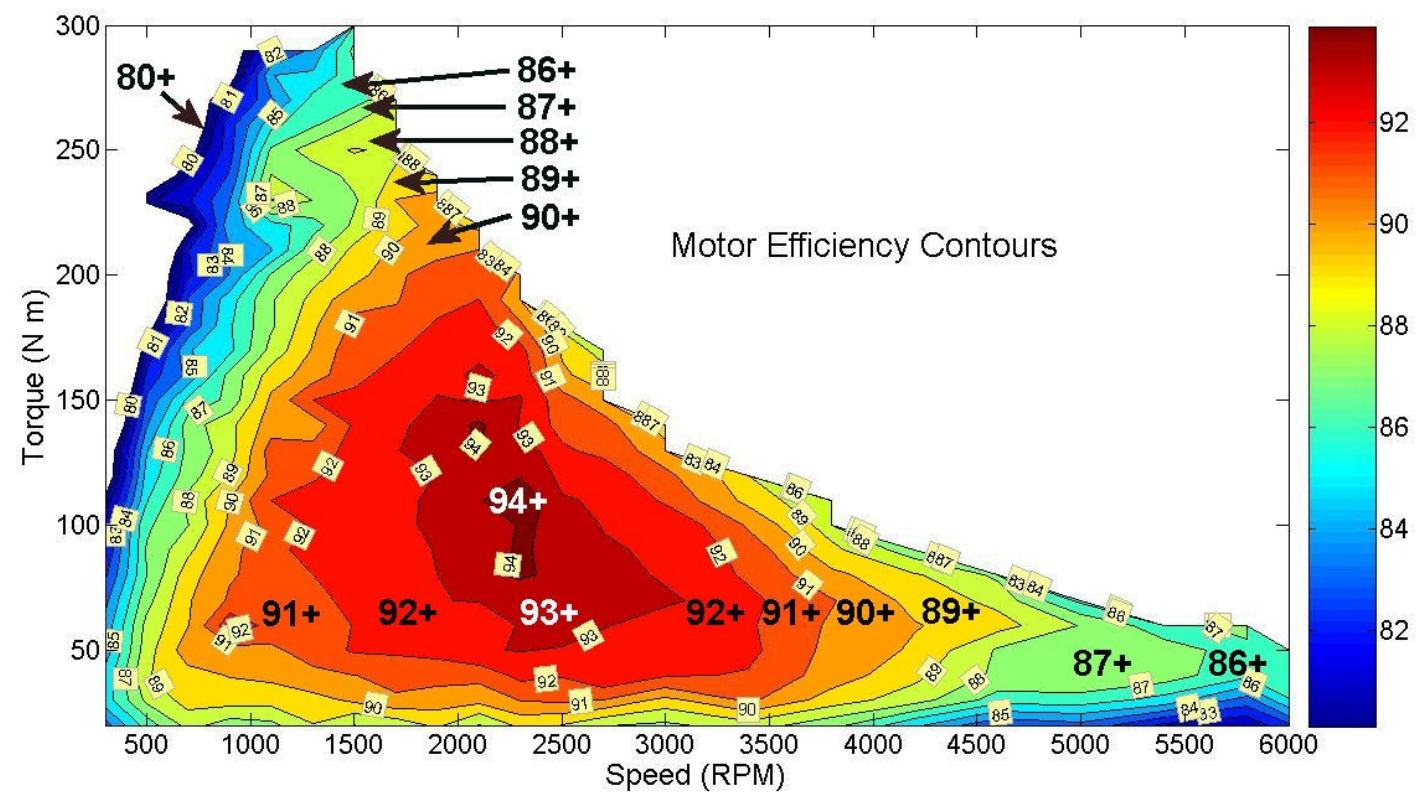

Fig. 3.18. 2004 Prius motor efficiency contour map.

The inverter efficiency contour map, ranging from 300-6000 rpm, is presented in Fig. 3.19. It shows a large area of high $98-99 \%$ efficiencies above $\sim 1800 \mathrm{rpm}$. Although colored regions generally denote a spanned efficiency range of $1 \%$, the regions denoted as " 99 " had $99.0 \%$ efficiency in 23 torque-speed settings, $99.1 \%$ efficiency in 13 torque-speed settings, $99.2 \%$ efficiency in 6 torque-speed settings, and $>99.2 \%$ efficiency in 1 torque-speed setting. The higher-than-expected efficiencies led to data verification tests (Section 3.3.2). At lower motor speeds, inverter efficiency drops down gradually to $92 \%$ and even lower in small regions of the contour. Clearly, motor torque levels generally have little effect on inverter efficiency.

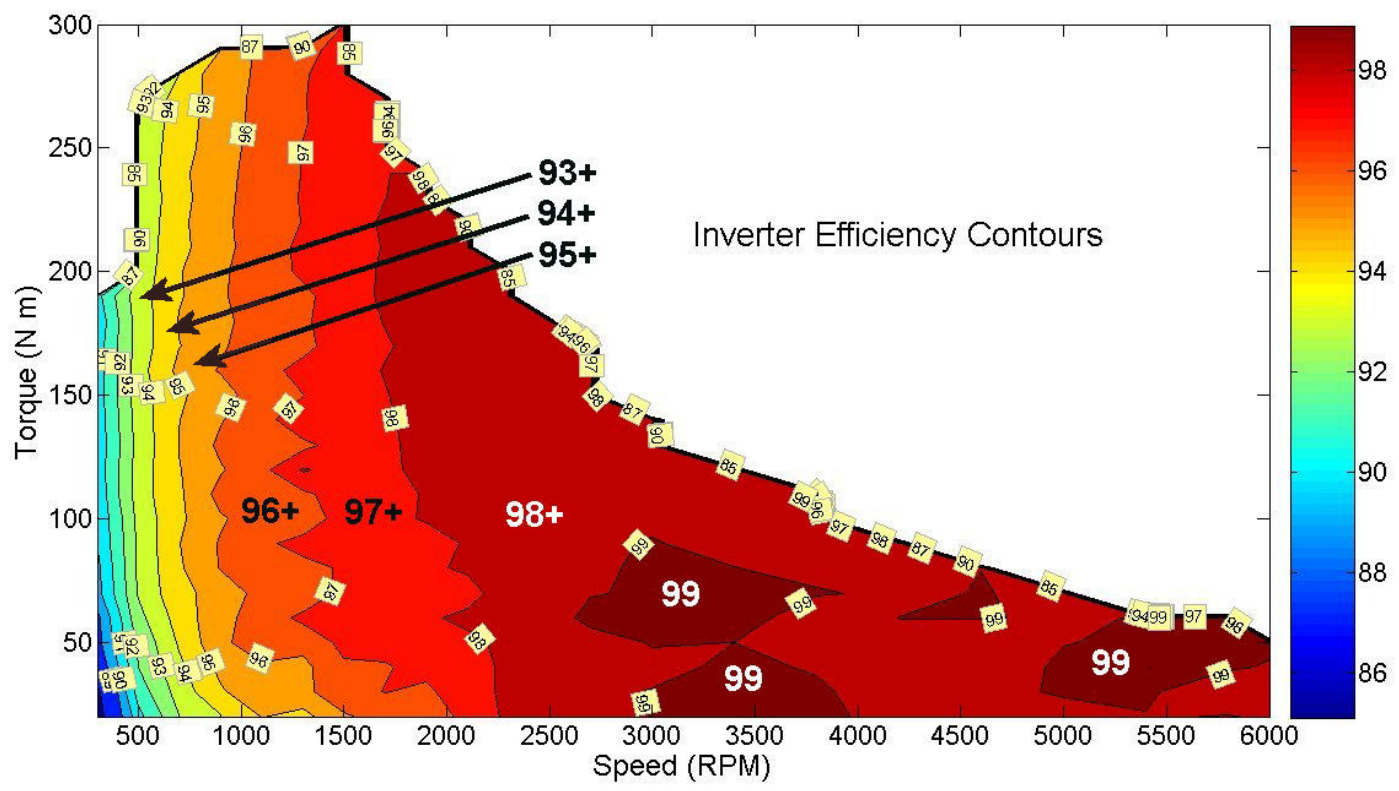


Fig. 3.19. 2004 Prius inverter efficiency contour map.

The combined motor/inverter efficiency contour map ranging from 400-6000 rpm is shown in Fig. 3.20. Motor/inverter efficiency is in the $92-93 \%$ range from $\sim 2200-3000 \mathrm{rpm}$ (depending on load) over a range of moderate torque levels $(60-140 \mathrm{Nm})$. The most significant region of relatively low efficiencies is at speeds below $1500 \mathrm{rpm}$, especially at higher load levels.

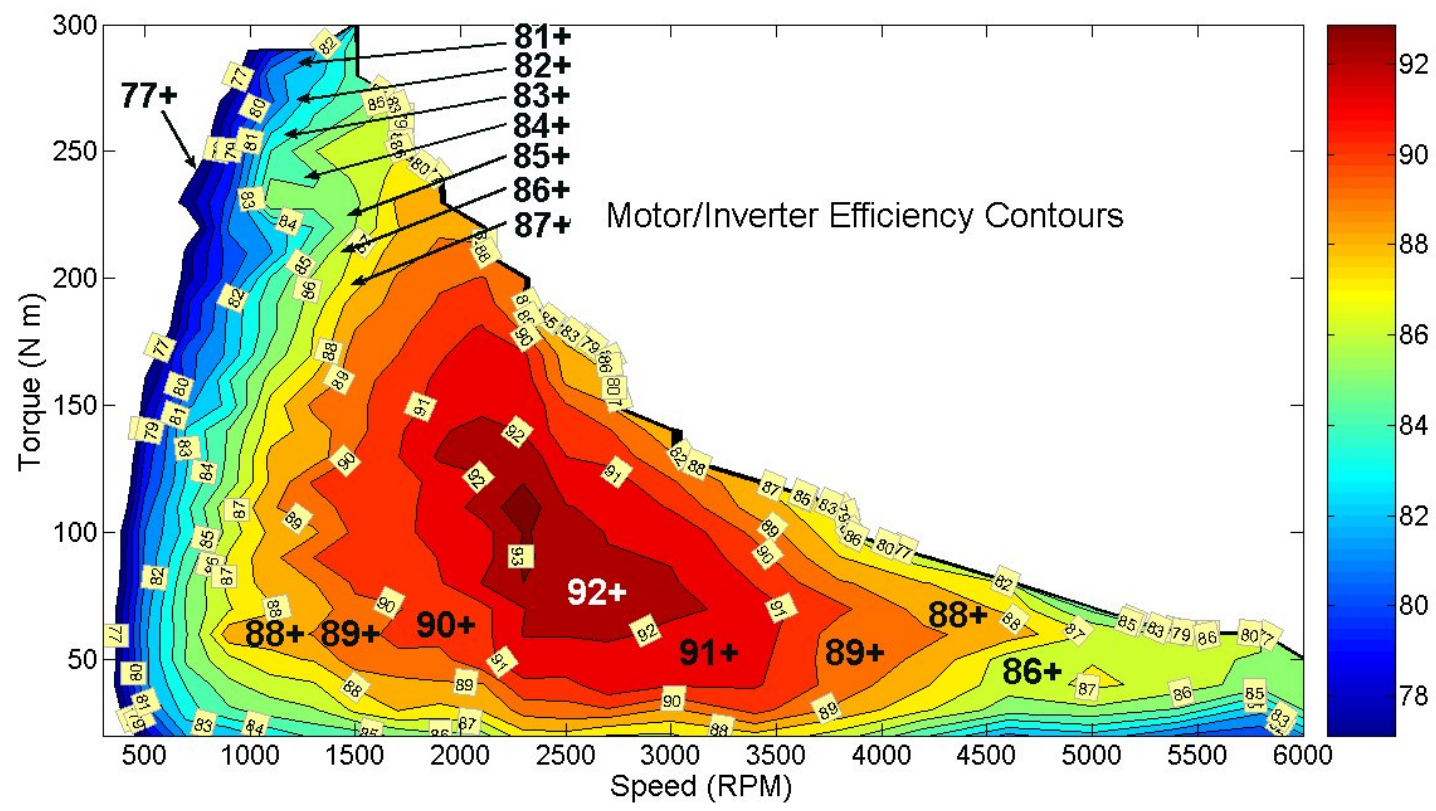

Fig. 3.20. 2004 Prius combined motor/inverter efficiency contour map.

A summary set of mechanical, operational, electrical, and thermal data obtained from the Prius subsystem performance-mapping test is provided in the table found in Appendix B. In support of FCVT objectives, the full set of test data has been made available to technical partners as needed. Data on the performance of the buck/boost converter is provided in the next section. 


\subsubsection{Buck/Boost-Converter Test Data and Efficiency Maps}

This section contains boost-converter information based on converter, inverter, and motor system testing in the ORNL test cell which immediately followed the testing described in Section 3.3.3. This testing was constrained by the power rating of the converter, which is less than half the peak-power rating of the motor. The testing of the boost converter was performed at minimum-, mid-, and maximum-output voltages. The voltage-buck performance of the converter was not tested.

The input voltage to the boost converter was set at $233 \mathrm{Vdc}$ throughout the test. This voltage was based on ANL's drive-cycle data that showed the converter's dc input fairly steady at $\sim 230 \mathrm{~V}$. Although the Prius battery voltage is $201.6 \mathrm{Vdc}$, the generator is apparently responsible for an elevated voltage during vehicle operation. The Vdc output of the converter was set at 240,365, and 500, and these output settings comprised the three parts of the test.

The converter tests were carried out under the following conditions:

- Motor speed: $1500 \mathrm{rpm}$

- Motor shaft torque: $0-130 \mathrm{Nm}$ in increments of $10 \mathrm{Nm}$

- Motor shaft mechanical Power: 0-20.4 kW

- Boost converter output power range: 0-25 kW

- Motor, converter, and inverter coolant temp: $55^{\circ} \mathrm{C}$

- Coolant flow rate: 7 Liters/minute

Figure 3.21 shows the boost-converter efficiency versus output power for all three output voltages and Fig. 3.22 shows efficiency versus output current. Polynomial curve fitting is used where oscillations are evident in the data. The most apparent conclusion is that the efficiency drops as the output voltage of the boost converter increases. Additionally, for all output voltages the efficiency is lowest for high power/current conditions and, to a somewhat lesser extent, when power/current is very low. The efficiency is at the minimum, $96.7 \%$, when the maximum boost and power is required.

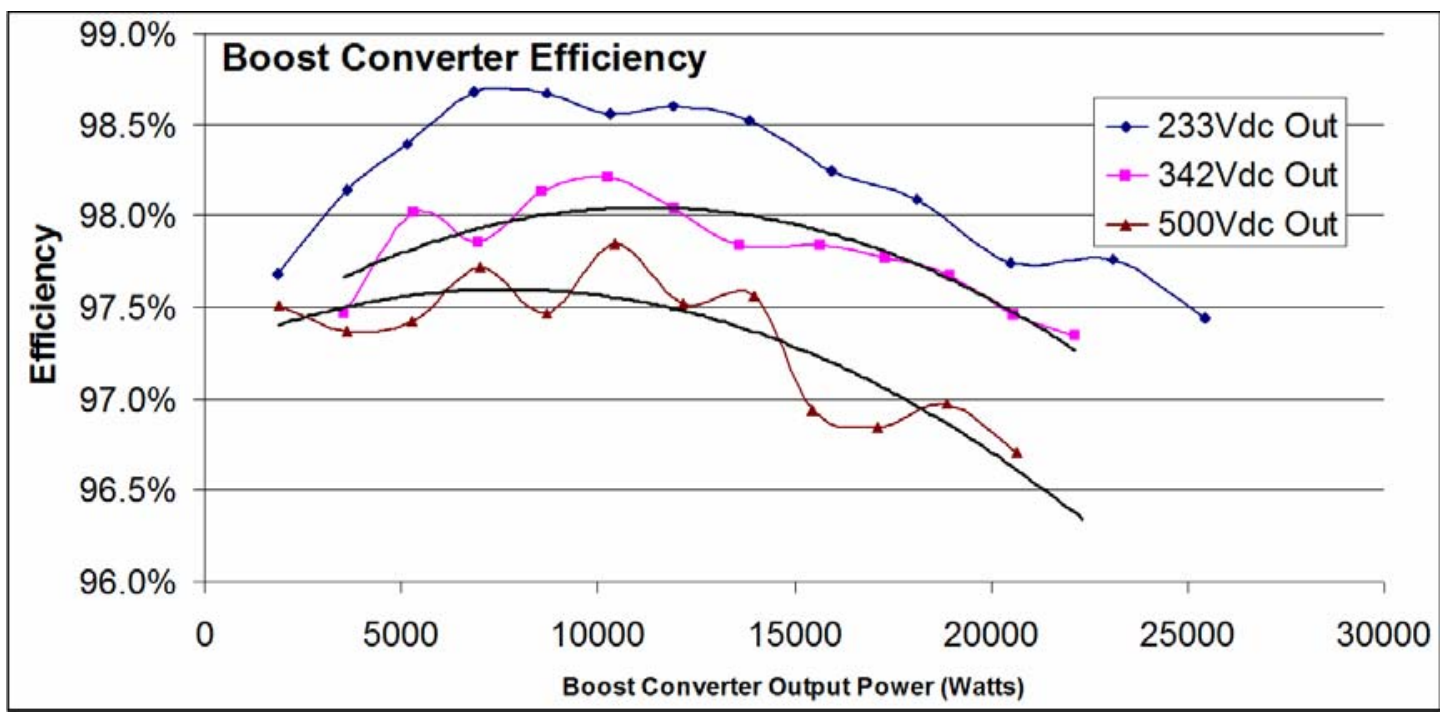

Fig. 3.21. Boost-converter efficiency vs. output power. 


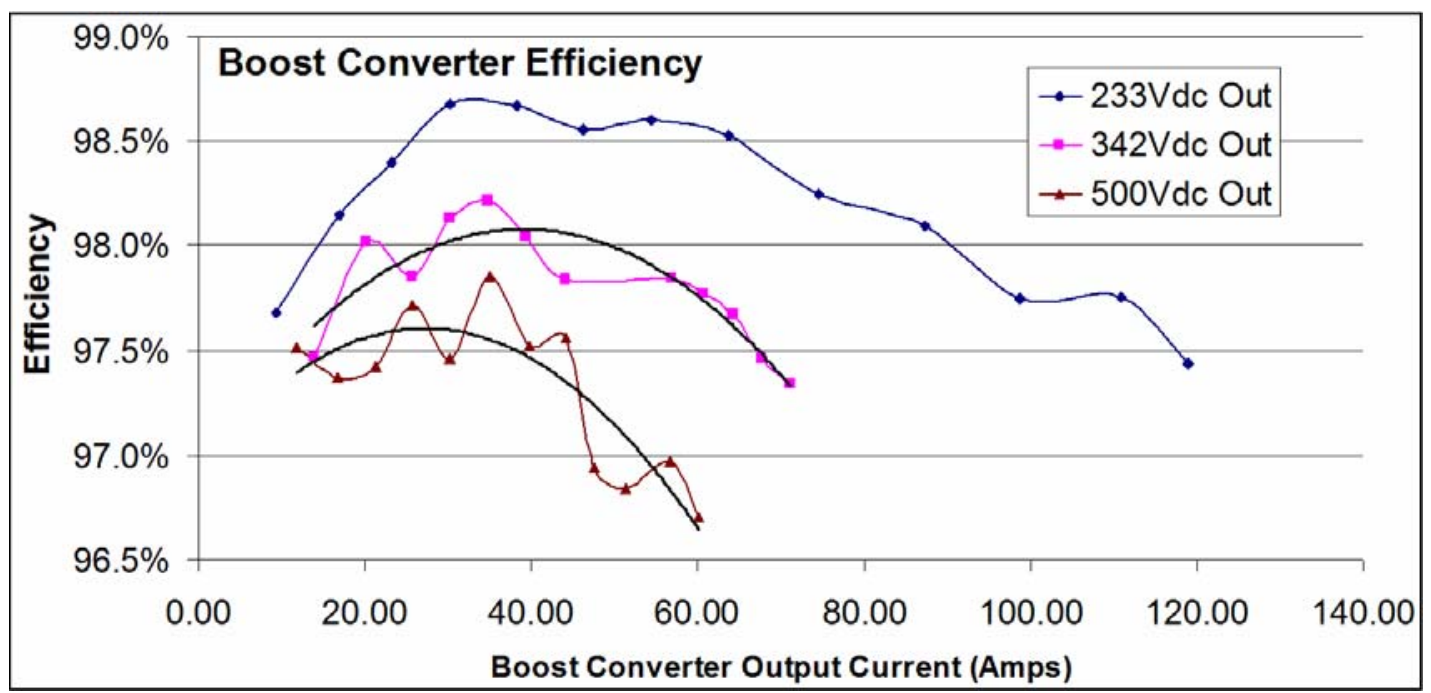

Fig. 3.22. Boost-converter efficiency vs. output current.

The motor load, efficiency, and electrical data obtained from the converter test are tabulated in Table 3.15. The data is presented in three sections (denoted by heavy lines) to show results using the three different voltage output settings of the converter. 
Table 3.15. Boost-converter test data including efficiency, motor load, and electrical parameters

\begin{tabular}{|c|c|c|c|c|c|c|c|c|c|c|}
\hline \multirow[b]{2}{*}{ Torque } & \multicolumn{3}{|c|}{ Efficiency (\%) } & \multicolumn{3}{|c|}{ Power (W) } & \multicolumn{2}{|c|}{ Input rms } & \multicolumn{2}{|c|}{ Output rms } \\
\hline & Converter & $\begin{array}{l}\text { Inverter- } \\
\text { Motor }\end{array}$ & Total & In & Out & Mech. & Vdc & Idc & Vdc & Idc \\
\hline 10.00 & 97.7 & 85.2 & 83.2 & 1888 & 1844 & 1571 & 232 & 8.6 & 236 & 9.3 \\
\hline 20.00 & 98.1 & 86.8 & 85.1 & 3690 & 3621 & 3142 & 232 & 16.2 & 235 & 16.9 \\
\hline 30.00 & 98.4 & 91.7 & 90.2 & 5222 & 5138 & 4712 & 232 & 22.8 & 235 & 23.2 \\
\hline 40.00 & 98.7 & 91.6 & 90.4 & 6951 & 6860 & 6283 & 232 & 30.2 & 235 & 30.2 \\
\hline 50.00 & 98.7 & 90.3 & 89.1 & 8813 & 8695 & 7854 & 232 & 38.6 & 234 & 38.2 \\
\hline 60.00 & 98.6 & 91.5 & 90.2 & 10446 & 10295 & 9425 & 232 & 45.3 & 234 & 46.2 \\
\hline 70.00 & 98.6 & 92.1 & 90.8 & 12104 & 11934 & 10996 & 232 & 52.5 & 234 & 54.5 \\
\hline 80.00 & 98.5 & 90.8 & 89.5 & 14046 & 13838 & 12566 & 232 & 60.9 & 233 & 63.7 \\
\hline 90.00 & 98.2 & 88.6 & 87.1 & 16240 & 15955 & 14137 & 232 & 70.5 & 233 & 74.6 \\
\hline 100.00 & 98.1 & 86.7 & 85.0 & 18470 & 18118 & 15708 & 231 & 80.4 & 232 & 87.2 \\
\hline 110.00 & 97.7 & 84.3 & 82.4 & 20965 & 20492 & 17279 & 231 & 91.1 & 232 & 98.7 \\
\hline 120.00 & 97.8 & 81.5 & 79.7 & 23650 & 23119 & 18850 & 231 & 102.6 & 231 & 110.9 \\
\hline 130.00 & 97.4 & 80.2 & 78.2 & 26118 & 25449 & 20420 & 231 & 113.3 & 231 & 118.9 \\
\hline 10.00 & 98.1 & 80.8 & 79.3 & 1982 & 1944 & 1571 & 231 & 8.7 & 358 & 7.5 \\
\hline 20.00 & 97.5 & 88.6 & 86.4 & 3636 & 3544 & 3142 & 231 & 16.4 & 345 & 13.9 \\
\hline 30.00 & 98.0 & 88.7 & 87.0 & 5418 & 5311 & 4712 & 231 & 24.0 & 345 & 20.2 \\
\hline 40.00 & 97.9 & 90.2 & 88.3 & 7119 & 6966 & 6283 & 231 & 31.5 & 344 & 25.7 \\
\hline 50.00 & 98.1 & 91.4 & 89.7 & 8753 & 8589 & 7854 & 231 & 38.6 & 344 & 30.2 \\
\hline 60.00 & 98.2 & 91.8 & 90.2 & 10454 & 10267 & 9425 & 231 & 46.1 & 343 & 34.8 \\
\hline 70.00 & 98.0 & 92.0 & 90.2 & 12186 & 11946 & 10996 & 231 & 53.3 & 343 & 39.4 \\
\hline 80.00 & 97.8 & 92.4 & 90.4 & 13903 & 13602 & 12566 & 231 & 60.8 & 342 & 44.1 \\
\hline 90.00 & 97.8 & 90.2 & 88.2 & 16022 & 15676 & 14137 & 231 & 70.2 & 341 & 57.0 \\
\hline 100.00 & 97.8 & 90.7 & 88.7 & 17710 & 17314 & 15708 & 231 & 77.6 & 341 & 60.6 \\
\hline 110.00 & 97.7 & 91.2 & 89.0 & 19407 & 18956 & 17279 & 230 & 85.2 & 340 & 64.2 \\
\hline 120.00 & 97.5 & 91.6 & 89.2 & 21120 & 20583 & 18850 & 230 & 92.5 & 339 & 67.8 \\
\hline 130.00 & 97.3 & 92.2 & 89.8 & 22751 & 22146 & 20420 & 230 & 99.5 & 339 & 71.1 \\
\hline
\end{tabular}


Table 3.15. Boost-converter test data including efficiency, motor load, and electrical parameters (cont'd)

\begin{tabular}{|c|c|c|c|c|c|c|c|c|c|c|}
\hline \multirow[b]{2}{*}{ Torque } & \multicolumn{3}{|c|}{ Efficiency (\%) } & \multicolumn{3}{|c|}{ Power (W) } & \multicolumn{2}{|c|}{ Input rms } & \multicolumn{2}{|c|}{ Output rms } \\
\hline & Converter & $\begin{array}{l}\text { Inverter- } \\
\text { Motor }\end{array}$ & Total & In & Out & Mech. & Vdc & Idc & Vdc & Idc \\
\hline 10.00 & 95.5 & 82.3 & 78.5 & 2000 & 1910 & 1571 & 231 & 9.6 & 495 & 6.3 \\
\hline 20.00 & 97.5 & 86.6 & 84.5 & 3719 & 3627 & 3142 & 231 & 16.7 & 468 & 11.8 \\
\hline 30.00 & 97.4 & 89.1 & 86.8 & 5429 & 5286 & 4712 & 231 & 24.6 & 463 & 16.7 \\
\hline 40.00 & 97.4 & 89.6 & 87.3 & 7199 & 7012 & 6283 & 231 & 32.5 & 462 & 21.4 \\
\hline 50.00 & 97.7 & 90.4 & 88.4 & 8889 & 8685 & 7854 & 231 & 40.0 & 461 & 25.7 \\
\hline 60.00 & 97.5 & 90.2 & 87.9 & 10721 & 10449 & 9425 & 231 & 48.1 & 460 & 30.3 \\
\hline 70.00 & 97.8 & 90.3 & 88.4 & 12440 & 12172 & 10996 & 231 & 55.4 & 460 & 35.0 \\
\hline 80.00 & 97.5 & 90.0 & 87.8 & 14314 & 13958 & 12566 & 230 & 63.3 & 458 & 39.8 \\
\hline 90.00 & 97.6 & 91.5 & 89.2 & 15845 & 15458 & 14137 & 230 & 69.6 & 458 & 44.1 \\
\hline 100.00 & 96.9 & 91.7 & 88.9 & 17670 & 17129 & 15708 & 230 & 77.6 & 457 & 47.6 \\
\hline 110.00 & 96.8 & 91.6 & 88.7 & 19482 & 18866 & 17279 & 230 & 85.5 & 456 & 51.3 \\
\hline 120.00 & 97.0 & 91.3 & 88.5 & 21302 & 20656 & 18850 & 230 & 93.5 & 455 & 56.6 \\
\hline 130.00 & 96.7 & 91.5 & 88.5 & 23083 & 22322 & 20420 & 230 & 101.3 & 454 & 60.2 \\
\hline
\end{tabular}




\section{INVERTER, CONTROLLER, AND Z-SOURCE ACTIVITIES}

This section begins by briefly assessing the early and upgraded Prius inverter designs based on disassemblies to reveal its architecture and method of cooling. An earlier description of the inverter and its components is provided in Section 2.2.5. This section also describes the modifications performed on the 2004 inverter by ANL to support performance testing at ORNL. Next, the controller development which is essential for operating the HEV system outside the vehicle is summarized. Lastly, the Prius inverter is compared to the new, experimental Z-source inverter design.

\subsection{INVERTER ARCHITECTURE OVERVIEW}

After careful study of a 2003 and 2004 Prius inverter, differences were noted between the two models. The 2004 inverter/converter package has roughly the same volume as the 2003 unit; however, the 2004 package contains the new buck/boost converter.

The 2004 Prius inverter is cooled using a cold plate located in the center of the package. This cold plate serves as a separator between the generator-motor-boost sections that are located above the cold plate and the air-conditioning compressor inverter and dc-to-dc converter located below the cold plate. The cold plate transfers excess heat from the inverter to the hybrid drive system coolant as it circulates through internal passages in the cold plate. A flow diagram for the hybrid drive system coolant is presented in Fig. 2.3. The power electronic active switching devices for the main inverter sections (motor and generator) are packaged in one IPEM that contains 18 insulated-gate bipolar transistors (IGBTs). The buck/boost-converter power electronics are contained in a separate module from the IPEM.

The main dc-link capacitors in the 2004 Prius are slightly smaller in volume than those in the 2003 Prius and are packaged in a plastic module making them different from the commercially available can-type electrolytic capacitors used in the 2003 model. Most of the integrated circuits in the 2004 Prius are identified with a Toyota label, as compared to those in the 2003 unit that used commercially available electronic components primarily from International Rectifier (IR). However, the circuits appear to be basically unchanged.

\subsection{INVERTER MODIFICATIONS}

A 2004 Prius inverter was modified at ANL with installation of instrumentation to allow monitoring of the system to provide electrical power and thermal data from the inverter and converter. The inverter was returned to ORNL and used for the PMSM/inverter tests after being modified with conventional sensors that are similar in design and configuration to those installed in the ANL inverter for chassis-dyne testing. ${ }^{10}$

The instrumentation modifications performed on the ORNL inverter by ANL include the installation of:

\footnotetext{
10 Additional inverter instrumentation was required to achieve ANL chassis-dyne testing goals and this effort was included as part of the benchmarking project. The additional instrumentation involves developmental sensors and installation techniques including (1) installation of Giant Magneto Resistive (GMR) current sensors directly on the $\mathrm{dc}$ bus bars (embedded in the IPEM) to sense current in the feed to the traction motor inverter section, and (2) installation of GMRs on the dc bus bars that feed the generator inverter section.
} 
1. Shunt-style current sensors on dc-link bus bars on both the $200 \mathrm{~V}$ and $500 \mathrm{~V}$ sides of the boost converter,

2. Voltage divider sensing points on the $200 \mathrm{~V}$ and $500 \mathrm{~V}$ bus bars,

3. A shunt-style current sensor on the $12 \mathrm{~V}$ auxiliary charging system, and

4. TCs at power electronic devices as described below.

After the modifications were performed, it was realized that the buck/boost converter has only $\sim 40 \%$ the peak power rating of the PMSM. This is because the generator provides most of the power to the PMSM, and the HEV battery and converter provide less than half the power. For these reasons, the converter was not used during full-power laboratory testing of the inverter/PMSM system.

TCs were installed between certain power electronics components such as the IGBT modules and the cold plate. Figure 4.1 depicts the placement of TCs on the cold plate in the area on which the IPEM is mounted where two TCs were located under motor inverter IGBTs and two under generator IGBTs.

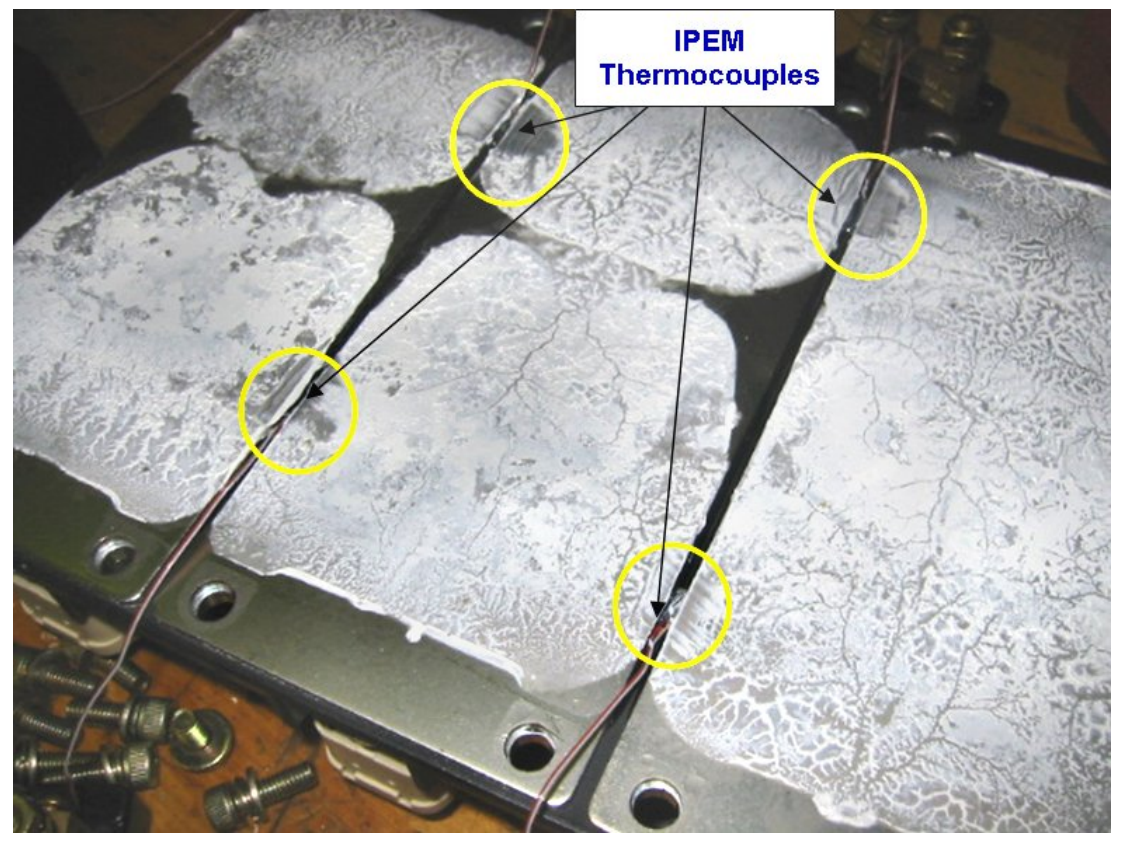

Fig. 4.1. TC placement at IPEM area of cold plate (2004 Prius inverter).

\subsection{CONTROLLER DEVELOPMENT}

In order to perform subsystem-level tests, the inverter/PMSM system had to be severed from the vehicle control system or ECU. The ECU not only controls essentially all vehicle electrical systems, but it also contains a sophisticated algorithm for the operation of the inverter/PMSM system over the full design range. Therefore, the ECU may certainly be considered as part of the HEV traction-drive system.

This project is designed to test the operation of the inverter/PMSM system to determine their capabilities and performance apart from the ECU-specified operation. If this was not the case, the project could not continue because it is not possible to determine precisely what the ECU algorithm is intended to do. For instance, does the ECU attempt to maximize torque or performance? How do the ECU algorithm goals change with vehicle speed or other operational parameters? How does the ECU's control of PWM change with speed and by what algorithm does the ECU control the voltage boost in the dc converter? 
ORNL developers decided to create an entirely new controller that would operate the inverter/PMSM system at maximum torque per current from 1-6000 rpm. This would provide the answer to what the Prius traction system is capable of producing. Since the Prius motor is an interior PM design, developers knew that the model would have to be capable of operating a salient PM motor; the saliency is due to the fact that the reactances for the direct and quadrature axes are not equal, $X_{d} \neq X_{q}$. Furthermore, the voltage-boost circuit alone would not enable the system to attain speeds close to $6000 \mathrm{rpm}$; therefore, a field-weakening scheme would have to be used. Lastly, speed and position feedback signals from the motor would be essential for the new control system.

\subsubsection{Establishing the Need for Field Weakening}

The Prius inverter/PMSM drive system relies partly on a control system that increases the dc-link voltage such that the field-weakening current, $i_{d}$, is zero. Up to a certain speed, this is the most efficient way to operate the motor but there is a speed at which the back-emf voltage is greater than the voltage supplied by the inverter (related to the dc-link voltage).

The $500 \mathrm{Vdc}$ link produces a maximum voltage of $390 \mathrm{~V}_{L L}(\mathrm{rms})$ during a six-step inverter-square wave operation based on:

$$
V_{L L(R M S)}=\frac{\sqrt{3}}{\sqrt{2}} \frac{4}{\pi} \frac{V_{d}}{2}=0.78 V_{d}
$$

Using $\mathrm{V}_{L L(\mathrm{RMS})}=390$, the back-emf test data indicate that the corresponding motor speed is:

$$
390 \frac{1}{1.338}=291.5 \mathrm{~Hz} \Rightarrow 4372 \mathrm{rpm}
$$

The $1.338 \mathrm{~Hz} / \mathrm{V}_{L L}(\mathrm{rms})$ relationship is based on ANL and ORNL back-emf test data. Thus, the theoretical maximum speed without field weakening and under no-load conditions is $4372 \mathrm{rpm}$. This calculation neglects inverter-voltage drop, so the actual upper speed limit for operation without field weakening is lower, likely in the range 3250-3750 rpm (see Fig. 4.2). This speed limit decreases even further as the motor is loaded.

Reluctance torque increases as $\mathrm{L}_{d}-\mathrm{L}_{q}$ is maximized as evident in the second term of the following torque equation:

$$
T=P_{n} \phi_{m} i_{q}+P_{n}\left(L_{d}-L_{q}\right) i_{d} i_{q}
$$

If $\mathrm{L}_{q}$ is greater than $\mathrm{L}_{d}$ (which is the case for the Prius based on static measurements: $5 \mathrm{mH}$ and $1.92 \mathrm{mH}$, respectively), then the contribution from the reluctance torque is positive only if $i_{d}$ is negative (i.e., the application of field weakening). The quadrature-axis current $\left(i_{q}\right)$ is positive in motoring operation and the number of pole pairs, $\mathrm{P}_{\mathrm{n}}$, is always positive. Therefore, to maximize the torque-per-ampere ratio, $\mathrm{i}_{d}$ must be negative. Thus, Toyota has clearly designed the motor to operate with field weakening. 


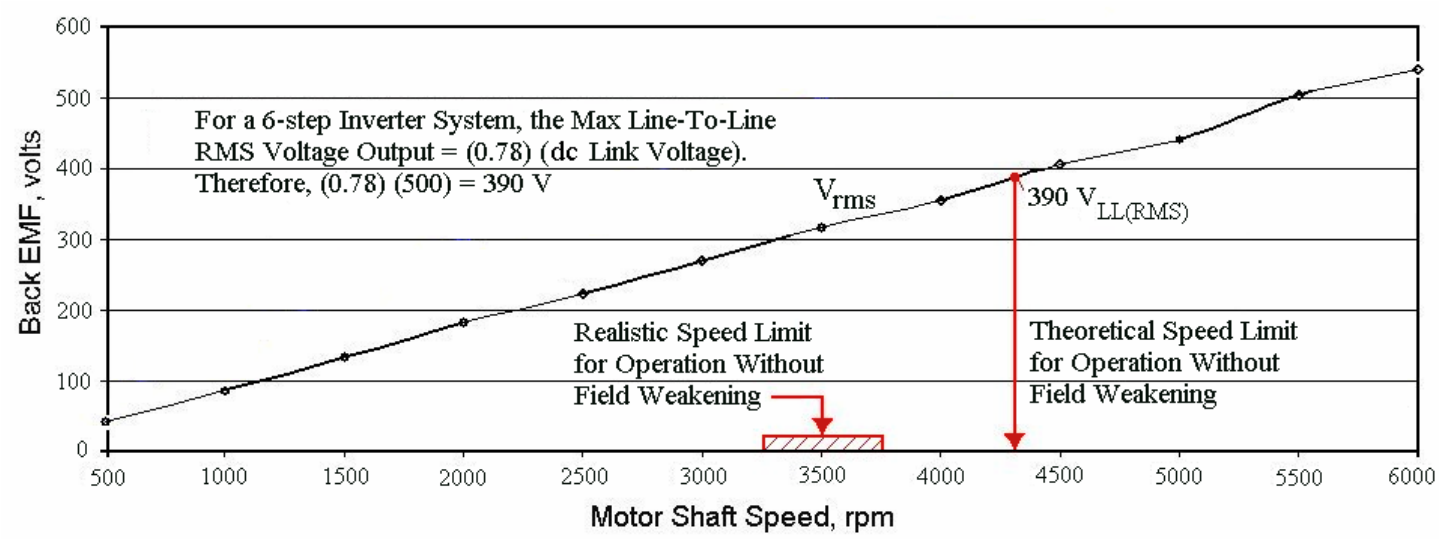

Fig. 4.2. Limitations in operation of PMSM where field weakening is not used.

The total torque, including reluctance torque, was originally measured during locked rotor tests. However, in system testing over the full torque and speed range, the approach take was to "explore" for the right value of $i_{d}$ (field weakening) to find the optimal efficiency point. Specifically, during the full performance speed-torque mapping tests, torque and speed are maintained constant and the rms current is monitored as the field-weakening current $i_{d}$ is varied. The value of $i_{d}$ which maximizes the torque-perampere ratio is then defined as an optimal point. Varying $i_{d}$ not only has a profound effect on the torque, but at high speeds $i_{d}$ must be supplied or the motor will not operate. In practical terms, it was observed that efficiency was highest when the minimum $i_{d}$ was applied that permitted stable motor operation.

\subsubsection{Controller Software}

The algorithm for the controller was divided into three speed regimes, (1) a low-speed regime where operation is limited by current, (2) a mid-speed regime where operation is limited by voltage and current, and (3) a high-speed regime where operation is limited by voltage. In each case, the code was designed to maximize torque per current in a salient, PMSM over a wide speed range with voltage boost set to the 500 volt maximum.

First, a model of a salient PMSM was setup and simulated in Simulink/Opal-RT. This was developed to help in verifying the controller algorithm. The machine model in the in the direct/quadrature coordinate system is given by:

$$
\begin{aligned}
L_{d} \frac{d i_{d}}{d t} & =-R_{S} i_{d}+n_{p} \omega L_{q} i_{q}+u_{d}, \\
L_{q} \frac{d i_{q}}{d t} & =-R_{S} i_{q}-n_{p} \omega L_{d} i_{d}-K_{m} n_{p} \omega+u_{q}, \text { and } \\
J \frac{d \omega}{d t} & =n_{p} K_{m} i_{q}+n_{p}\left(L_{d}-L_{q}\right) i_{d} i_{q}-\tau_{L} .
\end{aligned}
$$

Where $R_{S}=$ stator resistance, $n_{p}=$ number of pole pairs, $\omega=$ rotational speed $(\mathrm{rad} / \mathrm{s}), L=$ inductance, $J=$ the inertia constant, $i=$ current, $u=$ voltage, $K_{m}=$ the torque constant in the dq frame, and $\tau_{L}=$ load torque.

The field weakening problem is to maximize the torque, that is 


$$
n_{p} K_{m} i_{q}+n_{p}\left(L_{d}-L_{q}\right) i_{d} i_{q}
$$

Subject to the following constraints:

$$
\begin{gathered}
V=\sqrt{u_{d}^{2}+u_{q}^{2}} \leq V_{\max }, \text { and } \\
I=\sqrt{i_{d}^{2}+i_{q}^{2}} \leq I_{\max } .
\end{gathered}
$$

A controller algorithm was developed that for any fixed speed, $\omega$, derives the values of $i_{d}(\omega), i_{q}(\omega), u_{d}(\omega)$, and $u_{q}(\omega)$ that maximize torque for motoring and minimize the torque for braking.

This is broken down into three cases

$$
\begin{aligned}
& \text { 1. } \sqrt{i_{d}^{2}+i_{q}^{2}}=I_{\max }, \sqrt{u_{d}^{2}+u_{q}^{2}} \leq V_{\max }, \\
& \text { 2. } \sqrt{i_{d}^{2}+i_{q}^{2}} \leq I_{\max }, \sqrt{u_{d}^{2}+u_{q}^{2}}=V_{\text {max }} \text {, and } \\
& \text { 3. } \sqrt{i_{d}^{2}+i_{q}^{2}}=I_{\max }, \sqrt{u_{d}^{2}+u_{q}^{2}}=V_{\max } .
\end{aligned}
$$

This was further developed in a Matlab ${ }^{\mathrm{TM}}$ program that solves a static optimization problem. The control algorithm was used on the simulated PMSM with excellent agreement. The next step was to validate the simulation model with data from the Prius machine.

Having a very high power density, the Prius motor operates well into the saturation regime. This has added complexity to the motor modeling and controller development efforts. Furthermore, the agreement between the model and motor operation data has not been as good as expected. Recent research papers $[8,9]$ indicate that the flux linkage in the $q$ axis depends on both the $d$ and $q$ currents. This also appears true for the $d$ axis flux linkage. Therefore, the model required revision so that it corresponded better with the data; furthermore, additional finite-element analysis (FEA) runs were deemed necessary to account more accurately for saturation. These efforts are expected to lead to an improved understanding of how a high energy-density, interior PM motor such as the Prius should be modeled and controlled.

\subsubsection{Controller Hardware}

The RT-LAB real-time computing platform from OPAL-RT Technologies was used to model and replace the Prius control system. The RT-LAB system interfaces with the MATLAB SIMULINK software for quick controller development without tedious programming. The system consists of a host PC running a user-selected operating system and two target PCs running the QNX Neutrino operating system. One of the PCs is a dual-processor computer with additional counter, encoder, and analog/digital I/O boards.

The model of the Prius controller and a user interface is built in MATLAB SIMULINK using both builtin SIMULINK blocks and RT-LAB blocks as illustrated in Fig. 4.3. This figure is an upper-level representation; most blocks can be opened for additional detail. Using the Real-Time Workshop Toolbox of SIMULINK, the model is converted to C-source code and the executable is uploaded to the target PCs. The controller software runs on two target PCs that communicate with each other through a firewire connection while the host $\mathrm{PC}$ is used to command the controller through an Ethernet connection. The 
software allows the control development to be flexible and versatile, with the capability of quickly making required development changes. This approach bypasses some of the more difficult hardware development efforts required to allow the inverter to be controlled outside the vehicle. It also enhances the ability to make changes during testing, if required. 


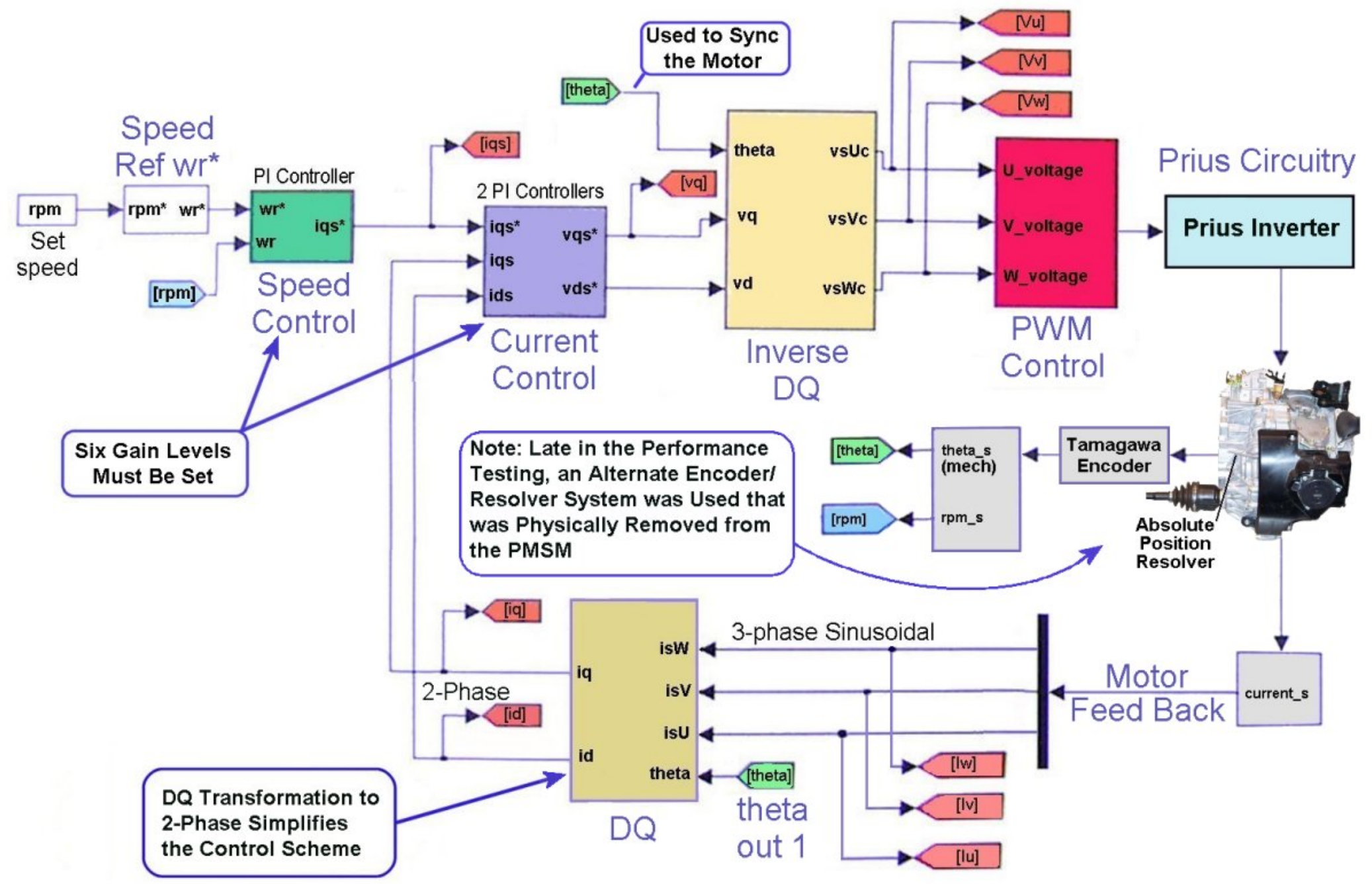

Fig. 4.3. Upper-level flow diagram of Prius controller system. 


\subsection{COMPARISON OF PRIUS INVERTER AND Z-SOURCE INVERTER}

The Prius contains a conventional inverter for powering the PMSM with a voltage-boost circuit that is helpful in both reducing the stresses in the switching devices and expanding the motor's constant power speed ratio (CPSR). On the negative side, the dc-to-dc boosted PWM inverter topology suffers the cost and complexity associated with the two-stage power conversion.

In 2004, Fang Peng of Michigan State University performed a study [10] for ORNL that compared conventional inverter systems to a new inverter topology, Z-source, for applications including HEV systems and fuel-cell vehicles. The dc-to-dc boosted PWM inverter and Z-source basic circuit topologies are represented in Fig. 4.4. The comparison study was based on the use of a $50 \mathrm{~kW}$ (max) fuel-cell stack providing power to a $34 \mathrm{~kW}(50 \mathrm{~kW}$ max) Solectria AC55 motor for traction drive.

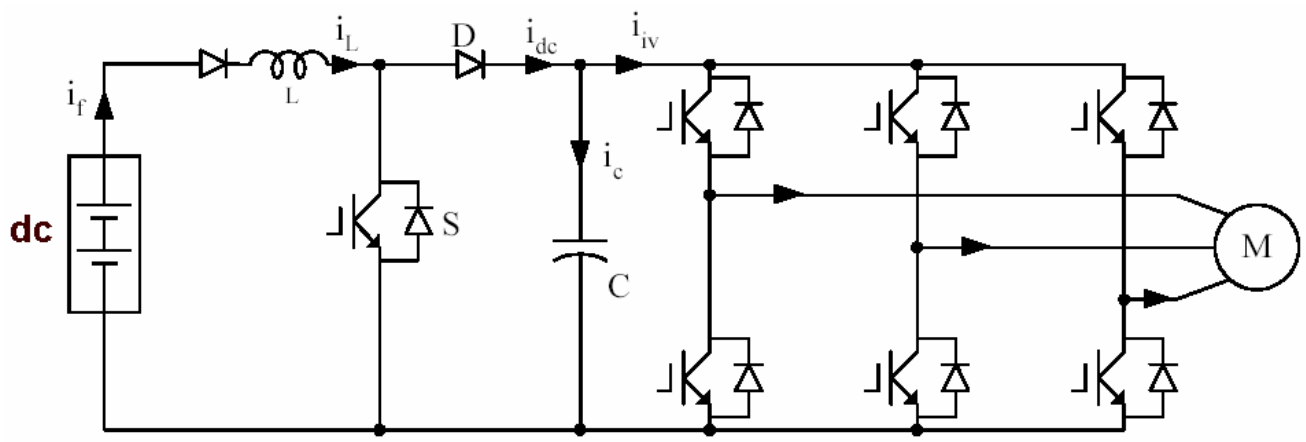

(a) System configuration using dc/dc boost + PWM inverter

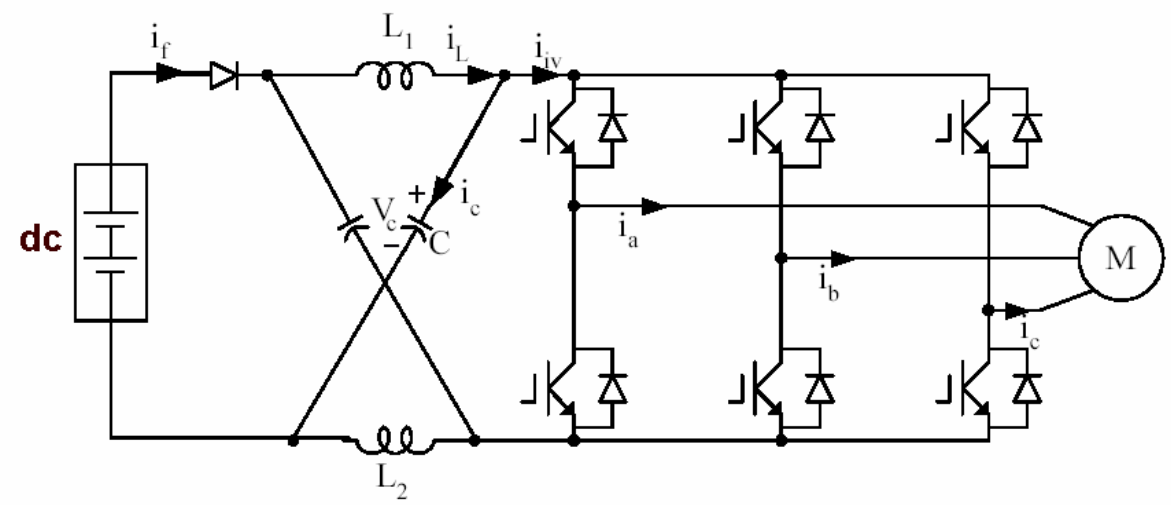

(b) System configuration using the Z-source inverter

Fig. 4.4. Configurations for (a) conventional boosted inverter and (b) new Z-source inverter.

The study considered switching device power (SDP) as a means of quantifying the voltage and current stress (or requirement) of the inverters. Total SDP is the aggregate of SDP of all the switching devices used in the circuit.

Equations were developed to compare inverter SDPs for the following conditions:

- Maximum power: $50 \mathrm{KW}$

- Motor power factor at max power: 0.9

- Boost-converter output: $420 \mathrm{~V}$ 
The equations produced results indicating that the Z-source inverter benefited from a lower total average SDP than the conventional boosted converter (199 kVA vs. $225 \mathrm{kVA})$; however, this was reversed in the case of total peak SDP (605 kVA vs. $528 \mathrm{kVA})$.

Perhaps the key findings of the study were efficiency data produced for the different inverter topologies. Table 4.1 indicates that, for five different power levels, the inverter efficiencies were higher for the Zsource inverter by $0.7 \%$ on the average. Considering the motor-inverter system, the Z-source system efficiency was higher in all cases except at the $50 \mathrm{~kW}$ power level. The average improvement at the motor-inverter system level was significantly higher at $0.87 \%$. These data are plotted in Fig. 4.5.

Table 4.1. Efficiency comparisons of inverter topologies and inverter/motor systems

\begin{tabular}{|c|c|c|c|c|c|c|}
\hline \multirow{2}{*}{ Power (kW) } & \multicolumn{3}{|c|}{ Inverter Efficiency } & \multicolumn{3}{c|}{ System Efficiency } \\
\cline { 2 - 7 } & $\begin{array}{c}\text { Conventional } \\
\text { with Boost }\end{array}$ & Z-Source & $\begin{array}{c}\text { \% Improve- } \\
\text { ment }\end{array}$ & $\begin{array}{c}\text { Conventional } \\
\text { with Boost }\end{array}$ & Z-Source & $\begin{array}{c}\text { \% Improve- } \\
\text { ment }\end{array}$ \\
\hline 10 & 0.964 & 0.973 & 0.93 & 0.936 & 0.949 & 1.39 \\
\hline 20 & 0.966 & 0.973 & 0.72 & 0.917 & 0.93 & 1.42 \\
\hline 30 & 0.966 & 0.973 & 0.72 & 0.902 & 0.913 & 1.22 \\
\hline 40 & 0.965 & 0.971 & 0.62 & 0.89 & 0.896 & 0.67 \\
\hline 50 & 0.964 & 0.969 & 0.52 & 0.88 & 0.877 & -0.34 \\
\hline
\end{tabular}

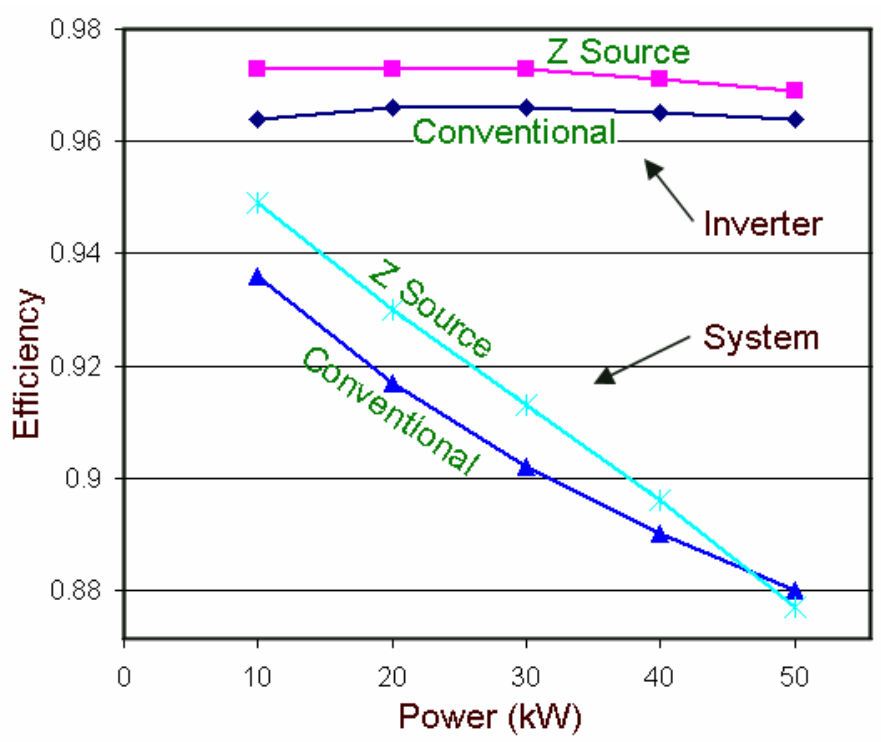

Fig. 4.5. Efficiency comparisons of inverter topologies and inverter/motor systems.

The potential advantages of using the Z-source inverter include the following:

1. Nearly a $1 \%$ improvement in system efficiency,

2. Improved reliability since shoot-through cannot cause failure,

3. Elimination of in-rush current facilitates startup,

4. Reduced vulnerability to EMI and related misgating-induced failures, and

5. Reduced cost through the elimination of dc-to-dc boost-conversion circuit. 


\section{HEV SYSTEM MANUFACTURING AND PACKAGING}

This section will present certain details relating to the manufacturing, assembly, and packaging of the HEV system in the 2004 Prius. This information will help to more fully characterize the design and to determine key parameters, such as specific power and power density, in support of the FCVT program.

\subsection{PMSM}

Figure 5.1 shows three views of the PMSM housing with selected dimensions ${ }^{11}$ called out. As indicated, about 3/4th of the casing houses the PMSM rotor and stator and the remainder encloses part of the gearbox. The portion of the casing that houses the PMSM is roughly cylindrical and that is the geometry used for the purposes of estimating the PMSM casing volume. Based on the average of three measurements of casing diameter, the cylinder diameter can be assumed to be $\sim 29.9 \mathrm{~cm}$. The depth of the PMSM housing extending from the end plate to the surface identified in the upper left photo in Fig. 5.1 is $20.5 \mathrm{~cm}$. This results in a volume of $14,400 \mathrm{~cm}^{3}$ excluding the three-phase terminal-block housing and the cooling passages that protrude from the surface of the casing. Including all three volumes results in a total of $15,400 \mathrm{~cm}^{3}(15.4 \mathrm{~L})$. This volume and the $50 \mathrm{~kW}$ peak-power specifications result in a peakpower density of $3.25 \mathrm{~kW} / \mathrm{L}$.

The mass of the PMSM was determined in order to estimate the specific power. The masses of the components of the Prius PMSM are:

\begin{tabular}{|c|c|}
\hline Stator: & $25.9 \mathrm{~kg}$ \\
\hline Rotor: & $10.2 \mathrm{~kg}$ \\
\hline Case: & $6.36 \mathrm{~kg}$ (machined - see below) \\
\hline Case cover: & $2.49 \mathrm{~kg}$ \\
\hline Total mass of motor: & $45.0 \mathrm{~kg}$ \\
\hline
\end{tabular}

The casing for the PMSM has (1) a portion that encloses one end of the gear box, and (2) compartments that enclose the gear-shift-lever-to-shift-plunger linkages. These areas are unrelated to the PMSM and were therefore machined off of the structure to obtain a new $6.36 \mathrm{~kg}$ mass (the original casing mass was $13.9 \mathrm{~kg}$ ). The resulting specific power for the PMSM is $1.11 \mathrm{~kW} / \mathrm{kg}$.

\footnotetext{
${ }^{11}$ The casing in the figure was obtained from a 2003 Prius; however, the dimensions were obtained from the very similar 2004 casing used in performance testing.
} 

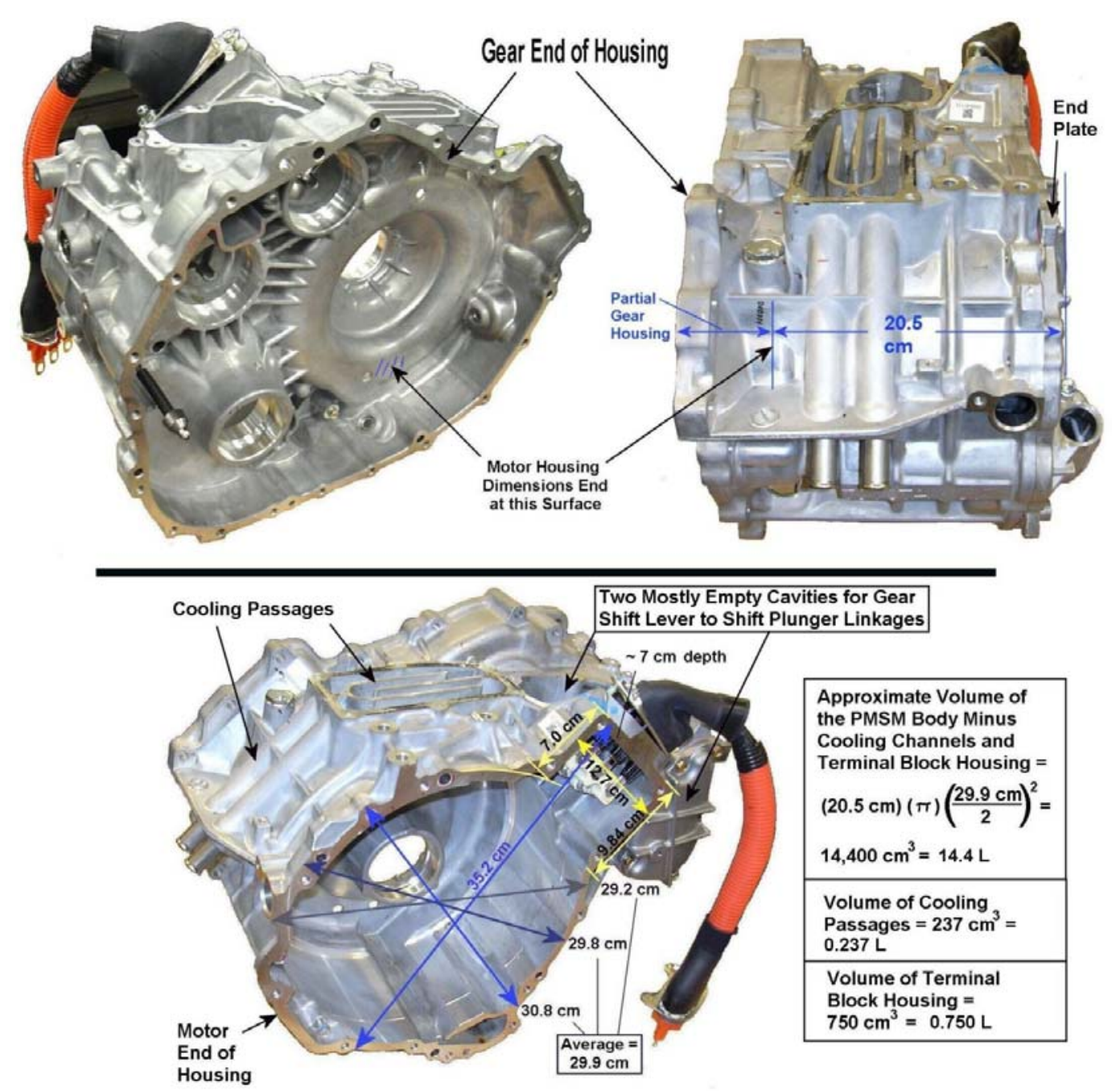

Fig. 5.1. Casing of the 2004 Prius PMSM with dimensions and volume calculations.

\subsection{INVERTER/CONVERTER}

As indicated in Section 2.2.5, the inverter package contains several important circuits that include the

- Motor inverter

- Generator inverter

- Buck/boost converter

- Air-conditioning compressor inverter

- A dc-to-dc inverter

Figure 5.2 shows how these circuits are packaged in the inverter casing. The PMSM inverter and generator inverter driver circuitry is contained on a circuit board mounted below the inverter capacitor module and above the power module that contains the IGBTs and diodes for both inverter circuits. The power module contains 6 IGBTs and 6 diodes for the generator inverter and 12 IGBTs and 12 diodes for the PMSM inverter to support its higher power rating (6 pairs of IGBTs are wired in parallel). The power module is mounted on a water-cooled cold plate for cooling. Adjacent to the inverter circuitry is the buck/boost converter (500-V clamp on the boost) and its associated IGBTs. The voltage is boosted from 
$200 \mathrm{~V}$ to $200-500 \mathrm{~V}$ for motor operation and bucked from the same $200-500 \mathrm{~V}$ range for charging the $200 \mathrm{~V}$ battery.

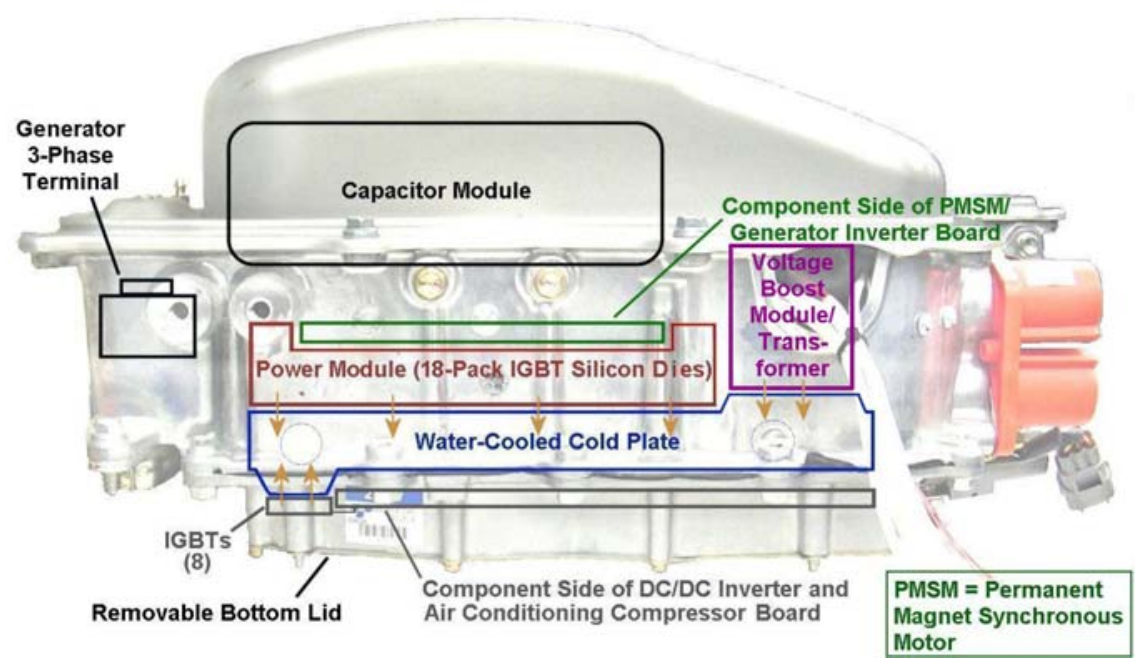

Fig. 5.2. Overall subsystem packaging in the 2004 Prius inverter/converter.

At the bottom of Fig. 5.2 is another compartment that is accessible by opening the bottom lid. This compartment holds a large circuit board containing (1) the inverter for powering the air-conditioning compressor, and (2) the dc-to-dc converter that takes the $200-500 \mathrm{~V}$ bus and provides $13.8 \mathrm{~V}$ for charging the battery and powering accessories. IGBTs for both circuits are mounted on the bottom of the cold plate. Many of the components and subassemblies mentioned above will be seen in the figures provided below.

Figure 5.3 shows the inverter casing with the lid removed. Most evident are the capacitor module, voltage-boost module and the main electrical connections. High current bus bars make all of the connections to the capacitor module, motor and generator terminals, and the boost converter.

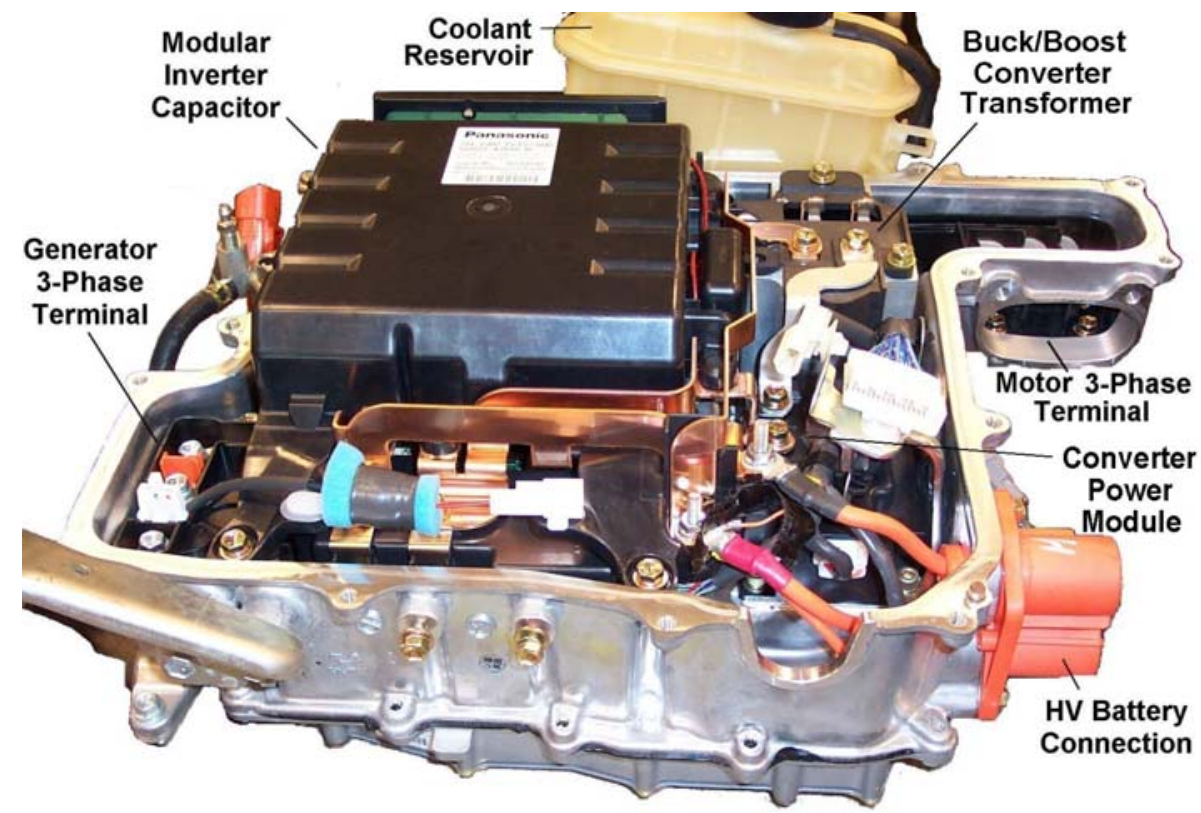

Fig. 5.3. Overview of packaging in an opened 2004 Prius inverter/converter. 
Figure 5.4 shows a similar view of the inverter casing but with the capacitor module removed. The general location of the buck/boost converter is indicated; however, the power electronic devices are located down near the cold plate and are not visible. The inverter-driver board is partially visible and the positions of the three motor bus bar terminals and three generator bus bar terminals indicate that the driver board is functionally divided into an upper half containing the motor inverter and a lower half containing the generator inverter.

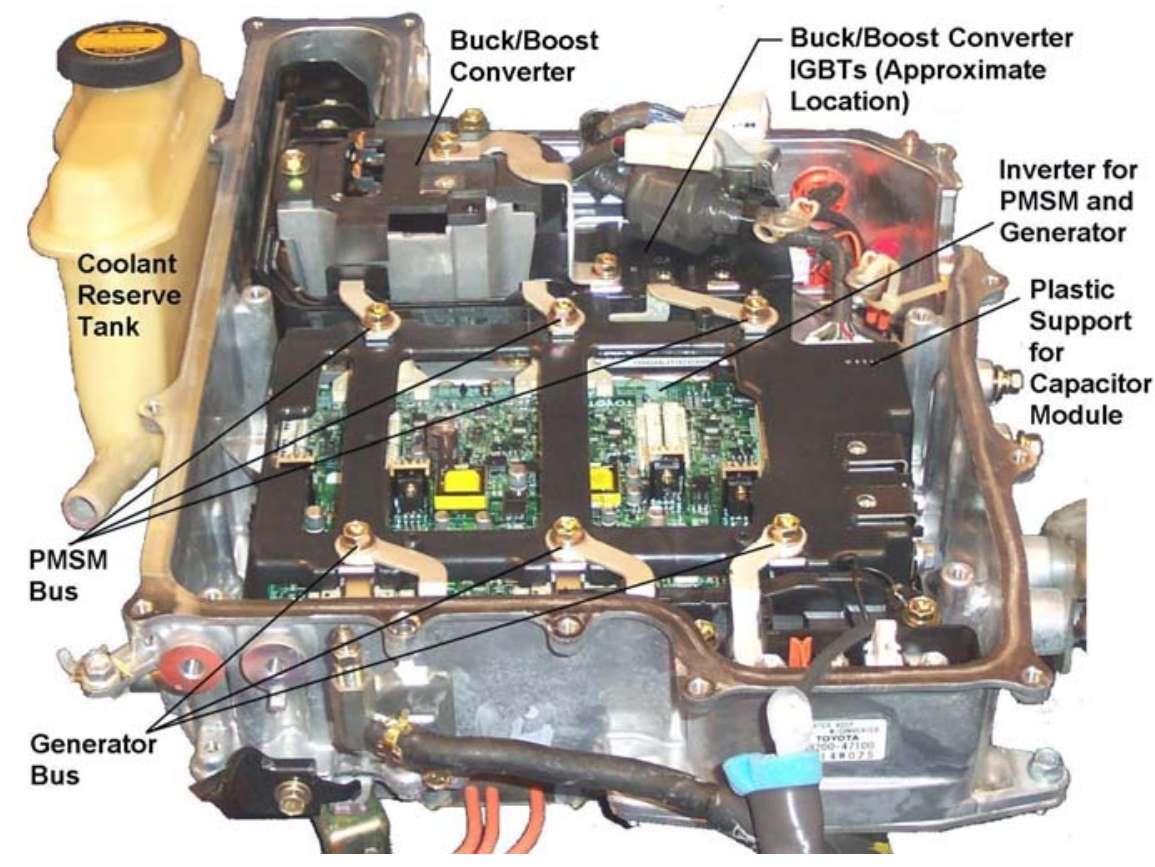

Fig. 5.4. Overview of packaging in a 2004 Prius inverter/converter with capacitor module removed.

The six bus bar "connections" are actually junctions above the driver board. They cause the currents to pass through current sensors located on the driver board and the conductors continue down until electrical connections are made on the power module.

The inverter-driver board in earlier year models had several IR chips and in later year boards these were often relabeled as "Toyota." The basic logic or architecture of the circuits remained the same. IR gate driver and bridge drivers are described on the IR internet site (http://www.irf.com/product-info/cic), and the circuit design is somewhat unique. For instance, the IR gate driver approach eliminates the need for an isolated upper branch when driving the IGBT. This results in significant parts savings. The only requirement is that the circuit must turn on the lower branch first. This approach is reflected in the Toyota inverter-driver boards.

The empty inverter/converter casing is shown in Fig. 5.5. The photo shows the high usage the casing design makes of the cold plate surface area for the cooling of the IPEM, the voltage-boost transformer, and the buck/boost converter. The inverter cold plate measures $250 \mathrm{~mm} \mathrm{X} \sim 255 \mathrm{~mm} \mathrm{X} \sim 19 \mathrm{~mm}$ for a total volume of $1.21 \mathrm{~L}$, excluding additional aluminum surrounding the cold plate where component mounting holes are located. The power module, converter, and transformers mount on this cold plate. The IPEM alone requires a cold plate measuring $250 \mathrm{~mm} \mathrm{X} \sim 155 \mathrm{~mm} \mathrm{X} \sim 19 \mathrm{~mm}$ for a total volume of $0.74 \mathrm{~L}$.

The IPEM is shown in Fig. 5.6 with the cover removed. This IPEM photo was taken by ANL during their disassembly and instrumenting of the 2004 Prius inverter for ORNL. The six pairs of parallel-wired IGBT dies for the motor inverter are shown on the top and the six IGBT dies for the generator inverter are shown on the bottom. The $200 \mathrm{~V}$ battery terminal posts are shown on the right. Figure 5.7 provides a 
close-up of a single IGBT die and related diode die. This image was obtained looking through the silicone gel.

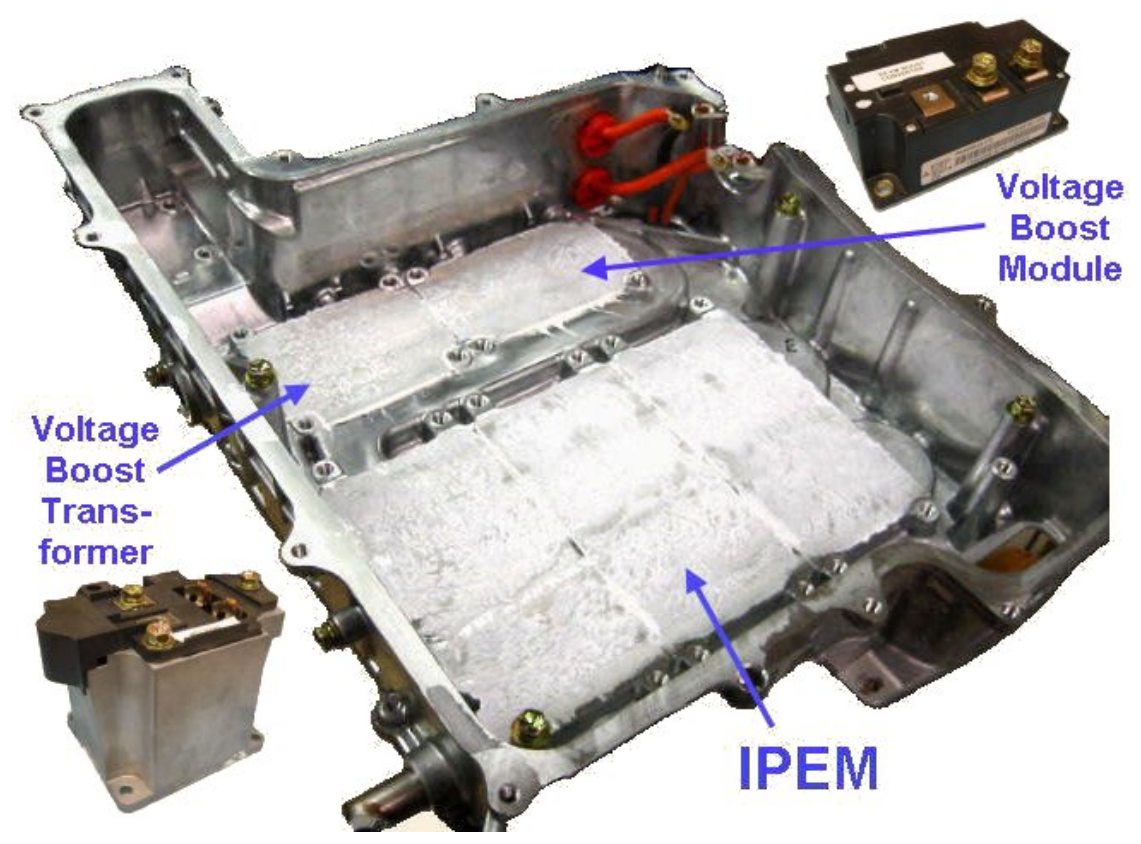

Fig. 5.5. Empty inverter/converter housing showing cold plate surfaces.

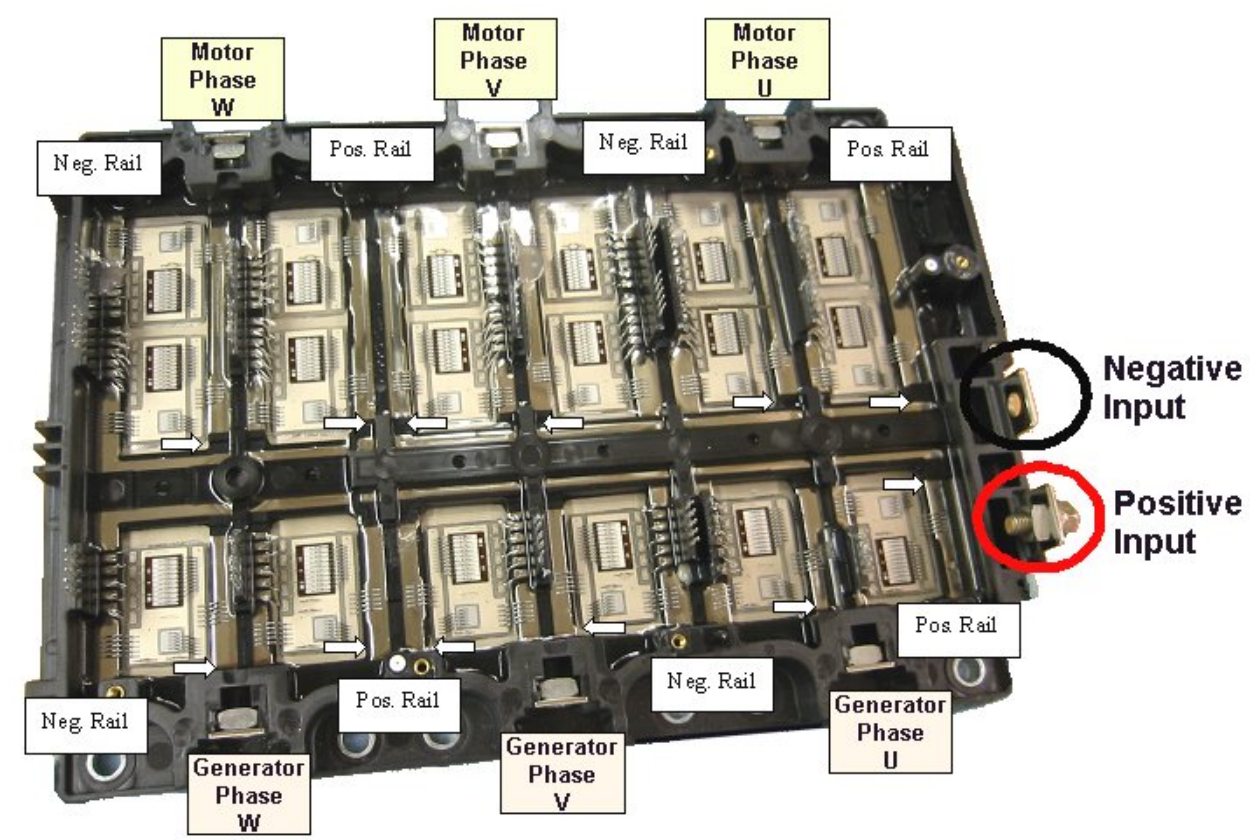

Fig. 5.6. Power module 18-pack dye array in a 2004 Prius inverter (photo provided by ANL). 


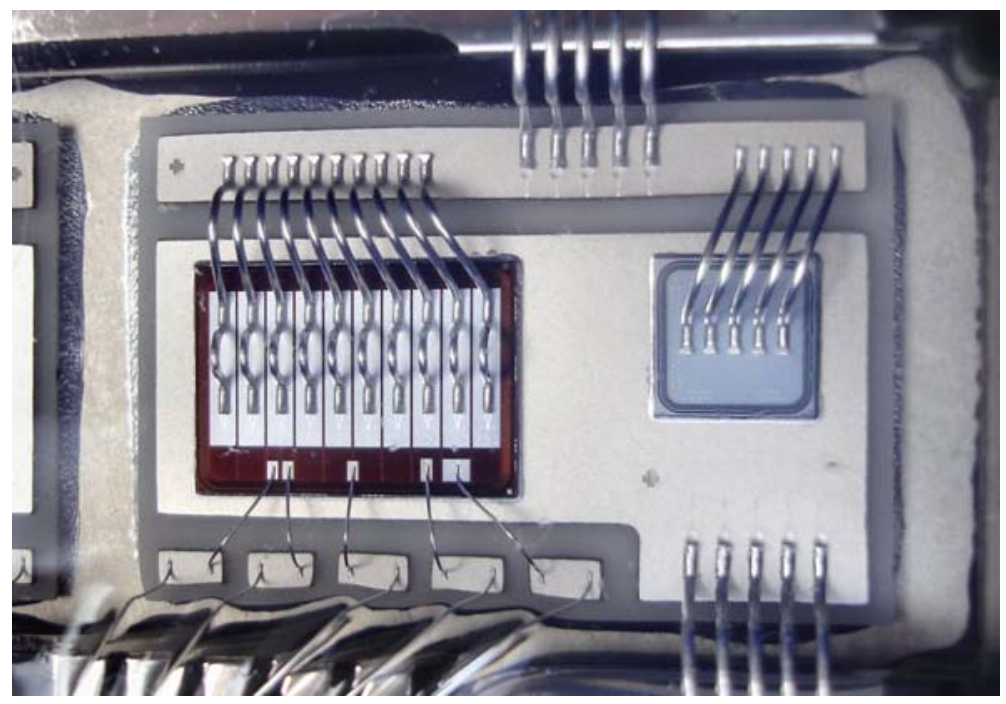

Fig. 5.7. Close-up of an IGBT/diode pair in the 2004 Prius inverter.

Figure 5.8 shows a board located in a separate compartment located under the water-cooled cold plate. As mentioned above, this board contains the inverter for powering the air-conditioning compressor and the dc-to-dc converter. The converter takes the $200-500 \mathrm{~V}$ bus and provides $13.8 \mathrm{~V}$ for charging the battery and powering accessories such as lights, the audio system, and ECU. The inverter is located across the top of the board in the figure and the dc-to-dc converter circuitry fills up the remainder of the compartment (i.e., about $75 \%$ of the volume shown).

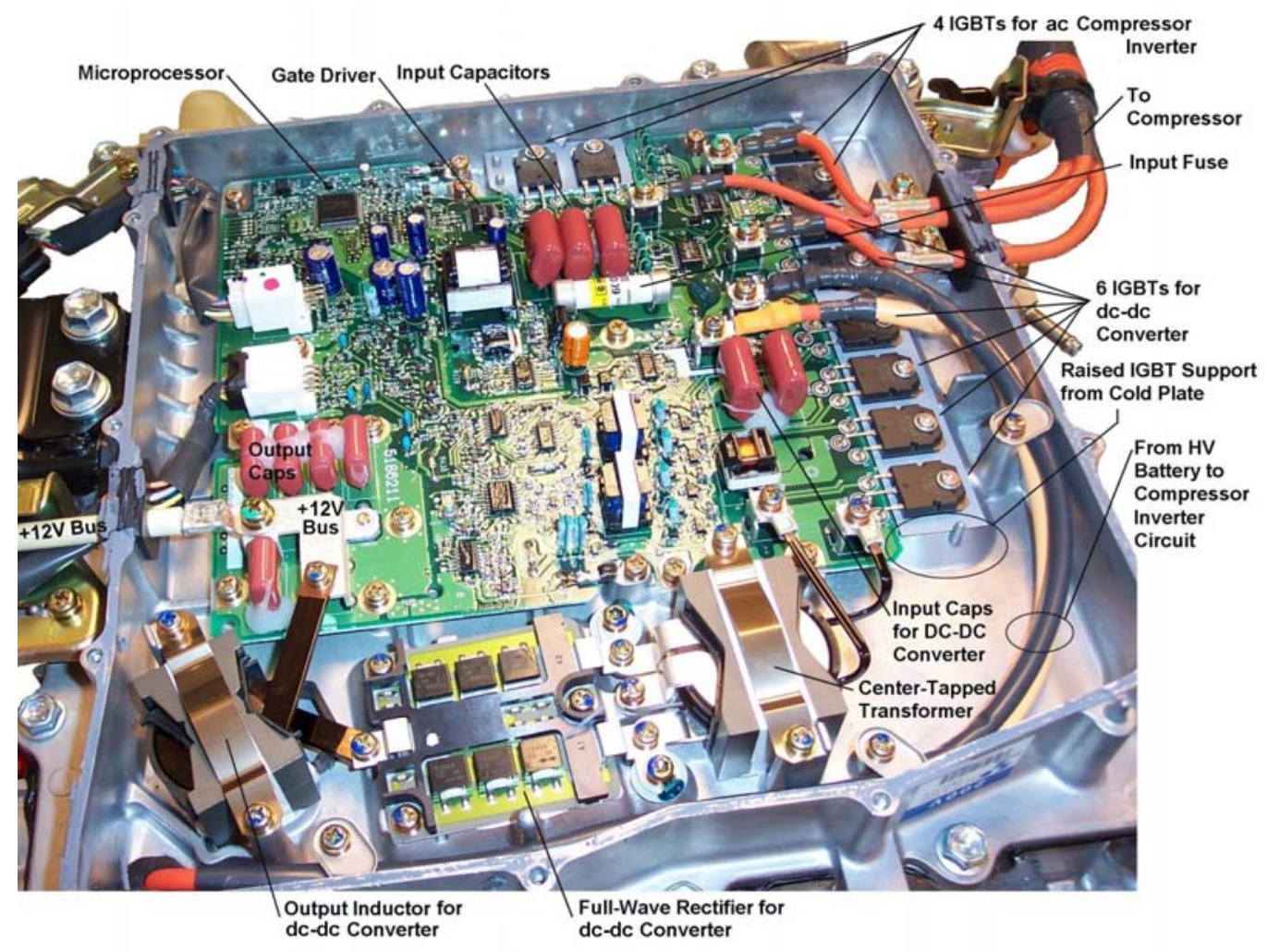

Fig. 5.8. Packaging of the 2004 Prius compressor inverter and dc-to-dc converter circuit. 
The volume and mass of the inverter/converter casing was assessed to determine the peak-power density and specific power for the power electronics. Figure 5.9 indicates the overall mass and volume of the unit. The volume of the lid was calculated in four parts with a few simplifying assumptions in order to produce a reasonably close estimate of volume. Likewise volume estimates were derived for the mid section and the bottom section. The motor operation is supported by $1 / 2$ of the inverter-driver board, $2 / 3$ of the IPEM, and all of the voltage-boost circuit. The fact that half the driver board can be disregarded has only a small bearing on the volume. Thus, power density can be approximated by the motor power rating of $50 \mathrm{~kW}$ and the volumes of the lid and mid sections, which together total $14.5 \mathrm{~L}$. Thus, the peakpower density is $3.45 \mathrm{~kW} / 1$. The volumes occupied by the housing for the three-phase connection to the motor and the connector for the HEV battery were not included since these can be located anywhere on the casing that is convenient to the designer making the actual volume penalty negligible. The volume used in the calculation could likely be reduced by $\sim 25 \%$ if a designer so desired. This is because of the circuits not supporting the operation of the motor and because there is some amount of wasted space in the lid surrounding the capacitor module for the purposes of improved styling/appearance (the inverter/converter casing lid is quite visible/predominant when the Prius hood is raised).
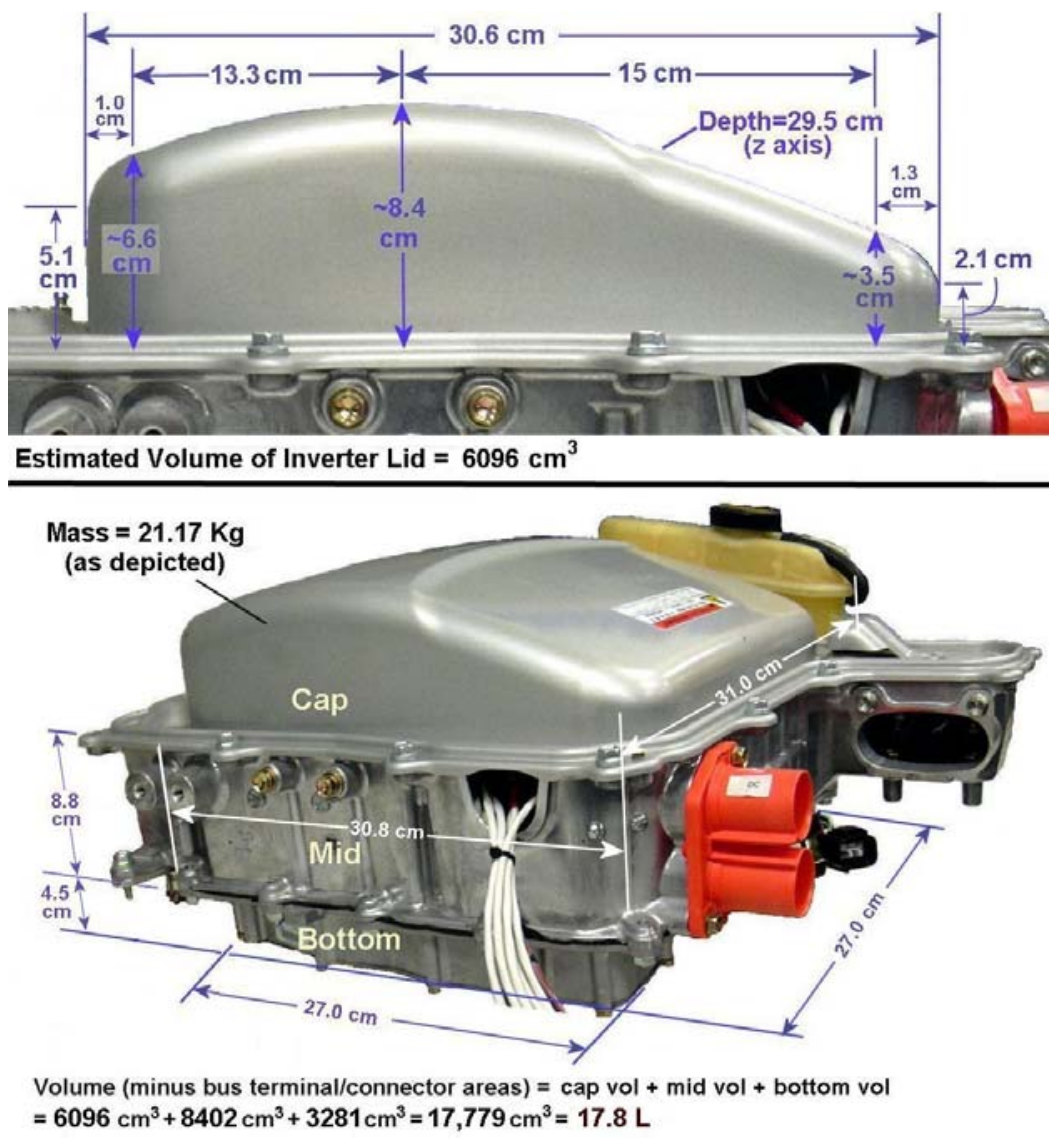

Fig. 5.9. Overall volume and mass of the 2004 Prius inverter/converter.

The mass of the inverter/converter unit was also closely considered to develop an estimate of specific power. The mass of the bottom compartment housing and internal components for the dc-to-dc converter and ac compressor inverter were excluded from the full mass $(21.17 \mathrm{~kg})$ since these circuits are not part of the PMSM/inverter system. This resulted in $19.37 \mathrm{~kg}$. The resulting specific power is $2.6 \mathrm{~kW} / \mathrm{kg}$ which, as in the case of the power density, could easily be improved for the same reasons discussed above. 
No discussion of the PMSM and inverter/converter would be complete without a description of the cooling system that serves both. The cooling system is comprised of a $12-\mathrm{V}$ electric pump (344 g), four $5 / 8$-inch hoses, and a small, lightweight radiator. A single radiator structure, weighing $2.05 \mathrm{~kg}$, serves both the engine and the hybrid subsystems including the PMSM and the inverter/converter. The portion of the radiator serving only the hybrid subsystems has (1) a mass estimated to be $\sim 0.55 \mathrm{~kg}$, and (2) dimensions of $16 \mathrm{~mm} \mathrm{X} 706 \mathrm{~mm} \times 101 \mathrm{~mm}$ for a total volume of $1.14 \mathrm{~L}$. Figure 5.10 shows the radiator after being separated from the air-conditioning condenser that was located behind it.

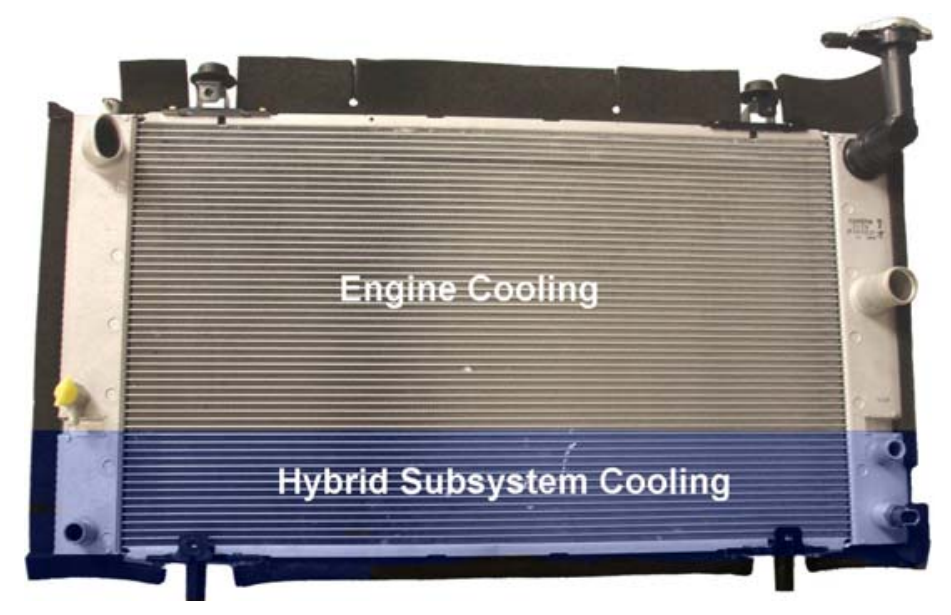

Fig. 5.10. Radiator for Prius engine (upper) and hybrid subsystems (lower).

\subsection{CONVERTER COMPONENTS}

Due to recent, high interest in converter design, additional details are provided on the 2004 Prius voltageboost-converter circuit. The general circuit diagram in Fig. 5.11 shows that the converter contains two IGBTs and two diodes instead of one of each. This allows for two-way power flow - battery to integrated power module (IPM) and IPM to battery. During periods of maximum power demand from the IPM/PMSM system, the converter provides $\sim 20 \mathrm{~kW}$ and the vehicle generator supplies $\sim 30 \mathrm{~kW}$. This power split allows a reduction in size of the high-cost HEV battery and the converter. Therefore, the power rating of the converter is $\sim 20 \mathrm{~kW}$, not $50 \mathrm{~kW}$.

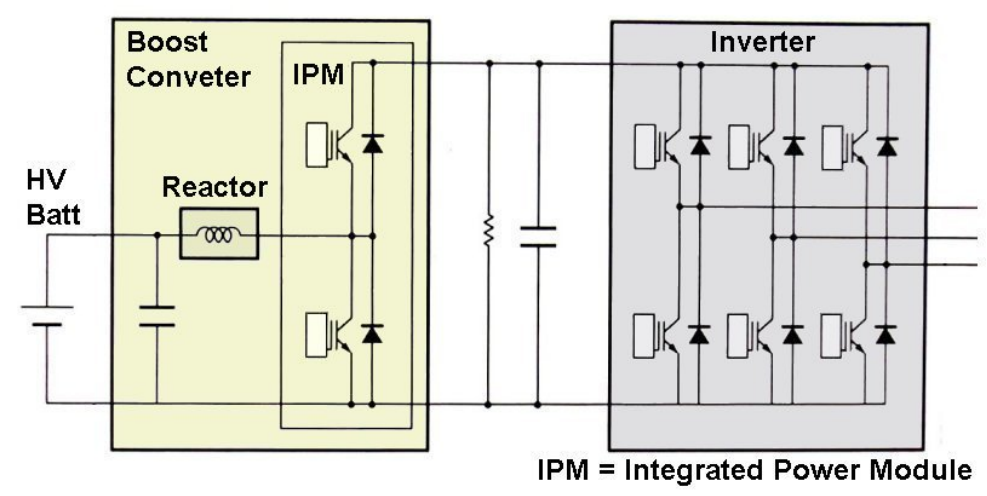

Fig. 5.11. General circuit schematic of the Prius inverter.

Figure 5.12 shows the disassembly of the IPM. Figure 5.12(a) shows the gate-driver board with a 18-pin connector on the left, Fig. 5.12(b) shows the EMI shield located immediately below the gate-driver board, and Fig. 5.12(c) shows the IGBTs and diodes. The gate-driver board contains circuitry that includes 
protection logic for short circuit, over current, over temperature, and under-voltage conditions. Since non-standard chip numbers were observed, further information was not readily attainable.

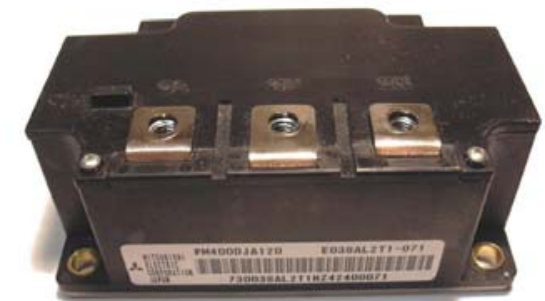

(a)

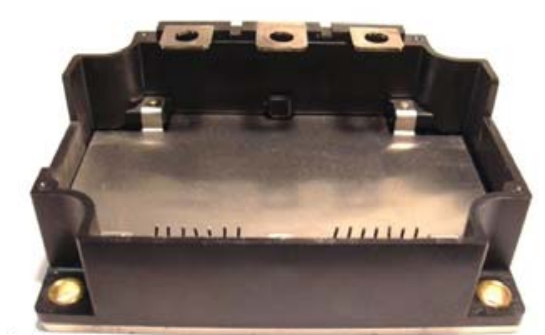

(c)

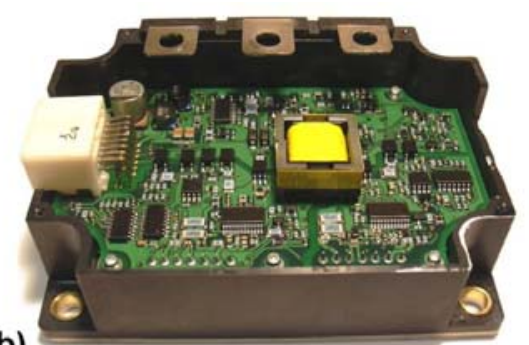

(b)

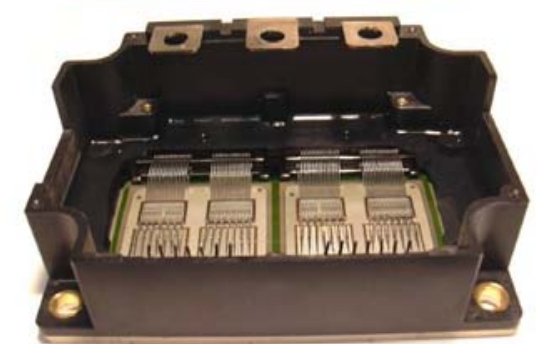

(d)

Fig. 5.12. Disassembly of the converter power module.

A close-up of the IGBTs and diodes, immersed in a high-temperature silicone sealer/gel and conformal coating, are shown in Fig. 5.13. Note that the IGBTs and diodes are paired (connected in parallel) to meet current requirements. This produces a total silicon surface area of $7.84 \mathrm{~cm}^{2}$ for the two IGBT pairs and $3.78 \mathrm{~cm}^{2}$ for the two diode pairs or $11.6 \mathrm{~cm}^{2}$ total for the IPM. The volume of the IPM is $421 \mathrm{~cm}^{3}$ if treated as a simple rectangle or $\sim 375 \mathrm{~cm}^{3}$ if derived in a more precise manner (subtracting cut-away areas from the top and the four corners). The mass of the IPM is $0.662 \mathrm{~kg}$.

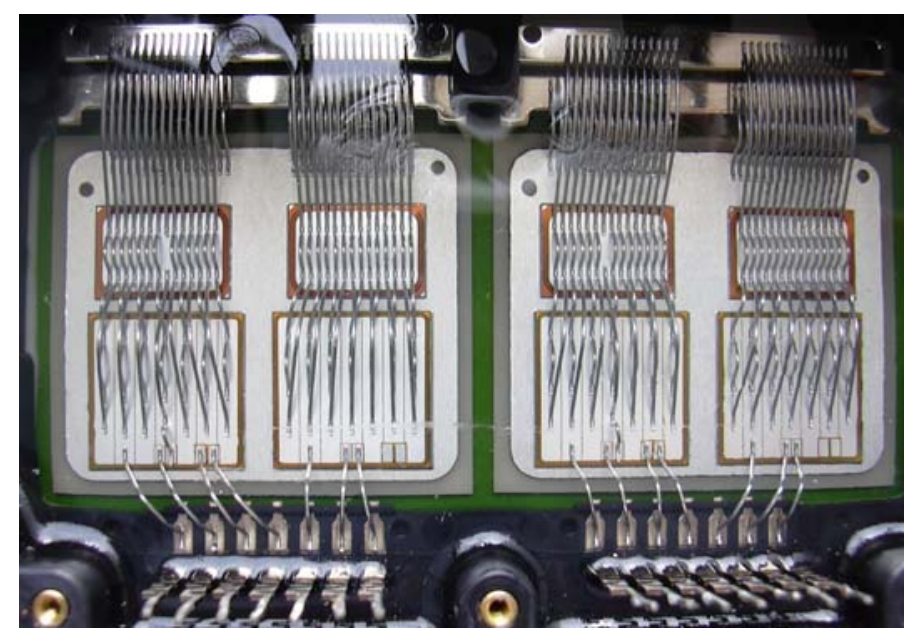

Fig. 5.13. Close-up of converter IGBTs and diodes.

The voltage-boost converter auto transformer (or reactor) is shown in Fig. 5.14. The mass of the transformer is $2.57 \mathrm{~kg}$. The geometry of the transformer casing has several curves, angles, indentations, etc.; however, a close approximation of its total volume is $\sim 742 \mathrm{~cm}^{3}$. Excluding any type of cold plate, the volume and mass totals for the $\sim 20 \mathrm{~kW}$ boost converter (IPM and transformer) are $\sim 1.12 \mathrm{~L}$ and 
$3.23 \mathrm{~kg}$, respectively. These estimates are modified below to include portions of the casing and cold plate.

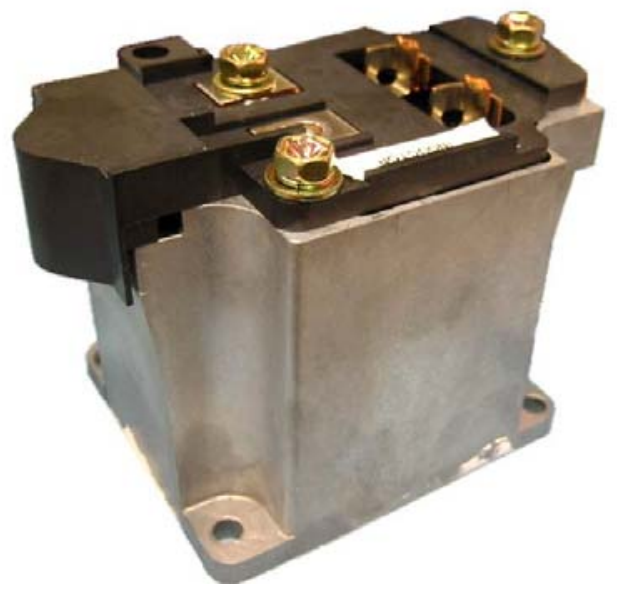

Fig. 5.14. Voltage-boost converter auto-transformer.

The following derivations of converter volume consider even the cold plate and/or the converter volume enclosed by the casing:

Volume Calculation Approach A: The cold plate surfaces for the converter are shown in Fig. 5.15 (left photo). The volume of the cold plate under the two converter components (including adjacent mounting holes) is $19 \mathrm{~mm} \mathrm{X} 100 \mathrm{~mm} \mathrm{X} 250 \mathrm{~mm}=0.48 \mathrm{~L}$. However, this approach ignores the space enclosed by the converter portion of the casing.

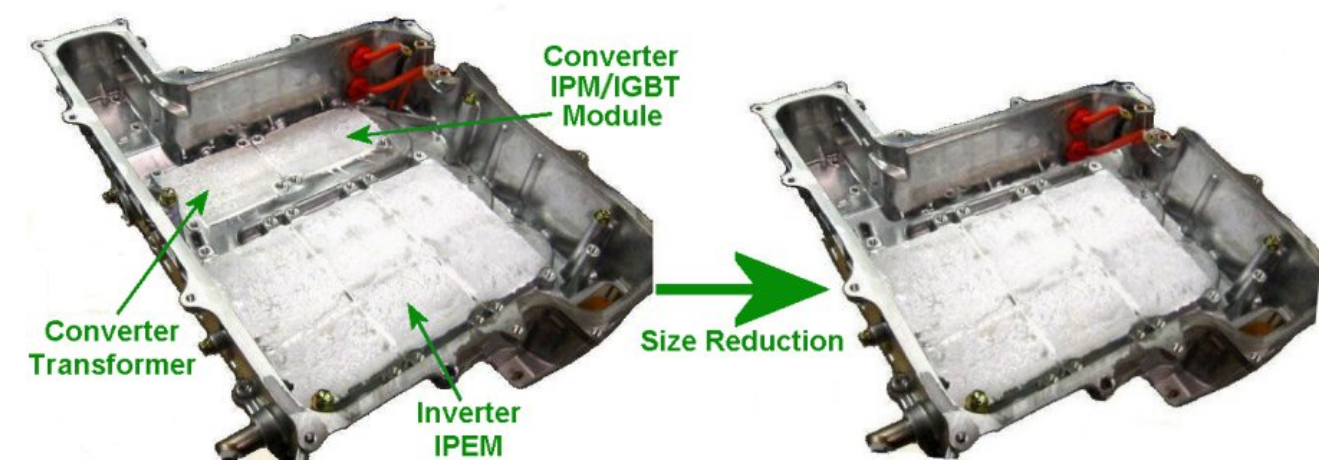

Fig. 5.15. Conceptual change to inverter/converter casing for excluding the buck/boost converter.

Volume Calculation Approach B: Comparing the two casing designs in Fig. 5.15, consider the entire volume that includes the cold plate, converter components mounted on it, and surrounding space enclosed in the casing. This overall volume is $335 \mathrm{~mm} \mathrm{X} 100 \mathrm{~mm} \mathrm{X}$ $140 \mathrm{~mm}=4.7 \mathrm{~L}$.

Again comparing casing designs in Fig. 5.15, it is estimated that converter uses $15 \%$ of the casing mass. Since the casing shell is $6.45 \mathrm{~kg}$, the casing mass dedicated to the converter is $\sim 1 \mathrm{~kg}$.

Conclusions: Accounting for the transformer, IPM, and casing the total converter system volume is $4.7 \mathrm{~L}$ and the mass is $4.2 \mathrm{~kg}$. From this information, specific power and power density can be determined keeping in mind that the rating of the buck/boost converter is $\sim 20 \mathrm{~kW}$. 
Table 5.1 summarizes the estimates of volumes, masses, power density, and specific power presented earlier in this section.

Table 5.1. Physical characterization of the PMSM, inverter, converter, and cooling system

\begin{tabular}{|c|c|c|c|c|}
\hline Item & Volume, L & $\begin{array}{c}\text { Peak power } \\
\text { density, kW/L }\end{array}$ & Mass, kg & $\begin{array}{c}\text { Specific power, } \\
\mathrm{kW} / \mathrm{kg}\end{array}$ \\
\hline PMSM & 15.4 & 3.25 & 44.9 & 1.11 \\
\hline Inverter/converter assembly & 14.5 & 3.45 & 19.4 & 2.6 \\
\hline \multicolumn{5}{|l|}{ COOLING SYSTEM } \\
\hline Full radiator assembly & 4.19 & - & 2.05 & - \\
\hline Radiator: portion for hybrid cooling & 1.14 & - & 0.55 & - \\
\hline Hybrid cooling water pump & $\sim 0.6$ & - & 0.344 & - \\
\hline \multicolumn{5}{|l|}{ BUCK/BOOST CONVERTER } \\
\hline Converter assembly (complete) & 4.7 & 4.3 & 4.2 & 4.8 \\
\hline Transformer & 0.74 & - & 2.57 & - \\
\hline Power module & 0.38 & - & 0.66 & - \\
\hline
\end{tabular}




\section{SUMMARY AND CONCLUSIONS}

The performance benchmarking of the 2004 Prius PMSM and inverter systems was accomplished through system inspections/evaluations, a review of manufacturing and packaging, controller development in preparation for testing, and laboratory evaluations that included back-emf tests, locked rotor tests, loss tests, and full-range performance testing of the HEV system. In essence, the overall approach of this project was to thoroughly define the systems and then perform a detailed evaluation of their performance in a controlled laboratory environment. This approach proved to be technically sound and successful.

Specifically, the subsystem-level performance testing involved:

- Collecting back-emf voltage waveforms for both the PMSM (and generator),

- Performing locked rotor tests at varying torque angles (over the range, 90-134 ${ }^{\circ}$,

- Determining gear, bearing, and other friction losses for various operating speeds and lubricating oil temperatures, and

- Mapping motor/inverter performance over the full speed and shaft-loading ranges using $50^{\circ} \mathrm{C}$ and $90^{\circ} \mathrm{C}$ motor/inverter coolant temperatures.

\subsection{FINDINGS AND OBSERVATIONS}

Subassembly-level testing at ORNL revealed that gearbox related friction losses were found to be significant. These losses are approximately $2.4 \mathrm{~kW}$ at a motor speed of $6000 \mathrm{rpm}$. The predominant loss of about $1.6 \mathrm{~kW}$ is associated with the main reduction gears and drive chain while the motor, power-split device, and generator yielded losses of about $0.8 \mathrm{~kW}$. Gear-train losses are primarily associated with oil splashing within the hybrid drive housing and oil slinging from the generator and motor rotors to provide needed lubrication and removal of excess heat. These losses, which are summarized in Table 6.1, were determined with the lubricating oil at or near room temperature (about $25^{\circ} \mathrm{C}$ ). The tests also revealed that overall losses decreased about $20 \%$ when the temperature of the lubricating oil increased from $27-80^{\circ} \mathrm{C}$. This finding indicates that total losses for the hybrid electric drive system equal approximately $1.9 \mathrm{~kW}$ at a lubricating oil temperature of $80^{\circ} \mathrm{C}$.

Table 6.1. Summary of gear-train losses at $25^{\circ} \mathrm{C}$

\begin{tabular}{lc}
\hline Subassembly & $\begin{array}{c}\text { Contribution to Loss, } \\
\mathbf{\%}\end{array}$ \\
\hline Reduction Gears and & 68 \\
$\quad$ Drive Chain & \\
Motor Rotor & 21 \\
Generator and & 11 \\
$\quad$ Planetary Gears & \\
\hline
\end{tabular}

Gear-reduction ratios were determined and documented for both the motor rotor and the generator rotor (with engine spline locked). This determination was primarily performed to allow accurate calculation of speed, torque, and loads but the findings also provided a basis for comparison with other drives and to identify engineering choices and compromises that were made as part of the overall design process. The following relationships are based on results of the gear-reduction determinations:

2004 Prius Motor Speed $\quad=\quad$ (4.113) $($ axle speed $)$ 


$$
\begin{array}{lll}
2003 \text { Prius Motor Speed } & =\quad(3.905)(\text { axle speed }) \\
2004 \text { Prius Generator Speed }= & (10.7) \text { (axle speed with engine spline locked) }
\end{array}
$$

Motor and generator testing yielded back-emf voltage and frequency data. During the tests, a dynamometer drive was used to control motor speed and generator speed. Results of the back-emf testing are summarized in Table 6.2.

Table 6.2. Summary of back-emf test results

\begin{tabular}{lc}
\hline \multicolumn{1}{c}{ Test Conditions } & Results \\
\hline Motor back-emf $(6000 \mathrm{rpm})$ & $540 \mathrm{Vrms}$ \\
Motor voltage constant & $1.33 \mathrm{Vrms} / \mathrm{Hz}$ \\
Generator back-emf $(6420 \mathrm{rpm})$ & $195 \mathrm{Vrms}$ \\
Generator voltage constant & $0.46 \mathrm{Vrms} / \mathrm{Hz}$ \\
\hline
\end{tabular}

A series of locked rotor tests was performed to determine general operating capabilities of the traction motor. In particular, the torque and current were studied during the locked rotor tests to characterize the startup torque capability of the motor. Current and corresponding torque values are presented in Table 6.3 and discussed in detail in Ref. [1].

Table 6.3. Summary of motor current and torque test results

\begin{tabular}{cc}
\hline Current, A & $\begin{array}{c}\text { Maximum Torque, } \\
\text { Nm }\end{array}$ \\
\hline 75 & 140 \\
150 & 260 \\
250 & 400 \\
\hline
\end{tabular}

The benchmarking project partially supported and funded the thermal testing of the Prius motor. These tests were successful in determining the continuous ratings of the Prius motor design at coolant temperatures ranging from $35-105^{\circ} \mathrm{C}$. This information has not been released by the Toyota Motor Company. The ratings at base speed $(1200 \mathrm{rpm})$ were projected from test data at $900 \mathrm{rpm}$. The continuous ratings were determined to be $15 \mathrm{~kW}$ using $105^{\circ} \mathrm{C}$ coolant, and $21 \mathrm{~kW}$ using $35^{\circ} \mathrm{C}$ coolant. As indicated in the full report on these thermal tests [1], these ratings are well below the $30 \mathrm{~kW}$ target of the DOE FCVT program.

The final testing of the Prius is the mapping of motor/inverter performance over the full speed and shaftloading ranges using primarily $55^{\circ} \mathrm{C}$ motor/inverter coolant temperatures. In early test runs while using only calibrated instrumentation, test data showed higher-than-expected inverter efficiency. This led to a series of tests designed to (1) verify the test procedures/approaches in use, and (2) provide a higher level of confidence in the test data.

The subsystem performance-mapping data tests were successfully completed in March 2006. The test data enabled ORNL researchers to generate the efficiency contour mapping plots for the motor, inverter, and combined motor/inverter system shown in Fig. 6.1. These are discussed in Section 3.3.3. 


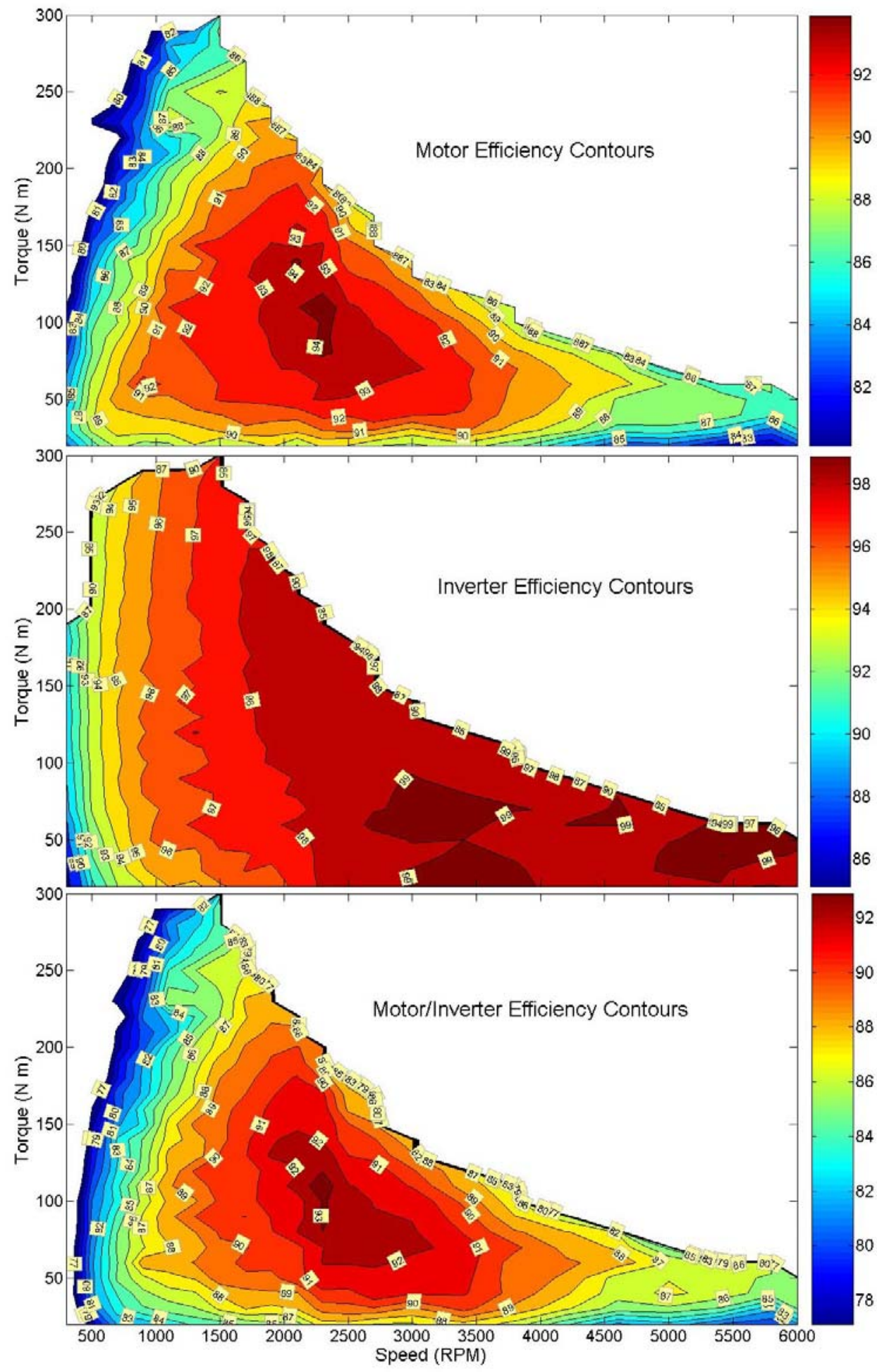

Fig. 6.1. Prius combined efficiency contour maps. 
The results of the Prius testing have provided a wealth of information on these innovative, high-powerdensity subsystems that would not have been available otherwise. The design and packaging information and data from various subsystem tests have been in very high demand over the last couple years necessitating the dissemination of these data to FCVT researchers even before the publishing of this report. The planning and management of the FCVT project itself has benefited from various sets of data including estimates of power density, specific power, and detailed characterizations of the motor, inverter, converter, and planetary-gear train subsystems.

\subsection{NEEDED RESEARCH AND DEVELOPMENT}

During FY2006, ORNL will perform benchmark testing of the hybrid Accord traction-drive system. The test data and design, packaging, and fabrication assessment will be combined to enable analysts to determine how the Accord system compares to the Prius system and program technology targets (peakpower-to-weight and -volume ratios). Other hybrid systems will be considered for limited analysis based on resources and the needs of the FCVT program.

Hybrid sport utility vehicles (SUVs) are emerging on the market and may represent significant deviations from existing hybrid technology. There may be some innovations in the drive system that merit benchmarking studies. Clearly, HEV systems sized appropriately for SUVs are of greatest interest to domestic manufacturers who have aggressively begun to introduce HEV systems into SUVs. Nationally, it is important to improve vehicle fuel efficiency to significantly reduce oil imports. This can be done most effectively on a vehicle-model basis by focusing on those with the poorest fuel efficiencies. With the global demand for oil increasing, fuel prices will increase significantly for years to come - no original equipment manufacturer (OEM) wants to find itself in poor fuel efficiency standings relative to other OEMs. There is also the potential for the return of Corporate Average Fuel Economy (CAFE) standards or similar requirements/incentives; however, increasing fuel prices are perhaps the most powerful incentive. 


\section{REFERENCES}

1. J. S. Hsu, S. C. Nelson, P. A. Jallouk et al., Report on Toyota Prius Motor Thermal Management, ORNL/TM-2005/33, UT-Battelle, LLC, Oak Ridge National Laboratory, Oak Ridge, Tennessee, February 2005.

2. J. S. Hsu, C. W. Ayers, C. L. Coomer, R. H. Wiles, S. L. Campbell, K. T. Lowe, and R. T. Michelhaugh, Report on Toyota/Prius Motor Torque Capability, Torque Property, No-Load Back-EMF, and Mechanical Losses, ORNL/TM-2004/185, UT-Battelle, LLC, Oak Ridge National Laboratory, Oak Ridge, Tennessee, October 2004.

3. Prius Repair Manual, 1, Pub. No. RM1075U1, Toyota Motor Corporation, 2003.

4. Prius Repair Manual, 2, Pub. No. RM1075U2, Toyota Motor Corporation, 2003.

5. Prius Repair Manual, 3, Pub. No. RM1075U3, Toyota Motor Corporation, 2003.

6. J. S. Hsu, C. W. Ayers, and C. L. Coomer, Report on Toyota/Prius Motor Design and Manufacturing Assessment, ORNL/TM-2004/137, UT-Battelle, LLC, Oak Ridge National Laboratory, Oak Ridge, Tennessee, August 2004.

7. Prius New Car Features 2004, Toyota Motor Corporation, 2004.

8. N. Bianchi, S. Bolognani, and B. J. Chalmers, "Salient-Rotor PM Synchronous Motors for an Extended Flux-Weakening Operation Range," IEEE Transactions on Industry Applications, 36(4), July/August 2000.

9. S. D. Rubira and M. D. McCulloch, "Control Method Comparison of Doubly Fed Wind Generators Connected to the Grid by Asymmetric Transmission Lines," IEEE Transactions on Industry Applications, 36(4), July/August 2000.

10. F. Z. Peng, Z-Source Inverter for Hybrid Electric and Fuel Cell Vehicles, Michigan State University, March 2004. 


\section{APPENDIX A DRIVE-CYCLE PLOTS SHOWING CONVERTER OPERATION}

This appendix supplements Section 3.1 .2 by further characterizing the operation of the voltagebuck/boost converter using Prius drive-cycle data.

All of the figures in this appendix plot the same five parameters: voltage and current output from the converter, accelerator pedal position output, brake-pedal position output, and vehicle speed. These five are identified in each plot. Note that positive current powers the PMSM and negative current charges the HEV battery. As in Section 3.1.2, units are omitted from the plots since only qualitative and/or trendrelated relationships are discussed.

Figure A-1 shows a rapid acceleration and how this acceleration locked the boosted voltage at the $500 \mathrm{~V}$ maximum. The highest and most sustained current occurs during the acceleration. The figure also shows how, whenever the accelerator pedal is momentarily released, battery charging begins immediately. The braking in the last third of the plot produces a high, sustained charging current that closely mirrors the output obtained from the brake-pedal transducer.

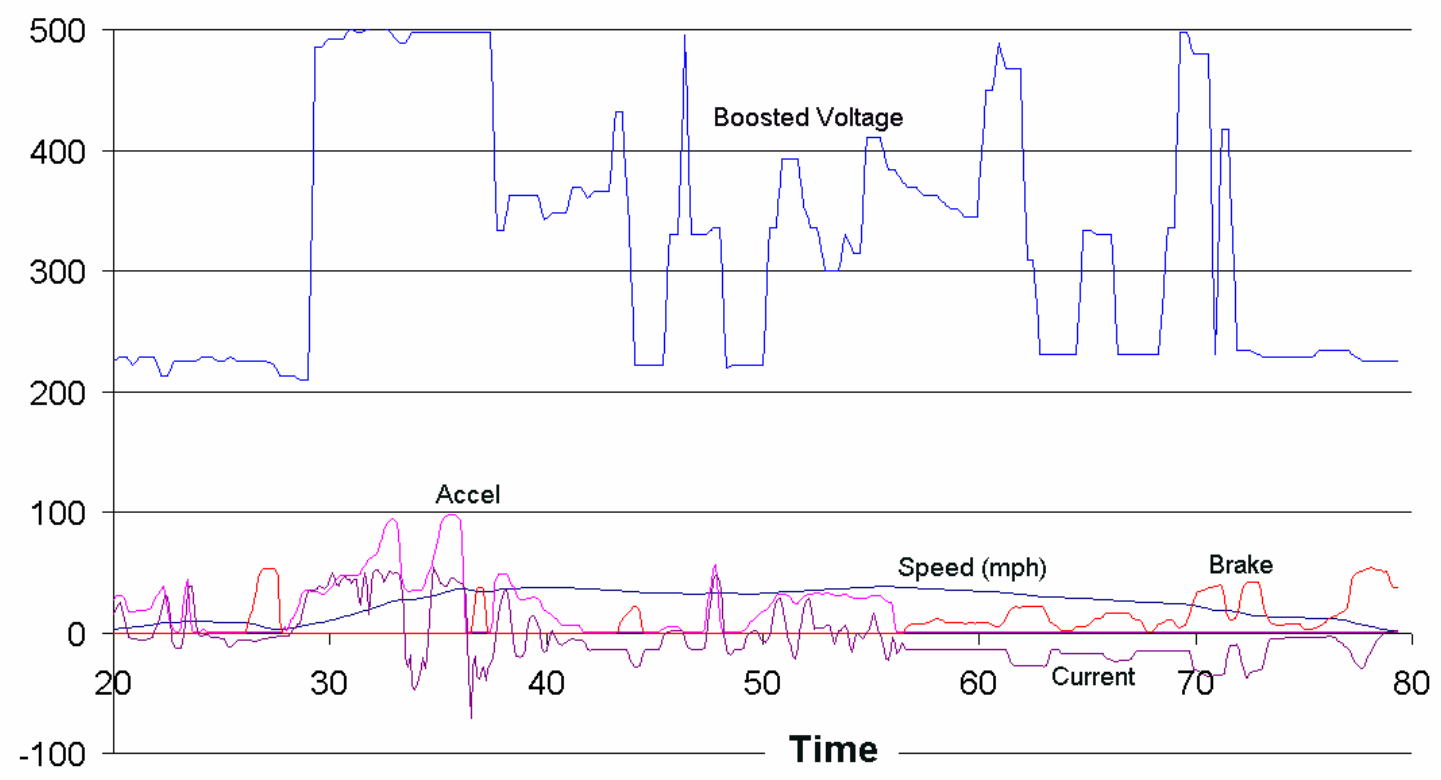

Fig. A-1. Drive-cycle plot chosen to illustrate a rapid acceleration (ANL data).

Figure A-2 shows a smooth, rapid acceleration that almost continuously maintains the boosted voltage at the maximum level. The sustained period of braking has a similar effect on the boosted voltage until the vehicle speed becomes low. The plotted data spans only $\sim 30 \mathrm{~s}$.

Figure A-3 was selected for its choppy converter output voltage. The boosted voltage stays at full output nearly continuously until the accelerator pedal output begins to level off. Immediately following this and until braking, the voltage and current fluctuate in a way that cannot be fully explained based on the data shown. The voltage has a 350-V floor most likely due to the vehicle speed (from 250-265 s, the speed ranged from 38.6-43.3 mph). A "zero-current zone" can be seen around $270 \mathrm{~s}$ where neither traction drive nor charging occurs. In the same timeframe, boosted voltage settled at $400 \mathrm{~V}$, presumably as determined only by vehicle speed. Reduced accelerator pedal output results in charging current in several instances. The period of braking in the last fourth of the plot creates a charging current proportional to the amount of braking. 


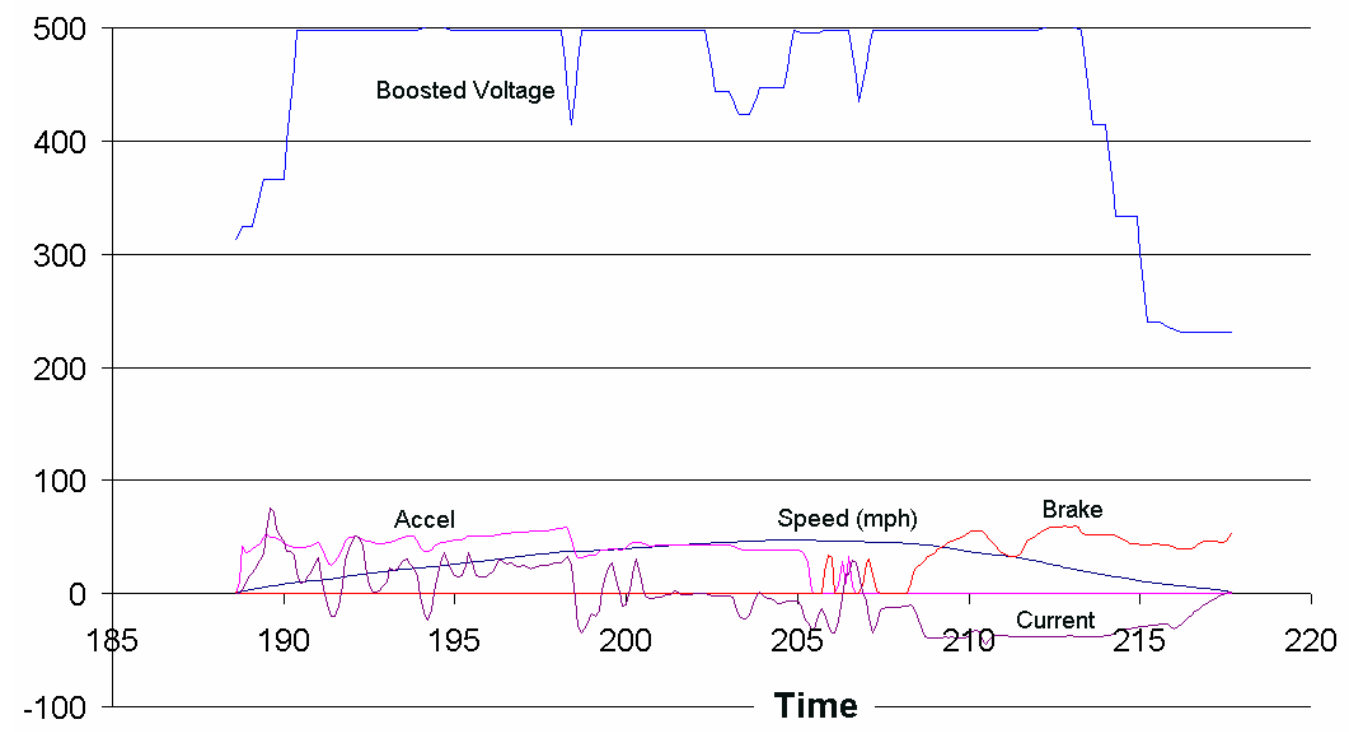

Fig. A-2. Second drive-cycle plot chosen to illustrate a rapid acceleration (ANL data).

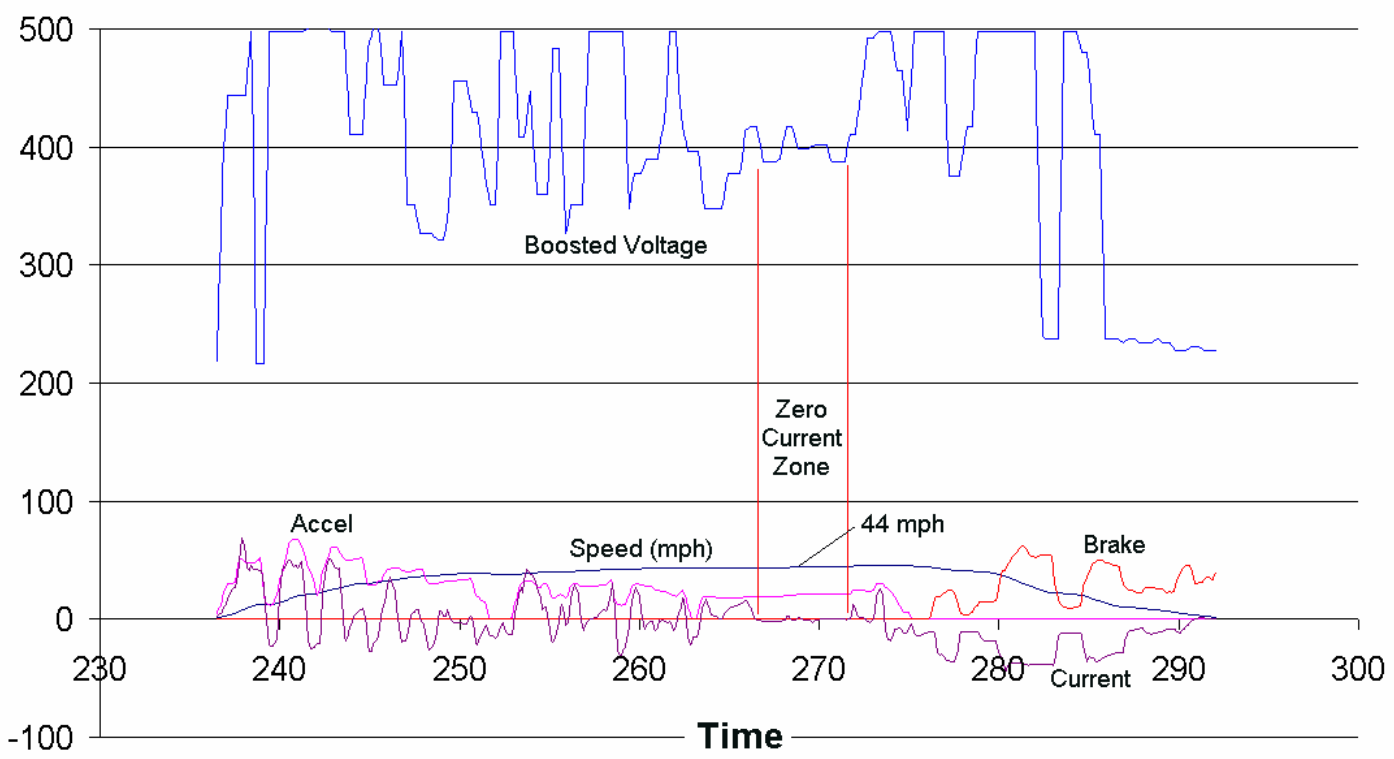

Fig. A-3. Drive-cycle plot chosen to illustrate a fluctuating boosted voltage (ANL data).

Figure A-4 was selected for its very gradual and slightly fluctuating acceleration. The slow acceleration had a dramatic effect on the boosted voltage, which was far lower than seen in preceding examples. There are many releases of the accelerator pedal with the corresponding reverse-current flow. As the speed continues to gradually increase, the boosted voltage floor rises from $215-315 \mathrm{~V}$, and then to $350 \mathrm{~V}$. The voltage fluctuations cannot be correlated with the corresponding current or other data shown in the figure. Because the fluctuations are very brief relative to other parameters, their significance is questionable. Therefore, Fig. A-5 was generated to compare vehicle speed to a smoothed-out ${ }^{12}$ portion of $^{-1}$ the boosted voltage plot. Except for the flat topping of the voltage plot, there is clearly some level of

${ }^{12}$ A time-based, moving-window average was used around each point in the plot. 
correlation. This flat topping would have been eliminated had the vehicle speed increased another $\sim 10 \mathrm{mph}$.

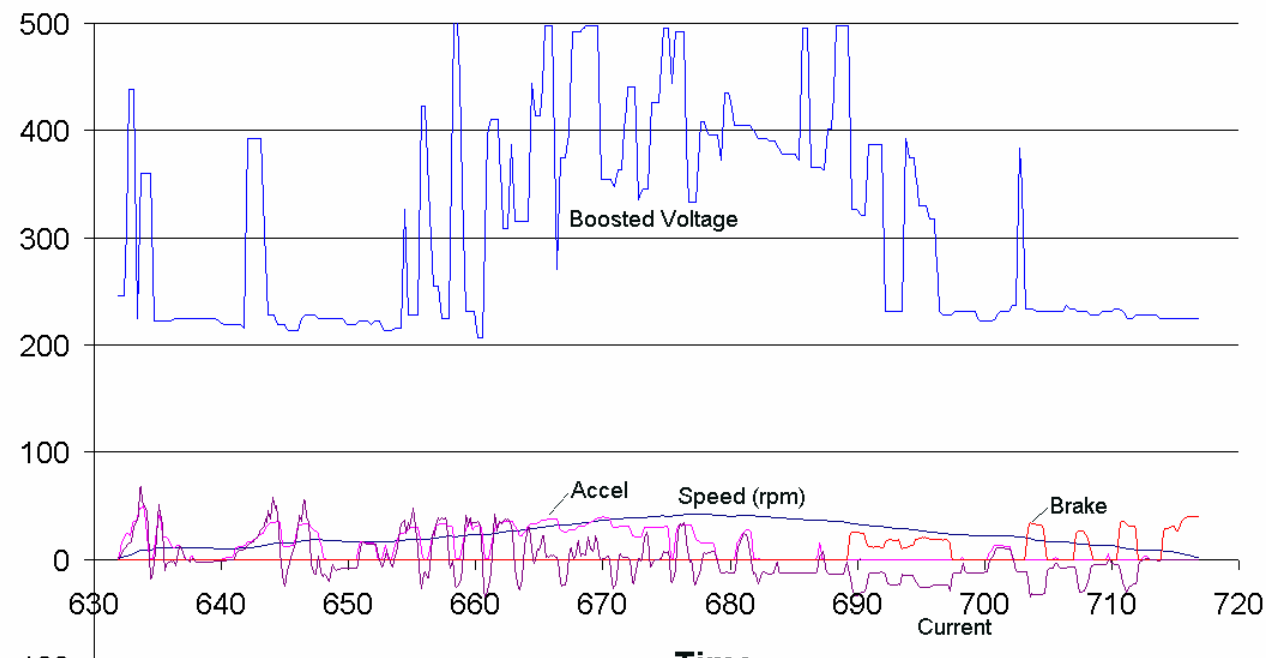

Fig. A-4. Drive-cycle plot chosen to illustrate a gradual acceleration (ANL data).

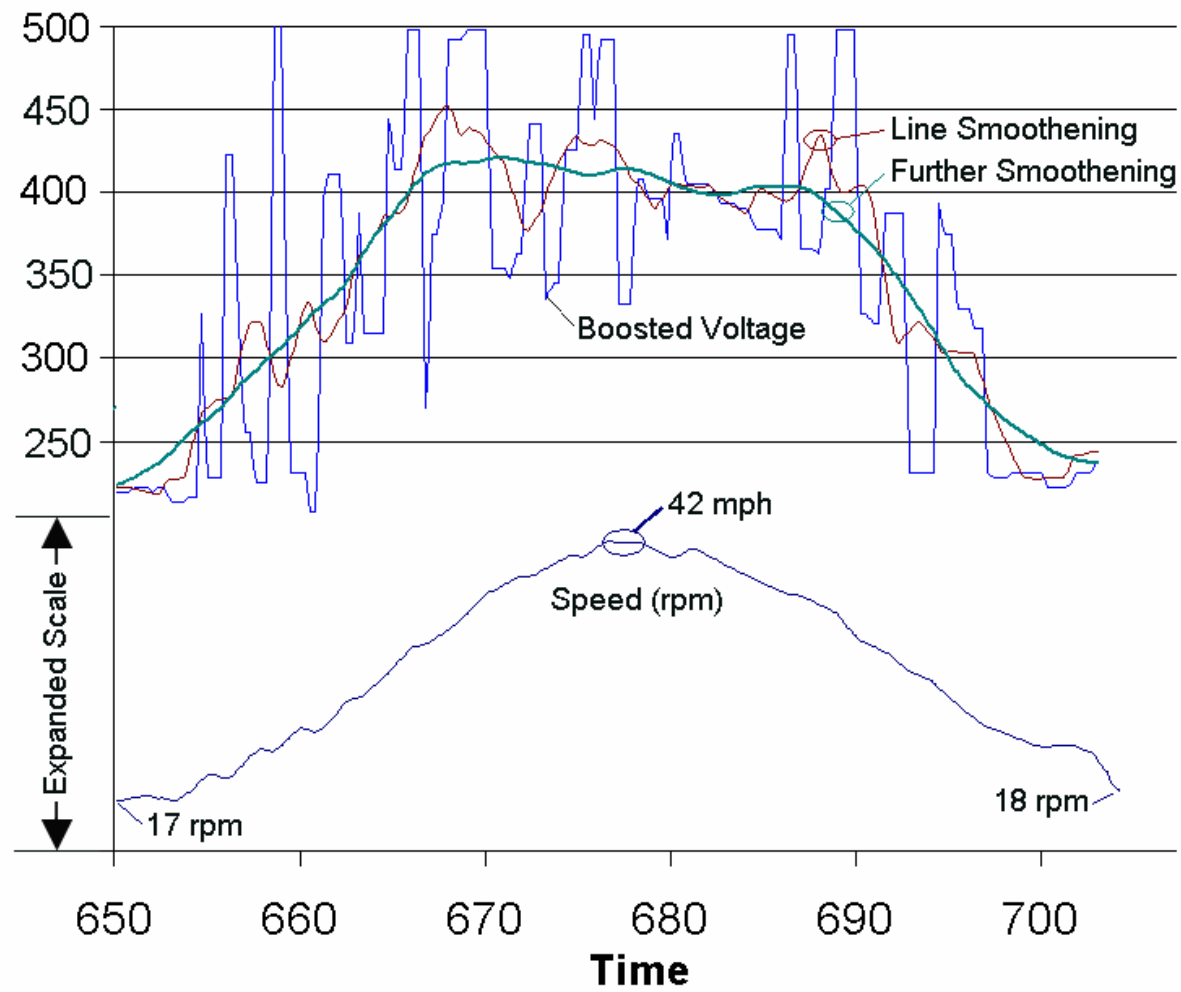

Fig. A-5. Consideration of curve smoothening on the boosted voltage plot (ANL data).

Spanning over three minutes (333 s.), Fig. A-6 is the longest-duration plot of drive-cycle data presented in this report. This figure was selected for its longer duration and continuously changing operating conditions (i.e., accelerator and brake positions). This produced a complex plot; however, trends of interest can still be seen. At first, the widely fluctuating boosted voltage with many very brief changes did not prove to be instructive or informative. Therefore, a time-based smoothening filter was applied. As indicated by the vertical, dotted lines, many of the peaks in the smoothed voltage plot correspond to 
peaks in the speed; however, with some degree of offset. The offset suggests that the voltage peaks were instrumental in bringing the vehicle to the speed peaks. Not surprisingly, numerous current peaks also appeared to be responsible for bringing the vehicle to the speed peaks.

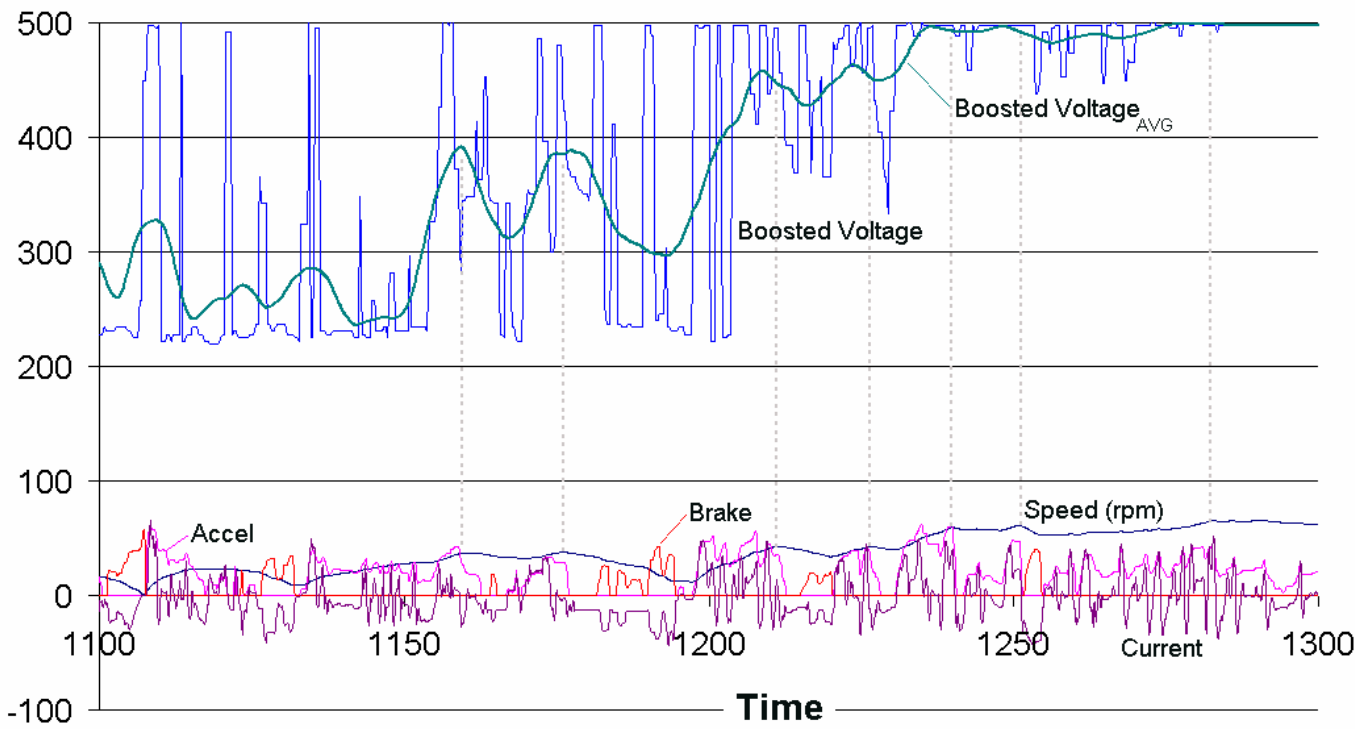

Fig. A-6. Drive-cycle plot chosen to illustrate a high level of change for each parameter (ANL data).

Figure A-7 was selected for its steady-state, high-speed conditions. Basically, only accelerator pedal position and current are changing. The positive current is made up of small spikes especially at times when the accelerator pedal is depressed. The absence of sustained positive current reflects how the vehicle operation is highly reliant on the engine and not the motor. Numerous, brief battery-charging surges are evident during pedal releases.

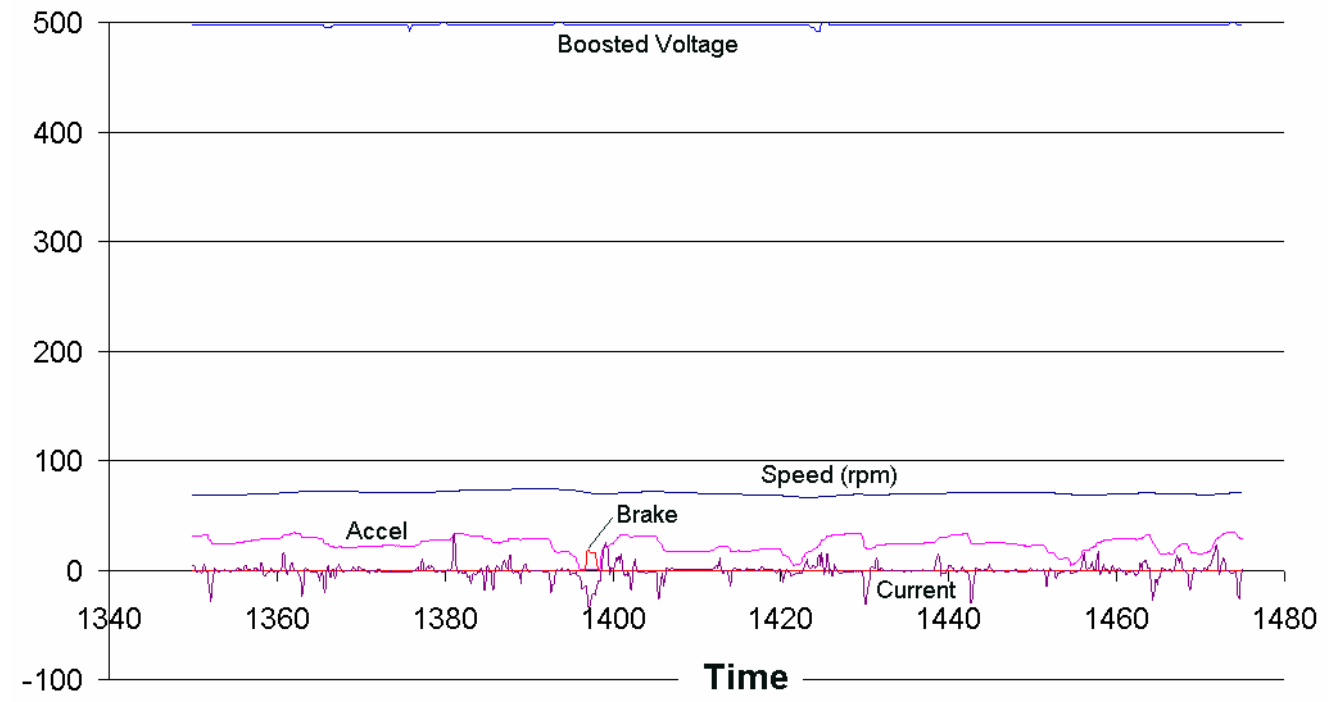

Fig. A-7. Drive-cycle plot chosen to illustrate a $70 \mathrm{mph}$ sustained speed. 


\section{APPENDIX B \\ PRIUS PERFORMANCE-MAPPING DATA}

Full design envelope testing of the operation of the 2004 Prius subsystems was described in Section 3.3. Section 3.3.3 provided efficiency-contour maps of the motor, inverter, and combined motor/inverter. This appendix provides the test data used to derive the contours and other summary data. Figure B.1 shows the actual speed-torque combinations at which all the data sets were recorded.

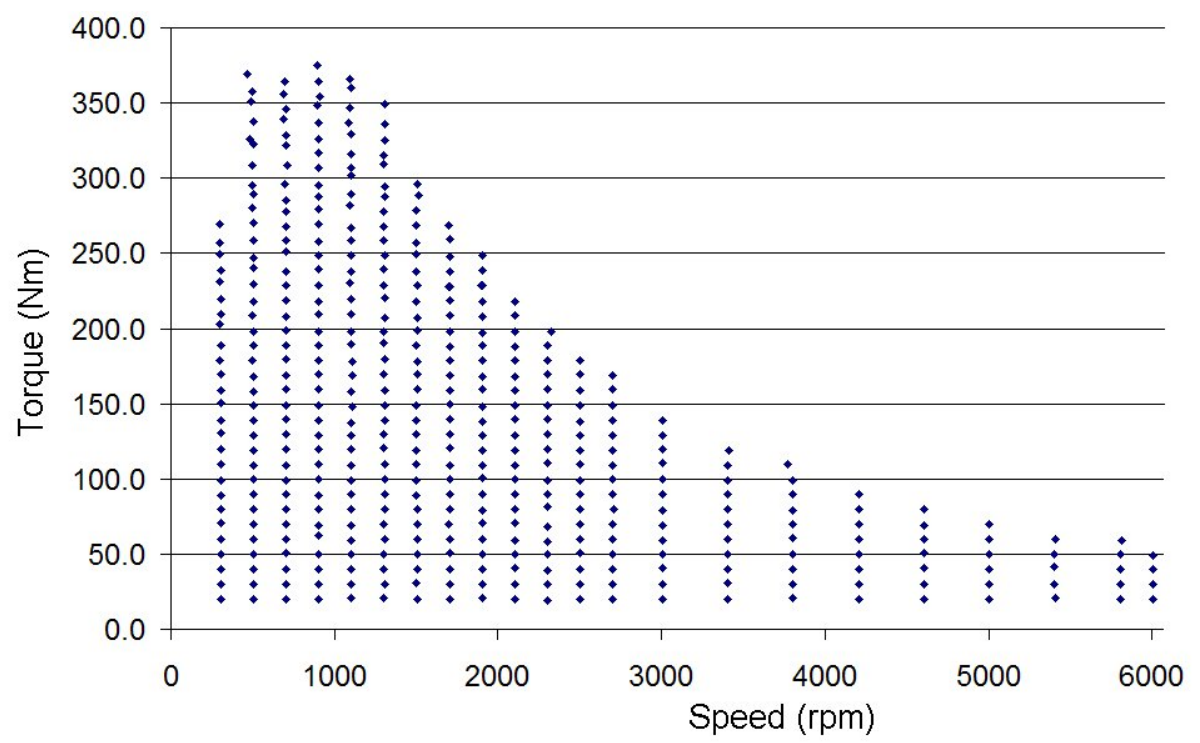

Fig. B.1. Speed-torque combinations at which data sets were obtained.

A selected portion of the mechanical, operational, electrical, and thermal data was prepared for presentation in this report. Table B-1 provides a selective sample of the most basic and significant measurements for characterizing the performance of the motor and inverter subsystems. To save on required space for the table, most of the thermal data was excluded and three-phase voltages and currents were averaged. Each row of data in the table is the average of generally 5-10 data sets; this averaging serves to eliminate data scatter, effects of noise, etc.

The table is sorted by increasing values of speed and then by increasing values of torque. The table is not arranged in the order by which the data was obtained. The three power columns provide the dc input to the inverter, the mechanical shaft power, and the three-phase power output from the inverter. The three efficiency columns provide the inverter, motor, and combined inverter-motor efficiencies. The two dc columns provide the inverter's de power supply voltages and current levels. The two three-phase columns provide the inverter output voltages and currents averaged over the three phases.

The last column provides the stator temperature from one of three stator TCs that was embedded between two stator windings. This particular TC agreed closely with the other two at low temperatures, but during high temperature excursions provided the highest temperature reading (often higher than the other two by $5-15^{\circ} \mathrm{C}$ ). This TC was located in the upper left region of the stator when viewing it with the motor casing end cap removed and with the three-phase terminals at the upper right. The other two TCs were located in the upper right and lower right. Even if data from all three TCs were provided, it would be of limited use since the actual temperatures were largely dependant on how long the motor had operated at a given load level before the data was obtained. Especially at low speeds and high shaft-load levels, data had to be obtained as quickly as possible while stator temperatures were rapidly climbing. 
Table B-1. Mechanical, operational, electrical, and thermal data from the Prius performance-mapping test

\begin{tabular}{|c|c|c|c|c|c|c|c|c|c|c|c|c|}
\hline \multicolumn{2}{|c|}{ Motor Conditions } & \multicolumn{3}{|c|}{ Power (W) } & \multicolumn{3}{|c|}{ Efficiency } & \multicolumn{2}{|c|}{$\begin{array}{l}\text { dc Input to } \\
\text { Inverter (rms) }\end{array}$} & \multicolumn{2}{|c|}{$\begin{array}{l}\text { Three-Phase } \\
\text { Average from } \\
\text { Inverter (rms) }\end{array}$} & \multirow{2}{*}{$\begin{array}{c}\begin{array}{c}\text { Therma } \\
\left({ }^{\circ} \mathrm{C}\right)\end{array} \\
\begin{array}{c}\text { Stator } \\
\text { winding }\end{array}\end{array}$} \\
\hline $\begin{array}{l}\text { Speed } \\
\text { (rpm) }\end{array}$ & $\begin{array}{c}\text { Torque } \\
\text { (Nm) }\end{array}$ & dc & Mech. & ac & Inverter & Motor & Total & V & I & V & I & \\
\hline 297 & 269.7 & 15145 & 8398 & 13572 & 0.896 & 0.619 & 0.555 & 498.1 & 46.72 & 212.3 & 129.8 & 192.9 \\
\hline 300 & 202.6 & 9665 & 6372 & 8522 & 0.882 & 0.748 & 0.660 & 498.2 & 28.57 & 211.3 & 97.8 & 69.9 \\
\hline 300 & 249.2 & 13338 & 7838 & 11938 & 0.895 & 0.657 & 0.588 & 498.1 & 40.92 & 212.3 & 121.1 & 149.9 \\
\hline 301 & 257.1 & 14086 & 8118 & 12647 & 0.898 & 0.642 & 0.576 & 498.1 & 44.21 & 212.2 & 123.1 & 172.1 \\
\hline 302 & 179.2 & 8893 & 5685 & 8034 & 0.903 & 0.708 & 0.639 & 504.0 & 21.32 & 108.0 & 87.3 & 163.2 \\
\hline 302 & 231.4 & 12120 & 7324 & 10778 & 0.889 & 0.680 & 0.604 & 498.2 & 38.13 & 212.4 & 114.1 & 108.0 \\
\hline 303 & 20.2 & 891 & 642 & 769 & 0.863 & 0.836 & 0.721 & 503.9 & 3.68 & 81.7 & 14.8 & 58.6 \\
\hline 303 & 30.2 & 1295 & 960 & 1123 & 0.867 & 0.855 & 0.741 & 504.1 & 4.29 & 82.7 & 19.9 & 91.2 \\
\hline 303 & 59.8 & 2544 & 1903 & 2257 & 0.887 & 0.843 & 0.748 & 504.0 & 6.67 & 89.1 & 33.7 & 85.5 \\
\hline 303 & 109.5 & 4810 & 3487 & 4342 & 0.903 & 0.803 & 0.725 & 504.1 & 11.51 & 99.1 & 54.9 & 99.6 \\
\hline 303 & 119.4 & 5337 & 3802 & 4827 & 0.904 & 0.788 & 0.712 & 504.1 & 13.01 & 101.1 & 59.2 & 106.9 \\
\hline 303 & 150.2 & 6978 & 4773 & 6318 & 0.905 & 0.756 & 0.684 & 504.1 & 16.57 & 104.7 & 73.0 & 124.5 \\
\hline 303 & 169.4 & 8142 & 5391 & 7374 & 0.906 & 0.731 & 0.662 & 504.1 & 19.38 & 107.0 & 82.1 & 141.8 \\
\hline 303 & 188.4 & 9664 & 5998 & 8770 & 0.907 & 0.684 & 0.621 & 504.0 & 23.32 & 110.4 & 92.9 & 179.9 \\
\hline 303 & 209.2 & 10499 & 6638 & 9246 & 0.881 & 0.718 & 0.632 & 498.3 & 31.91 & 211.9 & 103.7 & 88.5 \\
\hline 303 & 219.4 & 10976 & 6978 & 9772 & 0.890 & 0.714 & 0.636 & 498.2 & 34.96 & 211.6 & 105.9 & 76.8 \\
\hline 304 & 40.0 & 1696 & 1272 & 1491 & 0.879 & 0.853 & 0.750 & 504.0 & 4.97 & 83.8 & 24.7 & 85.8 \\
\hline 304 & 50.2 & 2138 & 1600 & 1895 & 0.887 & 0.844 & 0.748 & 504.0 & 5.81 & 86.6 & 29.5 & 85.1 \\
\hline 304 & 71.0 & 3021 & 2266 & 2707 & 0.896 & 0.837 & 0.750 & 504.0 & 7.70 & 92.0 & 38.5 & 87.4 \\
\hline 304 & 89.1 & 3846 & 2842 & 3463 & 0.901 & 0.821 & 0.739 & 504.0 & 9.26 & 95.9 & 46.1 & 94.5 \\
\hline 304 & 158.5 & 7547 & 5054 & 6828 & 0.905 & 0.740 & 0.670 & 504.1 & 18.15 & 105.8 & 77.2 & 131.9 \\
\hline 304 & 238.4 & 12556 & 7594 & 11218 & 0.893 & 0.677 & 0.605 & 498.1 & 37.98 & 211.9 & 114.0 & 134.5 \\
\hline 305 & 80.0 & 3443 & 2557 & 3088 & 0.897 & 0.828 & 0.743 & 504.0 & 8.52 & 93.2 & 42.5 & 92.0 \\
\hline 305 & 130.3 & 5875 & 4163 & 5305 & 0.903 & 0.785 & 0.709 & 504.1 & 14.10 & 102.3 & 63.8 & 111.5 \\
\hline 305 & 138.8 & 6400 & 4442 & 5786 & 0.904 & 0.768 & 0.694 & 504.1 & 15.45 & 104.2 & 68.5 & 114.9 \\
\hline 306 & 99.3 & 4309 & 3184 & 3878 & 0.900 & 0.821 & 0.739 & 504.0 & 10.42 & 97.7 & 50.4 & 96.2 \\
\hline 468 & 369.3 & 26103 & 18140 & 25848 & 0.990 & 0.702 & 0.695 & 504.9 & 124.49 & 224.1 & 189.2 & 162.7 \\
\hline
\end{tabular}


Table B-1. Mechanical, operational, electrical, and thermal data from the Prius performance-mapping test (cont'd)

\begin{tabular}{|c|c|c|c|c|c|c|c|c|c|c|c|c|}
\hline \multicolumn{2}{|c|}{ Motor Conditions } & \multicolumn{3}{|c|}{ Power (W) } & \multicolumn{3}{|c|}{ Efficiency } & \multicolumn{2}{|c|}{$\begin{array}{c}\text { dc Input to } \\
\text { Inverter (rms) }\end{array}$} & \multicolumn{2}{|c|}{$\begin{array}{l}\text { Three-Phase } \\
\text { Average from } \\
\text { Inverter (rms) }\end{array}$} & \multirow{2}{*}{$\begin{array}{c}\begin{array}{c}\text { Thermal } \\
\left({ }^{\circ} \mathrm{C}\right)\end{array} \\
\begin{array}{c}\text { Stator } \\
\text { winding }\end{array} \\
\end{array}$} \\
\hline $\begin{array}{l}\text { Speed } \\
\text { (rpm) }\end{array}$ & $\begin{array}{c}\text { Torque } \\
(\mathrm{Nm})\end{array}$ & dc & Mech. & ac & Inverter & Motor & Total & V & I & V & I & \\
\hline 485 & 325.9 & 24527 & 16585 & 23082 & 0.941 & 0.719 & 0.676 & 504.5 & 83.46 & 220.1 & 160.8 & 103.5 \\
\hline 492 & 351.3 & 27133 & 18113 & 26483 & 0.976 & 0.684 & 0.668 & 504.4 & 109.10 & 222.1 & 180.7 & 140.2 \\
\hline 497 & 357.5 & 27471 & 18613 & 27186 & 0.990 & 0.685 & 0.678 & 504.5 & 122.60 & 223.9 & 185.3 & 195.7 \\
\hline 499 & 280.3 & 20250 & 14669 & 18914 & 0.934 & 0.776 & 0.724 & 499.8 & 43.51 & 215.9 & 134.2 & 64.3 \\
\hline 500 & 308.2 & 24962 & 16161 & 22956 & 0.920 & 0.704 & 0.647 & 499.9 & 68.27 & 217.5 & 154.1 & 129.1 \\
\hline 501 & 178.5 & 12653 & 9379 & 11821 & 0.934 & 0.794 & 0.741 & 504.0 & 27.60 & 128.9 & 86.8 & 165.8 \\
\hline 501 & 208.6 & 15604 & 10963 & 14566 & 0.933 & 0.753 & 0.703 & 504.0 & 35.14 & 133.7 & 103.7 & 164.9 \\
\hline 501 & 295.0 & 22465 & 15478 & 20946 & 0.932 & 0.739 & 0.689 & 500.0 & 50.40 & 216.6 & 143.8 & 86.4 \\
\hline 502 & 70.0 & 4517 & 3686 & 4205 & 0.931 & 0.877 & 0.816 & 504.1 & 10.35 & 109.0 & 38.2 & 78.2 \\
\hline 502 & 79.6 & 5171 & 4190 & 4818 & 0.932 & 0.870 & 0.810 & 504.1 & 11.68 & 111.3 & 42.4 & 82.1 \\
\hline 502 & 188.8 & 13772 & 9936 & 12886 & 0.936 & 0.771 & 0.721 & 503.9 & 30.56 & 131.1 & 93.0 & 179.7 \\
\hline 502 & 229.6 & 16078 & 12074 & 14966 & 0.931 & 0.807 & 0.751 & 500.9 & 38.27 & 215.8 & 108.2 & 78.4 \\
\hline 502 & 289.0 & 21650 & 15219 & 20207 & 0.933 & 0.753 & 0.703 & 499.8 & 47.47 & 216.4 & 142.2 & 73.5 \\
\hline 503 & 20.2 & 1363 & 1067 & 1235 & 0.906 & 0.864 & 0.783 & 504.1 & 4.37 & 95.2 & 14.7 & 69.9 \\
\hline 503 & 30.2 & 1974 & 1592 & 1805 & 0.915 & 0.882 & 0.807 & 504.2 & 5.40 & 97.1 & 20.0 & 71.4 \\
\hline 503 & 49.9 & 3224 & 2634 & 2973 & 0.922 & 0.886 & 0.817 & 504.1 & 7.94 & 104.5 & 29.4 & 73.5 \\
\hline 503 & 60.0 & 3867 & 3165 & 3585 & 0.927 & 0.883 & 0.818 & 504.2 & 9.02 & 106.8 & 33.9 & 75.0 \\
\hline 503 & 108.9 & 7141 & 5738 & 6679 & 0.935 & 0.859 & 0.804 & 504.1 & 15.75 & 116.9 & 54.7 & 91.9 \\
\hline 503 & 119.0 & 7873 & 6275 & 7356 & 0.934 & 0.853 & 0.797 & 504.1 & 17.20 & 119.6 & 59.0 & 101.1 \\
\hline 503 & 128.5 & 8543 & 6777 & 7976 & 0.934 & 0.850 & 0.793 & 504.1 & 18.52 & 121.0 & 62.9 & 108.8 \\
\hline 503 & 148.8 & 10091 & 7848 & 9435 & 0.935 & 0.832 & 0.778 & 504.0 & 22.01 & 124.4 & 72.2 & 125.6 \\
\hline 503 & 240.6 & 17418 & 12686 & 16243 & 0.933 & 0.781 & 0.728 & 501.0 & 41.59 & 215.9 & 114.1 & 107.7 \\
\hline 503 & 247.0 & 18231 & 13011 & 16990 & 0.932 & 0.766 & 0.714 & 500.9 & 41.99 & 215.8 & 119.1 & 127.5 \\
\hline 503 & 258.9 & 19811 & 13653 & 18417 & 0.930 & 0.741 & 0.689 & 500.9 & 45.16 & 215.7 & 128.7 & 149.9 \\
\hline 503 & 337.3 & 27384 & 17782 & 26561 & 0.970 & 0.670 & 0.649 & 504.6 & 99.60 & 221.6 & 171.9 & 157.1 \\
\hline 504 & 40.1 & 2590 & 2118 & 2382 & 0.920 & 0.889 & 0.818 & 504.2 & 6.65 & 101.8 & 24.8 & 72.7 \\
\hline 504 & 89.7 & 5843 & 4740 & 5443 & 0.931 & 0.871 & 0.811 & 504.1 & 13.06 & 113.3 & 46.6 & 86.4 \\
\hline 504 & 157.6 & 10809 & 8330 & 10116 & 0.936 & 0.824 & 0.771 & 504.0 & 23.72 & 125.9 & 76.5 & 144.7 \\
\hline
\end{tabular}


Table B-1. Mechanical, operational, electrical, and thermal data from the Prius performance-mapping test (cont'd)

\begin{tabular}{|c|c|c|c|c|c|c|c|c|c|c|c|c|}
\hline \multicolumn{2}{|c|}{ Motor Conditions } & \multicolumn{3}{|c|}{ Power (W) } & \multicolumn{3}{|c|}{ Efficiency } & \multicolumn{2}{|c|}{$\begin{array}{l}\text { dc Input to } \\
\text { Inverter (rms) }\end{array}$} & \multicolumn{2}{|c|}{$\begin{array}{l}\text { Three-Phase } \\
\text { Average from } \\
\text { Inverter (rms) }\end{array}$} & \multirow{2}{*}{$\begin{array}{c}\begin{array}{c}\text { Thermal } \\
\left({ }^{\circ} \mathrm{C}\right)\end{array} \\
\begin{array}{c}\text { Stator } \\
\text { winding }\end{array}\end{array}$} \\
\hline $\begin{array}{c}\text { Speed } \\
(\mathrm{rpm})\end{array}$ & $\begin{array}{l}\text { Torque } \\
\text { (Nm) }\end{array}$ & dc & Mech. & ac & Inverter & Motor & Total & V & I & $\mathbf{V}$ & I & \\
\hline 505 & 99.5 & 6497 & 5265 & 6063 & 0.933 & 0.868 & 0.810 & 504.1 & 14.41 & 115.2 & 50.7 & 88.7 \\
\hline 505 & 139.1 & 9385 & 7362 & 8773 & 0.935 & 0.839 & 0.784 & 504.1 & 20.48 & 123.4 & 67.9 & 121.2 \\
\hline 505 & 197.8 & 14406 & 10463 & 13439 & 0.933 & 0.779 & 0.726 & 504.0 & 32.16 & 131.9 & 97.5 & 141.9 \\
\hline 505 & 218.3 & 16576 & 11555 & 15453 & 0.932 & 0.748 & 0.697 & 504.0 & 38.60 & 135.1 & 108.5 & 193.2 \\
\hline 505 & 270.5 & 21825 & 14308 & 20275 & 0.929 & 0.706 & 0.656 & 500.9 & 50.60 & 216.1 & 138.6 & 179.2 \\
\hline 507 & 167.7 & 11775 & 8906 & 11007 & 0.935 & 0.809 & 0.756 & 504.0 & 25.60 & 127.6 & 81.9 & 153.9 \\
\hline 508 & 323.0 & 25911 & 17217 & 24456 & 0.944 & 0.704 & 0.664 & 503.8 & 87.13 & 220.5 & 161.6 & 106.3 \\
\hline 687 & 339.2 & 31671 & 24435 & 31265 & 0.987 & 0.782 & 0.771 & 504.8 & 116.87 & 226.6 & 175.6 & 146.1 \\
\hline 692 & 356.0 & 34568 & 25823 & 34121 & 0.987 & 0.757 & 0.747 & 504.8 & 121.40 & 226.6 & 187.2 & 174.7 \\
\hline 693 & 364.5 & 36181 & 26458 & 35628 & 0.985 & 0.744 & 0.732 & 504.7 & 122.88 & 227.2 & 190.7 & 170.7 \\
\hline 697 & 296.2 & 28979 & 21639 & 27697 & 0.956 & 0.781 & 0.747 & 504.7 & 87.73 & 225.0 & 147.0 & 102.5 \\
\hline 700 & 346.1 & 34669 & 25394 & 34218 & 0.987 & 0.742 & 0.733 & 504.7 & 119.59 & 227.2 & 181.3 & 192.7 \\
\hline 701 & 129.6 & 11491 & 9523 & 10920 & 0.950 & 0.872 & 0.829 & 503.8 & 24.29 & 141.3 & 64.4 & 117.6 \\
\hline 701 & 159.8 & 14625 & 11741 & 13933 & 0.953 & 0.843 & 0.803 & 503.7 & 30.62 & 145.6 & 78.8 & 142.8 \\
\hline 701 & 198.7 & 18807 & 14595 & 17853 & 0.949 & 0.818 & 0.776 & 503.7 & 39.76 & 148.6 & 96.7 & 159.8 \\
\hline 701 & 237.7 & 22779 & 17455 & 21585 & 0.948 & 0.809 & 0.766 & 500.8 & 50.58 & 220.1 & 115.4 & 153.2 \\
\hline 702 & 40.0 & 3502 & 2944 & 3284 & 0.938 & 0.896 & 0.841 & 504.0 & 8.30 & 116.2 & 25.1 & 97.8 \\
\hline 702 & 59.6 & 5162 & 4385 & 4875 & 0.944 & 0.900 & 0.850 & 503.9 & 11.43 & 122.9 & 33.9 & 95.8 \\
\hline 702 & 228.8 & 21717 & 16822 & 20561 & 0.947 & 0.818 & 0.775 & 500.9 & 47.99 & 220.2 & 110.1 & 137.9 \\
\hline 702 & 321.4 & 33383 & 23650 & 32317 & 0.968 & 0.732 & 0.709 & 504.6 & 97.87 & 225.8 & 166.2 & 183.3 \\
\hline 703 & 20.2 & 1811 & 1487 & 1684 & 0.930 & 0.883 & 0.821 & 504.0 & 5.11 & 106.4 & 14.8 & 106.4 \\
\hline 703 & 30.2 & 2661 & 2224 & 2487 & 0.935 & 0.894 & 0.836 & 504.0 & 6.74 & 112.3 & 20.2 & 99.6 \\
\hline 703 & 179.8 & 16779 & 13252 & 15953 & 0.951 & 0.831 & 0.790 & 503.7 & 35.65 & 146.6 & 87.6 & 167.8 \\
\hline 703 & 188.4 & 17604 & 13878 & 16703 & 0.949 & 0.831 & 0.788 & 503.7 & 37.15 & 146.6 & 91.5 & 141.6 \\
\hline 703 & 251.0 & 24627 & 18486 & 23296 & 0.946 & 0.794 & 0.751 & 500.8 & 55.28 & 220.5 & 122.9 & 171.0 \\
\hline 703 & 258.7 & 25752 & 19064 & 24363 & 0.946 & 0.783 & 0.740 & 500.8 & 57.09 & 220.5 & 128.2 & 187.0 \\
\hline 703 & 267.7 & 26635 & 19719 & 25165 & 0.945 & 0.784 & 0.740 & 500.7 & 60.15 & 220.8 & 134.3 & 131.7 \\
\hline 703 & 277.5 & 28555 & 20458 & 26962 & 0.944 & 0.759 & 0.716 & 500.7 & 65.24 & 221.3 & 140.8 & 170.1 \\
\hline
\end{tabular}


Table B-1. Mechanical, operational, electrical, and thermal data from the Prius performance-mapping test (cont'd)

\begin{tabular}{|c|c|c|c|c|c|c|c|c|c|c|c|c|}
\hline \multicolumn{2}{|c|}{ Motor Conditions } & \multicolumn{3}{|c|}{ Power (W) } & \multicolumn{3}{|c|}{ Efficiency } & \multicolumn{2}{|c|}{$\begin{array}{l}\text { dc Input to } \\
\text { Inverter (rms) }\end{array}$} & \multicolumn{2}{|c|}{$\begin{array}{l}\text { Three-Phase } \\
\text { Average from } \\
\text { Inverter (rms) }\end{array}$} & \multirow{2}{*}{$\begin{array}{c}\begin{array}{c}\text { Thermal } \\
\left({ }^{\circ} \mathrm{C}\right)\end{array} \\
\begin{array}{c}\text { Stator } \\
\text { winding }\end{array} \\
\end{array}$} \\
\hline $\begin{array}{c}\text { Speed } \\
(\mathrm{rpm})\end{array}$ & $\begin{array}{c}\text { Torque } \\
(\mathrm{Nm})\end{array}$ & dc & Mech. & ac & Inverter & Motor & Total & $\mathbf{V}$ & I & v & I & \\
\hline 703 & 328.2 & 33845 & 24169 & 33147 & 0.979 & 0.729 & 0.714 & 504.5 & 104.44 & 225.9 & 167.6 & 206.8 \\
\hline 704 & 79.4 & 6892 & 5856 & 6537 & 0.949 & 0.896 & 0.850 & 503.9 & 14.93 & 128.6 & 42.4 & 97.6 \\
\hline 704 & 89.7 & 7844 & 6612 & 7451 & 0.950 & 0.887 & 0.843 & 503.9 & 16.73 & 130.6 & 46.9 & 101.5 \\
\hline 704 & 119.6 & 10616 & 8820 & 10082 & 0.950 & 0.875 & 0.831 & 503.8 & 22.34 & 138.6 & 59.9 & 114.9 \\
\hline 704 & 139.6 & 12392 & 10302 & 11771 & 0.950 & 0.875 & 0.831 & 503.8 & 25.84 & 142.0 & 68.4 & 123.1 \\
\hline 704 & 149.0 & 13430 & 10988 & 12746 & 0.949 & 0.862 & 0.818 & 503.7 & 28.11 & 144.7 & 73.5 & 135.4 \\
\hline 704 & 169.2 & 15468 & 12473 & 14690 & 0.950 & 0.849 & 0.806 & 503.7 & 32.70 & 147.9 & 83.0 & 148.2 \\
\hline 704 & 218.9 & 21520 & 16157 & 20390 & 0.947 & 0.792 & 0.751 & 503.8 & 46.18 & 154.5 & 109.4 & 189.3 \\
\hline 704 & 285.5 & 27426 & 21048 & 25919 & 0.945 & 0.812 & 0.767 & 504.7 & 74.47 & 224.0 & 140.0 & 51.7 \\
\hline 705 & 50.5 & 4375 & 3728 & 4118 & 0.941 & 0.905 & 0.852 & 503.9 & 9.94 & 119.8 & 29.9 & 96.5 \\
\hline 705 & 69.8 & 6051 & 5155 & 5735 & 0.948 & 0.899 & 0.852 & 503.9 & 13.20 & 125.8 & 38.4 & 96.9 \\
\hline 705 & 99.0 & 8768 & 7312 & 8315 & 0.948 & 0.880 & 0.834 & 503.8 & 18.72 & 133.2 & 51.1 & 104.6 \\
\hline 705 & 108.8 & 9605 & 8042 & 9110 & 0.949 & 0.883 & 0.837 & 503.8 & 20.18 & 136.5 & 55.2 & 109.2 \\
\hline 705 & 208.0 & 19804 & 15371 & 18757 & 0.947 & 0.820 & 0.776 & 503.7 & 41.86 & 150.7 & 101.1 & 173.6 \\
\hline 715 & 308.2 & 30100 & 23087 & 29611 & 0.984 & 0.780 & 0.767 & 504.7 & 108.79 & 226.3 & 158.6 & 141.9 \\
\hline 892 & 348.1 & 39620 & 32546 & 39205 & 0.990 & 0.830 & 0.822 & 503.5 & 124.88 & 231.0 & 182.5 & 186.8 \\
\hline 892 & 374.8 & 40929 & 35011 & 40418 & 0.988 & 0.866 & 0.856 & 501.2 & 127.04 & 229.8 & 191.4 & 98.7 \\
\hline 900 & 139.2 & 15423 & 13128 & 14796 & 0.959 & 0.887 & 0.851 & 503.7 & 31.89 & 158.4 & 68.0 & 120.1 \\
\hline 900 & 257.9 & 30836 & 24315 & 29442 & 0.955 & 0.826 & 0.789 & 500.6 & 67.56 & 224.9 & 128.0 & 133.5 \\
\hline 901 & 148.8 & 16878 & 14048 & 16102 & 0.954 & 0.872 & 0.832 & 503.6 & 34.99 & 162.0 & 74.0 & 125.2 \\
\hline 901 & 188.5 & 21684 & 17803 & 20794 & 0.959 & 0.856 & 0.821 & 503.7 & 45.21 & 167.0 & 92.7 & 163.7 \\
\hline 901 & 337.1 & 40151 & 31813 & 39408 & 0.981 & 0.808 & 0.793 & 503.5 & 112.79 & 229.6 & 174.3 & 128.3 \\
\hline 902 & 99.9 & 10922 & 9441 & 10472 & 0.959 & 0.902 & 0.864 & 503.8 & 22.98 & 150.6 & 51.0 & 101.1 \\
\hline 902 & 169.4 & 19483 & 16008 & 18672 & 0.958 & 0.857 & 0.822 & 503.6 & 40.30 & 165.4 & 84.3 & 142.4 \\
\hline 902 & 217.8 & 25331 & 20579 & 24284 & 0.959 & 0.847 & 0.812 & 500.8 & 54.49 & 224.2 & 105.9 & 130.9 \\
\hline 902 & 228.8 & 26915 & 21627 & 25765 & 0.957 & 0.839 & 0.804 & 500.8 & 58.37 & 224.5 & 111.7 & 154.5 \\
\hline 902 & 239.4 & 28435 & 22623 & 27205 & 0.957 & 0.832 & 0.796 & 500.7 & 61.09 & 224.6 & 117.7 & 174.0 \\
\hline 902 & 279.1 & 34960 & 26375 & 33370 & 0.955 & 0.790 & 0.754 & 500.6 & 79.43 & 226.1 & 142.1 & 194.0 \\
\hline
\end{tabular}


Table B-1. Mechanical, operational, electrical, and thermal data from the Prius performance-mapping test (cont'd)

\begin{tabular}{|c|c|c|c|c|c|c|c|c|c|c|c|c|}
\hline \multicolumn{2}{|c|}{ Motor Conditions } & \multicolumn{3}{|c|}{ Power (W) } & \multicolumn{3}{|c|}{ Efficiency } & \multicolumn{2}{|c|}{$\begin{array}{l}\text { dc Input to } \\
\text { Inverter (rms) }\end{array}$} & \multicolumn{2}{|c|}{$\begin{array}{l}\text { Three-Phase } \\
\text { Average from } \\
\text { Inverter (rms) }\end{array}$} & \multirow{2}{*}{$\begin{array}{c}\begin{array}{c}\text { Thermal } \\
\left({ }^{\circ} \mathrm{C}\right)\end{array} \\
\begin{array}{c}\text { Stator } \\
\text { winding }\end{array} \\
\end{array}$} \\
\hline $\begin{array}{c}\text { Speed } \\
(\mathrm{rpm})\end{array}$ & $\begin{array}{c}\text { Torque } \\
(\mathrm{Nm})\end{array}$ & dc & Mech. & ac & Inverter & Motor & Total & V & I & V & I & \\
\hline 902 & 288.1 & 36287 & 27229 & 34531 & 0.952 & 0.789 & 0.750 & 500.6 & 85.00 & 226.4 & 149.1 & 160.9 \\
\hline 903 & 20.2 & 2321 & 1908 & 2181 & 0.940 & 0.875 & 0.822 & 503.9 & 5.96 & 122.2 & 15.0 & 105.8 \\
\hline 903 & 29.8 & 3326 & 2821 & 3156 & 0.949 & 0.894 & 0.848 & 503.9 & 7.81 & 125.3 & 20.1 & 100.4 \\
\hline 903 & 40.0 & 4415 & 3787 & 4205 & 0.952 & 0.901 & 0.858 & 503.8 & 9.95 & 131.5 & 25.2 & 99.0 \\
\hline 903 & 50.1 & 5459 & 4735 & 5228 & 0.958 & 0.906 & 0.867 & 503.8 & 11.94 & 136.7 & 29.8 & 97.2 \\
\hline 903 & 62.6 & 6679 & 5925 & 6390 & 0.957 & 0.927 & 0.887 & 503.8 & 14.46 & 137.9 & 34.8 & 96.7 \\
\hline 903 & 178.4 & 20501 & 16874 & 19647 & 0.958 & 0.859 & 0.823 & 503.5 & 43.01 & 165.3 & 87.3 & 154.0 \\
\hline 903 & 248.4 & 29760 & 23502 & 28456 & 0.956 & 0.826 & 0.790 & 500.7 & 65.77 & 225.3 & 121.7 & 190.3 \\
\hline 903 & 269.9 & 32824 & 25520 & 31324 & 0.954 & 0.815 & 0.778 & 500.6 & 72.43 & 225.4 & 135.4 & 161.5 \\
\hline 903 & 306.8 & 36776 & 29046 & 35760 & 0.972 & 0.812 & 0.790 & 503.4 & 99.81 & 229.0 & 153.3 & 103.0 \\
\hline 904 & 128.8 & 14315 & 12195 & 13774 & 0.962 & 0.885 & 0.852 & 503.7 & 29.48 & 157.9 & 64.3 & 114.7 \\
\hline 904 & 295.2 & 34547 & 27962 & 33127 & 0.959 & 0.844 & 0.809 & 503.3 & 85.64 & 227.8 & 143.8 & 43.5 \\
\hline 904 & 325.9 & 41078 & 30861 & 39863 & 0.970 & 0.774 & 0.751 & 503.4 & 103.61 & 229.0 & 165.4 & 184.4 \\
\hline 905 & 69.4 & 7571 & 6581 & 7218 & 0.953 & 0.912 & 0.869 & 503.8 & 16.25 & 143.2 & 38.2 & 97.0 \\
\hline 905 & 79.9 & 8679 & 7579 & 8337 & 0.961 & 0.909 & 0.873 & 503.7 & 18.27 & 146.4 & 42.8 & 97.8 \\
\hline 905 & 89.4 & 9718 & 8474 & 9339 & 0.961 & 0.907 & 0.872 & 503.7 & 20.28 & 146.7 & 46.7 & 99.6 \\
\hline 905 & 109.5 & 11967 & 10384 & 11532 & 0.964 & 0.901 & 0.868 & 503.7 & 24.86 & 152.9 & 55.2 & 104.5 \\
\hline 905 & 159.4 & 18004 & 15109 & 17302 & 0.961 & 0.873 & 0.839 & 503.6 & 37.25 & 162.4 & 78.3 & 132.5 \\
\hline 905 & 197.8 & 23301 & 18768 & 22336 & 0.959 & 0.840 & 0.806 & 503.6 & 48.57 & 168.9 & 98.5 & 172.3 \\
\hline 905 & 317.0 & 38709 & 30076 & 37727 & 0.975 & 0.797 & 0.777 & 503.4 & 102.53 & 229.2 & 159.0 & 142.9 \\
\hline 906 & 120.1 & 13340 & 11398 & 12795 & 0.959 & 0.891 & 0.854 & 503.7 & 27.62 & 156.8 & 60.6 & 109.4 \\
\hline 906 & 209.6 & 24763 & 19898 & 23717 & 0.958 & 0.839 & 0.804 & 503.5 & 51.61 & 170.7 & 104.9 & 186.2 \\
\hline 906 & 364.6 & 43683 & 34608 & 42998 & 0.984 & 0.805 & 0.793 & 503.9 & 126.14 & 231.3 & 190.9 & 150.5 \\
\hline 913 & 353.9 & 43617 & 33848 & 42934 & 0.984 & 0.789 & 0.777 & 503.7 & 123.41 & 230.8 & 188.6 & 156.1 \\
\hline 1089 & 337.0 & 46589 & 38446 & 45849 & 0.984 & 0.839 & 0.825 & 501.1 & 122.72 & 233.3 & 175.4 & 148.0 \\
\hline 1096 & 230.0 & 30727 & 26416 & 29650 & 0.965 & 0.891 & 0.860 & 500.4 & 64.96 & 228.3 & 107.8 & 86.4 \\
\hline 1096 & 366.3 & 51279 & 42077 & 50509 & 0.985 & 0.833 & 0.821 & 501.7 & 134.30 & 234.4 & 191.3 & 192.0 \\
\hline 1097 & 282.1 & 39656 & 32413 & 38151 & 0.962 & 0.850 & 0.818 & 500.3 & 87.29 & 230.4 & 137.3 & 194.4 \\
\hline
\end{tabular}


Table B-1. Mechanical, operational, electrical, and thermal data from the Prius performance-mapping test (cont'd)

\begin{tabular}{|c|c|c|c|c|c|c|c|c|c|c|c|c|}
\hline \multicolumn{2}{|c|}{ Motor Conditions } & \multicolumn{3}{|c|}{ Power (W) } & \multicolumn{3}{|c|}{ Efficiency } & \multicolumn{2}{|c|}{$\begin{array}{l}\text { dc Input to } \\
\text { Inverter (rms) }\end{array}$} & \multicolumn{2}{|c|}{$\begin{array}{l}\text { Three-Phase } \\
\text { Average from } \\
\text { Inverter (rms) }\end{array}$} & \multirow{2}{*}{$\begin{array}{c}\begin{array}{c}\text { Thermal } \\
\left({ }^{\circ} \mathrm{C}\right)\end{array} \\
\begin{array}{c}\text { Stator } \\
\text { winding }\end{array} \\
\end{array}$} \\
\hline $\begin{array}{c}\text { Speed } \\
(\mathrm{rpm})\end{array}$ & $\begin{array}{c}\text { Torque } \\
(\mathrm{Nm})\end{array}$ & dc & Mech. & ac & Inverter & Motor & Total & v & I & v & I & \\
\hline 1097 & 346.4 & 47779 & 39817 & 47151 & 0.987 & 0.845 & 0.834 & 501.2 & 132.09 & 234.5 & 183.7 & 206.0 \\
\hline 1100 & 359.7 & 48612 & 41456 & 47925 & 0.986 & 0.865 & 0.853 & 501.8 & 131.03 & 233.6 & 188.4 & 130.6 \\
\hline 1101 & 267.3 & 38166 & 30817 & 36774 & 0.964 & 0.838 & 0.807 & 500.3 & 85.33 & 230.1 & 131.8 & 181.1 \\
\hline 1102 & 119.6 & 15652 & 13804 & 15138 & 0.967 & 0.912 & 0.882 & 503.6 & 32.12 & 169.3 & 59.0 & 88.9 \\
\hline 1102 & 237.6 & 32303 & 27430 & 31158 & 0.965 & 0.880 & 0.849 & 500.4 & 68.76 & 228.6 & 112.7 & 100.4 \\
\hline 1102 & 258.3 & 36100 & 29820 & 34786 & 0.964 & 0.857 & 0.826 & 500.3 & 78.55 & 229.2 & 125.3 & 132.4 \\
\hline 1102 & 307.2 & 43249 & 35478 & 42288 & 0.978 & 0.839 & 0.820 & 501.3 & 108.06 & 232.2 & 154.1 & 108.7 \\
\hline 1103 & 158.3 & 21161 & 18281 & 20443 & 0.966 & 0.894 & 0.864 & 503.6 & 43.35 & 177.7 & 77.4 & 138.3 \\
\hline 1103 & 248.9 & 34232 & 28766 & 32994 & 0.964 & 0.872 & 0.840 & 500.4 & 73.76 & 229.0 & 119.1 & 114.7 \\
\hline 1103 & 289.8 & 42243 & 33478 & 40658 & 0.962 & 0.823 & 0.793 & 500.2 & 96.10 & 231.4 & 145.6 & 172.2 \\
\hline 1103 & 329.6 & 46775 & 38095 & 45983 & 0.983 & 0.829 & 0.815 & 501.3 & 121.10 & 233.3 & 170.7 & 187.0 \\
\hline 1104 & 20.4 & 2827 & 2356 & 2686 & 0.950 & 0.877 & 0.834 & 503.8 & 6.98 & 135.4 & 14.7 & 69.3 \\
\hline 1104 & 30.3 & 4101 & 3505 & 3923 & 0.957 & 0.893 & 0.855 & 503.8 & 9.41 & 137.9 & 20.1 & 68.7 \\
\hline 1104 & 40.1 & 5367 & 4644 & 5144 & 0.958 & 0.903 & 0.865 & 503.8 & 11.91 & 142.8 & 25.0 & 68.9 \\
\hline 1104 & 50.1 & 6603 & 5794 & 6380 & 0.966 & 0.908 & 0.877 & 503.8 & 14.09 & 150.9 & 29.6 & 69.8 \\
\hline 1104 & 59.4 & 7766 & 6867 & 7493 & 0.965 & 0.917 & 0.884 & 503.7 & 16.50 & 149.4 & 33.7 & 70.6 \\
\hline 1104 & 69.2 & 9115 & 8009 & 8784 & 0.964 & 0.912 & 0.879 & 503.7 & 19.26 & 155.7 & 37.8 & 72.1 \\
\hline 1104 & 79.6 & 10407 & 9205 & 10074 & 0.968 & 0.914 & 0.884 & 503.6 & 21.72 & 161.5 & 42.3 & 73.7 \\
\hline 1104 & 89.5 & 11671 & 10352 & 11298 & 0.968 & 0.916 & 0.887 & 503.6 & 24.25 & 160.7 & 46.3 & 78.0 \\
\hline 1104 & 128.7 & 16848 & 14886 & 16279 & 0.966 & 0.914 & 0.884 & 503.7 & 34.77 & 173.3 & 63.2 & 94.6 \\
\hline 1104 & 198.0 & 27227 & 22899 & 26285 & 0.965 & 0.871 & 0.841 & 503.4 & 56.33 & 184.9 & 97.7 & 166.0 \\
\hline 1104 & 209.4 & 29563 & 24211 & 28504 & 0.964 & 0.849 & 0.819 & 503.4 & 61.99 & 188.1 & 105.7 & 177.0 \\
\hline 1104 & 316.1 & 45409 & 36566 & 44559 & 0.981 & 0.821 & 0.805 & 501.2 & 115.20 & 233.2 & 163.5 & 148.5 \\
\hline 1105 & 99.2 & 13016 & 11481 & 12566 & 0.965 & 0.914 & 0.882 & 503.6 & 26.96 & 163.9 & 50.4 & 81.7 \\
\hline 1105 & 109.3 & 14242 & 12660 & 13759 & 0.966 & 0.920 & 0.889 & 503.6 & 29.39 & 166.5 & 54.4 & 84.2 \\
\hline 1105 & 137.1 & 18169 & 15882 & 17544 & 0.966 & 0.905 & 0.874 & 503.6 & 37.40 & 172.3 & 66.6 & 100.9 \\
\hline 1105 & 189.5 & 25876 & 21932 & 24954 & 0.964 & 0.879 & 0.848 & 503.4 & 53.31 & 182.9 & 93.0 & 157.2 \\
\hline 1105 & 219.2 & 30816 & 25364 & 29675 & 0.963 & 0.855 & 0.823 & 503.3 & 64.65 & 189.3 & 110.1 & 194.1 \\
\hline
\end{tabular}


Table B-1. Mechanical, operational, electrical, and thermal data from the Prius performance-mapping test (cont'd)

\begin{tabular}{|c|c|c|c|c|c|c|c|c|c|c|c|c|}
\hline \multicolumn{2}{|c|}{ Motor Conditions } & \multicolumn{3}{|c|}{ Power (W) } & \multicolumn{3}{|c|}{ Efficiency } & \multicolumn{2}{|c|}{$\begin{array}{l}\text { dc Input to } \\
\text { Inverter (rms) }\end{array}$} & \multicolumn{2}{|c|}{$\begin{array}{l}\text { Three-Phase } \\
\text { Average from } \\
\text { Inverter (rms) }\end{array}$} & \multirow{2}{*}{$\begin{array}{c}\begin{array}{c}\text { Thermal } \\
\left({ }^{\circ} \mathrm{C}\right)\end{array} \\
\begin{array}{c}\text { Stator } \\
\text { winding }\end{array}\end{array}$} \\
\hline $\begin{array}{c}\text { Speed } \\
(\mathrm{rpm})\end{array}$ & $\begin{array}{c}\text { Torque } \\
(\mathrm{Nm})\end{array}$ & dc & Mech. & ac & Inverter & Motor & Total & v & I & v & I & \\
\hline 1105 & 301.5 & 42211 & 34896 & 41051 & 0.972 & 0.850 & 0.827 & 501.3 & 103.54 & 231.7 & 149.7 & 77.4 \\
\hline 1106 & 148.4 & 19669 & 17190 & 19050 & 0.969 & 0.902 & 0.874 & 503.7 & 40.29 & 175.2 & 72.4 & 133.0 \\
\hline 1107 & 168.6 & 22889 & 19556 & 22134 & 0.967 & 0.884 & 0.854 & 503.5 & 47.28 & 179.6 & 82.4 & 143.3 \\
\hline 1107 & 177.9 & 24365 & 20624 & 23479 & 0.964 & 0.878 & 0.846 & 503.5 & 50.89 & 182.7 & 88.3 & 147.2 \\
\hline 1297 & 258.9 & 41788 & 35178 & 40505 & 0.969 & 0.868 & 0.842 & 500.3 & 90.82 & 233.6 & 127.3 & 147.6 \\
\hline 1299 & 169.4 & 26456 & 23044 & 25581 & 0.967 & 0.901 & 0.871 & 503.8 & 53.91 & 193.8 & 82.2 & 127.1 \\
\hline 1301 & 120.2 & 18186 & 16385 & 17847 & 0.981 & 0.918 & 0.901 & 503.6 & 37.24 & 183.3 & 59.3 & 94.0 \\
\hline 1301 & 309.3 & 50326 & 42142 & 49358 & 0.981 & 0.854 & 0.837 & 501.7 & 118.33 & 235.5 & 156.7 & 137.4 \\
\hline 1302 & 228.9 & 36584 & 31234 & 35512 & 0.971 & 0.880 & 0.854 & 500.4 & 77.18 & 232.8 & 111.5 & 135.1 \\
\hline 1302 & 267.8 & 43640 & 36535 & 42307 & 0.969 & 0.864 & 0.837 & 500.3 & 96.18 & 233.8 & 132.9 & 165.7 \\
\hline 1302 & 278.1 & 45978 & 37933 & 44558 & 0.969 & 0.851 & 0.825 & 500.2 & 101.45 & 234.3 & 140.0 & 189.3 \\
\hline 1302 & 315.0 & 53418 & 42960 & 52405 & 0.981 & 0.820 & 0.804 & 501.7 & 122.76 & 235.8 & 167.4 & 183.7 \\
\hline 1303 & 20.4 & 3309 & 2784 & 3131 & 0.946 & 0.889 & 0.842 & 503.8 & 7.83 & 141.7 & 14.7 & 81.9 \\
\hline 1303 & 49.8 & 7725 & 6804 & 7442 & 0.963 & 0.914 & 0.881 & 503.9 & 16.40 & 159.0 & 29.5 & 77.1 \\
\hline 1303 & 69.6 & 10757 & 9497 & 10362 & 0.963 & 0.916 & 0.883 & 503.7 & 22.47 & 166.1 & 38.2 & 78.4 \\
\hline 1303 & 130.0 & 20076 & 17740 & 19415 & 0.967 & 0.914 & 0.884 & 503.6 & 41.10 & 185.6 & 64.0 & 102.9 \\
\hline 1303 & 197.8 & 31327 & 26991 & 30440 & 0.972 & 0.887 & 0.862 & 503.1 & 64.67 & 199.5 & 96.9 & 160.0 \\
\hline 1304 & 40.0 & 6283 & 5458 & 6013 & 0.957 & 0.908 & 0.869 & 503.6 & 13.79 & 156.8 & 25.0 & 77.1 \\
\hline 1304 & 190.2 & 30090 & 25990 & 29113 & 0.968 & 0.893 & 0.864 & 503.4 & 61.77 & 198.0 & 93.0 & 152.2 \\
\hline 1304 & 239.2 & 38559 & 32678 & 37413 & 0.970 & 0.873 & 0.848 & 500.4 & 82.29 & 233.9 & 116.9 & 154.7 \\
\hline 1305 & 29.9 & 4754 & 4082 & 4552 & 0.958 & 0.897 & 0.859 & 503.8 & 10.53 & 148.1 & 20.0 & 78.0 \\
\hline 1305 & 80.1 & 12318 & 10959 & 11914 & 0.967 & 0.920 & 0.890 & 503.9 & 25.62 & 173.1 & 42.6 & 79.4 \\
\hline 1305 & 100.1 & 15407 & 13686 & 14859 & 0.964 & 0.921 & 0.888 & 503.6 & 31.75 & 178.4 & 50.9 & 86.2 \\
\hline 1305 & 139.2 & 21509 & 19036 & 21050 & 0.979 & 0.904 & 0.885 & 503.3 & 44.12 & 187.5 & 68.4 & 107.7 \\
\hline 1305 & 149.3 & 22877 & 20413 & 22184 & 0.970 & 0.920 & 0.892 & 503.5 & 46.56 & 189.5 & 72.1 & 114.7 \\
\hline 1305 & 220.3 & 35875 & 30131 & 34810 & 0.970 & 0.866 & 0.840 & 503.0 & 75.37 & 204.5 & 111.0 & 189.1 \\
\hline 1305 & 294.5 & 48046 & 40260 & 46711 & 0.972 & 0.862 & 0.838 & 501.8 & 107.86 & 235.1 & 148.1 & 87.8 \\
\hline 1305 & 325.5 & 53902 & 44488 & 52914 & 0.982 & 0.841 & 0.825 & 501.5 & 125.52 & 235.4 & 174.5 & 117.5 \\
\hline
\end{tabular}


Table B-1. Mechanical, operational, electrical, and thermal data from the Prius performance-mapping test (cont’d)

\begin{tabular}{|c|c|c|c|c|c|c|c|c|c|c|c|c|}
\hline \multicolumn{2}{|c|}{ Motor Conditions } & \multicolumn{3}{|c|}{ Power (W) } & \multicolumn{3}{|c|}{ Efficiency } & \multicolumn{2}{|c|}{$\begin{array}{l}\text { dc Input to } \\
\text { Inverter (rms) }\end{array}$} & \multicolumn{2}{|c|}{$\begin{array}{l}\text { Three-Phase } \\
\text { Average from } \\
\text { Inverter (rms) }\end{array}$} & \multirow{2}{*}{$\begin{array}{c}\begin{array}{c}\text { Thermal } \\
\left({ }^{\circ} \mathrm{C}\right)\end{array} \\
\begin{array}{c}\text { Stator } \\
\text { winding }\end{array}\end{array}$} \\
\hline $\begin{array}{c}\text { Speed } \\
(\mathrm{rpm})\end{array}$ & $\begin{array}{l}\text { Torque } \\
\text { (Nm) }\end{array}$ & dc & Mech. & ac & Inverter & Motor & Total & V & $\mathbf{I}$ & V & I & \\
\hline 1305 & 335.7 & 55954 & 45889 & 55029 & 0.983 & 0.834 & 0.820 & 501.5 & 131.62 & 235.9 & 183.4 & 180.2 \\
\hline 1306 & 59.9 & 9200 & 8194 & 8943 & 0.972 & 0.916 & 0.891 & 503.7 & 19.32 & 162.6 & 34.0 & 77.6 \\
\hline 1306 & 89.6 & 13623 & 12260 & 13255 & 0.973 & 0.925 & 0.900 & 503.2 & 28.20 & 176.1 & 46.5 & 83.0 \\
\hline 1306 & 158.7 & 24629 & 21705 & 23974 & 0.973 & 0.905 & 0.881 & 503.3 & 50.43 & 193.2 & 77.6 & 118.1 \\
\hline 1306 & 179.8 & 28280 & 24599 & 27389 & 0.969 & 0.898 & 0.870 & 503.5 & 58.05 & 196.1 & 87.7 & 143.4 \\
\hline 1306 & 248.9 & 39613 & 34045 & 38442 & 0.970 & 0.886 & 0.859 & 500.4 & 85.45 & 234.3 & 120.9 & 114.6 \\
\hline 1307 & 110.1 & 16815 & 15072 & 16281 & 0.968 & 0.926 & 0.896 & 503.7 & 34.44 & 181.2 & 55.1 & 90.4 \\
\hline 1307 & 207.4 & 33340 & 28402 & 32418 & 0.972 & 0.876 & 0.852 & 503.0 & 69.69 & 202.7 & 104.3 & 173.6 \\
\hline 1307 & 349.3 & 55774 & 47827 & 54916 & 0.985 & 0.872 & 0.858 & 501.7 & 134.65 & 236.5 & 186.2 & 124.0 \\
\hline 1312 & 288.0 & 48430 & 39567 & 46928 & 0.969 & 0.843 & 0.817 & 500.2 & 105.68 & 236.5 & 147.3 & 186.6 \\
\hline 1500 & 88.9 & 15502 & 13965 & 15087 & 0.973 & 0.926 & 0.901 & 504.3 & 31.70 & 186.5 & 46.0 & 71.5 \\
\hline 1501 & 99.1 & 17272 & 15580 & 16828 & 0.974 & 0.926 & 0.902 & 504.4 & 35.26 & 191.9 & 50.5 & 78.1 \\
\hline 1502 & 218.0 & 39882 & 34306 & 38900 & 0.975 & 0.882 & 0.860 & 504.0 & 80.99 & 219.1 & 110.4 & 174.4 \\
\hline 1502 & 237.9 & 43408 & 37430 & 42373 & 0.976 & 0.883 & 0.862 & 500.2 & 90.42 & 237.1 & 116.8 & 122.0 \\
\hline 1502 & 249.7 & 45221 & 39301 & 44128 & 0.976 & 0.891 & 0.869 & 500.2 & 94.61 & 237.4 & 122.1 & 141.1 \\
\hline 1502 & 257.2 & 47121 & 40473 & 45947 & 0.975 & 0.881 & 0.859 & 500.2 & 98.14 & 237.7 & 127.1 & 161.9 \\
\hline 1502 & 278.6 & 51887 & 43838 & 50573 & 0.975 & 0.867 & 0.845 & 500.1 & 110.28 & 238.9 & 141.0 & 142.4 \\
\hline 1503 & 30.6 & 5533 & 4824 & 5349 & 0.967 & 0.902 & 0.872 & 504.4 & 12.16 & 159.0 & 20.2 & 58.9 \\
\hline 1503 & 109.4 & 19067 & 17221 & 18565 & 0.974 & 0.928 & 0.903 & 504.5 & 38.83 & 193.2 & 54.5 & 81.6 \\
\hline 1503 & 119.2 & 20760 & 18765 & 20248 & 0.975 & 0.927 & 0.904 & 504.6 & 42.08 & 195.3 & 58.7 & 84.5 \\
\hline 1503 & 129.7 & 22668 & 20422 & 22102 & 0.975 & 0.924 & 0.901 & 504.4 & 46.05 & 201.1 & 63.8 & 87.7 \\
\hline 1503 & 138.9 & 24391 & 21863 & 23722 & 0.973 & 0.922 & 0.896 & 504.5 & 49.30 & 200.5 & 67.5 & 94.0 \\
\hline 1503 & 148.9 & 26079 & 23452 & 25426 & 0.975 & 0.922 & 0.899 & 504.4 & 52.66 & 203.3 & 71.8 & 99.2 \\
\hline 1503 & 188.9 & 33580 & 29735 & 32766 & 0.976 & 0.908 & 0.886 & 504.3 & 67.82 & 211.4 & 91.4 & 128.5 \\
\hline
\end{tabular}


Table B-1. Mechanical, operational, electrical, and thermal data from the Prius performance-mapping test (cont'd)

\begin{tabular}{|c|c|c|c|c|c|c|c|c|c|c|c|c|}
\hline \multicolumn{2}{|c|}{ Motor Conditions } & \multicolumn{3}{|c|}{ Power (W) } & \multicolumn{3}{|c|}{ Efficiency } & \multicolumn{2}{|c|}{$\begin{array}{l}\text { dc Input to } \\
\text { Inverter (rms) }\end{array}$} & \multicolumn{2}{|c|}{$\begin{array}{l}\text { Three-Phase } \\
\text { Average from } \\
\text { Inverter (rms) }\end{array}$} & \multirow{2}{*}{$\begin{array}{c}\begin{array}{c}\text { Thermal } \\
\left({ }^{\circ} \mathrm{C}\right)\end{array} \\
\begin{array}{c}\text { Stator } \\
\text { winding }\end{array} \\
\end{array}$} \\
\hline $\begin{array}{c}\text { Speed } \\
(\mathrm{rpm})\end{array}$ & $\begin{array}{c}\text { Torque } \\
(\mathrm{Nm})\end{array}$ & dc & Mech. & ac & Inverter & Motor & Total & v & I & v & I & \\
\hline 1503 & 268.7 & 50187 & 42318 & 48931 & 0.975 & 0.865 & 0.843 & 500.1 & 105.47 & 238.3 & 134.8 & 185.7 \\
\hline 1504 & 20.3 & 3794 & 3199 & 3637 & 0.958 & 0.880 & 0.843 & 504.6 & 8.80 & 152.3 & 14.6 & 57.8 \\
\hline 1504 & 49.9 & 8771 & 7859 & 8529 & 0.972 & 0.921 & 0.896 & 504.4 & 18.47 & 176.5 & 29.6 & 61.4 \\
\hline 1504 & 69.4 & 12185 & 10940 & 11850 & 0.973 & 0.923 & 0.898 & 504.5 & 25.22 & 180.0 & 37.8 & 67.9 \\
\hline 1504 & 159.3 & 28049 & 25101 & 27356 & 0.975 & 0.918 & 0.895 & 504.4 & 56.72 & 207.2 & 77.2 & 105.7 \\
\hline 1504 & 177.7 & 31455 & 27995 & 30681 & 0.975 & 0.912 & 0.890 & 504.4 & 63.51 & 208.6 & 85.2 & 121.3 \\
\hline 1504 & 228.7 & 42051 & 36035 & 41021 & 0.975 & 0.878 & 0.857 & 503.9 & 85.30 & 218.2 & 113.5 & 191.0 \\
\hline 1504 & 295.8 & 55755 & 46601 & 54131 & 0.971 & 0.861 & 0.836 & 500.0 & 133.40 & 230.3 & 153.5 & 201.1 \\
\hline 1505 & 40.2 & 7198 & 6343 & 6972 & 0.969 & 0.910 & 0.881 & 504.4 & 15.40 & 169.3 & 25.0 & 59.8 \\
\hline 1505 & 60.2 & 10633 & 9497 & 10319 & 0.970 & 0.920 & 0.893 & 504.5 & 22.25 & 174.3 & 34.0 & 64.4 \\
\hline 1505 & 169.4 & 29842 & 26712 & 29126 & 0.976 & 0.917 & 0.895 & 504.3 & 60.28 & 207.5 & 81.8 & 110.9 \\
\hline 1505 & 206.8 & 37395 & 32605 & 36515 & 0.976 & 0.893 & 0.872 & 504.0 & 75.72 & 215.1 & 101.2 & 164.5 \\
\hline 1506 & 198.9 & 35915 & 31375 & 35039 & 0.976 & 0.895 & 0.874 & 504.1 & 72.71 & 215.3 & 98.6 & 141.1 \\
\hline 1507 & 79.6 & 13945 & 12571 & 13542 & 0.971 & 0.928 & 0.901 & 504.5 & 28.55 & 187.8 & 42.5 & 68.7 \\
\hline 1512 & 288.8 & 53954 & 45737 & 52403 & 0.971 & 0.873 & 0.848 & 500.0 & 120.66 & 234.7 & 147.2 & 148.0 \\
\hline 1701 & 228.0 & 46043 & 40622 & 45119 & 0.980 & 0.900 & 0.882 & 500.1 & 94.13 & 240.2 & 112.5 & 125.4 \\
\hline 1702 & 69.8 & 13845 & 12445 & 13487 & 0.974 & 0.923 & 0.899 & 504.5 & 28.34 & 188.2 & 38.6 & 90.1 \\
\hline 1702 & 268.5 & 55479 & 47866 & 54376 & 0.980 & 0.881 & 0.863 & 500.0 & 112.82 & 241.4 & 135.5 & 197.9 \\
\hline 1703 & 19.9 & 4173 & 3556 & 4022 & 0.964 & 0.884 & 0.852 & 504.6 & 9.46 & 160.6 & 14.6 & 107.9 \\
\hline 1703 & 50.3 & 10026 & 8983 & 9751 & 0.973 & 0.921 & 0.896 & 504.4 & 20.78 & 173.1 & 30.6 & 91.7 \\
\hline 1703 & 60.1 & 11862 & 10731 & 11587 & 0.977 & 0.926 & 0.905 & 504.4 & 24.42 & 183.9 & 34.3 & 90.4 \\
\hline 1703 & 79.7 & 15714 & 14223 & 15358 & 0.977 & 0.926 & 0.905 & 504.2 & 32.06 & 192.5 & 42.7 & 90.3 \\
\hline 1703 & 99.5 & 19646 & 17762 & 19226 & 0.979 & 0.924 & 0.904 & 504.3 & 39.85 & 202.9 & 51.3 & 92.0 \\
\hline 1703 & 158.9 & 31306 & 28347 & 30698 & 0.981 & 0.923 & 0.905 & 504.1 & 63.06 & 218.2 & 76.9 & 117.4 \\
\hline 1703 & 247.8 & 50830 & 44200 & 49777 & 0.979 & 0.888 & 0.870 & 500.1 & 104.10 & 240.8 & 124.3 & 164.3 \\
\hline 1704 & 40.0 & 8053 & 7146 & 7806 & 0.969 & 0.915 & 0.887 & 504.5 & 16.96 & 169.5 & 25.5 & 95.3 \\
\hline 1704 & 129.5 & 25413 & 23110 & 24879 & 0.979 & 0.929 & 0.909 & 504.2 & 51.26 & 207.7 & 63.4 & 100.8 \\
\hline 1704 & 139.9 & 27480 & 24968 & 26904 & 0.979 & 0.928 & 0.909 & 504.2 & 55.26 & 210.9 & 68.0 & 107.0 \\
\hline
\end{tabular}


Table B-1. Mechanical, operational, electrical, and thermal data from the Prius performance-mapping test (cont'd)

\begin{tabular}{|c|c|c|c|c|c|c|c|c|c|c|c|c|}
\hline \multicolumn{2}{|c|}{ Motor Conditions } & \multicolumn{3}{|c|}{ Power (W) } & \multicolumn{3}{|c|}{ Efficiency } & \multicolumn{2}{|c|}{$\begin{array}{l}\text { dc Input to } \\
\text { Inverter (rms) }\end{array}$} & \multicolumn{2}{|c|}{$\begin{array}{l}\text { Three-Phase } \\
\text { Average from } \\
\text { Inverter (rms) }\end{array}$} & \multirow{2}{*}{$\begin{array}{c}\begin{array}{c}\text { Thermal } \\
\left({ }^{\circ} \mathrm{C}\right)\end{array} \\
\begin{array}{c}\text { Stator } \\
\text { winding }\end{array} \\
\end{array}$} \\
\hline $\begin{array}{c}\text { Speed } \\
(\mathrm{rpm})\end{array}$ & $\begin{array}{c}\text { Torque } \\
(\mathrm{Nm})\end{array}$ & dc & Mech. & ac & Inverter & Motor & Total & v & I & v & I & \\
\hline 1704 & 149.4 & 29565 & 26658 & 28960 & 0.980 & 0.921 & 0.902 & 504.1 & 59.47 & 212.9 & 72.4 & 112.3 \\
\hline 1704 & 168.7 & 33465 & 30112 & 32763 & 0.979 & 0.919 & 0.900 & 504.0 & 67.32 & 215.5 & 81.0 & 126.0 \\
\hline 1704 & 178.6 & 35573 & 31876 & 34878 & 0.980 & 0.914 & 0.896 & 504.0 & 71.53 & 218.7 & 86.0 & 134.7 \\
\hline 1704 & 197.6 & 39572 & 35273 & 38830 & 0.981 & 0.908 & 0.891 & 503.9 & 79.94 & 224.5 & 95.7 & 155.4 \\
\hline 1704 & 238.0 & 48651 & 42484 & 47657 & 0.980 & 0.891 & 0.873 & 500.1 & 99.41 & 240.6 & 118.7 & 144.5 \\
\hline 1705 & 30.3 & 6141 & 5407 & 5959 & 0.970 & 0.907 & 0.881 & 504.6 & 13.19 & 161.5 & 20.8 & 98.7 \\
\hline 1705 & 90.1 & 17884 & 16093 & 17491 & 0.978 & 0.920 & 0.900 & 504.3 & 36.33 & 200.3 & 47.4 & 90.6 \\
\hline 1705 & 109.3 & 21533 & 19524 & 21042 & 0.977 & 0.928 & 0.907 & 504.3 & 43.49 & 202.2 & 55.1 & 96.9 \\
\hline 1705 & 218.5 & 44372 & 39019 & 43546 & 0.981 & 0.896 & 0.879 & 503.8 & 89.72 & 230.9 & 107.9 & 177.3 \\
\hline 1705 & 227.8 & 46617 & 40677 & 45685 & 0.980 & 0.890 & 0.873 & 503.8 & 93.79 & 229.0 & 111.7 & 192.0 \\
\hline 1705 & 259.7 & 53594 & 46384 & 52495 & 0.979 & 0.884 & 0.866 & 500.0 & 109.53 & 241.7 & 130.9 & 183.4 \\
\hline 1706 & 120.2 & 23751 & 21480 & 23229 & 0.978 & 0.925 & 0.904 & 504.2 & 47.89 & 208.5 & 59.9 & 98.4 \\
\hline 1706 & 188.2 & 37702 & 33642 & 37002 & 0.981 & 0.909 & 0.892 & 504.0 & 75.96 & 223.3 & 91.3 & 149.7 \\
\hline 1707 & 208.4 & 42159 & 37278 & 41335 & 0.980 & 0.902 & 0.884 & 503.9 & 84.96 & 226.3 & 101.5 & 171.1 \\
\hline 1900 & 229.0 & 51348 & 45578 & 50442 & 0.982 & 0.904 & 0.888 & 500.0 & 104.20 & 242.1 & 118.3 & 144.5 \\
\hline 1902 & 40.0 & 8972 & 7973 & 8723 & 0.972 & 0.914 & 0.889 & 504.3 & 18.76 & 172.7 & 26.5 & 61.8 \\
\hline 1902 & 109.1 & 23774 & 21724 & 23315 & 0.981 & 0.932 & 0.914 & 504.1 & 47.96 & 212.4 & 54.7 & 90.1 \\
\hline 1903 & 30.0 & 6834 & 5990 & 6618 & 0.968 & 0.905 & 0.877 & 504.3 & 14.61 & 166.5 & 21.6 & 60.8 \\
\hline 1903 & 70.4 & 15451 & 14033 & 15098 & 0.977 & 0.929 & 0.908 & 504.2 & 31.55 & 198.1 & 38.4 & 70.5 \\
\hline 1903 & 79.0 & 17322 & 15749 & 16934 & 0.978 & 0.930 & 0.909 & 504.2 & 35.29 & 192.6 & 43.5 & 74.2 \\
\hline 1903 & 89.6 & 19621 & 17870 & 19183 & 0.978 & 0.932 & 0.911 & 504.2 & 39.89 & 194.1 & 48.8 & 77.1 \\
\hline 1904 & 59.6 & 13158 & 11883 & 12865 & 0.978 & 0.924 & 0.903 & 504.2 & 26.96 & 188.8 & 34.3 & 69.6 \\
\hline 1904 & 119.2 & 25992 & 23765 & 25542 & 0.983 & 0.930 & 0.914 & 504.0 & 52.44 & 219.3 & 59.1 & 92.8 \\
\hline 1904 & 129.1 & 27939 & 25748 & 27430 & 0.982 & 0.939 & 0.922 & 504.1 & 56.24 & 219.4 & 62.9 & 100.7 \\
\hline 1904 & 167.8 & 36829 & 33477 & 36215 & 0.983 & 0.924 & 0.909 & 503.9 & 74.60 & 228.6 & 81.1 & 131.8 \\
\hline 1904 & 178.8 & 39346 & 35663 & 38709 & 0.984 & 0.921 & 0.906 & 503.8 & 79.41 & 231.6 & 86.2 & 141.2 \\
\hline 1904 & 208.1 & 46503 & 41502 & 45726 & 0.983 & 0.908 & 0.892 & 503.9 & 93.46 & 231.3 & 102.0 & 167.6 \\
\hline 1904 & 238.3 & 54123 & 47518 & 53193 & 0.983 & 0.893 & 0.878 & 499.9 & 109.81 & 242.6 & 124.3 & 170.8 \\
\hline
\end{tabular}


Table B-1. Mechanical, operational, electrical, and thermal data from the Prius performance-mapping test (cont'd)

\begin{tabular}{|c|c|c|c|c|c|c|c|c|c|c|c|c|}
\hline \multicolumn{2}{|c|}{ Motor Conditions } & \multicolumn{3}{|c|}{ Power (W) } & \multicolumn{3}{|c|}{ Efficiency } & \multicolumn{2}{|c|}{$\begin{array}{l}\text { dc Input to } \\
\text { Inverter (rms) }\end{array}$} & \multicolumn{2}{|c|}{$\begin{array}{l}\text { Three-Phase } \\
\text { Average from } \\
\text { Inverter (rms) }\end{array}$} & \multirow{2}{*}{$\begin{array}{c}\begin{array}{c}\text { Thermal } \\
\left({ }^{\circ} \mathrm{C}\right)\end{array} \\
\begin{array}{c}\text { Stator } \\
\text { winding }\end{array} \\
\end{array}$} \\
\hline $\begin{array}{c}\text { Speed } \\
(\mathrm{rpm})\end{array}$ & $\begin{array}{c}\text { Torque } \\
(\mathrm{Nm})\end{array}$ & dc & Mech. & ac & Inverter & Motor & Total & v & I & V & I & \\
\hline 1904 & 249.0 & 57109 & 49658 & 56146 & 0.983 & 0.885 & 0.870 & 499.9 & 115.74 & 241.2 & 130.4 & 193.8 \\
\hline 1905 & 20.6 & 4796 & 4113 & 4615 & 0.962 & 0.891 & 0.858 & 504.4 & 10.55 & 159.5 & 16.7 & 60.3 \\
\hline 1905 & 148.4 & 32323 & 29610 & 31805 & 0.984 & 0.931 & 0.916 & 504.1 & 65.28 & 225.0 & 71.8 & 119.7 \\
\hline 1905 & 159.4 & 34891 & 31803 & 34335 & 0.984 & 0.926 & 0.912 & 503.9 & 70.62 & 229.3 & 77.1 & 124.4 \\
\hline 1905 & 197.2 & 43791 & 39343 & 43045 & 0.983 & 0.914 & 0.898 & 504.0 & 88.21 & 230.3 & 95.9 & 159.0 \\
\hline 1905 & 218.1 & 49006 & 43538 & 48200 & 0.984 & 0.903 & 0.888 & 503.7 & 98.55 & 232.9 & 107.4 & 177.5 \\
\hline 1905 & 228.6 & 51714 & 45611 & 50837 & 0.983 & 0.897 & 0.882 & 503.6 & 103.82 & 232.3 & 114.3 & 190.3 \\
\hline 1906 & 50.1 & 11149 & 10003 & 10832 & 0.972 & 0.923 & 0.897 & 504.2 & 22.98 & 173.9 & 32.3 & 63.2 \\
\hline 1906 & 100.4 & 21850 & 20046 & 21422 & 0.980 & 0.936 & 0.918 & 504.1 & 44.17 & 209.3 & 51.0 & 86.0 \\
\hline 1906 & 138.4 & 30119 & 27633 & 29597 & 0.983 & 0.934 & 0.917 & 504.1 & 60.57 & 222.1 & 67.3 & 113.4 \\
\hline 1906 & 189.0 & 41874 & 37730 & 41171 & 0.983 & 0.916 & 0.901 & 503.9 & 84.33 & 230.2 & 91.5 & 152.4 \\
\hline 2102 & 217.8 & 54387 & 47946 & 53434 & 0.982 & 0.897 & 0.882 & 503.5 & 109.03 & 233.1 & 117.1 & 180.7 \\
\hline 2103 & 79.5 & 19025 & 17510 & 18683 & 0.982 & 0.937 & 0.920 & 504.1 & 38.64 & 211.8 & 42.2 & 76.2 \\
\hline 2103 & 119.0 & 28546 & 26216 & 28095 & 0.984 & 0.933 & 0.918 & 504.0 & 57.57 & 224.4 & 59.3 & 90.4 \\
\hline 2104 & 29.6 & 7399 & 6520 & 7219 & 0.976 & 0.903 & 0.881 & 504.3 & 15.73 & 179.4 & 20.3 & 70.9 \\
\hline 2104 & 40.4 & 10026 & 8908 & 9755 & 0.973 & 0.913 & 0.889 & 504.5 & 20.89 & 186.4 & 25.8 & 71.0 \\
\hline 2104 & 70.4 & 17106 & 15513 & 16666 & 0.974 & 0.931 & 0.907 & 504.4 & 34.83 & 204.5 & 38.8 & 74.7 \\
\hline 2104 & 90.0 & 21659 & 19832 & 21238 & 0.981 & 0.934 & 0.916 & 504.4 & 43.82 & 220.7 & 46.7 & 79.5 \\
\hline 2104 & 99.7 & 23997 & 21975 & 23540 & 0.981 & 0.934 & 0.916 & 504.0 & 48.45 & 220.6 & 50.8 & 82.1 \\
\hline 2104 & 129.3 & 30821 & 28496 & 30311 & 0.983 & 0.940 & 0.925 & 504.2 & 61.98 & 227.4 & 63.3 & 93.6 \\
\hline 2104 & 198.1 & 48496 & 43661 & 47740 & 0.984 & 0.915 & 0.900 & 503.7 & 97.16 & 233.4 & 100.5 & 140.7 \\
\hline 2105 & 139.4 & 33132 & 30730 & 32620 & 0.985 & 0.942 & 0.928 & 503.6 & 66.83 & 227.7 & 67.9 & 97.1 \\
\hline 2105 & 148.8 & 35864 & 32804 & 35303 & 0.984 & 0.929 & 0.915 & 504.1 & 72.18 & 227.9 & 73.4 & 103.7 \\
\hline 2105 & 158.7 & 38106 & 34993 & 37546 & 0.985 & 0.932 & 0.918 & 503.9 & 76.52 & 231.2 & 77.3 & 111.5 \\
\hline 2105 & 168.2 & 40548 & 37081 & 39959 & 0.985 & 0.928 & 0.915 & 503.8 & 81.51 & 232.0 & 82.5 & 118.6 \\
\hline 2105 & 178.6 & 43223 & 39378 & 42566 & 0.985 & 0.925 & 0.911 & 503.7 & 86.81 & 233.0 & 88.0 & 127.6 \\
\hline 2106 & 20.4 & 5251 & 4494 & 5112 & 0.974 & 0.879 & 0.856 & 504.4 & 11.54 & 177.9 & 14.8 & 71.3 \\
\hline 2106 & 49.7 & 12075 & 10955 & 11786 & 0.976 & 0.929 & 0.907 & 504.4 & 24.81 & 192.5 & 29.8 & 71.7 \\
\hline
\end{tabular}


Table B-1. Mechanical, operational, electrical, and thermal data from the Prius performance-mapping test (cont'd)

\begin{tabular}{|c|c|c|c|c|c|c|c|c|c|c|c|c|}
\hline \multicolumn{2}{|c|}{ Motor Conditions } & \multicolumn{3}{|c|}{ Power (W) } & \multicolumn{3}{|c|}{ Efficiency } & \multicolumn{2}{|c|}{$\begin{array}{l}\text { dc Input to } \\
\text { Inverter (rms) }\end{array}$} & \multicolumn{2}{|c|}{$\begin{array}{l}\text { Three-Phase } \\
\text { Average from } \\
\text { Inverter (rms) }\end{array}$} & \multirow{2}{*}{$\begin{array}{c}\begin{array}{c}\text { Thermal } \\
\left({ }^{\circ} \mathrm{C}\right)\end{array} \\
\begin{array}{c}\text { Stator } \\
\text { winding }\end{array} \\
\end{array}$} \\
\hline $\begin{array}{c}\text { Speed } \\
(\mathrm{rpm})\end{array}$ & $\begin{array}{c}\text { Torque } \\
(\mathrm{Nm})\end{array}$ & dc & Mech. & ac & Inverter & Motor & Total & V & I & V & I & \\
\hline 2106 & 59.4 & 14448 & 13100 & 14210 & 0.984 & 0.922 & 0.907 & 504.5 & 29.55 & 202.2 & 34.0 & 72.4 \\
\hline 2106 & 109.3 & 26090 & 24114 & 25682 & 0.984 & 0.939 & 0.924 & 504.1 & 52.83 & 224.5 & 54.7 & 86.7 \\
\hline 2106 & 187.8 & 45739 & 41427 & 45026 & 0.984 & 0.920 & 0.906 & 503.7 & 91.83 & 231.9 & 94.8 & 126.0 \\
\hline 2106 & 208.4 & 51326 & 45955 & 50499 & 0.984 & 0.910 & 0.895 & 503.6 & 102.90 & 234.5 & 106.3 & 155.9 \\
\hline 2302 & 129.9 & 33763 & 31326 & 33411 & 0.990 & 0.938 & 0.928 & 496.5 & 69.10 & 241.2 & 66.2 & 88.3 \\
\hline 2302 & 139.4 & 36593 & 33620 & 36189 & 0.989 & 0.929 & 0.919 & 496.5 & 75.02 & 240.6 & 73.4 & 96.7 \\
\hline 2303 & 29.8 & 8047 & 7195 & 7902 & 0.982 & 0.910 & 0.894 & 496.7 & 17.56 & 231.8 & 19.7 & 46.8 \\
\hline 2303 & 58.2 & 15255 & 14042 & 15079 & 0.988 & 0.931 & 0.920 & 496.7 & 31.77 & 238.9 & 33.3 & 57.3 \\
\hline 2303 & 89.4 & 23158 & 21571 & 22906 & 0.989 & 0.942 & 0.931 & 496.6 & 47.59 & 240.2 & 46.2 & 67.3 \\
\hline 2303 & 110.8 & 28530 & 26730 & 28142 & 0.986 & 0.950 & 0.937 & 496.3 & 58.41 & 240.3 & 55.8 & 73.0 \\
\hline 2303 & 149.1 & 39151 & 35972 & 38645 & 0.987 & 0.931 & 0.919 & 496.2 & 80.13 & 241.1 & 78.6 & 105.2 \\
\hline 2303 & 159.5 & 42021 & 38469 & 41509 & 0.988 & 0.927 & 0.915 & 496.2 & 85.86 & 241.4 & 84.7 & 114.7 \\
\hline 2303 & 169.8 & 44918 & 40959 & 44357 & 0.988 & 0.923 & 0.912 & 496.1 & 91.57 & 240.4 & 90.4 & 124.7 \\
\hline 2303 & 188.6 & 51287 & 45490 & 50545 & 0.986 & 0.900 & 0.887 & 496.1 & 104.48 & 240.4 & 109.1 & 186.7 \\
\hline 2304 & 19.0 & 5247 & 4594 & 5151 & 0.982 & 0.892 & 0.876 & 496.7 & 12.10 & 227.6 & 14.0 & 44.9 \\
\hline 2304 & 39.4 & 10484 & 9519 & 10314 & 0.984 & 0.923 & 0.908 & 496.7 & 22.46 & 235.5 & 24.9 & 49.2 \\
\hline 2304 & 68.2 & 17905 & 16467 & 17701 & 0.989 & 0.930 & 0.920 & 496.7 & 37.31 & 240.2 & 38.5 & 63.3 \\
\hline 2304 & 99.2 & 25733 & 23947 & 25448 & 0.989 & 0.941 & 0.931 & 496.7 & 52.60 & 240.7 & 50.4 & 72.3 \\
\hline 2304 & 119.5 & 31024 & 28841 & 30696 & 0.989 & 0.940 & 0.930 & 496.7 & 63.49 & 240.9 & 60.8 & 81.2 \\
\hline 2304 & 178.8 & 48004 & 43149 & 47300 & 0.985 & 0.912 & 0.899 & 496.5 & 97.83 & 241.6 & 100.3 & 151.7 \\
\hline 2305 & 49.7 & 13101 & 11993 & 12892 & 0.984 & 0.930 & 0.916 & 496.6 & 27.47 & 239.1 & 30.5 & 51.7 \\
\hline 2305 & 81.2 & 21082 & 19605 & 20817 & 0.987 & 0.942 & 0.930 & 496.7 & 43.40 & 240.6 & 42.7 & 62.7 \\
\hline 2329 & 197.7 & 53735 & 48209 & 53010 & 0.987 & 0.909 & 0.897 & 496.3 & 110.22 & 238.3 & 114.1 & 197.6 \\
\hline 2502 & 119.3 & 34123 & 31262 & 33698 & 0.988 & 0.928 & 0.916 & 496.6 & 70.40 & 239.1 & 69.2 & 108.0 \\
\hline 2503 & 89.9 & 25463 & 23567 & 25187 & 0.989 & 0.936 & 0.926 & 496.6 & 52.55 & 238.6 & 50.5 & 95.9 \\
\hline 2503 & 109.4 & 31161 & 28679 & 30813 & 0.989 & 0.931 & 0.920 & 496.6 & 64.37 & 239.5 & 61.6 & 102.0 \\
\hline 2503 & 138.3 & 40100 & 36255 & 39560 & 0.987 & 0.916 & 0.904 & 496.6 & 82.48 & 239.3 & 85.2 & 126.0 \\
\hline 2504 & 20.2 & 6033 & 5285 & 5939 & 0.984 & 0.890 & 0.876 & 497.0 & 13.39 & 229.7 & 15.2 & 119.8 \\
\hline
\end{tabular}


Table B-1. Mechanical, operational, electrical, and thermal data from the Prius performance-mapping test (cont'd)

\begin{tabular}{|c|c|c|c|c|c|c|c|c|c|c|c|c|}
\hline \multicolumn{2}{|c|}{ Motor Conditions } & \multicolumn{3}{|c|}{ Power (W) } & \multicolumn{3}{|c|}{ Efficiency } & \multicolumn{2}{|c|}{$\begin{array}{l}\text { dc Input to } \\
\text { Inverter (rms) }\end{array}$} & \multicolumn{2}{|c|}{$\begin{array}{l}\text { Three-Phase } \\
\text { Average from } \\
\text { Inverter (rms) }\end{array}$} & \multirow{2}{*}{$\begin{array}{c}\begin{array}{c}\text { Thermal } \\
\left({ }^{\circ} \mathrm{C}\right)\end{array} \\
\begin{array}{c}\text { Stator } \\
\text { winding }\end{array}\end{array}$} \\
\hline $\begin{array}{l}\text { Speed } \\
\text { (rpm) }\end{array}$ & $\begin{array}{c}\text { Torque } \\
\text { (Nm) }\end{array}$ & dc & Mech. & ac & Inverter & Motor & Total & V & I & V & I & \\
\hline 2504 & 30.2 & 8820 & 7907 & 8667 & 0.983 & 0.912 & 0.896 & 496.9 & 19.11 & 234.4 & 20.8 & 111.2 \\
\hline 2504 & 39.8 & 11532 & 10452 & 11349 & 0.984 & 0.921 & 0.906 & 497.0 & 24.33 & 238.9 & 26.3 & 106.4 \\
\hline 2504 & 50.3 & 14379 & 13195 & 14197 & 0.987 & 0.929 & 0.918 & 496.9 & 29.85 & 239.2 & 30.3 & 102.4 \\
\hline 2504 & 60.0 & 17109 & 15745 & 16869 & 0.986 & 0.933 & 0.920 & 497.0 & 35.37 & 237.7 & 34.9 & 92.9 \\
\hline 2504 & 69.6 & 19733 & 18247 & 19506 & 0.988 & 0.935 & 0.925 & 496.7 & 40.82 & 237.7 & 39.8 & 93.0 \\
\hline 2504 & 79.7 & 22558 & 20915 & 22315 & 0.989 & 0.937 & 0.927 & 496.8 & 46.59 & 238.2 & 45.1 & 94.0 \\
\hline 2504 & 99.4 & 28116 & 26057 & 27773 & 0.988 & 0.938 & 0.927 & 496.7 & 57.90 & 238.7 & 55.9 & 98.1 \\
\hline 2504 & 129.2 & 37241 & 33890 & 36773 & 0.987 & 0.922 & 0.910 & 496.4 & 76.10 & 238.9 & 77.2 & 118.8 \\
\hline 2504 & 149.0 & 43382 & 39081 & 42745 & 0.985 & 0.914 & 0.901 & 496.5 & 88.83 & 239.9 & 93.2 & 134.6 \\
\hline 2504 & 159.0 & 46987 & 41695 & 46243 & 0.984 & 0.902 & 0.887 & 496.5 & 95.83 & 240.4 & 101.9 & 148.1 \\
\hline 2505 & 169.6 & 50293 & 44504 & 49521 & 0.985 & 0.899 & 0.885 & 496.3 & 102.65 & 240.8 & 110.0 & 163.5 \\
\hline 2505 & 178.7 & 53754 & 46888 & 52857 & 0.983 & 0.887 & 0.872 & 496.2 & 109.40 & 240.4 & 118.7 & 184.4 \\
\hline 2703 & 89.7 & 27580 & 25399 & 27277 & 0.989 & 0.931 & 0.921 & 496.7 & 57.11 & 238.6 & 53.9 & 99.8 \\
\hline 2703 & 99.7 & 30721 & 28240 & 30381 & 0.989 & 0.930 & 0.919 & 496.7 & 63.71 & 239.6 & 59.8 & 102.4 \\
\hline 2703 & 109.2 & 33630 & 30899 & 33261 & 0.989 & 0.929 & 0.919 & 496.6 & 69.41 & 240.2 & 65.2 & 105.5 \\
\hline 2703 & 119.1 & 36841 & 33730 & 36429 & 0.989 & 0.926 & 0.916 & 496.5 & 75.97 & 240.6 & 73.0 & 112.8 \\
\hline 2703 & 128.8 & 40243 & 36479 & 39768 & 0.988 & 0.917 & 0.906 & 496.8 & 82.99 & 240.8 & 81.5 & 122.4 \\
\hline 2704 & 20.2 & 6591 & 5731 & 6511 & 0.988 & 0.880 & 0.869 & 497.0 & 14.58 & 232.1 & 15.4 & 107.4 \\
\hline 2704 & 30.3 & 9539 & 8572 & 9423 & 0.988 & 0.910 & 0.899 & 497.0 & 20.43 & 237.2 & 20.9 & 102.9 \\
\hline 2704 & 40.3 & 12445 & 11412 & 12285 & 0.987 & 0.929 & 0.917 & 497.1 & 25.98 & 237.6 & 25.5 & 98.8 \\
\hline 2704 & 49.9 & 15517 & 14145 & 15310 & 0.987 & 0.924 & 0.912 & 496.7 & 32.22 & 238.2 & 30.6 & 96.8 \\
\hline 2704 & 59.6 & 18282 & 16892 & 18145 & 0.992 & 0.931 & 0.924 & 496.9 & 37.78 & 238.5 & 35.7 & 95.5 \\
\hline 2704 & 69.8 & 21358 & 19761 & 21133 & 0.989 & 0.935 & 0.925 & 497.0 & 44.20 & 239.1 & 41.0 & 95.4 \\
\hline 2704 & 138.9 & 43658 & 39338 & 43025 & 0.985 & 0.914 & 0.901 & 496.5 & 89.54 & 240.5 & 91.8 & 135.5 \\
\hline 2704 & 148.8 & 47309 & 42135 & 46646 & 0.986 & 0.903 & 0.891 & 496.5 & 96.98 & 240.7 & 102.9 & 146.0 \\
\hline 2704 & 159.5 & 51170 & 45168 & 50486 & 0.987 & 0.895 & 0.883 & 496.2 & 104.89 & 239.4 & 110.7 & 164.2 \\
\hline 2704 & 169.2 & 54925 & 47915 & 54152 & 0.986 & 0.885 & 0.872 & 496.3 & 115.48 & 238.6 & 121.5 & 180.8 \\
\hline 2705 & 79.5 & 24385 & 22530 & 24084 & 0.988 & 0.935 & 0.924 & 496.6 & 50.44 & 239.4 & 46.4 & 96.2 \\
\hline
\end{tabular}


Table B-1. Mechanical, operational, electrical, and thermal data from the Prius performance-mapping test (cont'd)

\begin{tabular}{|c|c|c|c|c|c|c|c|c|c|c|c|c|}
\hline \multicolumn{2}{|c|}{ Motor Conditions } & \multicolumn{3}{|c|}{ Power (W) } & \multicolumn{3}{|c|}{ Efficiency } & \multicolumn{2}{|c|}{$\begin{array}{l}\text { dc Input to } \\
\text { Inverter (rms) }\end{array}$} & \multicolumn{2}{|c|}{$\begin{array}{l}\text { Three-Phase } \\
\text { Average from } \\
\text { Inverter (rms) }\end{array}$} & \multirow{2}{*}{$\begin{array}{c}\begin{array}{c}\text { Thermal } \\
\left({ }^{\circ} \mathrm{C}\right)\end{array} \\
\begin{array}{c}\text { Stator } \\
\text { winding }\end{array} \\
\end{array}$} \\
\hline $\begin{array}{c}\text { Speed } \\
(\mathrm{rpm})\end{array}$ & $\begin{array}{c}\text { Torque } \\
(\mathrm{Nm})\end{array}$ & dc & Mech. & ac & Inverter & Motor & Total & v & I & V & I & \\
\hline 3003 & 79.4 & 27104 & 24966 & 26897 & 0.992 & 0.928 & 0.921 & 496.5 & 56.11 & 240.2 & 50.0 & 99.5 \\
\hline 3003 & 110.3 & 38169 & 34697 & 37779 & 0.990 & 0.918 & 0.909 & 496.6 & 78.90 & 240.6 & 74.3 & 120.6 \\
\hline 3004 & 20.3 & 7354 & 6390 & 7281 & 0.990 & 0.878 & 0.869 & 497.1 & 16.13 & 235.3 & 15.5 & 105.5 \\
\hline 3004 & 30.1 & 10676 & 9481 & 10574 & 0.990 & 0.897 & 0.888 & 497.1 & 22.53 & 236.4 & 21.4 & 100.9 \\
\hline 3004 & 40.5 & 13990 & 12735 & 13820 & 0.988 & 0.922 & 0.910 & 496.9 & 29.04 & 237.4 & 27.0 & 98.4 \\
\hline 3004 & 50.0 & 17241 & 15732 & 17077 & 0.990 & 0.921 & 0.913 & 496.9 & 35.71 & 238.4 & 32.7 & 97.3 \\
\hline 3004 & 59.5 & 20437 & 18707 & 20247 & 0.991 & 0.924 & 0.915 & 497.0 & 42.31 & 238.8 & 38.4 & 96.9 \\
\hline 3004 & 69.1 & 23541 & 21755 & 23334 & 0.991 & 0.932 & 0.924 & 496.7 & 48.93 & 239.4 & 43.8 & 97.4 \\
\hline 3004 & 89.9 & 30775 & 28296 & 30479 & 0.990 & 0.928 & 0.919 & 496.5 & 63.86 & 240.1 & 57.8 & 104.4 \\
\hline 3004 & 119.5 & 41719 & 37598 & 41203 & 0.988 & 0.913 & 0.901 & 496.7 & 86.13 & 241.0 & 84.7 & 129.4 \\
\hline 3004 & 128.9 & 45493 & 40563 & 44856 & 0.986 & 0.904 & 0.892 & 496.4 & 93.52 & 240.7 & 95.7 & 138.7 \\
\hline 3005 & 99.6 & 34111 & 31341 & 33737 & 0.989 & 0.929 & 0.919 & 496.7 & 70.08 & 240.9 & 63.3 & 109.5 \\
\hline 3005 & 139.0 & 49554 & 43738 & 48894 & 0.987 & 0.895 & 0.883 & 496.3 & 102.34 & 238.9 & 106.6 & 154.6 \\
\hline 3403 & 50.1 & 19571 & 17874 & 19375 & 0.990 & 0.923 & 0.913 & 497.1 & 40.31 & 238.8 & 35.9 & 97.4 \\
\hline 3403 & 89.9 & 35413 & 32037 & 34975 & 0.988 & 0.916 & 0.905 & 496.7 & 72.82 & 239.7 & 69.0 & 110.0 \\
\hline 3403 & 109.3 & 44010 & 38953 & 43429 & 0.987 & 0.897 & 0.885 & 496.4 & 90.01 & 240.6 & 91.2 & 128.8 \\
\hline 3404 & 20.1 & 8197 & 7180 & 8122 & 0.991 & 0.885 & 0.877 & 497.2 & 17.58 & 235.0 & 17.0 & 106.9 \\
\hline 3404 & 30.4 & 12007 & 10849 & 11895 & 0.991 & 0.912 & 0.904 & 497.3 & 25.09 & 236.3 & 23.6 & 100.4 \\
\hline 3404 & 40.0 & 15631 & 14243 & 15498 & 0.992 & 0.919 & 0.911 & 497.1 & 32.38 & 237.7 & 29.6 & 98.2 \\
\hline 3404 & 69.9 & 27239 & 24911 & 27008 & 0.992 & 0.922 & 0.915 & 496.9 & 56.12 & 239.7 & 50.1 & 99.7 \\
\hline 3404 & 79.6 & 31217 & 28387 & 30908 & 0.990 & 0.918 & 0.909 & 496.6 & 64.26 & 239.8 & 58.3 & 105.3 \\
\hline 3404 & 99.3 & 39436 & 35392 & 38955 & 0.988 & 0.909 & 0.897 & 496.6 & 81.04 & 239.9 & 80.0 & 120.2 \\
\hline 3405 & 59.9 & 23347 & 21372 & 23199 & 0.994 & 0.921 & 0.915 & 497.0 & 48.08 & 240.2 & 42.0 & 97.6 \\
\hline 3409 & 119.2 & 48236 & 42556 & 47675 & 0.988 & 0.893 & 0.882 & 496.2 & 99.82 & 237.9 & 100.4 & 140.8 \\
\hline 3772 & 109.4 & 49553 & 43223 & 49133 & 0.992 & 0.880 & 0.872 & 499.0 & 105.18 & 236.4 & 101.0 & 164.9 \\
\hline 3803 & 79.2 & 35399 & 31558 & 34967 & 0.988 & 0.903 & 0.892 & 499.2 & 72.26 & 239.3 & 70.8 & 112.2 \\
\hline 3804 & 40.1 & 17816 & 15962 & 17626 & 0.989 & 0.906 & 0.896 & 499.6 & 36.60 & 238.6 & 33.9 & 75.6 \\
\hline 3804 & 49.8 & 22185 & 19843 & 21879 & 0.986 & 0.907 & 0.894 & 499.5 & 45.43 & 236.3 & 44.7 & 78.8 \\
\hline
\end{tabular}


Table B-1. Mechanical, operational, electrical, and thermal data from the Prius performance-mapping test (cont'd)

\begin{tabular}{|c|c|c|c|c|c|c|c|c|c|c|c|c|}
\hline \multicolumn{2}{|c|}{ Motor Conditions } & \multicolumn{3}{|c|}{ Power (W) } & \multicolumn{3}{|c|}{ Efficiency } & \multicolumn{2}{|c|}{$\begin{array}{l}\text { dc Input to } \\
\text { Inverter (rms) }\end{array}$} & \multicolumn{2}{|c|}{$\begin{array}{l}\text { Three-Phase } \\
\text { Average from } \\
\text { Inverter (rms) }\end{array}$} & \multirow{2}{*}{$\begin{array}{c}\begin{array}{c}\text { Thermal } \\
\left({ }^{\circ} \mathrm{C}\right)\end{array} \\
\begin{array}{c}\text { Stator } \\
\text { winding }\end{array} \\
\end{array}$} \\
\hline $\begin{array}{c}\text { Speed } \\
(\mathrm{rpm})\end{array}$ & $\begin{array}{c}\text { Torque } \\
(\mathrm{Nm})\end{array}$ & dc & Mech. & ac & Inverter & Motor & Total & v & I & V & I & \\
\hline 3804 & 60.4 & 26877 & 24059 & 26482 & 0.985 & 0.908 & 0.895 & 499.5 & 55.17 & 235.6 & 55.8 & 84.8 \\
\hline 3804 & 69.7 & 30798 & 27789 & 30509 & 0.991 & 0.911 & 0.902 & 499.2 & 62.71 & 240.2 & 57.2 & 100.5 \\
\hline 3804 & 89.5 & 40491 & 35655 & 39939 & 0.986 & 0.893 & 0.881 & 499.1 & 82.36 & 240.5 & 84.9 & 125.4 \\
\hline 3804 & 98.6 & 45021 & 39291 & 44410 & 0.986 & 0.885 & 0.873 & 499.0 & 91.37 & 241.0 & 95.6 & 140.2 \\
\hline 3805 & 20.4 & 9393 & 8130 & 9314 & 0.992 & 0.873 & 0.865 & 499.7 & 19.87 & 240.7 & 17.1 & 75.1 \\
\hline 3805 & 30.2 & 13564 & 12034 & 13446 & 0.991 & 0.895 & 0.887 & 499.5 & 28.05 & 241.4 & 23.7 & 73.9 \\
\hline 4204 & 30.1 & 15204 & 13254 & 14982 & 0.985 & 0.885 & 0.872 & 499.5 & 31.38 & 235.7 & 32.1 & 101.8 \\
\hline 4204 & 40.2 & 20108 & 17721 & 19851 & 0.987 & 0.893 & 0.881 & 499.4 & 41.26 & 238.0 & 38.6 & 101.2 \\
\hline 4204 & 50.3 & 24912 & 22139 & 24640 & 0.989 & 0.899 & 0.889 & 499.6 & 50.80 & 238.4 & 47.4 & 102.9 \\
\hline 4204 & 59.8 & 29538 & 26338 & 29244 & 0.990 & 0.901 & 0.892 & 499.5 & 60.11 & 239.2 & 55.9 & 106.6 \\
\hline 4204 & 69.6 & 34577 & 30664 & 34191 & 0.989 & 0.897 & 0.887 & 499.3 & 70.21 & 239.9 & 67.2 & 117.4 \\
\hline 4204 & 79.7 & 39838 & 35087 & 39361 & 0.988 & 0.891 & 0.881 & 499.5 & 80.70 & 241.0 & 78.3 & 128.1 \\
\hline 4204 & 89.4 & 45559 & 39365 & 45041 & 0.989 & 0.874 & 0.864 & 499.2 & 92.67 & 239.1 & 95.2 & 159.6 \\
\hline 4205 & 20.2 & 10564 & 8884 & 10434 & 0.988 & 0.852 & 0.841 & 499.7 & 22.13 & 239.0 & 21.1 & 107.5 \\
\hline 4604 & 30.0 & 16922 & 14463 & 16719 & 0.988 & 0.865 & 0.855 & 499.8 & 34.92 & 235.1 & 37.1 & 90.8 \\
\hline 4604 & 40.4 & 22559 & 19499 & 22216 & 0.985 & 0.878 & 0.864 & 499.5 & 46.27 & 234.1 & 48.7 & 95.6 \\
\hline 4604 & 50.4 & 28080 & 24293 & 27647 & 0.985 & 0.879 & 0.865 & 499.4 & 57.51 & 234.9 & 60.3 & 102.2 \\
\hline 4604 & 69.4 & 38080 & 33450 & 37710 & 0.990 & 0.887 & 0.878 & 499.2 & 77.08 & 240.8 & 72.2 & 120.6 \\
\hline 4605 & 20.2 & 11911 & 9732 & 11725 & 0.984 & 0.830 & 0.817 & 499.9 & 24.87 & 237.8 & 25.9 & 89.7 \\
\hline 4605 & 60.1 & 32733 & 28996 & 32421 & 0.990 & 0.894 & 0.886 & 499.4 & 66.37 & 240.4 & 60.8 & 109.0 \\
\hline 4606 & 79.7 & 44257 & 38452 & 43813 & 0.990 & 0.878 & 0.869 & 499.2 & 89.65 & 239.4 & 87.5 & 145.1 \\
\hline 5003 & 40.1 & 24083 & 21005 & 23878 & 0.991 & 0.880 & 0.872 & 499.5 & 49.05 & 240.3 & 43.6 & 99.8 \\
\hline 5004 & 50.1 & 30195 & 26252 & 29885 & 0.990 & 0.878 & 0.869 & 499.5 & 61.35 & 238.9 & 57.6 & 106.3 \\
\hline 5004 & 59.8 & 36053 & 31347 & 35657 & 0.989 & 0.879 & 0.870 & 499.4 & 73.17 & 239.7 & 71.1 & 113.7 \\
\hline 5005 & 30.0 & 18344 & 15734 & 18176 & 0.991 & 0.866 & 0.858 & 500.0 & 37.68 & 238.0 & 37.0 & 92.6 \\
\hline 5005 & 69.9 & 43252 & 36650 & 42753 & 0.988 & 0.857 & 0.847 & 499.4 & 87.96 & 239.4 & 91.8 & 118.7 \\
\hline 5006 & 20.0 & 12716 & 10495 & 12552 & 0.987 & 0.836 & 0.826 & 500.0 & 26.43 & 240.8 & 25.6 & 92.3 \\
\hline 5402 & 41.3 & 26956 & 23349 & 26685 & 0.990 & 0.875 & 0.866 & 499.7 & 54.73 & 240.3 & 48.7 & 96.7 \\
\hline
\end{tabular}


Table B-1. Mechanical, operational, electrical, and thermal data from the Prius performance-mapping test (cont'd)

\begin{tabular}{|c|c|c|c|c|c|c|c|c|c|c|c|c|}
\hline \multicolumn{2}{|c|}{ Motor Conditions } & \multicolumn{3}{|c|}{ Power (W) } & \multicolumn{3}{|c|}{ Efficiency } & \multicolumn{2}{|c|}{$\begin{array}{l}\text { dc Input to } \\
\text { Inverter (rms) }\end{array}$} & \multicolumn{2}{|c|}{$\begin{array}{l}\text { Three-Phase } \\
\text { Average from } \\
\text { Inverter (rms) }\end{array}$} & \multirow{2}{*}{$\begin{array}{c}\begin{array}{c}\text { Therma } \\
\left({ }^{\circ} \mathrm{C}\right)\end{array} \\
\begin{array}{c}\text { Stator } \\
\text { winding }\end{array}\end{array}$} \\
\hline $\begin{array}{l}\text { Speed } \\
\text { (rpm) }\end{array}$ & $\begin{array}{c}\text { Torque } \\
\text { (Nm) }\end{array}$ & dc & Mech. & ac & Inverter & Motor & Total & V & I & V & I & \\
\hline 5403 & 49.8 & 32495 & 28169 & 32208 & 0.991 & 0.875 & 0.867 & 499.6 & 65.98 & 239.9 & 60.2 & 104.9 \\
\hline 5404 & 30.3 & 20222 & 17157 & 20042 & 0.991 & 0.856 & 0.848 & 499.8 & 41.37 & 242.1 & 35.0 & 97.3 \\
\hline 5405 & 20.7 & 14455 & 11699 & 14305 & 0.990 & 0.818 & 0.809 & 499.9 & 29.88 & 238.9 & 31.0 & 98.2 \\
\hline 5804 & 29.6 & 21854 & 17979 & 21522 & 0.985 & 0.835 & 0.823 & 499.7 & 44.97 & 234.3 & 47.6 & 107.9 \\
\hline 5804 & 40.0 & 28447 & 24311 & 28190 & 0.991 & 0.862 & 0.855 & 499.7 & 57.90 & 238.8 & 53.8 & 111.9 \\
\hline 5805 & 20.1 & 15197 & 12198 & 15050 & 0.990 & 0.811 & 0.803 & 499.9 & 31.49 & 240.9 & 30.8 & 108.3 \\
\hline 5805 & 50.0 & 35466 & 30397 & 35120 & 0.990 & 0.866 & 0.857 & 499.6 & 71.92 & 240.3 & 67.8 & 120.5 \\
\hline 5815 & 59.4 & 41730 & 36187 & 41341 & 0.991 & 0.875 & 0.867 & 499.5 & 85.71 & 237.2 & 78.1 & 150.8 \\
\hline 6004 & 30.1 & 22279 & 18951 & 22050 & 0.990 & 0.859 & 0.851 & 499.7 & 45.48 & 239.5 & 42.4 & 97.5 \\
\hline 6005 & 20.3 & 15604 & 12781 & 15440 & 0.990 & 0.828 & 0.819 & 500.1 & 32.10 & 241.8 & 31.0 & 93.4 \\
\hline 6005 & 49.4 & 36322 & 31044 & 36006 & 0.991 & 0.862 & 0.855 & 499.6 & 73.60 & 240.7 & 68.2 & 117.0 \\
\hline
\end{tabular}




\section{DISTRIBUTION}

\section{Internal}
1. D. J. Adams
6. L. D. Marlino
2. C. W. Ayers
6. M. Olszewski
3. M. A. Brown
7. R. H. Staunton
4. T. A. Burress
8. Laboratory Records
5. K. P. Gambrell

\section{External}

9. J. N. Chiasson, The Universisty of Tennessee-Knoxville, ECE Department, Knoxville, Tennessee 37996.

10. T. Q. Duong, U.S. Department of Energy, Forrestal Building/EE2G, 1000 Independence Avenue, S.W., Washington, D.C. 20585.

11. R. R. Fessler, BIZTEK Consulting, Inc., 820 Roslyn Place, Evanston, Illinois 60201-1724.

12. K. Fiegenschuh, Ford Motor Company, Scientific Research Laboratory, 1505 Commerce Drive, North, Dearborn, Michigan 48120-1261.

13. V. Garg, Ford Motor Company, 15050 Commerce Drive, North, Dearborn, Michigan 481201261.

14. E. Jih, Ford Motor Company, Scientific Research Laboratory, 1505 Commerce Drive, North, Dearborn, Michigan 48120-1261.

15. A. Lee, Daimler Chrysler, CIMS 484-08-06, 800 Chrysler Drive, Auburn Hills, Michigan 483262757.

16. F. Liang, Ford Motor Company, Scientific Research Laboratory, 2101 Village Road, MD1170, Rm. 2331/SRL, Dearborn, Michigan 48121.

17. M. W. Lloyd, Energetics, Inc., 7164 Columbia Gateway Drive, Columbia, Maryland 21046.

18. M. Mehall, Ford Motor Company, Scientific Research Laboratory, 2101 Village Road, MD-2247, Rm. 3317, Dearborn, Michigan 48124-2053.

19. N. M. Olds, United States Council for Automotive Research, nolds@uscar.org.

20. J. Rogers, Chemical and Environmental Sciences Laboratory, GM R\&D Center, 30500 Mound Road, Warren, Michigan 48090-9055.

21. S. A. Rogers, U.S. Department of Energy, Forrestal Building/EE2G, 1000 Independence Avenue, S.W., Washington, D.C. 20585.

22. G. S. Smith, General Motors Advanced Technology Center, 3050 Lomita Boulevard, Torrance, California 90505.

23. E. J. Wall, U.S. Department of Energy, Forrestal Building/EE2G, 1000 Independence Avenue, S.W., Washington, D.C. 20585.

24. B. Welchko, General Motors Advanced Technology Center, 3050 Lomita Boulevard, Torrance, California 90505.

25. P. G. Yoshida, U.S. Department of Energy, Forrestal Building/EE2G, 1000 Independence Avenue, S.W., Washington, D.C. 20585. 